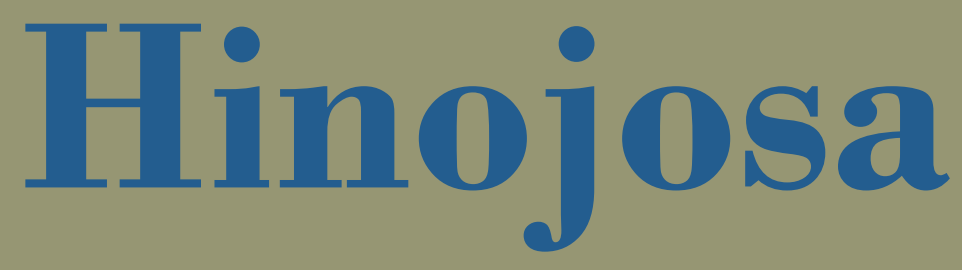
en la Real Academia de Ciencias Morales y Políticas

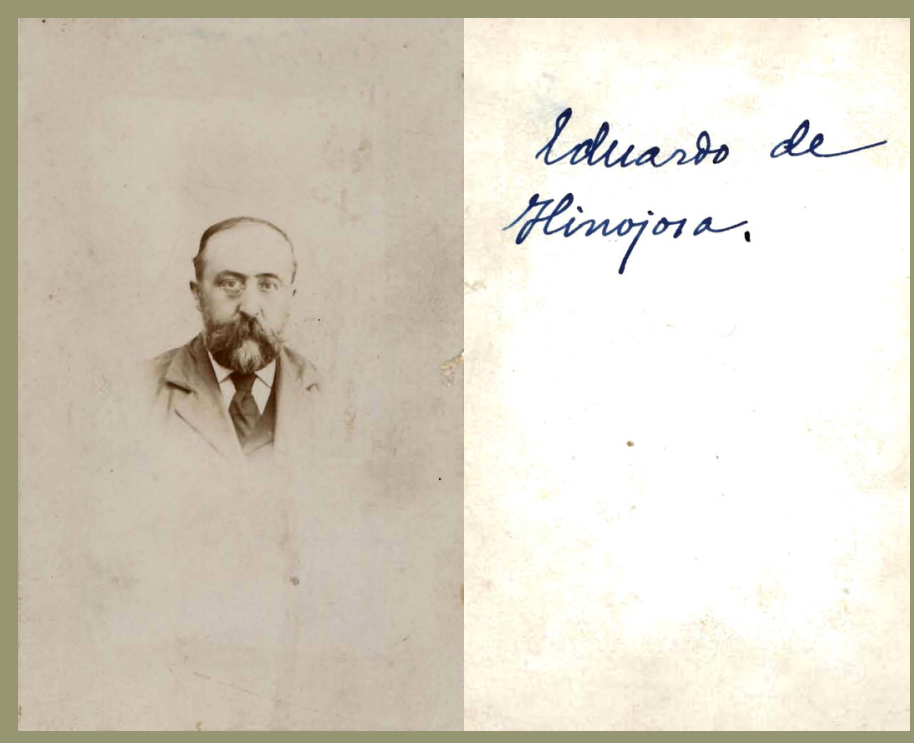

\footnotetext{
Manuel Martínez Neira

Pablo Ramírez Jerez
} 

HINOJOSA

EN LA

REAL ACADEMIA DE CIENCIAS MORALES Y POLÍTICAS 
The Figuerola Institute

Programme: Legal History

The Programme "Legal History" of the Figuerola Institute of Social Science History -a part of the Carlos III University of Madrid- is devoted to improve the overall knowledge on the history of law from different points of view -academically, culturally, socially, and institutionally- covering both ancient and modern eras. A number of experts from several countries have participated in the Programme, bringing in their specialized knowledge and dedication to the subject of their expertise.

To give a better visibility of its activities, the Programme has published in its Book Series a number of monographs on the different aspects of its academic discipline.

Publisher:

Carlos III University of Madrid

Book Series:

Legal History

Editorial Committee:

Manuel Ángel Bermejo Castrillo, Universidad Carlos III de Madrid

Catherine Fillon, Université Jean Moulin Lyon 3

Manuel Martínez Neira, Universidad Carlos III de Madrid

Carlos Petit, Universidad de Huelva

Cristina Vano, Università degli studi di Napoli Federico II

More information at www.uc3m.es/legal_history 


\section{Hinojosa en la Real Academia \\ de Ciencias Morales y Políticas}

Manuel Martínez Neira

Universidad Carlos III de Madrid

orcid id: 000o-0003-2572-4366

Pablo Ramírez Jerez

Bibliotecario de la Real Academia

de Ciencias Morales y Políticas

\section{DYKINSON}

2018 
Esta publicación forma parte del proyecto "La memoria del jurista español: génesis y desarrollo de las disciplinas jurídicas” (ref. DER2014-55035-C2-2-P), financiado por el Ministerio de Economía, Industria y Competitividad (España).

Historia del derecho, 67

ISSN: $2255-5137$

(C) 2018 Autores

Primera edición 2018, reimpresión

Motivo de cubierta:

fotografía y autógrafo de Hinojosa,

Archivo RACMyP

Editorial Dykinson

c/ Meléndez Valdés, 61 - 28015 Madrid

Tlf. (+34) 915442846

E-mail: info@dykinson.com

http://www.dykinson.com

Preimpresión: TALLERONCE

ISBN: 978-84-9148-955-9

Depósito Legal: M-41152-2018

Versión electrónica disponible en e-Archivo

http://hdl.handle.net/10016/27810

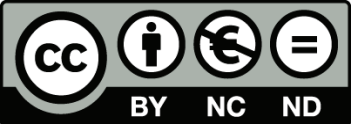

Licencia Creative Commons Atribución-NoComercial-SinDerivadas 3.o España 
Presentación $\quad 9$

1. ¿Se puede biografiar un mito? 11

2. Estudiante 14

3. Anticuario 17

4. Catedrático 26

5. Académico 28

6. Otros desempeños 36

7. La verdadera y auténtica escuela de Hinojosa 40

Fuentes y bibliografía $\quad 45$

Apéndice

- Cronología (1852-1919) 51

- Expediente académico. Universidad de Granada (1872) 56

- Programa de historia de las instituciones (1876) 59

- Relación de méritos y servicios (1884) 87

- Obras incluidas como méritos (1884) 91

- Convocatoria del premio (1887) 95

- Anuncio en la Gaceta de las memorias presentadas (1889) 97

- Encargo a Pidal del dictamen (1889) 98

- Dictamen (1890) 99

- Declaración del premio (1890) 103

- Comunicación a Hinojosa de la fecha de la solemne adjudicación del premio (1890) 104

- Memoria premiada: Influencia que tuvieron en el derecho público de su patria y singularmente en el derecho penal los filósofos y teólogos españoles anteriores a nuestro siglo (1890) 105

- Discurso de recepción: La condición civil de la mujer en el derecho español antiguo y moderno (1907) 227

- Discurso de contestación (1907) 266 


\section{SIGLAS}

AGA Archivo General de la Administración

AGUCM Archivo General Universidad Complutense de Madrid

AHN Archivo Histórico Nacional

AUG Archivo Universitario de Granada

BRAH Boletín de la Real Academia de la Historia

CEH Centro de Estudios Históricos

JAE Junta para Ampliación de Estudios

e Investigaciones Científicas

RACMyP Real Academia de Ciencias Morales y

Políticas

RAE Real Academia Española

RAH Real Academia de la Historia 


\section{Presentación}

Con el presente volumen, continuamos la tarea de dar a conocer algunos fondos de la Real Academia de Ciencias Morales y Políticas fundamentales para el análisis de la cultura jurídica de la España liberal ${ }^{1}$. En esta ocasión, se trata de editar los documentos relacionados con el académico Eduardo de Hinojosa, considerado generalmente por la historiografía especializada como el fundador de la moderna historia del derecho en España ${ }^{2}$.

Sobre Hinojosa existen muchos estudios específicos; así, en la trabajada voz que le dedica el Diccionario biográfico español, Luis Miguel de la Cruz Herranz da buena cuenta de ellos al informar sobre cuarenta obras que tratan del erudito granadino 3 . El último "gran trabajo" que relaciona De la Cruz es el elaborado por Mariano Peset ${ }^{4}$, que seguramente sea la mejor biografía de Hinojosa entre las elaboradas hasta el momento. En ella, el catedrático valenciano proyecta su vasta erudición para analizar la ingente obra de Hinojosa, desde los "pequeños" escritos de juventud -dedicados fundamentalmente a la arqueología- hasta las "grandes" obras de madurez, entre las que se encuentran dos relacionadas directamente con la Real Academia de Ciencias Morales y Políticas. En esas páginas aparece siempre como referencia el es-

1 Hace un año publicamos: Pablo Ramírez Jerez/Manuel Martínez Neira, La historia del derecho en la Real Academia de Ciencias Morales y Políticas. Los concursos de derecho consuetudinario, Madrid 2017.

2 Véase, por todos, Francisco Tomás y Valiente, Manual de historia del derecho español, $4 .^{\text {a }}$ ed., Madrid 1983, p. 55; donde indica que "gracias a Hinojosa, se produce la recepción en España de la obra historiográfica de la Escuela Histórica, y no tan solo de las ideas programáticas de Savigny o de su concepción teórica acerca de la historicidad del Derecho, lo que se recibe es la obra de Mommsen y su metodología”.

Y añade después (p. 56): "Desde Hinojosa la Historia del Derecho ha tenido en España rigor y calidad científica. Y su labor no fue efímera porque la continuaron sus discípulos".

3 Editado por la Real Academia de la Historia, véase la versión electrónica actualizada disponible en <dbe.rah.es $>$.

4 Mariano Peset, "Eduardo de Hinojosa. Historiador y político", en Eduardo de Hinojosa y Naveros, El régimen señorial y la cuestión agraria en Cataluña durante la edad media, Navarra 2003, pp. 7-114 (numeradas en romanos).

Cierra la relación Alejandro Martínez Dhier, “150 años del nacimiento de Eduardo de Hinojosa y Naveros, historiador del Derecho español”, Revista de la Facultad de Derecho de la Universidad de Granada, 2003, pp. 549-559. 
tudio que en su día redactó García-Gallo, otro referente a tener en cuenta en cualquier incursión sobre Hinojosa.

La documentación que Peset utiliza es muy rica, sin embargo -por el motivo que sea- no menciona los diversos archivos en los que se conservan distintos expedientes de Hinojosa. En estas páginas queremos colmar esta laguna dando a conocer el contenido de esos documentos ${ }^{5}$.

Comenzamos el volumen con una reflexión sobre las dificultades que ofrece biografiar un mito, es decir -y en concreto- sobre el círculo autorreferencial que se formó - partiendo de algunos recuerdos de los discípulos- a través de las obras de García-Gallo y de Hinojosa Ferrer. Luego aparecen unos trazos biográficos que no tienen la pretensión de constituir una biografía, son solo algunos aspectos -fotogramas si se quiere- que consideramos relevantes en el contexto de este volumen: la formación académica, su pertenencia al cuerpo de archiveros y las cátedras que ocupó en la Escuela Superior de Diplomática, su vinculación a distintas academias y en especial a la de Morales, el trabajo en el CEH. (Para compensar esta opción selectiva, ofrecemos en apéndice una amplia cronología ${ }^{6}$.)

$\mathrm{Al}$ concluir esta presentación, reivindicamos una idea de Ignacio Peiró y Gonzalo Pasamar - que la Escuela Superior de Diplomática fue el centro pautador de la profesionalización de la historiografía española ${ }^{7}$, y la aplicamos a la historia del derecho a través de la figura de Hinojosa.

Aunque el trabajo ha sido discutido y revisado por los dos autores del mismo, el resultado final es fruto de un reparto de tareas. Pablo Ramírez Jerez ha redactado los capítulos 5 y 6, y se ha encargado de la transcripción de la memoria de Hinojosa premiada por la RACMyP, la documentación de archivo referente a dicho tema, el discurso de ingreso en la misma Academia y la relación de obras especificadas como méritos. Manuel Martínez Neira se ha encargado de las otras cuestiones.

5 Que sepamos, la primera referencia a uno de los expedientes del AGA se encuentra en Ignacio Peiró Martín/Gonzalo Pasamar Alzuria, "Eduardo de Hinojosa”, Diccionario Akal de historiadores españoles contemporáneos (1840-1980), Madrid 2002, pp. 326327; los del AGUCM nunca los hemos visto citados.

6 Véase apéndice, p. 51 ss.

7 Ignacio Peiró Martín/Gonzalo Pasamar Alzuria, La Escuela Superior de Diplomática. Los archiveros en la historiografía española contemporánea, Madrid 1996, p. 12. 


\section{¿Se puede biografiar un mito?}

Estudiar la persona de Eduardo de Hinojosa supone sin duda enfrentarse a un mito, al menos para el gremio de los historiadores del derecho españoles, aunque seguramente no solo para ellos. Pero, ¿se puede biografiar un mito? ¿Cómo hacerlo, cómo abordarlo? Y, sobre todo, ¿̇por qué se ha mitificado? Al reflexionar sobre ello viene a la cabeza una cita ${ }^{1}$ con la que Pio Caroni encabezaba uno de los artículos que conforman sus Escritos sobre la codificación:

La verdadera identidad de mi tío se descubrió el día de su muerte. Desde entonces vivimos angustiados. He pensado que al publicarla, esta historia se convertirá en una leyenda y, como todos sabemos, los mitos y las leyendas son más llevaderos que la cruda realidad.

¿Cuáles eran esas "angustias" - por utilizar el lenguaje de la cita aludidaque llevaron a tal desenlace? Una respuesta total a esta cuestión requiere un análisis que supera el objeto de esta publicación, que como ya hemos indicado -y por otro lado se desprende de su título- se centra en la actividad que desarrolló Hinojosa en la Real Academia de Ciencias Morales y Políticas. Sin embargo, sí podemos apuntar algunas dudas y señalar algunas cuestiones que ayuden a su comprensión. Seguramente, en el caso que nos atañe, el proceso de mitificación tiene un momento clave, que claramente puede identificarse con la publicación póstuma del primer tomo de sus Obras en 1948 (cuando se cumplía el veintinueve aniversario de su muerte), gracias al detallado estudio preliminar de Alfonso García-Gallo². Ese texto ha marcado una visión de Hinojosa y de alguna manera ha impedido otras miradas.

Como el propio autor indica ${ }^{3}$, fuente principal de su Estudio son unas me-

1 La cita corresponde a Tahar Ben Jelloun, L'enfant de sable. Véase, Pio Caroni, Escritos sobre la codificación, Madrid 2012, p. 301.

2 Eduardo de Hinojosa y Naveros, Obras, tomo 1, Estudios de investigación, con un estudio de Alfonso García Gallo sobre Hinojosa y su obra, Madrid, Ministerio de Justicia/ CSIC, 1948 (= Publicaciones del Instituto Nacional de Estudios Jurídicos, núm. 1). El estudio de García-Gallo ocupa las páginas 11-124, numeradas en romanos; en realidad, por su volumen, una monografía. En adelante nos referimos al mismo como Estudio. Con posterioridad se publicaron otros dos volúmenes, Madrid 1955 y Madrid 1974.

3 Estudio, p. xvi, nota 1. 
morias escritas por el hijo de Hinojosa, inéditas en ese momento, pero publicadas poco después, en $1950^{4}$.

Para los datos biográficos he utilizado en la más amplia medida la obra inédita Eduardo de Hinojosa, historiador y varón justo, escrita por D. Juan de Hinojosa Ferrer, hijo del ilustre historiador del Derecho, a quien he de agradecer su gentileza al poner en mis manos esta sugestiva y sentida biografía, autorizándome a utilizarla. Sin ella este bosquejo de Hinojosa, como hombre y como historiador, nunca hubiera podido ofrecer la riqueza de datos personales que contiene.

En las 58 páginas de esta biografía ${ }^{5}$, como la califica García-Gallo (aunque más bien deberíamos hablar de memorias), solo hay una nota, en la última página, para remitirse al "trabajo verdaderamente definitivo de D. Alejandro [sic] García Gallo al frente de sus Obras".

Además, García-Gallo nos informa de la existencia de unos papeles:

Los papeles de Hinojosa pasaron después de su muerte, por generosa donación de sus hijos, al Seminario de Historia del Derecho de la Universidad de Madrid, donde tuve holgada ocasión de examinarlos en los años 1932 a 19367.

Y de un expediente ${ }^{8}$ " $L a$ tesis doctoral se conserva autógrafa en el expediente de estudios de la Facultad de Filosofía y Letras, guardado en la Biblioteca Universitaria de Madrid".

Sin embargo, papeles y expediente parecen hoy perdidos ${ }^{9}$. ¿Se perdieron

4 Juan de Hinojosa Ferrer, "Eduardo de Hinojosa, historiador del derecho y varón justo”, Información jurídica, 83 (1950), pp. 503-561.

5 El escrito de Hinojosa Ferrer se difundió más como separata que a través de la propia revista, con la dificultad de que poseen distinta paginación y diferente caja; por ello la separata consta de 60 páginas y el artículo de la revista 58.

6 El error en el nombre de pila fue corregido en la separata. No es la única errata que contiene, confunde los apellidos de los padres de Hinojosa (es decir, de sus abuelos), el de Maldonado y otros que se mantienen así en la separata, y que se arrastran en estudios posteriores.

7 Véase Estudio, notas 55 y 68.

8 Véase, Estudio, nota 34.

9 El expediente de alumno de la Facultad de Filosofía y Letras está perdido. No se encuentra en la Facultad, ni en el Archivo de la Universidad, ni en su Biblioteca. Tampoco está junto a los expedientes de ese periodo en el AHN (donde debería estar). Hemos hablado con varios responsables de la Complutense y la búsqueda no ha tenido frutos.

La Biblioteca sí conserva 13 cajas del archivo personal de Eduardo de Hinojosa. Esas 
durante la guerra civil española? ¿Pudo volver a verlos García-Gallo para redactar su Estudio? Esta falta de fuentes archivísticas, y el recurso a los recuerdos (memoria), facilitaba sin duda la construcción mitológica, fundada sobre textos autorreferenciales. Una construcción claramente dirigida a insertar una tradición disciplinar -la historia jurídica- en el ecosistema del primer franquismo.

Jesús Vallejo se ha interesado por ello en su inteligente y sugerente estudio "La secuela de Hinojosa y las cuestiones de Altamira"10, donde muestra las distintas tradiciones que convergen en la cristalización de la disciplina, entre las que sobresale la de los institucionistas ${ }^{11}$. Aparece así Rafael Altamira como un autor clave para la maduración de su contenido ${ }^{12}$. Y es que, en un tiempo de redes y descentralización de la censura como en el que vivimos ${ }^{13}$, en el que las grandes corporaciones tecnológicas han arrebatado al Estado el monopolio de la censura (algo tan típicamente barroco), nos es fácil comprender cómo García-Gallo, de manera más o menos consciente, quiso construir un "cordón sanitario" que aislase la disciplina de las impurezas republicanas. Frente a la diversidad/pluralismo (términos tan ajenos a los valores de la dictadura), se construyó un relato uniforme y se situó a Hinojosa como protagonista. Los otros, los institucionistas, habrían despreciado -al menos eso dice García-Gallo, aunque resulte difícil compartir esa opinión- la tradición española, algo inaceptable para las nuevas coordenadas.

cajas, de tamaño cuarto, no están catalogadas. Las hemos revisado una a una, a conciencia. Contienen fichas de sus viajes a archivos, manuscritos de sus investigaciones, alguna carta.

Además, el AGUCM conserva un expediente de catedrático de la Facultad de Filosofía y Letras, y tres que proceden de la Escuela Superior de Diplomática.

Y en el AGA hay dos expedientes suyos, el referido a su plaza de funcionario de la Escuela Superior de Diplomática y el de catedrático de la Universidad Central.

10 Jesús Vallejo, Maneras y motivos en Historia del Derecho, Madrid 2014, pp. 57-79.

11 Por ejemplo la de Gumersindo de Azcárate, quien fue catedrático tanto de historia del derecho como de legislación comparada, mostrando en sus explicaciones la naturaleza híbrida de estas materias. Pero también Claudio Sánchez-Albornoz, a quien volveremos para concluir.

12 Véase, ahora: Carlos Petit, "Altamira en Chicago", en Rafael Altamira, Spain. Sources and Development of Law, estudio preliminar y edición de Carlos Petit, Madrid 2018, pp. xi ss.

13 Recordemos, entre otros, los trabajos de Paul Coleman, La censura maquillada, Madrid 2018; José M. Faraldo, Las redes del terror, Barcelona 2018; Niall Ferguson, La plaza y la torre, Barcelona 2018; Jonathan Kay, "When Censorship Is Crowdsourced", Quillette (September 9, 2018). 
Pero como ya hemos indicado, el presente trabajo no es una biografía de Hinojosa, ni de su escuela, aunque uno y otro asunto nos interese. Su objeto principal es poner de relieve la vinculación de Hinojosa con la Real Academia de Ciencias Morales y Políticas. Por ello, en apéndice, se publica toda la documentación (o al menos la fundamental) sobre el premio al que se presentó -y que además ganó- y sobre su ingreso en la corporación.

De esta manera queremos llamar la atención sobre los otros "Hinojosas" que existieron, es decir sobre las otras facetas de su personalidad, y sobre los archivos no utilizados habitualmente para su estudio. Con ello pueden corregirse algunos datos erróneos que circulan sobre él, pero sobre todo se puede situar al personaje en otros contextos. Así, aunque estuvo colegiado como abogado en Madrid, firmó varias cátedras universitarias, desarrolló un gran trabajo en distintas academias, fue senador, jugó un papel fundamental en el Centro de Estudios Históricos, pensamos que durante toda su vida permaneció fiel a su primera profesión, la del cuerpo de archiveros. Quizás por ello para comprender el llamado método Hinojosa ${ }^{14}$ haya que situarlo en los trabajos de su cátedra de la Escuela Superior de Diplomática, su especificidad -la atención al diploma- puede tener mucho que ver con la formación que se impartía en dicha Escuela y así con el cuerpo facultativo que formaba. Considerándolo desde esta perspectiva emergen elementos que nos ayudan a reconstruir la génesis y el desarrollo de la disciplina académica denominada historia del derecho.

14 Véase, Tomás y Valiente, Manual, cit., p. 55; donde indica que Hinojosa "siempre concibió la Historia del Derecho como una rama especializada de la Historia, que debe ser cultivada dentro de ésta y con su método”. 


\section{Estudiante}

Hinojosa nació en Alhama de Granada, municipio de la provincia de Granada, el 25 de noviembre de 1852. Su padre se llamaba Juan Hinojosa y aparece en la partida de bautismo como labrador (en otros documentos como propietario, lo que en realidad era lo mismo, es decir propietario de tierras de labranza). Su madre era Manuela Naveros. Sus abuelos paternos eran Juan Hinojosa Castillo y María Teresa Almenara Pérez; y los maternos Sebastián Naveros Sánchez y María Alcántara Castroํ. Fue el segundo de los seis hijos del matrimonio: Eloísa, Eduardo, Juan, Ricardo, Soledad y María del Amparo.

Con ocho años comenzó los estudios de segunda enseñanza como alumno interno en el Colegio de las Escuelas Pías de Archidona (incorporado al Instituto de Málaga), en el curso académico 1861-1862; donde permaneció otros dos cursos. El curso 1864-1865 lo hizo en el Instituto de Málaga. Y luego se trasladó al Colegio de las Escuelas Pías de San Fernando (incorporado al Instituto de San Isidro, Madrid). Allí, con tan solo 13 años de edad, el 1 de julio de 1866 obtuvo el grado de bachiller en artes con nota de aprobado.

$\mathrm{Al}$ no tener la edad legal necesaria, el curso 1866-1867 no pudo comenzar los estudios universitarios ${ }^{2}$.

Con 14 años, en el curso 1867-1868 comenzó los estudios de facultad en la Universidad de Granada (como becario del Real Colegio de San Bartolomé y Santiago). Siguió por lo tanto el plan aprobado para la facultad de derecho en 1866. Pero al año siguiente, la revolución de 1868 instauró la libertad de enseñanza y suprimió el plan de 1866. Así, si en el curso 1867-1868 solo cursó las tres asignaturas previstas en ese plan, en el siguiente cursó diez asignaturas: las seis restantes previas al grado de bachiller en Derecho civil y canónico, y las cuatro de la licenciatura. Además en ese mismo curso, con tan solo 16 años, aprobó los ejercicios propios del grado de bachiller y de licenciado.

1 Una copia de la partida de bautismo se encuentra en AUG 769-71: expediente del grado de licenciado (Facultad de Derecho). Para el contenido de este capítulo continúa siendo útil el trabajo de José Moreno Casado, “Eduardo de Hinojosa, estudiante”, Boletín de la Universidad de Granada, 16 (1944), pp. 421-431.

2 De todas maneras, el análisis de las papeletas de examen producen perplejidad pues la edad que se indica no es cierta. Véase AUG 2534-11. 
Siempre en la Universidad de Granada, en el curso 1869-1870 cursó las tres asignaturas del doctorado. Sin embargo, ese año comenzó a vivir en Madrid y seguramente por ello en octubre de 1870 pidió trasladar su expediente a la Universidad Central para poder realizar allí los ejercicios del grado de doctor.

Petición que hizo compatible con haberse matriculado en el curso 18701871 en la facultad de filosofía y letras granadina. El 9 de mayo de 1871 trasladó a la Central su expediente, pero el 21 de agosto de 1872 fue autorizado para examinarse en Granada. Y luego aprobó las del curso 1871-1872 como alumno libre en Granada. De esta forma, y con 19 años de edad, hizo el ejercicio del grado de doctor en derecho, es decir lo que habitualmente se llama tesis, el 28 de junio de 1872. El tema que eligió para su disertación fue "Investigación y examen del fundamento verdaderamente filosófico de la propiedad"3.

Y el 30 de septiembre obtuvo el grado de licenciado en la facultad de filosofía y letras, también en la Universidad de Granada. Para el grado de doctor en esa facultad habrá que esperar a 1883, ya en la Universidad Central, con una disertación titulada "Doctrina de los filósofos escolásticos sobre la autoridad en Filosofía y en particular sobre la autoridad de Aristóteles"4.

Frente a lo que se ha escrito, Hinojosa no fue un estudiante mediocre. La libertad de enseñanza declarada en 1868 permitió a los alumnos brillantes poder examinarse de varios cursos a la vez, como hizo Hinojosa, licenciado con 16 años. Por otro lado, esas reformas redujeron las calificaciones a solo dos: aprobado y suspenso ${ }^{5}$, por ello cuando en una materia o grado obtuvo la calificación de aprobado hay que comprobar si era o no la única posible. De esta manera podemos recuperar un fotograma de su vida, la de estudiante precoz, con un doctorado en derecho (por la Universidad de Granada) y otro en letras (por la Universidad Central).

3 AUG 4608-14. Expediente del grado de doctor. Facultad de Derecho. La tesis se encuentra transcrita en Moreno Casado, Eduardo de Hinojosa, estudiante, cit., pp. 425-431.

4 Según los datos de García-Gallo presidió el tribunal Alfredo Adolfo Camús, fueron vocales Mariano Viscasillas, Manuel Ortí y Lara y Antonio Sánchez Moguel, y secretario Federico Sanz. Véase, Estudio, p. xxxvii, nota 34.

5 Así lo indica el Decreto del 5 de mayo de 1869: Art. $3 \cdot^{\circ}$ No habrá más censuras que las de aprobado y suspenso. 


\section{Anticuario}

En 1870, Hinojosa se trasladó a Madrid para convertirse -con 18 años recién cumplidos- en conservador de las antigüedades de la Academia de la Historia ${ }^{1}$. El nombramiento para el cargo tiene fecha de 16 de diciembre de 1870. Y como él mismo escribió más adelante, mediante el cual fue

Comisionado por la Real Academia de la Historia en Diciembre de 1870 para auxiliar los trabajos del Anticuario en el arreglo y catalogación del Museo de Antigüedades de la Corporación, se ocupó durante más de cuatro años, sin retribución alguna, en esta tarea.

Esta tarea de auxiliar - que consiguió gracias a las relaciones sociales que le acompañarían toda la vida, donde sobresale quien puede calificarse de su verdadero mentor, Juan de Dios de la Rada y Delgado ${ }^{2}-$ le permitió publicar sus primeros trabajos ${ }^{3} \mathrm{y}$ le introdujo en lo que a partir de ese momento fue el ámbito privilegiado de su existencia, la RAH.

En efecto, aunque al obtener el título de doctor, comenzó a firmar oposiciones a cátedras universitarias ${ }^{4}$ y dio clases de derecho romano ${ }^{5}$, su vinculación a lo que era el mundo de la Academia siempre estuvo firme. Así, el 10 de marzo de 1874, la Real Academia de la Historia le nombró auxiliar de la comisión de cortes ${ }^{6}$.

En esa dirección apunta también al matricularse -tras concluir el doctorado en derecho y la licenciatura en letras- en la Escuela Superior de Diplomática, tan vinculada a la Academia.

Allí permaneció como alumno los cursos 1873-74 y 1874-75; y luego 1879-

1 AGA 31/15954-14.

2 Véase, Peset, Eduardo de Hinojosa, cit., p. xiii.

3 Esos primeros trabajos están especificados en el apéndice, véase p. 91 ss.

4 Así, el 24 de mayo de 1873 presentó en la secretaría de la Universidad Central la memoria, programas y demás documentos para ser admitido a los ejercicios de oposición de varias cátedras de derecho romano a los que luego no concurrió. Retiró esa documentación en 1880, véase el recibo en AGA 31/15954, exp. 14.

5 En 1874 fue nombrado profesor de Derecho romano en los estudios de la Asociación de católicos de España.

6 Sobre la comisión de cortes, véase: Peiró/Pasamar, La Escuela Superior de Diplomática, cit., p. 128. 
$80^{7}$. En esos años regía en la Escuela la reforma de 1868, es decir la que se dictó al comenzar el Sexenio para adaptar esa institución al nuevo principio de libertad de enseñanza ${ }^{8}$.

Para lo que nos interesa, por decreto del 21 de noviembre de 1868 (Gaceta del 28) -firmado por Ruiz Zorrilla- se creó una asignatura denominada Historia de la organización administrativa y judicial de España en los tiempos medios, que era enseñada por Santos de Isasa y Valseca ${ }^{9}$. Esta materia sustituía a otra denominada Historia de España en los tiempos medios, y en particular de sus instituciones sociales, civiles y políticas, que existía desde la fundación de la Escuela. El mismo decreto decía que en la nueva asignatura se estudiarían "las instituciones antiguas y los usos, costumbres y ceremonias de los actos públicos”. Sin embargo, más allá del cambio oficial de denominación, parece que se trató siempre de la misma materia.

En efecto, de Isasa conocemos tres programas, uno manuscrito (Historia de las instituciones civiles, políticas y sociales de España en los siglos medios, 1860) y dos impresos: Historia de España en los tiempos medios y en particular de sus instituciones sociales, civiles y políticas, 1865 ; y otro de 1876, es decir cuando ya estaba vigente la reforma ${ }^{10}$.

Hinojosa cursó esta materia en el año académico 1873-74. Cuando el titular de la misma, Isasa, era sustituido con frecuencia por Antonio Rodríguez Villa.

7 Para documentarse sobre la organización de la Escuela, véase Fermín de los Reyes/ José María de Francisco (eds.), 150 aniversario de la fundación de la Escuela Superior de Diplomática (1856-2006). Reglamento y programas, Madrid 2007.

Gracias a los expedientes conservados (AGUCM ED-8-50 y ED-12-9) sabemos que en el curso 1873-74 superó las asignaturas de Latín, Paleografía, Historia de las Instituciones, Bibliografía; en 1874-75, Arqueología, Numismática; en 1879-80, Geografía, Bellas Artes. Se denominan aquí como aparece en el expediente, aunque no sea la manera oficial.

8 El elenco de los planes de estudios que se sucedieron y de las asignaturas que los compusieron ha sido publicado por Luis Miguel de la Cruz Herranz, "Cuadro de las asignaturas de la Escuela Superior de Diplomática”, en Reyes/De Francisco (eds.), 150 aniversario de la fundación, cit., pp. 33-42.

9 Isasa fue una pieza clave en la escuela, miembro fundador, permaneció en ella hasta su paso al Tribunal Supremo (1856-1884), momento en el que fue sustituido por Hinojosa en la cátedra. Véase, Luis Miguel de la Cruz Herranz, El Archivo Histórico Nacional y el nacimiento del medievalismo español (1866-1955), en prensa (que hemos consultado por gentileza del autor).

10 Programa de la asignatura de historia de las instituciones de España en la Edad Media, Madrid 1876 (Apéndice, pp. 59-86). Nótese de nuevo la discordancia entre denominaciones oficiales y académicas. Véase, Cruz Herranz, El Archivo Histórico Nacional, cit. 
Se trata de un dato esencial, pues como veremos existe una clara continuidad entre el contenido de esta cátedra y el denominado método Hinojosa.

Así, ya en el Reglamento de la Escuela de Diplomática de 1857, leemos en su art. 9, que distribuía los estudios ${ }^{11}$ :

Historia de España en los tiempos medios, y en particular de sus instituciones sociales, civiles y políticas. Al explicar los usos y costumbres, la legislación y gobierno de la Península en aquel periodo, se inculcará a los alumnos la utilidad que para su conocimiento han de sacar del estudio de los diplomas.

Descripción que cambia poco en el Reglamento posterior de $1860^{12}$; y que vuelve a reproducir el real decreto de 15 de julio de 1863, Gaceta del 25, al distribuir de nuevo la enseñanza de la Escuela:

Historia de España en los tiempos medios, y en particular de sus instituciones sociales, civiles y políticas, inculcando a los alumnos la utilidad que para su conocimiento han de sacar del estudio de los diplomas.- Tres lecciones semanales.

Recordemos que el denominado método Hinojosa, que influyó en la manera de trabajar de los historiadores del derecho, es sobre todo conocido por su aprecio a los diplomas para el conocimiento de las instituciones: nada que no estuviera en el reglamento de la Escuela mucho antes de la llegada de Hinojosa.

Por fin, en 1875 se produjo su ingreso en el cuerpo facultativo; contaba entonces con 22 años. En efecto, el 5 de marzo de ese año, mediante escrito fechado en Madrid -en el que se presentaba como conservador de las antigüedades de la Academia de la Historia-, solicitó una de las plazas vacantes de oficial de $3{ }^{\text {er }}$ grado en el cuerpo de Archiveros, Bibliotecarios y Anticuarios. Y en consecuencia, el 19 de marzo fue nombrado oficial de $3 .^{\text {er }}$ grado en la sección de museos con destino al Museo arqueológico nacional; el 24 tomó posesión ${ }^{13}$.

11 Reglamento de la Escuela de Diplomática aprobado por real decreto del 11 de febrero de 1857 , Gaceta del 13.

12 Reglamento de la Escuela Superior de Diplomática aprobado por real decreto del 31 de mayo de 1860, Gaceta del 2 de junio. Véase su artículo 38 que trata de la distribución de la enseñanza:

Historia de España en los tiempos medios, y en particular de sus instituciones sociales, civiles y políticas, inculcando a los alumnos la utilidad que para su conocimiento han de sacar del estudio de los diplomas.- Tres lecciones semanales.

13 AGA 31/6527. Su entrada en el cuerpo ha generado cierta polémica historiográfica, 
Comienzan así los 25 años de pertenencia a ese cuerpo, fructíferos por muchos motivos, pero sobre todo porque en ellos desarrolló y consolidó el método de trabajo que permea sus grandes obras y por el que Hinojosa es considerado. Siempre como individuo del cuerpo, por real orden del 26 de agosto de 1878 se le confirió comisión por tres meses para estudiar en Francia y Alemania las publicaciones y los descubrimientos arqueológicos de los últimos años. En la real orden se decía que estos estudios se relacionaban "por tantos conceptos con la historia y las antigüedades patrias", y se le recordaba que debía "dar cuenta en una memoria del resultado de sus investigaciones" ${ }^{14}$.

Este viaje está poco documentado, más allá de las publicaciones que fueron consecuencia del mismo y que son de consulta obligada para comprenderlo. Después, la mitificación de la escuela -tan ligada al germanismo-, olvidó la parte francesa del viaje, quizás la más importante.

Concluidos sus estudios en la Escuela Superior de Diplomática, el 7 de junio de 1880 solicitó el certificado de aptitud para Archivero, Bibliotecario y Anticuario. Para ello, el 10 de junio sacó puntos, el 11 de junio realizó el primer ejercicio, el 12 de junio realizó el segundo ejercicio. Obtuvo la calificación de sobresaliente por mayoría de votos ${ }^{15}$. Este certificado le abrió las puertas al desempeño del magisterio.

En efecto, en la Gaceta del 4 de junio de 1882 se anunció a oposición la cátedra -que hasta ese momento desempeñaba Ángel Allende Salazar- de Geografía antigua y de la Edad Media vacante en la Escuela Superior de Diplomática:

Se halla vacante en la Escuela superior de Diplomática la cátedra de Geografía antigua y de la Edad Media, la cual debe proveerse, con arreglo al art. 13 del reglamento de 25 de Marzo de 1881, por oposición entre los individuos que reúnan los siguientes requisitos exigidos por el art. $2 .^{\circ}$ del reglamento de oposiciones de 17 de Mayo último:

Haber cumplido 21 años de edad.

Poseer el certificado de aptitud para Archivero, Bibliotecario y Anticuario o tener aprobados los ejercicios para la expedición del mismo.

al considerarse que Hinojosa no cumplía las condiciones exigidas en la convocatoria para este puesto. En este sentido Peiró/Pasamar, La Escuela Superior de Diplomática, cit., p. 72. Un análisis más amplio en Cruz Herranz, El Archivo Histórico Nacional, cit.

14 AGA 31/15954-14. Como indemnización se le asignó por una sola vez la cantidad de 3.000 pesetas.

15 AGUCM ED-8-50. 
Ser Jefe u Oficial del cuerpo de Archiveros, Bibliotecarios y Anticuarios. También podrán presentarse a la oposición los Ayudantes si durante un curso académico han desempeñado cátedras de la Escuela de Diplomática.

Los opositores presentarán sus solicitudes en esta Dirección general en el plazo de dos meses, a contar desde la publicación de este anuncio en la Gaceta de Madrid, acompañando los documentos que acrediten la aptitud legal, una relación autorizada de méritos y servicios, y un programa de la asignatura, dividido en lecciones y precedido del razonamiento que se crea necesario para dar a conocer en forma breve y sencilla las ventajas del plan y del método de enseñanza propuestos.

Sólo se admitirán instancias hasta las cinco de la tarde del día en que el citado plazo espire.

Madrid $1 .^{\circ}$ de Junio de 1882. = El Director general, Juan Facundo Riaño.

\section{Y en la Gaceta del 4 de agosto se hizo público el tribunal.}

Ilmo. Sr.: Para componer el Tribunal de oposiciones a la cátedra de Geografía antigua y de la Edad media, vacante en la Escuela superior de Diplomática, S. M. el Rey (Q. D. G.), a propuesta de esa Dirección, se ha servido nombrar Presidente a D. Sandalio Pereda, Consejero de Instrucción pública, y Vocales a D. Aureliano Fernández Guerra y D. Francisco Coello y Quesada, Académicos de la Historia; D. Martin Ferreiro, individuo del Depósito hidrográfico; D. Juan de Dios de la Rada y Delgado, Director de la Escuela de Diplomática; D. Manuel María del Valle, Catedrático de la Universidad de Madrid, y D. Juan de la Gloria Artero, Catedrático de la Universidad de Granada.

De Real orden lo digo a V. I. para los efectos correspondientes.

Dios guarde a V. I. muchos años. Madrid 1. ${ }^{\circ}$ de Agosto de 1882.

ALBAREDA.

Sr. Director general de Instrucción pública.

Ese mismo día Hinojosa solicitó ser admitido a los ejercicios de oposición. ¿'Tuvo que ver el anuncio del tribunal con esta decisión? Seguramente su composición le animó a presentar la solicitud. En su expediente personal se conserva el programa de la materia ${ }^{16}$ :

Programa de Geografía antigua y de la Edad Media de España

El real decreto de 15 de julio de 1863, en cuya virtud se añadió esta asignatura a las que ya constituían el cuadro de las enseñanzas de la Escuela Superior de Diplomática, mien-

16 AGA 31/15954-14. Luis Miguel de la Cruz prepara una edición crítica del mismo. Por otro lado existían manuales de la materia de amplia difusión, como el de José María Anchoriz (Ensayo de Geografía histórica antigua, Madrid 1853) que era uno de los indicados por el gobierno para el estudio de la materia. Véase, por ejemplo, la real orden del 23 de septiembre de 1857, Gaceta del 24. 
tras hace algunas indicaciones respecto del objeto y el método de las demás, nada dice respecto de la que nos ocupa, que a la sazón formaba con la Epigrafía una sola asignatura, concretándose a exponer su título que es, por cierto, el mismo que lleva en la actualidad.

El título de "Geografía antigua y de la Edad Media”, si se le considera aisladamente, es susceptible por lo vago, general e indeterminado de dos interpretaciones diferentes.

Tras finalizar las oposiciones, el tribunal que calificó los ejercicios le propuso para la cátedra. Y en consecuencia, de conformidad con el dictamen del Consejo de Instrucción pública, se le nombró por real orden del 29 de noviembre de 1882 catedrático de Geografía antigua y de la edad media de la Escuela Superior de Diplomática. Tomó posesión el 12 de diciembre, acababa de cumplir 30 años ${ }^{17}$.

Desde ese momento, aparecerá en los Anuarios de la Universidad Central rodeado de sus compañeros de la Escuela: Juan de Dios de la Rada y Delgado (director), Vicente Vignau y Ballester (secretario), Jesús Muñoz y Rivero, Juan Facundo Riaño, Toribio del Campillo y Casamor, Santos de Isasa y Valseca $^{18}$. Y muy pronto desempeñó con frecuencia el cargo de secretario de la Escuela.

Sin embargo, el disfrute de esa cátedra no le impidió seguir solicitando otras, aunque no llegó a hacer los ejercicios. Así, el 21 de mayo de 1883 presentó la documentación necesaria para tomar parte en los ejercicios de oposición a la cátedra de derecho romano vacante en la Universidad de Valencia y anunciada en la Gaceta del 22 de febrero. El 15 de enero de 1884 presentó la documentación necesaria para realizar los ejercicios de oposición a las cátedras de Reseña histórica de las principales transformaciones sociales y políticas de los pueblos europeos, vacantes en las universidades de Madrid, Barcelona, Granada, Salamanca, Sevilla y Zaragoza ${ }^{19}$.

Por otro lado, su carrera como individuo del cuerpo siguió su curso. Así, fue nombrado secretario general de la Junta facultativa de Archivos, Bibliotecas y Museos ${ }^{20}$. También fue nombrado jefe de tercer grado de la sección de

17 AGUCM ED-32-20 y AGA 31/15954-14.

18 Gracias a esos Anuarios conocemos los frecuentes cambios de domicilio: Góngora 3, Travesía de la Ballesta 8, Costanilla de los Ángeles 8, Leganitos 3, Cuesta de Santo Domingo 11, León 21.

19 AGA 31/15954-14. Se trataba de una cátedra creada por el Plan de 1883.

20 El 28 de enero de 1884, la dirección general de Instrucción pública le nombró secretario general de la Junta facultativa de Archivos, Bibliotecas y Museos. Cargo en el 
museos del cuerpo facultativo de Archiveros, Bibliotecarios y Anticuarios ${ }^{21}$. Y fue comisionado para inspeccionar las instalaciones de los museos arqueológicos de provincias ${ }^{22}$.

Debido a la reforma del plan de estudios de la Escuela ${ }^{23}$, la cátedra de Historia de la organización administrativa y judicial de España en la Edad Media se dividió en dos de Historia de las instituciones, una dedicada a la Edad Media y otra a la Edad Moderna, ambas de lección diaria. Además, Santos de Isasa había sido nombrado fiscal del Tribunal Supremo ${ }^{24}$. De esta manera quedó vacante la Historia de las instituciones de España en la Edad Media, y el art. 4 del mismo decreto dictaminó que se proveyese por traslación entre los catedráticos de la Escuela si alguno de ellos la solicitaba. Lo cual hizo Hinojosa, que así fue nombrado por real orden del 30 de septiembre de 1884 catedrático de Historia de las instituciones de España en la Edad Media. Un cambio fundamental para Hinojosa, pues le permitió dedicarse de lleno a la materia que más apreciaba y por la que todavía hoy es conocido.

De nuevo, en 1897, el cuadro de asignaturas de la Escuela sufrió otra modificación, y como consecuencia la cátedra de Hinojosa pasó a denominarse Historia de las instituciones de España en las Edades Media y Moderna ${ }^{25}$. De esta forma se ampliaba el horizonte temporal de sus estudios.

A pesar de ocupar esta cátedra, dedicada claramente a sus intereses y que gozaba de la misma dignidad que las de facultad, siguió firmando alguna oposición. Así, al anunciarse a oposición -en enero de 1886- la cátedra de Historia general del derecho español de la Universidad Central ${ }^{26}$. En efecto, el 19

que cesó el 23 de noviembre de 1887. Véase, Enrique Pérez Boyero y otros, Inventario del fondo documental de la Junta Facultativa de Archivos, Bibliotecas y Museos, vol. 2, Madrid 2016.

21 Siendo oficial de tercer grado, por real orden del 9 de abril de 1884, fue nombrado por concurso jefe de tercer grado de la sección de museos del cuerpo facultativo de Archiveros, Bibliotecarios y Anticuarios. El nombramiento está firmado por su amigo el ministro de Fomento Alejandro Pidal y Mon. Hinojosa hizo la solicitud el 3 de abril, la plaza fue anunciada en la Gaceta de 6 de marzo. La solicitud está acompañada de una relación de méritos. Véase apéndice, p. 87 ss. Toda la documentación en AGA 31/15954-14.

22 Por real orden del 28 de junio de 1884.

23 Real decreto reorganizando los estudios de la Escuela superior de Diplomática del 25 de septiembre de 1884, Gaceta del 27.

24 Por real decreto del 22 de enero de 1884, Gaceta del 23.

25 Real orden del 30 de julio de 1897, Gaceta del 18 de agosto.

26 Véase, Javier Carlos Díaz Rico (ed.), Oposiciones a cátedras de derecho (1847- 
de abril Hinojosa hizo la solicitud para formar parte de esa oposición; pero después, el 12 de mayo del mismo año, en escrito dirigido al director general de Instrucción pública declaró que había desistido presentarse a la plaza y solicitaba la devolución del programa y documentos presentados.

Su dedicación a la Escuela se vió interrumpida esporádicamente por la necesidad de atender las peticiones para que ocupase el cargo de gobernador civil, en sucesivas ocasiones, en las provincias de Alicante ${ }^{27}$, Valencia ${ }^{28}$ y Barcelona $^{29}$. También fue nombrado director general de Instrucción pública ${ }^{30}$.

Por otro lado, el tiempo continuaba pasando y así los ascensos normales por antigüedad; como su primer quinquenio ${ }^{31} \mathrm{o}$ su nombramiento como jefe de $2^{\circ}$ grado $^{32}$. Además, por real orden de 24 de enero de 1900 , en virtud del

1943), Madrid 2018, p. 116. Con posterioridad, el 27 enero de 1894, presentó la documentación necesaria para tomar parte en los ejercicios de oposición a la cátedra derecho romano vacante en la Universidad Central.

27 El día 1 de abril 1891 manifestó que había tomado posesión del cargo de gobernador civil de la provincia de Alicante para el que fue nombrado con fecha 20 de marzo y en su virtud pidió que se le declarase incluido en el artículo 17 del reglamento del cuerpo (es decir se le declarase excedente), con reserva de la cátedra de que era profesor numerario y su plaza y número en el escalafón del cuerpo. Por real orden de 12 mayo de 1891 se le concedió la excedencia. El 9 de diciembre de 1892 solicitó volver al servicio activo como catedrático numerario de la Escuela y jefe de segundo grado del cuerpo facultativo de Archiveros, Bibliotecarios y Anticuarios. Se declaró al efecto terminada la excedencia que le fue concedida.

28 El 1 de marzo de 1896 solicitó excedencia en el cuerpo con arreglo a la ley de Instrucción pública en virtud de haber sido nombrado por real decreto del 28 de febrero gobernador civil de la provincia de Valencia. Tomó posesión el 3 de marzo. Por real orden del 12 de mayo de 1896 se le declaró excedente en concepto de catedrático de la Escuela Superior de Diplomática. Por orden del 20 de mayo de 1896 se acordó que la excedencia había empezado el 2 de marzo.

29 Nombrado gobernador civil de Barcelona, cesó el 20 de octubre de 1897. Por real orden del 28 de octubre de 1897 se declaró terminada la excedencia y su vuelta a jefe de primer grado.

30 Nombrado por real decreto del 5 de marzo de 1899, tomó posesión el 7.

31 Tras cumplir cinco años como catedrático, el 12 de diciembre de 1887, solicitó un premio de 500 pesetas por haber cumplido un quinquenio en el servicio de la enseñanza. El Consejo de instrucción pública informó que al haber pasado el quinquenio, procedía proponer la concesión del primer ascenso por razón de antigüedad y, de consiguiente, un aumento de 500 pesetas anuales sobre el sueldo que disfrutaba. AGA 31/15954-14.

32 Por real orden de 29 agosto 1890 , fue nombrado jefe de $2 .^{\circ}$ grado del cuerpo facultativo de Archiveros, Bibliotecarios y Anticuarios. Tomó posesión ese día. 
art. 11 del reglamento orgánico del cuerpo facultativo de Archiveros, Bibliotecarios y Anticuarios del 18 de septiembre de 1887, se le nombró vocal académico de la junta facultativa de Archivos, Bibliotecas y Museos ${ }^{33}$.

Más adelante, por real decreto del 15 de febrero de 1895 ascendió a jefe de primer grado del cuerpo facultativo de Archiveros, Bibliotecarios y Anticuarios por ascenso de escala. 33 AGA 31/6527. Cesó el 2 de julio de 1900 por haber sido nombrado catedrático de filosofía y letras. 


\section{Catedrático}

En el marco de una reforma de la facultad de Filosofía y Letras, acometida por real decreto del 20 de julio de 1900, Gaceta del 22, la Escuela Superior de Diplomática fue suprimida (art. 1) y las enseñanzas que se tenían en esa sede se incorporaron a la facultad de Filosofía y Letras de la Central.

En realidad, la reforma confirmaba el éxito de la Escuela -si se quiere, su muerte de éxito-, ya que atestiguaba que había servido al desarrollo de los estudios históricos, algo que no se apreciaba en la facultad. De ahí que para hacer frente a esta carencia de la institución universitaria, se optó por apropiarse del acervo de la Escuela. Era en definitiva lo que recordaba el mismo real decreto del 25 de septiembre de 1884 (Gaceta del 27): "creada en 1856, no solo para servir de plantel de empleados al referido cuerpo, sino para contribuir al desarrollo de los estudios históricos”.

De esta manera Hinojosa por real orden del 22 de julio de 1900 se incorporó al claustro de la facultad de Filosofía y Letras ${ }^{1}$. Después, por real orden del 19 de septiembre se dispuso que se encargase como catedrático numerario de la asignatura de Historia antigua y media de España (sección de estudios históricos) ${ }^{2}$. Es decir, la Historia moderna y contemporánea de España quedaba fuera de su alcance pues el titular de esta materia era Fernando Segundo Brieva y Salvatierra, que se encargaba también de una cátedra de doctorado, la de Historia de América.

En esta nueva sede continuó su carrera hasta su muerte, así en 1903 se le concedió la categoría de accenso ${ }^{3}$. En 1904 solicitó ampliar estudios en Francia $^{4}$ y, como se le denegó, hizo una nueva petición en $1905^{5}$. Indicando que:

1 Se le reconocía antigüedad de 12 de diciembre de 1882. AGUCM P-542-18.

2 AGUCM P-542-18.

3 Por real orden del 1 de julio de 1903 se le concedió categoría honorífica de accenso en la sección de historia de la facultad de Filosofía y Letras. AGUCM P-542-18.

4 Hizo la petición el 5 de abril de 1904. Le fue denegada porque la subvención ese año correspondía a la sección de letras (no a la de estudios históricos). AGUCM P-542-18.

5 El 7 de marzo de 1905 expuso que deseaba ampliar sus estudios acerca de la enseñanza que le estaba encomendada, haciendo investigaciones en distintos archivos franceses. Por lo que suplicaba se le concedieraa la pensión para el extranjero que se correspondía a la sección de historia. 
Objeto especial de mi investigación habrán de ser las relaciones políticas entre los territorios del Mediodía de Francia y los Estados cristianos de España desde principios del siglo VIII hasta fines del XV. Algunos, como el Rosellón y el señorío de Montpellier, formaron parte de la Corona de Aragón; otros, como Bearne y Gascuña, sobre estar unidos por la comunidad de raza con la Vasconia española, pasaron durante siglos por las mismas visicitudes que esta región, y sus instituciones sociales y políticas ofrecen muchos puntos de semejanza. Guyena mantuvo relaciones estrechas y asiduas en el siglo XIV con la Corona de Castilla.

Los Archivos de los Pirineos, del Alto Garona y de la Gironda, existentes en las poblaciones anteriormente citadas y los Nacionales de París, contienen preciosos materiales, no utilizados aun para el estudio de que se trata, según consta al exponente, parte por las exploraciones que ha hecho personalmente en los de Perpignan y Burdeos, parte por noticias fidedignas de los eruditos regionales y por los Inventarios impresos. Esta investigación podría ser de extraordinario interés para completar en puntos de mucha importancia el conocimiento de la historia de España en la Edad Media.

En 1909 volvió a solicitar una pensión para estudiar en el extranjero ${ }^{6}$.

Al fallecer el catedrático de Historia moderna y contemporánea, Fernando Segundo Brieva y Salvatierra, quedó vacante la cátedra acumulada de Historia de América. A propuesta del decano y por real orden del 17 de septiembre de 1906 le fue encomendada a Hinojosa, que la desempeñó hasta $1912^{7}$.

También en esta sede su trabajo se vió interrumpido con otros compromisos. Así, volvió a ser gobernador civil en la provincia de Barcelona ${ }^{8}$.

En febrero de 1914 sufrió un ictus y como consecuencia su actividad se vio mermada, aunque en los Anuarios de la Universidad apareció desempeñando su cátedra hasta el momento de su fallecimiento en 1919.

Por real decreto del 15 de junio de 1905, a propuesta del Consejo de instrucción pública y en cumplimiento de lo preceptuado en el real decreto de 8 de mayo de 1903, se le concedió la subvención de 3.000 pts. para que desde el 1 de octubre de 1905 al 30 de septiembre de 1906, disfrutase de una estancia en Perpignan, Toulouse, Tarbes, Pau, Bayonne, Bordeaux y París, para ampliar los estudios sobre Historia antigua y media de España. AGUCM P-542-18 y AGA 31/15954-14.

6 AGUCM P-542-18.

7 AGA 31/15954-14.

8 Fue nombrado en noviembre de 1900, tomó posesión el 3. Cesó el 14 de marzo de 1901. Le sustituyó en la cátedra el catedrático supernumerario José Surroca y Grau. AGUCM P-542-18. 


\section{Académico}

Hinojosa fue uno de los grandes intelectuales de su época. Militó en el campo católico, algo que hay que reseñar en el contexto de las luchas ideológicas habidas durante la Restauración entre los krausistas y miembros de la Institución Libre de Enseñanza, por un lado, y los conservadores católicos de tendencias neoescolásticas, por otro lado. Ello no fue óbice para que mantuviese relaciones muy cordiales y hasta de amistad con personajes de la talla de Gumersindo de Azcárate, Joaquín Costa, Rafael Altamira o Giner de los Ríos, mientras que dos destacados neoescolásticos, el catedrático de Metafísica Juan Manuel Ortí y Lara, y el historiador Aureliano FernándezGuerra, fueron sus padrinos de boda en 1877. Más adelante veremos su estrecha relación con la familia Pidal.

Si bien puntualmente se dedicó a la política, las grandes pasiones de Hinojosa fueron el estudio y la enseñanza. Llevó una vida cultural muy activa, con varios viajes de estudio por el extranjero y una destacada labor en el Ateneo de Madrid. Su prestigio y aptitudes le valieron ser elegido para formar parte de varias Reales Academias.

$\mathrm{Al}$ poco tiempo de instalarse en Madrid, era ya miembro de la Academia de Jurisprudencia y Legislación, corporación en la que ingresó como socio el 20 de noviembre de $1871^{1}$. Esta Academia era un centro de reunión y estudio de gran parte de los estudiantes y licenciados en Derecho que llegaban a Madrid, siendo necesario únicamente tener aprobada la asignatura de Derecho Civil del primer curso para ser admitido como socio. Esta institución no se equiparó al resto de Reales Academias en estructura y funcionamiento hasta bien entrado el siglo XX. La actividad más relevante de Hinojosa en este centro consistió en leer la conferencia inaugural de la reunión del Instituto de Derecho Internacional que se celebró en la Academia en 1911, titulada Los precursores españoles de Grocio ${ }^{2}$. Además, colaboró en la obra "Jurisconsultos españoles. Biografías de los ex presidentes de la Academia y

1 Archivo de la Real Academia de Jurisprudencia y Legislación, Registro de académicos, libro 1.

2 Publicada póstumamente en el Anuario de Historia del Derecho Español, VI (1929), pp. 220-236. 
de los jurisconsultos anteriores al siglo XX inscritos en sus lápidas” (Madrid, 1911. 3 vol.), encargándose de las notas biográficas de Francisco de Vitoria y Francisco Suárez ${ }^{3}$.

Hinojosa ocupó plaza de académico de número en otras tres de las Reales Academias instaladas en Madrid. La primera de ellas fue la Real Academia de la Historia, donde ingresó en 1889; fue propuesto el 29 de febrero de 1884 por los académicos Aureliano Fernández Guerra, Manuel Oliver Hurtado, Juan de Dios de la Rada y Delgado y el propio Menéndez Pelayo ${ }^{4}$ para la medalla $\mathrm{n} .{ }^{\circ} 8$, que había quedado vacante por el fallecimiento del director de la Academia, D. Antonio Benavides. En su discurso de ingreso, leído el 10 de marzo de 1889, que llevó por título El dominico Francisco de Vitoria, y que fue contestado por su gran amigo Menéndez Pelayo, quiso dar a conocer la figura de Vitoria como internacionalista, siendo este uno de los trabajos pioneros en el estudio del ilustre profesor de Salamanca.

En esta Academia formó parte de las Comisiones permanentes de Cortes y Fueros (1898), de Indias, de Recompensas (1904) y del Compendio de Historia de España. Junto a otros académicos, Hinojosa participó en la redacción de la "Historia General de España" que, bajo la dirección de Cánovas del Castillo, publicó la Academia entre 1890 y 18945; en concreto, se ocupó Hinojosa del tomo II, que llevó por título Historia de España desde la invasión de los pueblos germánicos hasta la ruina de la monarquía visigoda, del que fueron coautores Juan de Dios de la Rada Delgado y Aureliano Fernández-Guerra, y dentro del mismo redactó la parte titulada "Historia del reino visigodo hasta Atanagildo".

Colaboró igualmente en la comisión encargada de estudiar y publicar el Breviario de Alarico, importante texto legal visigodo descubierto en un palimpsesto de la Catedral de León y que dio origen a la publicación de la obra Legis Romanae wisigothorum fragmenta ex codice palimpsesto Sanctae legionensis Ecclesiae protulit illustravit ac sumptu publico edidit Regiae Historiae Academia Hispana (Madrid, 1896).

En el Boletín de la Academia publicó trabajos como Una nueva edición

3 Las dos breves notas biográficas redactadas por Hinojosa aparecieron en el T. I, pp. XXVII-XXXIII.

4 Archivo de la Real Academia de la Historia. Expediente del Excmo. Sr. D. Eduardo de Hinojosa y Naveros.

5 Historia general de España / escrita por individuos de número de la Real Academia de la Historia bajo la dirección de Antonio Cánovas del Castillo. Madrid: El Progreso, 1890-1894. 18 vol. 
de las crónicas españolas anteriores a la invasión árabe ${ }^{6}$ y recensiones de diversas obras. También colaboró en la ordenación de documentos para la publicación de las Cortes medievales catalanas y la "Colección de documentos inéditos para la Historia de las antiguas posesiones españolas de América y Ultramar".

El 1 de diciembre de 1911 fue elegido Secretario perpetuo de la corporación, y desde el 13 de enero de 1918 era el Decano de la misma. Entre sus discursos e intervenciones académicas, cabe destacar la necrología que pronunció en honor del gran historiador y jurisconsulto alemán Theodor Mommsen, académico honorario de la RAH, fallecido en $1903^{7}$. Asimismo, como Secretario de la Academia y en representación de la misma, acudió a Gante en 1913, donde pronunció una conferencia en la Exposición Universal allí celebrada con el título Carlos Vy su siglo ${ }^{8}$. Se ocupó también, finalmente, de escribir el discurso de contestación al de ingreso de Ramón Menéndez Pidal (1916), que llevó por título Acerca de la Crónica General de Alfonso el Sabio. Su último trabajo escrito es un breve informe sobre el "Código de costumbres escritas de Tortosa”, fechado en diciembre de $1918^{9}$.

En 1919, ya gravemente enfermo, recibió los últimos sacramentos en presencia de sus compañeros el mismo día en que ingresó como académico el duque de Alba, 19 de mayo de 1919, falleciendo pocas horas después en la residencia oficial del secretario en la Casa del Nuevo Rezado, sede de la Academia de la Historia. La necrología oficial corrió a cargo de Juan Pérez de Guzmán y Gallo ${ }^{10}$, siendo asimismo recordado por la corporación en el XXV aniversario de su fallecimiento ${ }^{11} \mathrm{y}$ en el centenario de su nacimiento (1952).

En plena madurez intelectual, Hinojosa resultó elegido académico numerario de la Real Academia de Ciencias Morales y Políticas, concretamente el 27 de octubre de 1896, mientras ejercía como Gobernador Civil de Barcelona; lo fue a propuesta de Marcelino Menéndez Pelayo, Gumersindo de Azcárate y Raimundo Fernández Villaverde, aunque no ingresó en esta corporación hasta el 26 de mayo de 1907, con un discurso titulado La condición civil de

6 En BRAH, XXVII, cuad. IV (oct 1895), pp. 255-262.

7 En BRAH, t. XLV, cuad. VI (1904), pp. 531-541.

8 Publicada póstumamente en el BRAH, t. LXXVIII, cuad. II (1921), pp. 165-180.

9 En BRAH, t. LXXIV (1919), pp. 5-6.

10 Excmo. Sr. D. Eduardo de Hinojosa y Naveros, Necrología, en BRAH, t. LXXIV (1919).

11 V. Castañeda y Alcover, "El XXV aniversario del fallecimiento del Excmo. Sr. D. Eduardo de Hinojosa”, BRAH, t. CXIV (1944), p. 289. 
la mujer en el derecho español antiguo y moderno, con contestación de Luis Pidal ${ }^{12}$.

En esta casa ocupó la medalla n. ${ }^{0} 30$, vacante por el fallecimiento del marqués de la Fuensanta del Valle, y se le contabilizaron un total de 196 asistencias; fue elegido poco después Académico bibliotecario, cargo que ocupó entre 1909 y 1919, si bien, debido a su enfermedad, fue auxiliado en las tareas de la biblioteca por D. Luis Redonet.

Sin embargo, su primer contacto con la RACMyP es bastante anterior. Presentó una memoria al concurso ordinario de 1889 ( $2 .^{\circ}$ tema), titulada Influencia que tuvieron en el Derecho público de su patria y singularmente en el Derecho penal, los filósofos y teólogos españoles anteriores a nuestro siglo (Madrid, 1890), que resultaría premiada. Los concursos convocados por la RACMyP eran el medio por el cual la Academia se abría a la participación de otros investigadores y escritores ajenos a la misma. Ya fuesen ordinarios, extraordinarios, especiales o financiados por alguna fundación, se convocaron casi ininterrumpidamente entre 1860 y 1919, dando como resultado la publicación de 150 memorias de temática muy variada, como corresponde al heterogéneo conjunto de disciplinas que eran y son objeto de estudio en el seno de la Academia.

Hinojosa fue uno de los muchos investigadores que resultaron premiados en los concursos de la Academia y que se convirtieron posteriormente en miembros de la misma; así, por ejemplo, además de Hinojosa, recibieron algún premio antes de ser académicos personalidades de la talla de Rafael Altamira, Adolfo Bonilla y San Martín, Fermín Caballero, José García Barzanallana, José Gascón y Marín, Emilio Miñana y Villagrasa, Juan Manuel Ortí y Lara, Lorenzo Paret y Guasp, Julio Puyol Alonso, Luis Redonet, Ángel Salcedo Ruiz y Vicente Santamaría de Paredes.

En la época en que Hinojosa fue elegido académico estaban en pleno auge los estudios de derecho consuetudinario en España; esta Academia, a instancias de Joaquín Costa, había comenzado a convocar los Concursos de Derecho consuetudinario y Economía popular en 1897, tradición que se mantuvo hasta 1919. A este respecto, Hinojosa ocupó un destacado lugar en las co-

12 Es extraña la tardanza de tantos años en ingresar en esta Academia; según su expediente, no presentó el discurso de ingreso hasta octubre de 1903, y en marzo de 1907 se informa de que había terminado el marqués de Pidal su discurso de contestación. Quizá sea achacable a Luis Pidal la tardanza en todo el proceso. Expediente del Excmo. Sr. D. Eduardo de Hinojosa y Naveros. Archivo de la RACMyP, Ca 44. 
misiones que se encargaron de dictaminar sobre dichos concursos, tomando parte en los dictámenes de los concursos de 1909 (con Azcárate), 1910 (con Félix Pío de Aramburu), 1911 (único firmante), y 1913 (con Azcárate y Ureña). Sobre este asunto cabe resaltar además que en abril de 1910 escribió Hinojosa una carta a Joaquín Costa solicitándole su participación como conferenciante "sobre metodología de las investigaciones de derecho consuetudinario"13 en el recién creado Centro de Estudios Históricos.

Además de desarrollar su actividad intelectual en centros de la capital, justo después de dejar su cargo de Gobernador civil de Barcelona, Hinojosa fue elegido miembro de número de la Real Academia de Buenas Letras de Barcelona el 7 de marzo de 1901, juntamente con Enric Prat de la Riba; allí leyó su discurso de ingreso, el 16 de marzo del mismo año, que llevó por título Origen y visicitudes de la pagesía de remensa en Cataluña ${ }^{14}$; el discurso de contestación corrió a cargo de Francisco Carreras y Candi. Con todo, su pronto traslado a Madrid le impidió asistir a las sesiones académicas de esta corporación. Aún así, un trabajo suyo, La recepción del derecho romano en Cataluña, fue publicado por esta Academia ${ }^{15}$.

La siguiente Academia en abrirle sus puertas fue la Española. Propuesto el 14 de octubre de 1903 por los académicos Juan Valera, Mariano Catalina del Amo y Menéndez Pelayo para ocupar la silla T, vacante tras el fallecimiento de Gaspar Núñez de Arce, resultó elegido el 12 de noviembre de 1903 e ingresó el 6 de marzo de 1904 con un discurso que versó acerca de las Relaciones entre la poesía y el Derecho, siendo contestado por Alejandro Pidal en un acto solemne presidido por el rey Alfonso XIII. Allí colaboró en las comisiones del Diccionario vulgar y del Diccionario de Autoridades ${ }^{16}$, pero no queda constancia de que desarrollase en este centro una gran actividad.

Hay que citar igualmente el papel de Hinojosa en el Ateneo, la gran institución cultural madrileña que vivió su mayor esplendor durante la época de la Restauración. Entre otras cosas, fue Secretario $10^{\circ}$ de la Sección de Ciencias Históricas en el curso 1884-1885; en febrero de 1896 pronunció una confe-

13 Véase, Pablo Ramírez Jerez/Manuel Martínez Neira, La historia del derecho en la Real Academia de Ciencias Morales y Políticas. Los concursos de derecho consuetudinario, Madrid, Dykinson, 2017, p. 186, y la contestación de Costa en la p. 188.

14 Barcelona, Imp. de la casa Provincial de Caridad, 1902.

15 En Boletín de la Real Academia de Buenas Letras de Barcelona, t. 5 (1910), pp. 209-221. Es traducción de La réception du droit roman en Catalogne, en Mélanges Fitting (Montpelier, 1908).

$16 \mathrm{http} / /$ archivo.rae.es/index.php/expediente-personal-del-academico-de-numeroeduardo-de-hinojosa. 
rencia sobre Origen del régimen municipal en León y Castilla ${ }^{17}$ dentro de la iniciativa de Joaquín Costa sobre el tema "Tutela de pueblos en la historia", en la que participaron el propio Costa, Altamira e Hinojosa. Cuando se fundó en el Ateneo la Escuela de Estudios Superiores, Hinojosa impartió en 18981899 un curso titulado "Historia de la esclavitud y de la servidumbre de la gleba en Europa” (12 lecciones). Por último, poco antes de su enfermedad, en el curso 1909-1910, y dentro del ciclo de conferencias sobre historia contemporánea española (Los sucesos políticos de 1810), Hinojosa leyó la suya titulada Napoleón I, el Concordato y el Código Civil, el 3 de marzo de 1910 ${ }^{18}$.

En 1913, debido a un derrame cerebral que sufrió durante una sesión de la RAH, Hinojosa quedó afectado por una parálisis con la que hubo de convivir durante seis largos años y que paulatinamente le impidió continuar con sus tareas científicas y literarias. En consideración a su persona, la RAE le permitió dejar de asistir a las sesiones manteniendo a la vez los beneficios otorgados a los asistentes, mientras que la RAH y la RACMyP le mantuvieron en sus cargos de secretario y bibliotecario, respectivamente.

Fue de gran importancia para su carrera política y académica la amistad que mantuvo Hinojosa con la familia Pidal, especialmente con los hermanos Luis y Alejandro. Los Pidal, de raigambre asturiana y destacados miembros del conservadurismo católico español, fueron una de las familias más influyentes en la política de la época.

Pedro José Pidal y Carniado (1799-1865), marqués de Pidal, fue Ministro de la Gobernación y de Estado con Narváez, embajador en Roma, miembro de las Academias de la Historia y Bellas Artes, académico fundador y primer presidente de la RACMyP (1857-1865), y presidente asimismo de la Academia Matritense de Jurisprudencia y Legislación. Su primogénito, Luis Pidal y Mon (1842-1913), diputado y senador, fue Ministro de Fomento con Francisco Silvela, presidente del Senado y del Consejo de Estado, y embajador en Roma, además de académico de la RAE y de la RACMyP. Por último, Alejandro Pidal y Mon (1846-1913), apodado "el zar de Asturias", fue diputado y presidente del Congreso, ministro de Fomento con Cánovas, embajador ante la Santa Sede, académico y presidente de la RAE y miembro de la RACMyP. Los tres Pidal fueron además caballeros de la orden del Toisón de Oro. Un sobrino de los Pidal, Ramón Menéndez Pidal, fue alumno de Hinojosa en la Universi-

17 Publicado en "La Administración", julio de 1896.

18 Véase, Francisco Villacorta Baños, El Ateneo de Madrid (1885-1912), Madrid, CSIC, 1985 . 
dad Central y, como ha quedado señalado, el propio Hinojosa se encargó del discurso de contestación a su ingreso en la RAH en 1916, si bien, debido a su enfermedad, el discurso fue leído por Julián Ribera ${ }^{19}$.

Luis y Alejandro Pidal ingresaron en la RACMyP, con una semana de diferencia, en 1887; y ambos fallecieron, con dos meses de diferencia, en 1913. Y volviendo a su relación con Hinojosa, Alejandro Pidal fue el académico encargado de dictaminar sobre la memoria que aquel presentó al concurso de 1889, así como de responder a su discurso de ingreso en la RAE en 1904; Luis Pidal, por su parte, sería el académico que contestó a su discurso de ingreso en 1907 en la RACMyP. A Alejandro Pidal dedicó Hinojosa una de sus principales obras, El régimen señorial y la cuestión agraria en Cataluña durante la Edad Media (Madrid, 1905).

También a través de los Pidal entró en contacto Hinojosa con prominentes miembros del conservadurismo político español, como Cánovas del Castillo, Joaquín Sánchez de Toca y Javier Ugarte y Pagés, todos ellos miembros también de la RACMyP y quienes llamaron a Hinojosa a colaborar con ellos en algún momento de sus carreras políticas.

Otro amigo íntimo suyo, Marcelino Menéndez Pelayo, fue un personaje clave para el acceso de Hinojosa a las Reales Academias avalando su candidatura, como hemos visto; en justa compensación y como prueba de amistad, Hinojosa colaboró en el homenaje que se tributó al maestro santanderino en el vigésimo año de su profesorado, donde publicó su trabajo El derecho en el Poema del $\mathrm{Cid}^{20}$.

Pero su red de amistades era más amplia, y contaba entre sus amigos a intelectuales de otras tendencias como Joaquín Costa o Francisco Giner de los Ríos; este último, por ejemplo, le escribió una carta quejándose de que abandonase su cátedra de Historia Antigua y Media de España en noviembre de 1900 para ir a ejercer por segunda vez como Gobernador Civil de Barcelona.

Hinojosa recibió también el reconocimiento de diversas instituciones extranjeras; así, fue Doctor Honoris Causa por la Universidad de Friburgo, correspondiente del Instituto de Francia, Miembro honorario de la Sociedad

19 Por supuesto, la candidatura de Menéndez Pidal fue avalada por el propio Hinojosa (junto a Mélida, Ureña y Azcárate), si bien hubo de presentarse en una segunda ocasión para ganar la votación.

20 En: Estudios de erudición española: homenaje a Menéndez y Pelayo en el año vigésimo de su profesorado. Madrid, Lib. General de Victoriano Suárez, 1899. 2 vol. El trabajo de Hinojosa en el T. I, pp. 541-581. 
Jurídica de Berlín, correspondiente del Real Instituto Véneto de Ciencias, Letras y Artes, Miembro de la Junta de Historia y Numismática de Buenos Aires, y Oficial de la Legión de Honor de Francia. 


\section{Otros desempeños}

Como hemos visto, las actividades investigadoras, docentes y culturales de Hinojosa ocuparon la mayor parte de su vida activa. Sin embargo, en más de una ocasión hubo de ceder a las presiones de sus amigos políticos, especialmente los Pidal, y ocupar diversos cargos políticos, en los que siempre dio muestras de buen hacer.

De tendencias marcadamente católicas, colaboró Hinojosa con diversas asociaciones religiosas y la prensa afín de la época ${ }^{1}$. Políticamente conservador, militó en la Unión Católica de Alejandro Pidal, partido que acabó integrándose en el Partido Conservador de Cánovas del Castillo. Fue además Secretario de Relaciones de los Círculos y Obras Católicas, y miembro de la Junta Organizadora del Congreso Eucarístico Internacional de 1888.

Alejandro Pidal ocupó la cartera de Fomento en el gobierno de Cánovas entre enero de 1884 y noviembre de 1885 , y siendo Hinojosa su secretario fue enviado a Francia a estudiar su modelo de segunda enseñanza. Más tarde, bajo el gobierno conservador de Cánovas del Castillo, y a instancias de Joaquín Sánchez de Toca, fue nombrado Gobernador civil de Alicante el 21 de marzo de $1891^{2}$; poco después, el 26 de enero de 1892, pasó a ser Gobernador civil de Valencia, donde pudo compaginar la gestión política con el estudio. Cesó en noviembre de ese mismo año cuando Sagasta sustituye a Cánovas al frente del gobierno.

Tras una serie de gobiernos liberales, tiempo en el que se mantuvo apartado de la política, Cánovas le requiere de nuevo como gobernador, y rechazando primero ir a Sevilla, es nombrado otra vez Gobernador civil de Valencia el 28 de febrero de 1896, donde ha de lidiar con las revueltas promovidas por el grupo de Blasco Ibáñez, quien criticó su gestión desde el periódico "El Pueblo"; el 23 de mayo del mismo año Cánovas le envía a Barcelona como Gobernador, donde permanecería hasta el 21 de octubre de 1897, cuando cae

1 Son destacables sus artículos y recensiones publicados entre 1908 y 1911 en "El Universo", diario católico y conservador fundado y dirigido por el pedagogo y académico Rufino Blanco Sánchez.

2 Parece ser que una grave dolencia de su hijo mayor motivó a la familia a buscar un clima más templado, aunque de poco sirvió, puesto que el hijo falleció a los pocos meses. 
el gobierno de Azcárraga. Allí sobrevivió a un atentado anarquista durante la procesión del Corpus en junio de 1896, y supo manejar con buen tacto las reivindicaciones del movimiento catalanista. Como hemos visto, nunca ocultó sus preocupaciones científicas e investigadoras, y en Barcelona aprovechó para dedicarse al estudio en la medida de lo posible acudiendo a archivos y bibliotecas e interesándose vivamente por la historia de Cataluña, sobre la que empezaría a escribir abundantemente a partir de entonces.

Entre marzo de 1899 y abril de 1900, le correspondió a Luis Pidal ocupar la cartera de Fomento en el primer gobierno de Francisco Silvela, y entonces desempeñó Hinojosa el cargo de Director General de Instrucción Pública, donde se dedicó sobre todo a la reforma de la segunda enseñanza, y del que dimitió el 17 de abril de 1900 por motivos de salud. Pocos meses después volvió a ser Gobernador civil de Barcelona, entre noviembre de 1900 y marzo de 1901.

Pero Hinojosa deseaba seguir con sus estudios y ocupar la recién estrenada cátedra en la Facultad de Filosofía y Letras, y al gobierno le costó mucho convencerle de que aceptara su traslado a Barcelona en 1900, teniendo que pedírselo personalmente la propia reina María Cristina. Allí pasó apenas cuatro meses, y al margen de sus tareas políticas pudo seguir estudiando e investigando, y poco después de su cese fue elegido miembro de la Real Academia de Buenas Letras de Barcelona (vid. supra).

Ya instalado definitivamente en Madrid y dedicado a su cátedra, fue elegido senador por la Universidad de Santiago para las legislaturas 1899-1900, 1900-1901, y 1901-1902 si bien en la primera ocasión perdió el derecho al cargo en virtud de lo dispuesto en el art. $3 .^{\circ}$ de la Ley de 21 de mayo de 1885. Repitió el cargo por la misma Universidad en las legislaturas de 1903-1904 y 1907-1908. Siguió siendo senador, ya por la Real Academia de la Historia, en las legislaturas 1911-1914 y 1914-1915 .

En la legislatura de 1901 fue miembro de la comisión del ferrocarril de Tremañes a Veriña y tomó la palabra en la discusión sobre los presupuestos generales para 1902 y en la dedicada a remociones del personal directivo de establecimientos de enseñanza del distrito universitario de Santiago.

En la legislatura de 1903-1904 fue miembro de muchas comisiones: Administración Local, agregación del término municipal de Bouzas al de Vigo, ampliación de la Ley de reforma de la contribución industrial en Tarragona, cesión del terreno de Puerto Piojo al Ayuntamiento de La Coruña, de correc-

3 Puede consultarse todo su expediente en la web del Senado: http://www.senado.es. 
ción de estilo, de descanso dominical, de fomento y conservación de la Biblioteca, de prohibición de exportar obras de arte, de reforma de la Ley Común Electoral, de reforma de procedimientos y penalidad en los delitos de contrabando y defraudación, de responsabilidad civil de los funcionarios públicos, de retiros militares, de la carretera de Quincoces de Suso a Arciniega (Álava), de la carretera de Reus a Almoster, y de la carretera de Tarragona a la de Alcover y a Santa Cruz de Calafell. Presentó además una enmienda al artículo único, capítulo 10, del presupuesto de Instrucción Pública, e intervino en los discursos sobre descanso dominical (1 de febrero de 1904), presupuestos generales del Estado para 1904 (22 de diciembre de 1903) y Reforma de la Ley Electoral (10 de junio de 1904).

En la legislatura 1904-1905 formó parte de las siguientes comisiones: fomento y conservación de la biblioteca de Senado, jurisdicción judicial en las plazas del Norte de África, reforma de la legislación procesal y penal en materia de contratación y defraudación, delitos cometidos por medio de explosivos, y suplente de la Comisión de honor y mensaje para el pésame por el fallecimiento de S.A.R. la Serma. Sra. Princesa de Asturias. Asimismo, pronunció un discurso el 10 de diciembre de 1904 sobre represión de los delitos cometidos por medio de explosivos.

En la legislatura 1907-1908 fue miembro de las comisiones de administración municipal, de autorización al Ayuntamiento de Laredo para cubrir su déficit y ejecutar obras conforme a la ley de 1854, de concesión de bronce para erigir una estatua a Fray Luis de Granada, de fomento y conservación de la biblioteca, del Instituto Nacional de Previsión, de reforma del art. 90 del Código Penal (y presidente de la misma), de reforma del Código Penal en lo relativo al duelo, de reforma de la Ley electoral, de reglas para la emigración, de la carretera de Gandía al Puerto de Grao, de la carretera de Liérganes a la de Espinosa de los Monteros (Santander), y del ferrocarril de Ripoll a Puigcerdá. En cuanto a sus intervenciones, participó en el discurso de la reforma la Ley electoral vigente que tuvo lugar el 18 de julio de 1907.

En la legislatura 1908-1909 formó parte de las comisiones de amnistía por delitos políticos, de enseñanza obligatoria, de fomento y conservación de la biblioteca, de prisión preventiva para los menores de quince años, y varias comisiones de carreteras: de Charcones a la de Madrid a La Coruña, dos carreteras en Santander, de María (Almería) a Galera (Granada), del puente de Castro Urdiales a la general de Bilbao, de Santo Payo a Campelo (Pontevedra), y de Villalba del Rey a Santa María de Poyos. Presentó una enmienda 
al capítulo 16 de dictamen acerca del presupuesto de gastos de la Sección 7 . $^{\text {a }}$, Ministerio de Instrucción Pública y Bellas Artes para 1909, y participó ampliamente en el discurso sobre el Libro I del proyecto de ley respecto al régimen de Administración local (21 de enero de 1909); enmienda a la ley de presupuestos sobre gastos de instrucción pública, apéndice 31 al número 5 .

En la legislatura 1909-1910, última en la que fue elegido por la Universidad de Santiago, solo formó parte de la Comisión de fomento y conservación de la biblioteca.

Siendo ya senador por la Real Academia de la Historia, no tuvo participación activa en la legislatura de 1911, mientras que en la de 1914 solo fue miembro de la Comisión de honor y mensaje para el recibimiento y despedida de S.M. la Reina Dña. Cristina en la sesión regia de apertura.

Por último, aunque volvió a estar presente en el Senado en la legislatura de 1915, su enfermedad le impidió cualquier actividad en la Cámara Alta.

Por otro lado, su vinculación con el mundo de la educación estuvo presente a lo largo de toda su vida, pues al margen de la cátedra ocupó el ya mencionado cargo de Director General de Instrucción Pública, el de Consejero de Instrucción Pública (febrero de 1902), y el de vocal de la Junta de Fomento de la Educación Nacional (1907). 


\section{La verdadera y auténtica escuela de Hinojosa}

Con este título u otro similar, Carlos Petit nos debe un estudio sobre los historiadores que se formaron alrededor de Hinojosa en el Centro de Estudios Históricos. Un asunto que ha expuesto en distintos foros con su acostumbrada sabiduría. Mientras tanto, sirvan estas notas a manera de conclusión.

Como es conocido, por real decreto del 18 de marzo de 1910, Gaceta del 19, se creó el CEH, como centro dependiente de la JAE. Y enseguida se anunciaron los trabajos que sobre la historia de la edad media española debían desarrollarse en su seno, y en consecuencia se dispusieron las tareas organizadas en secciones':

1. ${ }^{\circ}$ Instituciones sociales y políticas de León y Castilla. Edición de una Colección crítica de diplomas públicos y privados de los siglos IX al XII, bajo la dirección de don Eduardo Hinojosa.

Aparece así Hinojosa como director de esta primera sección del CEH. Un nombramiento que venía preparándose al menos desde $1907^{2}$. Gracias a las memorias de la JAE podemos conocer muchas cosas sobre los trabajos desarrollados en la sección: a lo largo de los años 1910 y 1911 versaron "sobre la interpretación de Fueros municipales de los siglos XI y XII, como los de Palenzuela, Peralta, Covarrubias, Silos, Pozuelo, Lara y Medinaceli, e igualmente de títulos escogidos del Fuero Viejo de Castilla"3.

Al mismo tiempo, los alumnos de esta Sección se han ocupado en la elección y copia de diplomas y fueros de los conservados en el Archivo Histórico, en la Biblioteca Nacional y en la de la Academia de la Historia, y han hecho exploración metódica de los cartularios y documentos sueltos procedentes de iglesias y monasterios de León y Castilla (cartularios

1 Gaceta del 5 de mayo de 1910, en la que se inserta anuncio firmado el 23 de abril por el presidente de la JAE, Santiago Ramón y Cajal. Una reseña de los preparativos del Centro se encuentra en JAE, Memoria correspondiente a los años 1910 y 1911, Madrid 1912, pp. 131-134.

2 José María López Sánchez, "La escuela histórica del derecho madrileña: Eduardo de Hinojosa y Claudio Sánchez-Albornoz”, Cuadernos de historia de España, 81 (2007), pp. 165-180, en concreto 169.

3 JAE, Memoria correspondiente a los años 1910 y 1911, cit., pp. 134-135. 
de Celanova, Sobrado, Sahagún; los de la Orden de Santiago en León y Castilla, Aguilar de Campoo, Santa María del Puerto; los dos de la iglesia de Toledo; documentos sueltos de las colecciones de Celanova, Sobrado, Sahagún, Aguilar de Campoo; los siete tomos de pergaminos de la iglesia de Lugo; los de Melón, Samas, Osera, Meira, San Marcos de León, Carvajal, Sandoval, Oña, etc.), copiando los que deben incluirse en la Colección de textos para la historia de las instituciones sociales y políticas de León y Castilla en curso de impresión, e igualmente los que pueden servir como material científico para los ejercicios prácticos; se ha hecho el análisis de los documentos y la selección de los más típicos, y después de elaborados los materiales así reunidos ha podido comenzarse la publicación, que comprende, no sólo documentos inéditos, sino otros publicados ya, los más en colecciones poco accesibles. Una introducción histórica y las notas necesarias darán idea de la importancia y contenido de los documentos.

Sin embargo, la anunciada publicación de una colección diplomática no vio la luz hasta 1919, tras la muerte de Hinojosa ${ }^{4}$. Con una nota explicativa en la que podemos leer:

Don Eduardo de Hinojosa preparaba en el Centro de Estudios Históricos un libro sobre instituciones sociales en León y Castilla durante los primeros siglos de la Reconquista. La obra había de componerse de dos partes principales: una colección de los documentos más importantes referentes a aquéllas y un extenso análisis que recogiera las investigaciones de los historiadores de nuestras instituciones sociales, aumentándolas, rectificándolas y completándolas con aportaciones nuevas.

El volumen de documentos que ahora se entrega al público fue impreso en 1913; pero el Centro de Estudios Históricos creyó conveniente retenerlo para que saliera al mismo tiempo el estudio que el Sr. Hinojosa proyectaba.

Quebrantos de salud impidieron al autor realizar sus propósitos y el Centro de Estudios Históricos ha decidido poner a la venta la colección de documentos que tiene ya por sí misma un interés indudable. La integran materiales escogidos, muchos de ellos inéditos.

Dos discípulos del autor, los Sres. Vargas y Giner, transcribieron los documentos. El Sr. Longás hizo el índice alfabético y revisó las transcripciones, habiéndose insertado al final del presente volumen las correcciones más importantes señaladas por él. Las deficiencias que se observen en este libro podrán disculparse teniendo en cuenta las circunstancias en que ha sido compuesto.

En el anuncio de los trabajos de investigación científica y ampliación de estudios organizados para el curso 1912-1913 ${ }^{5}$, vuelve a aparecer -como con-

4 Documentos para la historia de las instituciones de León y de Castilla (siglos XXIII), coleccionados por Eduardo de Hinojosa, Madrid 1919.

5 Anuncio del 25 de noviembre de 1912 inserto en la Gaceta del 22 de diciembre de 1912. 
tinuación- la edición de la colección crítica de diplomas; y se añade ahora unas lecciones sobre la historiografía en el siglo XIX.

$10^{\circ}$ Instituciones sociales y políticas de León y Castilla, bajo la dirección de D. Eduardo de Hinojosa. (Continuación.)

Edición de una colección crítica de diplomas públicos y privados de los siglos IX al XIII.

2. ${ }^{\circ}$ La historiografía en el siglo XIX en los diversos países. Principales historiadores. Serie de lecciones por D. Eduardo de Hinojosa.

Por la Memoria correspondiente a esos años conocemos el contenido de las conferencias de Hinojosa, que versaron sobre los historiadores Macaulay, Taine, Mommsen, Fustel de Coulanges, Herculano, Menéndez y Pelayo, Costa y otros. Aparte se desarrollaron otras actividades dedicadas a traducir y comentar crónicas y fueros, y a transcribir documentos. Se informaba también de los trabajos personales de los alumnos realizados bajo la dirección de Hinojosa: José Giner Pantoja, preparaba el estudio de las Instituciones militares de León y Castilla hasta fines del siglo XIII; Pedro Longás Bartibás, tenía en preparación el Cartulario de Santa María del Puerto (transcripción, prólogo y notas); Galo Sánchez preparaba la edición del Fuero de Soria, con introducción y notas. A las clases de esta Sección asistieron también los alumnos Claudio Sánchez Albornoz, José María Ramos Loscertales, José María Vargas, Jesús Común y Cristóbal Pellejero ${ }^{6}$.

Pero enseguida, la enfermedad de Hinojosa impidió el normal desarrollo de la sección?7.

A pesar de la enfermedad que ha aquejado a su director, la Sección ha podido proseguir su obra, aunque con una intensidad disminuida.

Se han continuado los trabajos preparatorios de una Colección de documentos para la historia de las clases sociales de León y Castilla, comenzados en cursos anteriores.

Se ha publicado el texto castellano de El elemento germánico en el derecho español, por D. Eduardo de Hinojosa, monografía que había aparecido en una revista alemana. Para vulgarizar su conocimiento ha parecido conveniente esta versión castellana, hecha por D. Galo Sánchez y revisada y puesta al día por el autor.

6 Además, como curiosidad, en el último trimestre del bienio de 1912-1913 concurrió a esas clases un alumno de la Universidad de Harvard, Constantine E. Mc Guire, que estudiaba la historia del Derecho de asilo. JAE, Memoria correspondiente a los años 1912 y 1913, Madrid 1914, pp. 230-231.

7 JAE, Memoria correspondiente a los años 1914 y 1915, Madrid 1916, pp. 163-164. 
Está en prensa el Fuero de Soria, edición de D. Galo Sánchez, a base de tres manuscritos. Para el estudio de uno de ellos, existente en Soria, el Centro tiene que agradecer al Ayuntamiento de aquella ciudad las facilidades que ha dado remitiéndolo a Madrid. Al texto acompañan varios estudios complementarios referentes a la fecha del fuero, sus fuentes, relaciones con el Fuero Real, etc.

Hay en preparación una Colección de fueros inéditos y un estudio sobre Formularios jurídicos castellanos, por D. Galo Sánchez . Este último trabajo está ya muy avanzado.

En las memorias posteriores se sigue informando del desarrollo del trabajo de Galo Sánchez ${ }^{8}$, y de su conclusión”; así como de la muerte de Hinojosa:

Ha visto la Junta con el más hondo dolor la pérdida de uno de sus vocales, don Eduardo de Hinojosa, muerto en 19 de mayo de 1919 y arrancado ya antes, por larga enfermedad, a sus trabajos científicos, que quedarán como la contribución más sólida del siglo último a la historia social de la Edad Media en España. Dirigió una Sección en el Centro de Estudios Históricos sin haber podido, desgraciadamente, dar cima a la fundamental obra que se propuso. Mientras su salud se lo permitió fue asiduo concurrente a las reuniones de la Junta y aportó siempre las luces de su vastísima cultura y de su elevado sentido de justicia.

\section{Y del cierre de la sección:}

La muerte de don Eduardo de Hinojosa, de que en otro lugar se da cuenta, ha sido pérdida irreparable para la historia social y política de la Edad Media. Esa Sección fue cerrada y habrá que esperar que algún continuador intente reanudar la admirable labor que quedó truncada.

No será hasta años después que se anuncie de nuevo una "Sección de Historia del Derecho. Fundada por don Eduardo de Hinojosa y continuada por don Claudio Sánchez-Albornoz"10:

\section{SECCIÓN 4 . $^{\mathrm{a}}$ - HISTORIA DEL DERECHO ESPAÑOL.}

Esta Sección, que fue creada y dirigida por don Eduardo de Hinojosa, ha vuelto a nueva vida después de varios años en que tuvo interrumpidas sus tareas. El señor SánchezAlbornoz, sucesor de Hinojosa en su cátedra de la Universidad de Madrid, ha organizado y centralizado la actividad de los antiguos discípulos del maestro, Galo Sánchez y José Ramos Loscertales, y con la colaboración de otros profesores universitarios, como los señores

8 JAE, Memoria correspondiente a los años 1916 y 1917, Madrid 1918, p. 98.

9 JAE, Memoria correspondiente a los años 1918 y 1919, Madrid 1920, pp. 109-110.

10 JAE, Memoria correspondiente a los cursos 1924-5 y 1925-6, Madrid 1927, pp. 203, 223-224. 
Diez Canseco, Carande, de Sevilla [falta texto en el que se haría referencia al Anuario de historia del derecho español]; don Galo Sánchez, profesor de Historia del Derecho español. Constituye la primera publicación periódica dedicada a este estudio. En ella colaboran además reputados especialistas de Europa y América. Publica artículos, documentos, bibliografía, etc. Es director don L. Díez Canseco, profesor de Historia del Derecho en la Universidad de Madrid; redactores don R. Carande, profesor de Economía de la Universidad de Sevilla; don J. Ots Capdequi, profesor de Historia del Derecho en la Universidad de Sevilla: don Galo Sánchez, profesor de Historia del Derecho en la Universidad de Barcelona, y don J. Ramos Loscertales, profesor de Historia de España en la Universidad de Salamanca, y secretario de redacción don C. Sánchez-Albornoz, profesor de Historia medieval en la Universidad de Madrid.

El primer volumen apareció en 1924; el segundo en 1925, y el tercero se halla en prensa. Al final damos la lista de los trabajos publicados.

Aparte del Anuario, pero como anejos suyos, se publican obras que, por su volumen, no tienen fácil cabida en él. La primera ha sido la de Ernesto Mayer: Historia de las instituciones sociales y políticas de España y Portugal durante los siglos V a XVI, traducida del original alemán, por Galo Sánchez el tomo primero y por R. Carande el tomo segundo.

Nos enfrentamos aquí con la enésima fundación de la historia del derecho, con ocasión de la creación de la sección cuarta del CEH. Nótese que se postula como continuación de la sección creada por Hinojosa, aunque ahora estuviese frecuentada por otras personas y reciba una nueva denominación. Ya no se titulaba Instituciones sociales y políticas -el contenido de la cátedra que tantos años desempeñó Hinojosa- sino Historia del derecho español. Una sección que nació dirigida por Sánchez-Albornoz - quien también fue director del Anuario de historia del derecho español-, es decir por un ministro de la República. ¿No serán estas las “angustias" -los miedos- que contribuyeron a mitificar a Hinojosa?

En la genealogía de la disciplina, quizás debamos percibir una pluralidad de tradiciones, una de ella es sin duda la aportación de Sánchez-Albornoz, cuyo magisterio ha tenido -hasta hoy- un admirable desarrollo en Argentina. Pónganse todos los reparos que se quiera a esta idea de protagonismo compartido, seguramente razonables, pues ya desde 1919 encontramos una amplia "hagiografía" sobre Hinojosa ${ }^{11}$. Pero con frecuencia, mirar la realidad desde otro ángulo puede ayudarnos a aclarar las ideas.

11 Véase, Manuel Martínez Neira, "Hacia la madurez de una disciplina. Las oposiciones a cátedra de historia del derecho español entre 1898 y 1936”, Cuadernos del Instituto Antonio de Nebrija, 5 (2002), pp. 331-458, especialmente 442 ss. 


\title{
Fuentes y bibliografía
}

\author{
Fuentes
}

Archivo de la Real Academia de Ciencias Morales y Políticas

Expediente del Excmo. Sr. D. Eduardo de Hinojosa y Naveros, C 44.

Archivo de la Real Academia Española

Expediente del académico.

Archivo de la Real Academia de la Historia

Expediente del Excmo. Sr. D. Eduardo de Hinojosa y Naveros.

Archivo de la Real Academia de Jurisprudencia y Legislación

Registro de académicos, libro 1.

Archivo General de la Administración

AGA 31/6527 (antiguo 6151-15) Expediente personal del negociado de Archivos, Bibliotecas y Museos.

AGA 31/15954 (antiguo 754-14) Expediente personal de catedrático.

Archivo General de la Universidad Complutense de Madrid

AGUCM P-542-18 Expediente personal catedrático de la Facultad de Filosofía y Letras.

AGUCM ED-8-50 Expediente alumno de la Escuela Superior de Diplomática.

AGUCM ED-12-9 Expediente alumno de la Escuela Superior de Diplomática.

AGUCM ED-32-20 Expediente personal catedrático de la Escuela Superior de Diplomática.

Archivo del Senado

ES.28079.HIS-0224-05 Expediente personal del senador D. Eduardo de Hinojosa y Naveros.

Archivo Universitario de Granada

AUG 513-44: Grado de licenciado. Filosofía y Letras.

AUG 767-63: Grado de bachiller. Derecho.

AUG 769-71: Grado de licenciado. Facultad de Derecho.

AUG 2534-11: Expediente personal alumno.

AUG 4608-14: Grado de doctor. Derecho.

Biblioteca Histórica de la Universidad Complutense de Madrid

Archivo personal de Eduardo Hinojosa y Naveros. BH AP 7. 
Bibliografía citada

(No se incluyen las obras de Hinojosa)

Anchoriz, José María, Ensayo de Geografía histórica antigua, Madrid 1853.

Cánovas del Castillo, Antonio (dir), Historia general de España, 18 vols., Madrid 18901894.

Caroni, Pio, Escritos sobre la codificación, Madrid 2012.

Castañeda y Alcover, Vicente, "El XXV aniversario del fallecimiento del Excmo. Sr. D. Eduardo de Hinojosa", BRAH, t. CXIV (1944), pp. 289-290.

Coleman, Paul, La censura maquillada, Madrid 2018.

Cruz Herranz, Luis Miguel de la, "Eduardo de Hinojosa y Naveros", <dbe.rah.es>.

Cruz Herranz, Luis Miguel de la, El Archivo Histórico Nacional y el nacimiento del medievalismo español (1866-1955), en prensa.

Díaz Rico, Javier Carlos (ed.), Oposiciones a cátedras de derecho (1847-1943), Madrid 2018.

Faraldo, José M., Las redes del terror, Barcelona 2018.

Ferguson, Niall, La plaza y la torre, Barcelona 2018.

García-Gallo, Alfonso, "Hinojosa y su obra”, en Eduardo de Hinojosa y Naveros, Obras, tomo 1, Estudios de investigación, con un estudio de Alfonso García Gallo sobre Hinojosa y su obra, Madrid, Ministerio de Justicia/CSIC, 1948 (= Publicaciones del Instituto Nacional de Estudios Jurídicos, núm. 1), pp. 11-124, numeradas en romanos.

Hinojosa Ferrer, Juan de, "Eduardo de Hinojosa, historiador del derecho y varón justo", Información jurídica [ISSN 0303-9927], 83 (1950), pp. 503-561.

Kay, Jonathan, "When Censorship Is Crowdsourced”, Quillette (September 9, 2018).

López Sánchez, José María, "La escuela histórica del derecho madrileña: Eduardo de Hinojosa y Claudio Sánchez-Albornoz”, Cuadernos de historia de España, 81 (2007), pp. 165-180.

Martínez Dhier, Alejandro, “150 años del nacimiento de Eduardo de Hinojosa y Naveros, historiador del Derecho español”, Revista de la Facultad de Derecho de la Universidad de Granada, 2003, pp. 549-559.

Martínez Neira, Manuel, "Hacia la madurez de una disciplina. Las oposiciones a cátedra de historia del derecho español entre 1898 y 1936", Cuadernos del Instituto Antonio de Nebrija 5 (2002), pp. 331-458.

Moreno Casado, José, “Eduardo de Hinojosa, estudiante”, Boletín de la Universidad de Granada, 16 (1944), pp. 421-431.

Peiró Martín, Ignacio/Gonzalo Pasamar Alzuria, La Escuela Superior de Diplomática. Los archiveros en la historiografía española contemporánea, Madrid 1996. 
Peiró Martín, Ignacio/Gonzalo Pasamar Alzuria, "Eduardo de Hinojosa”, Diccionario Akal de historiadores españoles contemporáneos (1840-1980), Madrid 2002, pp. 326-327.

Pérez Boyero, Enrique y otros, Inventario del fondo documental de la Junta Facultativa de Archivos, Bibliotecas y Museos, vol. 2, Madrid 2016.

Peset, Mariano, "Eduardo de Hinojosa. Historiador y político", en Eduardo de Hinojosa y Naveros, El régimen señorial y la cuestión agraria en Cataluña durante la edad media, Navarra 2003, pp. 7-114 (numeradas en romanos).

Petit, Carlos, "Altamira en Chicago", en Rafael Altamira, Spain. Sources and Development of Law, estudio preliminar y edición de Carlos Petit, Madrid 2018, pp. xi ss.

Ramírez Jerez, Pablo/Manuel Martínez Neira, La historia del derecho en la Real Academia de Ciencias Morales y Políticas. Los concursos de derecho consuetudinario, Madrid 2017.

Reyes, Fermín de los/José María de Francisco (eds.), 150 aniversario de la fundación de la Escuela Superior de Diplomática (1856-2006). Reglamento y programas, Madrid 2007.

Tomás y Valiente, Francisco, Manual de historia del derecho español, $4 .^{\mathrm{a}}$ ed., Madrid 1983 .

Torreblanca López, Agustín, El cuerpo facultativo de Archiveros, Bibliotecarios y Arqueólogos (1858-2008). Historia burocrática de una institución sesquicentenaria, Madrid 2009.

Vallejo, Jesús, Maneras y motivos en Historia del Derecho, Madrid 2014, pp. 57-79.

Villacorta Baños, Francisco, El Ateneo de Madrid (1885-1912), Madrid, CSIC, 1985. 

APÉNDICE 



\section{CRONOLOGÍA DE EDUARDO DE HINOJOSA}

1852, 25 de noviembre. Nace en Alhama (Granada).

1861-1866. Estudios de segunda enseñanza. El 1 de julio de 1866 obtuvo el grado de bachiller en artes.

1867-1868. Comenzó los estudios de facultad en la Universidad de Granada.

1869, 25 de junio. Grado de bachiller en la facultad de derecho de la Universidad de Granada.

1869, 11 de octubre. Grado de licenciado en la facultad de derecho de la Universidad de Granada.

1870, 14 de septiembre. Nombrado promotor fiscal del Juzgado de Órgiva, tomando posesión el 28 de septiembre. Dimite por motivos de salud el 7 de octubre de 1870.

1870, 16 de diciembre. Nombrado conservador de las antigüedades de la Academia de la Historia.

1872, 28 de junio. Grado de doctor en la facultad de derecho de la Universidad de Granada.

1872, 30 de septiembre. Grado de licenciado en la facultad de filosofía y letras de la Universidad de Granada.

1873-74, 1874-75 y 1879-80. Durante estos tres cursos académicos fue alumno de la Escuela Superior de Diplomática.

1874. Profesor de Derecho romano en los estudios de la Asociación de católicos de España.

1874. Servicio militar (Leganés).

1874, 10 de marzo. Nombrado auxiliar de la comisión de cortes por la Real Academia de la Historia.

1875. Formó parte de la redacción de La España católica. 
1875, 19 de marzo. Ingresó en el cuerpo facultativo de Archiveros, Bibliotecarios y Anticuarios. El 24 de marzo empezó a servir en el Museo Arqueológico nacional.

1877, 10 de mayo. Contrajo matrimonio en la iglesia parroquial de S. José (Madrid) con Esperanza Ferrer y Fernández-Flórez.

1878. Comisionado por el gobierno español para una estancia por estudios en Francia y Alemania.

1880, 4 de marzo. Titulado por la Escuela Superior de Diplomática.

1880, 12 de junio. Obtuvo el certificado de aptitud para Archivero, Bibliotecario y Anticuario.

1882, 12 de diciembre. Tomó posesión como catedrático de Geografía antigua y de la Edad Media de la Escuela Superior de Diplomática.

1883,13 de diciembre. Obtuvo el grado de doctor en la facultad de filosofía y letras de la Universidad Central.

1883, 1884, 1886, 1894. Firmó distintas oposiciones a cátedras de universidad.

1884. Como secretario personal del ministro de Fomento Pidal viaja a Francia para estudiar la organización de la primera enseñanza.

1884. Secretario de la sección de geografía e historia del Ateneo de Madrid.

1884, 28 de enero. Nombrado secretario general de la Junta facultativa de Archivos, Bibliotecas y Museos y secretario de la Escuela Superior de Diplomática, cesó el 23 de noviembre de 1887.

1884, 29 de febrero. Elegido académico de la Real Academia de la Historia (el 10 de marzo de 1889 tomó posesión).

1884, 9 de abril. Nombrado jefe de $3{ }^{\text {er }}$ grado de la Sección de Museos del cuerpo facultativo.

1884, 28 de junio. Comisionado para inspeccionar las instalaciones de los museos arqueológicos de provincias. 
1884, 30 de septiembre. Nobrado por real orden de esa fecha catedrático de Historia de las instituciones de España en la edad media de la Escuela Superior de Diplomática.

1886, 19 de abril. Firmó la oposición para la cátedra de Historia general del derecho español vacante en la Universidad Central. Desistió.

1886, 10 de junio. Se incorporó al Ilustre colegio de abogados de Madrid. Desde el 1 de julio ejerció la profesión de abogado.

1887, 18 de noviembre. Nombrado vocal de la Junta Facultativa de Archivos, Bibliotecas y Museos.

1887, 12 de diciembre. Solicitó el primer quinquenio.

1888, 9 de febrero. Nombrado por el cardenal Moreno, arzobispo de Toledo, secretario de relaciones de círculos y obras católicas.

1889. Organización del archivo de Isabel II depositado en la Real Academia de la Historia.

1891, 21 de marzo. Gobernador civil de Alicante.

1892, 26 de enero. R. D. nombrando Gobernador civil de la provincia de Valencia, "que desempeña el mismo cargo en la de Alicante". (Gaceta del 28). Cesó en noviembre de ese año.

1896, 28 de febrero (Gaceta del 29). R. D. nombrando Gobernador civil de la provincia de Valencia "que ha desempeñado igual cargo en varias provincias". Cesa el 23 de mayo.

1896, 23 de mayo (Gaceta del 24). R. D. nombrando Gobernador civil de la provincia de Barcelona "que lo es actualmente de la de Valencia". El 12 de octubre de 1897 fue admitida su dimisión (Gaceta del 13).

1896, 27 de octubre. Elegido académico de la Real Academia de Ciencias Morales y Políticas (el 26 de mayo de 1907 tomó posesión).

1897, 30 de julio. Por real orden de esa fecha su cátedra pasa a denominarse Historia de las instituciones de España en las Edades Media y Moderna. 
1898-99. En ese curso dictó 12 lecciones en el Ateneo de Madrid.

1899, 5 de marzo (Gaceta del 8). R. D. por el que se le nombra Jefe superior de Administración civil, Director general de Instrucción pública. El 17 de abril de 1900 (Gaceta de 21 de abril) fue admitida su dimisión por motivos de salud.

1899, 30 de abril. Elegido senador por la Universidad de Santiago (perdió el derecho al cargo).

1900, 24 de enero. Nombramiento de vocal académico de la Junta Facultativa de Archivos, Bibliotecas y Museos.

1900, 22 de julio. Obtuvo el título de catedrático numerario de Historia antigua y media de España de la Facultad de Filosofía y Letras de la Universidad Central. Por real orden de 19 de septiembre de 1900 (Gaceta del 20) se dispone que se encargue de la asignatura de Historia antigua y media de España (clase diaria) desde el curso 1900-1901.

1900, 1 de noviembre (Gaceta del 2). R. D. por el que se le nombra "en comisión" Gobernador civil de la provincia de Barcelona. El 10 de marzo de 1901 (Gaceta del 11) se admitió su dimisión.

1901, 16 de marzo. Discurso de ingreso en la Reial Acadèmia de Bones Lletres.

1901, 2 de junio. Elegido senador por la Universidad de Santiago.

1902, 21 de febrero (Gaceta del 27). R. D. por el que se le nombra Consejero de Instrucción pública, con destino a la sección quinta.

1903, 10 de mayo. Elegido senador por la Universidad de Santiago.

1903, 12 de noviembre. Elegido para la silla T de la Real Academia Española. Tomó posesión el 6 de marzo de 1904.

1905, 15 de junio. Se le concede por el Ministerio una subvención para ampliar en distintas localidades francesas estudios sobre historia antigua y media de España.

1906, 17 de septiembre. Por real orden de esa fecha acumula la cátedra de Historia de América, del doctorado de Historia. Cesa en 1912. 
1907, 10 de enero (Gaceta del 14). R. D. nombrado vocal de la Junta para Fomento de la Educación Nacional. Cese por supresión de la Junta el 7 de diciembre de 1907 (Gaceta del 10)

1907, 5 de mayo. Elegido senador por la Universidad de Santiago.

1908, 10 de julio. R. O. fue nombrado -junto a Rafael Altamira- representante español para asistir al Congreso de Ciencias Históricas de Berlín, donde presentó el trabajo "El elemento germánico en el derecho español", becado por la Junta para ampliación de estudios.

1909, 18 de mayo. Solicita al ministerio de Instrucción pública una pensión para estudiar en el extranjero (Bélgica).

1909, 30 de junio. Nombrado académico bibliotecario de Morales. Reelegido y declarado bibliotecario perpetuo el 6 de diciembre de 1910.

1910, 23 de abril. La JAE anuncia la organización del CEH. La sección 1. ${ }^{a}$, Instituciones sociales y políticas de León y Castilla, estaba bajo la dirección de Hinojosa.

1911, 25 de mayo. Elegido senador por la Real Academia de la Historia.

1914, febrero. Sufrió un ictus.

1914, 22 de marzo. Elegido senador por la Real Academia de la Historia.

1919, 19 de mayo. Murió en Madrid. 
Expediente del grado de doctor de D. Eduardo Hinojosa Naveros Facultad de Derecho

Año de 1872

Granada 25 de junio de 1872

Teniendo aprobadas las asignaturas correspondientes al periodo de Doctorado en la facultad de Derecho, y deseando hacer los ejercicios de dicho grado, suplico se sirva mandar que sea admitido a ellos, en el más breve plazo posible.

Gracia que espera alcanzar.

El Secretario general certifica que Eduardo de Hinojosa y Naveros de 19 años tiene hechos los siguientes estudios.

En el Colegio de escuelas Pías de Archidona incorporado a el Instituto de Málaga De 1861 a 62

Latín y Castellano primer año - Sobresaliente

Principios de Aritmética - Notable

Doctrina cristiana - Mediano

De 1862 a 63

Segundo de Latín y Castellano - Sobresaliente

Geografía - Sobresaliente

Principios de Geometría - Sobresaliente

De 1863 a 64

Lengua griega primer año - Sobresaliente

Historia general - Sobresaliente

Aritmética y Álgebra - Sobresaliente

Francés - Sobresaliente

Instituto de Málaga

De 1864 a 65

Retórica y Poética - Sobresaliente

Geometría y Trigonometría - Notable

Segundo curso de Griego - Sobresaliente

En el Colegio de Escuelas Pías de S. Fernando incorporado a el Instituto de S. Isidro de Madrid

De 1865 a 66

Lógica - Notable 
Física y Química - Bueno

Historia natural - Bueno

Grado de Bachiller en Artes por el Instituto de S. Isidro de Madrid 1 de Julio de 1866 con nota de - Aprobado

\author{
Estudios de Facultad \\ Universidad de Granada
}

De 1867 a 68

Derecho Romano primer curso - Bueno

Economía política y Estadística primer curso - Bueno

Literatura general y española - Sobresaliente

De 1868 a 69

Derecho Romano segundo curso - Bueno

Economía política y Estadística segundo curso - Notable

Elementos de Derecho civil español común y foral - Aprobado

Instituciones de Derecho canónico - Aprobado

Derecho mercantil y penal - Aprobado

Derecho político y administrativo español - Notable

Grado de Bachiller en Derecho civil y canónico el 25 de junio del 69 con nota de Aprobado

En el mismo curso [1868 a 69 - alumno libre]

Ampliación del Derecho civil y Códigos españoles - Aprobado

Disciplina general de la Iglesia y particular de España - Aprobado

Teoría práctica de los procedimientos judiciales - Aprobado

Práctica forense - Aprobado

Grado de Licenciado en Derecho civil y canónico, el 11 de octubre de 1869 con nota de Aprobado.

De 1869 a 70

Filosofía del Derecho: Derecho internacional - Aprobado

Legislación comparada - Aprobado

Historia de la Iglesia, concilios y colecciones canónicas - Aprobado 
En virtud de los anteriores estudios y grados, este licenciado se halla en aptitud legal para aspirar al Doctorado en Derecho civil y canónico. Granada 26 de junio de 1872.

Se le admite a los ejercicios del grado.

Paga los derechos de examen.

Se señala para el ejercicio el 28 de junio de 1872, a las 4 de la tarde.

Tuvo lugar el ejercicio - Aprobado

Filosofía y Letras

Curso 1870 a 71

Geografía - Aprobado

Historia Universal - Aprobado

Historia de España - Aprobado

Lengua griega

El 9 de mayo de 1871 trasladó a la Central y el 21 de agosto de 1872 fue autorizado por aquella Escuela para examinarse en esta de Granada

Curso 1871-72

Lengua griega - Aprobado

Literatura clásica latina - Aprobado

Metafísica - Aprobado

Literatura clásica griega - Aprobado

Estudios críticos sobre los autores griegos - Aprobado

Lengua árabe - Aprobado

Los probó como alumno libre.

[30 de septiembre de 1872, ejercicios grado de licenciado en Filosofía y Letras Aprobado] 


\section{UNIVERSIDAD GENTRAL.}

\section{ESCUEL SUPERIOR DE DIPLOMÁTICA}

ESPECIAL DFI, CUFRPO FACUITATIVO

DE ARCHIVEROS, BIBLIOTECARIOS Y ANTICUARIOS.

\section{PROGRAMA}

DE LA ASIGNATURA DE HISTORIA DE LAS INSTITUGIONES HE ESPAN̂A EN TA RDAD MEDIA.

\section{MA D R I D}

IMPRENTA DE T. FORTANET

$$
\begin{gathered}
29 \text { - CAIJIE DE LA IMHERTAD }-29 \\
1876
\end{gathered}
$$




\section{PROGRAMA}

VI: I.A

\section{asIGYATURA DE IIISTORI DE LAS IISTIIUCIONES OE RSPAÑ}

EN LA EDAD MEDIA.

I.

PIEIIMINAR.

\section{LEGGION 1."}

Historia.-1. Definicion de la Historia. - Diversa manera de considerarla en la sucesion de los tiempos.-Sus verdaderos límiles.-De la certidumbre histórica.-Ciencias auxiliares de la Historia. - 2. Divisiones de la IListoria. - Edades históricas. - Divisiones propias de la Hisloria de España. - - 3. Historia de España en la Edadmedia con aplicacion al estudio y mejor inteligencia do los diplomas. - Concepro, utilidad y objeto especial de esta asignatura. - Division en épocas y períodos. - Método de enscñanza y de estudio. 
II. INTRODUCGION.

DESDE LOS TIEMPOS HISTÓHCOS Más AN'TGLOS HASTA LA caida dila imperio romano de ogcidente.

\section{LECGION ?:"}

Tiempos auteriores á la dominacion romana. - 1. Los Iberos.-Los Celtas.--Los Celtiberos. - Religion.-Usos y costumbres. - 2. Los Fenicios. -- Los Griegos. - Los Cartagineses. - Religion. - Leyes y costumbres.

\section{IECGION :"}

España romana.-1. Dominacion romina. - ․ Organizacion social. -- Estado y condicion de las personas. - Esclavitud. - Colonato. - Ia fimilia. - Formas dol matrimonio. - Propiclad del suelo. - Fórmulas jurídicas. - 3. Gobierno. - Division del lerrilorio. - Instituciones y forma de gohierno durante la República: desde Augusto hasta Constantino: desde Constantino hasta la irrupcion de los pueblos bárbaros. - Prefecturas. - Diócesis. - Provincias. - Concilios. - Conventos jurídicos. -4. Organizacion mmicipal.-Curia.--Magistrados.-Oficiales. - Atribuciones y derechos del munieipio.-.. Leyos municipales. - Estado del municipio í la caida del Imperio romano. - 5. Exámen de algunos nonumenlos jurídicos. 


\section{LEGGION 4."}

La Iglesia.-1. Predicacion y propagacion del Cristianismo. - Doctrina cristiana y su influencia social. ?. Organizacion y constitucion de la Iolesia.-Clérigos y legos. - Gerarduía de derecho divino.-- El Pontificado, cal)eza visible de li Iglesia. - Gerarquía de derecho eclesiástico. - 3. Concilios. - Sus varias clases. - Noticia de los colebrados en España. - 4. Cullo.-Medios de sustentacion del cullo y sus ministros. - Carácter de la propiedarl de la Iglesia. - 5. Exímen de actas y documentos r:Lsiáslicos.

\section{LECGION 5."}

Los pueblos bárbaros. - 1. La Gurmania. - Puchlos que invadieron el Imperio romano. - Sus semejanzas y diferencias.-2. Antigua teogonía germánica. - Conversion de estos pueblos al Crislimismo. -- 3. Opganizaleion social.-Clisses y gerarefuías. - La familia. - Lat 1ropiedal.-1. Insti!uciones de gobierno. Candillos o royes. - Placita germánica. 
EPOCA 1.": SIGLOS V, VI, VII Y PRINGIPIOS DEL VIII.

PRIMER PERIODO: SIGLOS V Y VI.

\section{IACCAION $6 . "$}

Reseña histórict.-- Lnvasion, correrials y asiento de los vándalos, alanos, suevos y godos.- $\Lambda$ taulfo. - Sigerico.- Walia. - Teodoredo. - Batalla de los Campos Cataláunicos. - Turismundo.--Teodorico. - Eurico. Terminacion del Imperio romano de Occidente. - Nlarico. - Amaleurico. - Teudis. - Teudisolo. - Agila. Atanagildo. - Liuvi. -- Lcovigrildo. - Los hijos de Leovigildo.

\section{LEGGION $7: "$}

Organizacion y estado social de la España góticoarriana. - 1. Razas que polialan la España al tienpo de la invasion de los bárbaros. - ¿Era romana toda la España en su lengua, leyes y coslumbres? - 2. Carácter de la dominacion goda.--Diferencias de religion y guerras por esta causa, entre godos, francos y romanos. Ocupacion y division del suelo.--Primeras leyes escritas de los godos: carácler y significacion de estas leyes. Lex romana ó Código de Teodosio..- Explicacion de la 
ley de raza. - 3. Organizacion social y manexa de gobierno en uno y otro pueblo. - Puntos de union y de divergencia. - Usos y costumbres. - 4. Cómo y cuíndo se inicia la fusion de ambos pucblos.

SEGUNDO PERIODO: SIGLO VII Y PRINCIPIOS DEL VIII.

\section{HECGIONN 8.:}

Reseña histórica.-Recarclo I. - $\Lambda$ bjuracion del arrianismo. - Concilio in de Toledo. - Liuva II. - Witerico.-Guntemaro. - Siscbuto.-Pecaredo II. - Suinlila. - Sisenando. - Concilio rv de Toledo. - Chintila. - Concilios v y vs. -Tulga. - Chindasvinto. - Concilio vir. - Recesvinlo. - Concilios vin y rx. - Wamba. - Concilios x y xr. - Ervigio. - Concilios xu, xir y xiv.-Egica. - Concilios xv y xvr. - Witiza. - Don Rodrigo. - Batalla de Guadalete. -- Ruina de la monarquía visiconda.

\section{HECGION $9 . "$}

Estado social. -- 1. Godos. - IIispano-romanos.—Judíos. - i Fstalua consumada la fusion de godos y romanos al caer la monarquía visigoda? - 2 . Condicion social de las personas. - $\boldsymbol{\Lambda}$. La nobleza goda. - Causas de nobleza. - Carácter de ésta. - Sus privilegios legales; sus usos y costumbres. - $B$. La libertad ó ingenuidad. Escasa imporlancia de la clase meramente libre. - Condicion del liberto y del adicto con relacion á su patrono ó protector. $-C$. De la servidumbre. - Clases y condicion de los siervos. - Manumision y sus formas. - 3. La fumilia. - Leyes lundamentales de su constitucion y or- 
ganizacion, en cuanto á las personas y en cuanto á los bienes. - 4. La propiedad. - ¿Subsistia aún en el siglo vin la distincion de tierras entre godos y romanos? - Bienes de la Iglesia. - Beneficios. - Tierras tributarias. - Idea de las leyes relativas á los modos de adquirir y trasmitir la propicdad.

\section{LEGGION 10.}

Gobierno y administracion civil. - 1. Ia monarguia. - Ldea de la legitimidad. - Leyes sobre eleccion y dofensa dol rey. - Comparacion de las leyes con la realidad de los hechos. - Atribulos y poder del monarca. - ?. Aula régia.—_Cúl liué su verdadera significacion é inportancia ? - Dignidades palatinas. - 3. De los Concilios nacionales de Toledo. - Garícter de estas asimbleas. Convocacion, reunion y mancra te celefrarse. - Exímen de algunas de sus actas. - 4. Division civil del territorio. - Su comparacion con la eclesística. - Autoridades y manera de gobicruo en las provincias, ciudades, términos y pagos. - 5. El municipio. - Sus condiciones en aquella organizacion.

\section{LEGGION 11}

Legislacion civil. - Forum judicum. - Su historial. Reseña de sus Libros. - Importancia de este Código, bajo el punto de vista legal ó histórico. - Reglas críticas para su estudio. - Ediciones del Fucro-Juzgo. - Códices consultados.

\section{IAEGGION $1 ?$.}

Juicios y otros actos juridicos. - 1. Jueces. - Cita- 
cion. - Pruebas. - Sentencia. - 2. Contratos. - Testamentos. - Escrituras.

\section{IEGGION 13.}

Instituciones de la Iglesia. - Golierno y disciplina de la Iglesia. - Preeminencia de la Sede de Toledo en España. - Orígen del monacato y su propagacion en Occidente. - Fxímen de la regla de San Benito.

\section{IEGGION 14.}

Hispana canonum collectio. - Antigüedad de las colecciones canónicas. - Primitiva Coleccion Española. La de San Martin de Bragal. - La Isidoriana. —Cómo se conservó la Coleccion despues de la invasion sarracena. - Trabajos que para su publicacion se hicieron desde el siglo xvr. - Guándo y bajo qué plan se realizó. - Códices consultidos.

\section{BECCION 15.}

Crónicas y otros trabajos históricos. - Orosii Presbyteri IIispani adversus paganos historiarum libri septem. - Idatii episcopi Chronicon. - Chronicon Biclarensis.Divi Isidori hispalensis Episcopi historia de regibus gothorum, vandalorum et suevorum. - Otras obras de San Isidoro.

\section{IEGCION 16.}

De los diplomas históricamente considerados. - Formularium instrumentorum regum wisigothorum. - Estudio de algunas de estas fórmulas y comparacion de las 
mismas con las leyes del Fuero-Juzgo. - De algunos diplomas insertos en este Cóligo, entre sus leyes.

BPOCA 2. ${ }^{\text {a: }}$ SIGLOS VIII, IX, X, XI, XII Y PRINCIPIOS DEL XIII.

PRIMER PERIODO: SIGLOS VIII, IX, X Y PRINGIPIOS DEL XI.

§.-España árabe.

\section{LECGION 17.}

Reseña histórica. - 1. Conquista árahe. - Mahoma. - Conquistas de los árabes en Asia y Ífrica. - Invasion y conquista de España. - Emires hasla el ano 75.5. - ?. Kalifado de Córdoba. - Fundacion del kalifado.-Brewe rescũa de los hechos más notables de los kalifas Abderrahman I, Hixem I, Alhacken I, Abderrahman II, Mohamch I, AJ)dalah, Abderrahman III, Alhacken II $\langle 970\rangle$. - 3. Almanzor. - Kalifado de Hixen II. - Nlmanzor y sus principales empresas. - Balalla de Calatañazor. Decadencia del kalilado.--- Hixen III.--Disolucion de aquel Imperio (10:37).

\section{I.EGGION 18.}

Religion é instituciones de los árabes. - 1. Fl Korant. -Sus dogmas: sus preceptos morales y políticos.--?. Carácter de la dominacion árabe. - Condicion y estado social de los mozírabos.-3. Gobierno de los árahes. Division del territorio. - Autoridades y modos de administracion. - 4. Condicion de la familia. - Leyes é ins- 
lifuciones relitivas í la propiedad. - j. Usos y costumbres que dejaron huella on muestra historial.

\section{§.-España cristiana.}

\section{I.EGGION 19.}

Reseña histórica. - Reinos cristianos de Asturias, Leon y Castilla (711 i 1035). - 1. Restauracion cristiana. - Reino de Astúrias. - Reseña de los principales acontecinien los duante los reinados de Pelayo, Favila, Alfonso I, fruela I, Aurelio, Silo, Mauregato, Bermudo 1 y Allonso II [84?).—. Reinos de $\Lambda$ stúrias, Leon y Galicia. - Reinados de Ramiro I, Ordoño I, Alfonso III, Garria, Ordoño II, Fruelia II, Alfonso IV, Ramiro II, Ordoño III, Sancho I y Ordoño IV (967). --3. Reinos de Astúrias, Icon y Galicia, y Condado de Castilla. - Reinados de Ramiro III, Bermudo II, Allonso V y Bermulo III. - Origen del Condado de Castilla. - Juedes y Comdes. - Nuño Rasura y Lain Galvo. - Fernan-Gonzalez. - Garci-Fernandez - Sancho Gar(cia.-Garcia II $(10: 9)$.

\section{LWCGION:0.}

Reino de Navarra. - Origen de este reino. - Cronolowia de sus Reyes más almilida. - García Jimenez. Iñigo Garcia. - Batalla de Roncesvalles. - Fortunio García. - Sancho L. - Jimeno Lñioguez. - Iñigo Jimenez. García Lñiguez.-Fortunio II.-Sancho García II.-García Sanchez.-Sancho III.-Gareía el Tembloroso $(999)$. 


\section{JEGGION $: 1$.}

Union de los reinos cristianos en Sancho Mayor de $\mathrm{Na}$ varra, y division de los mismos á su muerte. - Reseña histórica. - Division y reparticion de reinos.-Orígen del de Aragon (1035).

\section{LEGGION $: 9$.}

Condados de Cataluña. - Marea hispánica.-Conquistar de Barcelona. - Otros Condalos. - Condes foudatarios. - Wilredo, primer Conde indepentiente.-Wifredo II ó Borrell I. - Sumyer ó Sumiario.-Borrel II. - Ramon Borrell III. - Berenguer Ranon I (1035).)

\section{IAECGION $2: 3$.}

Constitucion social de los reinos cristianos. - 1. Razils pobladoras.-Godos: Sucvos: Ilispano-romanos: Vascones: Francos. - Influencia respectiva de estas razas en los diversos reinos. - Cristianos restaumalores y cristianos mozírabes. - Exagerala influencia atrihnida al mozarabismo. - Judios y moros, en las polhaciones cristianas. - 2. Condicion social de las personas entre los cristianos. - A. Nobleza. - Su orígen y desitrollo en las monarquias cristianas. - Sus privilegios. - Ordenes de nobleza. $-B$. I a clase libre. - Su desarrollo. - Privilegios y modos de garantir la libertarl. - Diversos órdenes y grados. - C. Ia servidumbre personal y de la glcba. - Morlos de ser ó hacerse siervo. - Condicion de los siervos. - Manumision. - Causas rue favorecen la general emancipacion. - 3. La familia. -- Constitucion 
legal de la fimilia, respecto á las personas y á los bienes. - Diferencias segun las clases sociales. - Usos y costumbres de la vida de fimilia, atento asimismo á la distincion de clases. - 4. La propiedad. - El feudo. Orígen de los feudos. - Glases de feudos. - Idea del señorío. - Señoríos que se constituyen áun ántes de que las leyes los regulen.

\section{LECCION 24.}

Restauracion de las leyes. - 1. ¿Continuó en obserrancia el Lìbro de los Jueces en todos los reinos cristianos? - Exímen de diplomas á este propósito. - Historia ulterior de ayuel código. - 2. A. Astúrias y Leon. Origen y causa de las cartas-pueblas. - Exámen de algunis. - Fuero de Leon $(10: 0)$ - B Castilla. - Fuero de Castrojeriz (970). - C. Navarra y Aragon. - Fuero de Sobrarbe y primilivos fineros de Aragon. - ¿Qué debe crecrse de estos fueros atribuidos í los primeros tiempos de arfuella monargula? - I). Condados de Cataluña.Jeyes de latzi. - Preceptos. - Ciarlas de poblaciones.3. ¿Existicron fueros generales de clase en esta época?¿Qué debe creerse del de los fijos-dalgo de Castilla atribuido al Conde D. Sanclio?

\section{JEGCION 25.}

De la constitucion y gobierno de los reinos cristianos. -. 1. Ial monirquia. - Eleccion y sucesion. - Idea del Soñorio del Rey. - Su porler. - Otros señorios. - Idea de su reciprocia relacion. - Corte ó curia del Rey.-Dignitlales y oficios de gobierno y administracion. - 2. Los Concilios. - Naturateza de estas asambleas. - Noticia de 
las principales celuhradas en este perioulo. - 3. El Concejo. - Giudadanos. - Gobicrno. - I Iueste. - Administracion, principalmente en lo judicial.

\section{IJEGGION 26.}

Del órden eclesiástico.- - Hstado de la Iglesia cristiana restaurada, y de la mozírabe. - El Pontificado en este período. - Soberanía temporal del Pontítice romano. Aparicion de las falsas Decrelales.-Del Poler Pontificio en sus relaciones con el de los Reyes y el de los Obispos.

\section{ILEGCION $: 7$.}

Crónicas. - Noticia históricorcrítica de las de Isidom Pacense; Sebastian de Salamanca; Vigila el Albeldense: el Monje de Silos; Sampiro, de Astorga, y D. Peliyo. de Oviedo.

\section{LEGGION $: 3$.}

Diplomas. - Leclura y análisis histórico-jurídico de diplomas españoles ó relativos á España, eclesiásticos y civiles de este período. - 1. A. Decrelales. - Reseriptos y Epístolas de Pontifices. - Aclas y Cúnones conciliarcs. - - B. Fundaciones monísticas y otros. - ?. A. Privileyios y cartas reales. - Fueros y cartis-puchlas. - Juicios y sentencias. - B. Testammonlos. - Contrilos. - Mammmisiones, y otros aclos juridiens. 
SEGUNDO PERIODO, - SIGLOS XI, XII Y PRINCIPIOS OEL XIII.

\section{LECGION 29.}

La Reconquista. - Reseña histórica de los reinos de Leon y Castilla. - Fernando I el Magno. - Reparticion de reinos entre sus hijos. - Alfonso VI. - Conquista de Toledo. - Doña Urraca. - Su matrimonio con Alfonso I de Aragon: tristes resultados de sus desavenencias.-Alfonso VII el Emperador. - Gloriosas expediciones á Andalucía. - Nueval reparticion de los reinos de Leon y Castillia entre sus hijos (1157.)

\section{LECGION 30.}

La Reconquista. - Reseña histúrica de los reinos de Leon y Castilla. - A. Castilla. - Sancho III. - Alfonso VIII. - Glorioso triunfo de las Navas de Tolosa.Enrique I (1917).-- B. Leon. - Fernando 1I. - Alfonso IX (1230). - C. Union definitiva de Leon y Castilla en Fernando 11 (1217-1230).-D. Independencia de Portugal. - Precedentes listóricos. - EI Conde Don Eurifue de Borgoña y su mujer Doña Teresa. - Alfonso Emirpuez. - Famosa bablallat de Ourirue. - Reconocimiento del reino por lat Santa Sede.

\section{LICCION 31.}

La Reconquista. - Reseña histórica de los reinos de Navarra y Aragon.-1. Aragon.- Ramiro I.--Sancho Ramirez (107i). - B. Navarra. - Garcia Sanchez.-- 
Sancho Garcés 1076j-C- G Cnion de los reinos de Aragon y Navaria. - Sancho Ramirez. - Pedro I. - Conquista de Huesca. - Alfonso I, cI Batallador. - Conquista de Zaragoza.-Gloriosas expediciones á Andalncía. - Nueva separacion de las Coronas de Nivarra y Mragon (1134.)

\section{LECCION 3:.}

La Reconquista. - Reseña histórica de los reinos de Navarra y Aragon, y Condado de Barcelcna. - $\Lambda$. Navarra. - Reinados de Garcia Ramirez, el Restaurador: Sancho Garcés, el Sabio: Sancho el Fucrte. (1231).- - B. Aragon. - Ramiro II, el Monje. - Su lijja Doña Potronila (1137).-G. Cataluña.-Ramon Berenguer I, el Vicjo. - Ramon Berenguer II y Berenguer Ramon II. - Conquista de Tarragona. - Ramon Berenguer III. Conquista de las Baleares. - Ramon Berenguer IV. Conquista de Tortosa, Lérida y kraga. - Completa dominacion por los cristianos del territorio catalan. - Matrimonio del Conde con Doña Petronila de Aragon. - D. Union definitiva de Aragon y Cataluña. - Muerte del Conde D. Ramon (1161).-E. Aragon y Cataluña.Alfonso II. - Don Pedro II. - Su alianza con los albigenses. - Su muerte (1213.)

\section{LEGGION 33.}

Feudalismo. -Época feudal. - Sus caractéres. - Gerarquía social. - Gobicmo foudal. - Justicia. - Costumbres. - Derecho. - Colecciones de derecho feudal. 


\section{LEGGION 34}

La Iglesia en si y en sus relaciones con el Estado.1. Relaciones grenerales. -- La Iglesia en el siglo xI.---. Gregorio VII. - Reformas. - Guestion de las investiduras. - Pretensiones al señorío temporal de España.Abolicion del rilo mozírabe en los reinos de España. Feudos á la Sinta Sede. - Inocencio III.-Los albigenses. - Orígen de la Inquisicion y su admision en el reino aragonés. - Concilios de Letran. - Cambios notables deste el siglo xr en el gohicrno y diseiplina de la Iglesia general y particularmente en España. -- 2. Relaciones 6 influcucias en el estato social y civil. - La paz y tregua de Dios. - Los asilos. - Colradías. - Doctrinas relativas al matrimonio; á la familial á los bienes; á cierlos contratos, y al procedimien to judicial, especialmente sobre las prucbas.

\section{LEGGION 35.}

Ordenes religiosas. - 1. La Congregacion de Cluny. - Los cluniacenses en Castilla. - Su influencia. - La reforma del Cistór. - Los 'cistercienses en España.--Órden de Predicadores. - Santo Domingo de Guzman.-Franciscanos. - Otras Órdenes. - Reglas monásticas.Servicios sociales de los instilutos monásticos.

\section{IACCION 36.}

La Caballeria - Época caballeresea. - La caballería como moral y como institucion. - Vila y ejercicios del caballero. - Código ó leyes del honor caballeresco.-Exageraciones y fáluulas. - Decalencia. 


\section{LEGGION 37.}

Las Cruzadas. - Epoca de las Gruzadas. _ Gruzadas :i Tierra Santa. - Cruzadas á España contra los infieles.Consecuencias de las Cruzadas.

\section{LECGION 38.}

Las Órdenes militares. - Ordenes militares de Tierra Santa. - Su orígen y su eslat)lecimienlo en España.Ordenes militares españolas. - Su origen y eslablecimiento en los diversos reinos. - Organizarion de las Orrdenes. - Territorios y señorios de las mismas.

\section{LECCION:39.}

Constitucion y gobierno de los reinos cristianos. - I. La Monarquáa.-Eleccion, sucesion y proclamacion del Rey. - Potestad real.-- Autoridades de su nombramiento y representacion. - Orígen del Justicia de Aragon. - II. Concilios y Córtes. - Concilios mistos del siglo xi. - Orígen de las Córtes. - Brazos do que constaban en los diversos reinos. - Mancra do convocalcion, reunion y eclebracion. - Asumtos de que trataban.- DIL. Sen̆orios. - Realengo. - Soliriego. - Abadengo. - Behetría. - Semejanzas y diferencias entre los señorios de Aragon y los de Castilla.-Fendos do Ciltaluña. - IV. Organizacion de los Concejos. - Cindadanos. - Sus clit ses y derechos. - Grenios y IIermandades. - Auloridat des: modos de eleccion: duracion de los cargos. - Oticiales del Concejo. - Bienes y renlas. - Ferias y murcados. - Policia. - Servicios en la Reconruista. 


\section{IJEGGION 40.}

De la legislacion en los varios reinos cristianos. - 1 . Epoca foral. - P'recerlentes. - Fucros municipales más notabjes de cada reino. - Sus principales capítulos ó disposiciones. - - . Usages do Barcelona.-- Su historia: sus vemontos. - Idea do sus capílulos más notables.

\section{LEGGION 11.}

Crónicas e historias. - I a Compostelana.--Ia dol Emperador Allonso VII. - Las de Iuícas de Tuy. - Las del Irzobispo D. Rodrieno Jimenez de Rada. - Gronicones bapcelomoses.

\section{LEGGTON 4?.}

Diplomas. - Lectura y ancilisis histórico-juridico do diplomas de este periodo bajo el método indicado en la Jeceinn 28 .

$$
\text { BPOCA 3." - SIGLOS XIII, XIV Y XV. }
$$

PRIMER PERIODO. - SIGLOS XIII, XIV Y HASTA ÚLTIMO TERCIO DEL XV.

\section{LEGGION 43.}

Reseña histórica de Castilla. - Reinado de D. Fernando III, el Santo.-Gloriosas conquistas. - Reinos círabes de Granada.-Reinado de Alfonso X. - Su gé- 
nio: su carácter y sus desgracias. - Reseña del loinado de Sancho IV. - Gnzman el Bueno. - Reinalo de Fernando IV. - Su minoría. - Alfonso XI. - Triunfo del Salado. - D. Pedro I. -. Su carácter : su muerte.

\section{ILEGION 4 '}

Reseña histórica de Castilla. - Reinados de D. Enuique II el Bastardo, D. Juan I, D. Enrifuce III, Don Juan II y D. Eurique IV.

\section{IEGCION 45.}

Reseña histórica de Aragon. - Roinarlo de D. Jaime I. - Gloriosas compuistas. - D. Pelro III. - La enpresa de Sicilia.-Alfonso III. - D. Jaime II. - Expedicion de catalanes y aragoneses contra lurcos y griegos. - Reseña histórical del reinado de Alfonso IV. 1). Peclio IV.

\section{I.ECGION 46 .}

Reseña histórica de Aragon. - Roinalos de Don Juan I. - D. Martin. - D. Fermando I, al de Anlequera. - D. Alfonso V.

\section{ILCGION 47.}

Reseña histórica de Navarra. - D. Teobalilo I. - Su carícter: importantes acontecimientos de su reinado. D. Teobaldo II. - Sus fucros. - D. Emrique. - Doña Juana. -D. Felipe [. - Doña Juana. - D. Luis IIutin.D. Juan, el de pocos dias. - D. Felipe II. - D. Cáir- 
los I. - Felipe III y Doña Juana. - Gírlos II, el Malo.Compraracion con los Pedros de Castilla y Aragon, sus coctíneos. - Gírlos III, el Noble.

\section{I.WCGION 48.}

Reseña histórica de Navarra y Aragon. - Doña Blanca de Navarra y I). Juan II, de Aragon. - Carácter de este Rey. - El Príncipe Cárlos de Vima. - Situacion del reino á su muerte. - Sucesos notables hasta la de Don Juan II.

\section{LEGGION 49.}

Influencia del estudio del derecho canónico y del romano. - 1. Fundacion de Universidades. - Estudios y Lniversidates en Castilla y Alagon. - Estado general de los conocinientos. - Ramos de enseñanza y de estudio. - - De las colecciones canónicas generales anteriores á la de Graciano. - Ia de Graciano. - Coleccion de Decretales de Gregorio IX. - Adiciones ulteriores. Corpus juris canónici. - 3. Renacimiento del Dorecho romano. - Las Pandectas. - Colecciones. - Corpus juris civilis. - 4 . Idea de los principalos tratados, y explicacion de la influencia del estudio de ambos Derechos en los princijios de constitucion y organizacion de los reinos.

\section{HEGGION 50 .}

Legislacion foral de Castilla. - 1. Nuevos fucros municipales. - Confirmacion y adicion de otros antiguos.Exímen de algunos. - :. Fuero Real. - Su historia.Noticia de sus libros y tralalos. - 3. El Fucro viejo de 
Gastilla. - Noticia de sus libros, especialmente del primoro.

\section{LEGGION 51.}

Legislacion general. - Las Sicto Partidas. - Su histrria. - Noticia de sus partes ó tratidos, especialmente los relativos á la organizacion polílica, arministmativa y judicial del reino.

\section{ITGGION 5?.}

Legislacion de la Corona de Aragon.- - I. Fueros municipales. - Noticia de los mís importantes que siguieron en observancia. - 2. Los Fueros generales do Aragon. - Su historia. - Nolicia de sus lihros y títulos. Adiciones á la primera coleccion. - 3. Usages y Constiluciones de Cataluña. - Otros elementos legales. - Manera como se fueron formando y ordenanilo.

\section{LEGGION 5i3.}

Legislacion de Navarra. - Fueros municipales. - Noticia de cllos. - El Fuero generall : ¿cuíndo se inició su idea y cómo se realizó? - Nolicia de sus elementos constitutivos.

\section{LEGGION 54.}

Legislacion foral de las Provincias Vascongadas.-Fueros castellanos dados á las principales ciudades y villas de aquellas Provincias. - Verdadera idea de estos fueros. - Cuándo y por qué han altunirido excepciona] importancia. 
LAGGION 55.

Constitucion y gobierno de Castilla. - I. La monarquía. - Ley do sucesion á la corona. - Potestad Real.La Córte. - Dignialales y oficios. - 2. Del gobierno y administracion, - Adelantados. - Merinos. - Otras autoridarles. --Oficiales inferiores. - 3. Servicio militar.Manera de desempeñarlo. - 4. Tributos. - Su clase 6 importancia.

\section{LEGGION 56.}

Castilla. -- Las Córtes. -- Precedentes históricos. Constitucion de las Górtes.--Modo de proceder en cllas.Sus facultades. - Su intervencion en la organizacion y administracion del reino.

\section{LAGGION 57.}

Castilla. - Consejo y Tribunales Reales. - Precedenles.-C Creacion do una Audiencia Real ó Chancillería.- Su orginizacion y planta. - Alteraciones que fué sufriendo. - Del Consejo Real. - Su creacion, organiza(:ion y atribueiones. - Lnfluencia de los legistas en estos crerpos. - Alia importancia de los mismos.

\section{LAGGION 58.}

Castilla. - Gobiemo de ciudades. - 1. Pueblos de scñoríos. - Señores y vasallos. - Autoridades. - Fueros roncedidos por los Señores. - 2. Pueblos realengos. Vecinos y moralores. - Autoridades y Oficiales del 
Concejo. - Instituciones de justicial. - Arministartion de bienes. - Rentas, tributos y arbitrios.

\section{LEGCION 59}

Aragon.-El Rey.-- Privilegios de la Nobleza.-Constitucion del reino on tiempo de D. Pedro IV, en punto á las relaciones de porler entre cl Rey y la Nohleza. - Extension y límites de la polestad real on la wobernacion elel reino.

\section{LEGCION bi).}

Aragon. - Córtes.-- 1. Córtes y Pinlamentos. - Córtes generales y particulares. - Modo de proceder en Córtes. - Prerogativals. - Diputacion, - 2. Córtes de Cataluña y de Valencia. - Su constitucion. - Sus brazos. - Mancra de proceder.

\section{IECGION 61.}

Aragon. - Justicia. - Su Auliencia Real. - Su orisen. - Su plimla. - Sus atribuciones. - El Justicia do Aragon. - Su Córte ó tribunal. - Importancia de esta Lagistratura. - Reeursos en justicia : lit manifostacion, las firmas.

\section{LECGION $6 ?$.}

Aragon. - Gobierno de pueblos y ciudades. - I Lils Universidades. - Las Commirlides. - Los puoblos di Señorío. - Su constitucion y organizacion. 


\section{LECCION 63.}

Crónicas. - Crónica general de España, de Alfonso X. - Crónicas de Sancho el Buvo y Fermando IV. Greacion del oticio de Cronista Real. - Crónica de Alfonso XI. - Tas do D. Podro I, Enriefuo IL, Juan I y Finrique ITI. -- Crónicas te I) .Juan II y Enrique IV.Las de los Royes Cabólieos, de IIemando del Pulgar y Antrix Bermaliles, el Cura de los Palacios.

\section{LHCGION bí.}

Diplomas. - Leceluma y análisis histólieo-jurílico do diplomas de este período, bajo el método indicato on la Lecrion :8.

SEGUNDO PERIOdO. - FINES DEL SIGLO XV Y PRINCIPIOS DEL XVI.

\section{LECGION 6.5.}

Cestille y Aragon. - Mstarlo de Castillat á la muerle do Enrigue [V.-. Thl le Aragon á la de D. Juan II. -- Isahe] y Fornando.-- Union de las dos Goronas. - z Cuńndo y

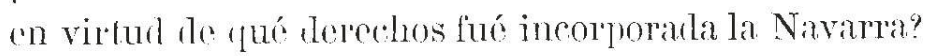

\section{IJCGION biti.}

Crlorioso término de la reconquista. - Rescina histórica to bil guerra con los moros hasta la rendicion de Granada. 


\section{LEGGION 67.}

El Poder Real en relacion con el Poder Pontificio.Precedentes. - Punlos cuestionables en apuella época sobre provision de bencficios y otros concernientes al gobierno del Estado. - Dofensa de los derechos de la Polestad Real. - Nuevas ideas sobro la materia.

\section{IECCION $65^{\circ}$}

El Poder Real. - Su relacion con la noblezu. - Cólebres Córtes de Toledo en 1480. - Incorporacion de los Maestrazgos de las Ordenes militares. - Disposiciones para mantener el órden púlslico. - Creacion y organiza•ion de la Santa Hermandad. --. Sus ordenanzas.

\section{HGGION (i:)}

La legislacion y la justicia. - Ordenanzas de Montalvo. - Otras leyes. - Nueva organizacion de Tribunales.

\section{WCGION 70 .}

La Inquisicion. - Precedenles. - Listablecimiento on Gistilla y en Aragon. - Inyuisirlores. - Gonsejo suprento de Ia Inyuisicion. - Instruceiones. - Tribunales suljalrruos. - Modos de proceder. 


\section{LECGION 71}

Del Poder Real. - Sucosion á la Corona. - Fngrandecinicnlo del Poiler Real, con relacion al Poler ectesístico y all do la noblozat, y respecto al rógimen de los

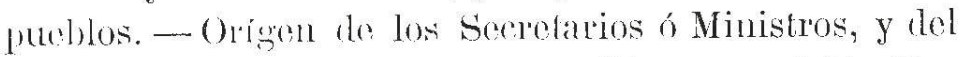
Poler ministrual. - Consejos y Cúmaras establecidos

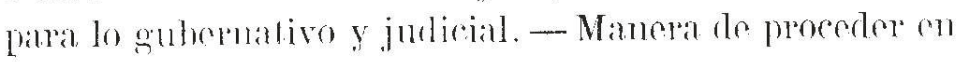
los asumfos.

\section{I.WTIION T?.}

De la Real jurisdiccion. - De las Chancillerias. - D' las Chancilloróas de Valladolid y Granada. - Su Ierriloro respectivo. - Su planta - Su juristiecion. - Modo

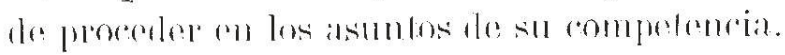

\section{LIVION}

De las Reales Audiencias. - Do las Roales Audiencias lo Galicia, Astúlias, Sevilla, Canarias, Extremadura, Aragon, Valeuria, Cataluña y Mallorea. - Sus respectivos torritorios. - Sil organizacion. - Modo de proceder

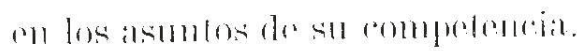

\section{HWGIION TH.}

Autoridades de la Real jurisdiccion. - Mealdes del 
crímen de las Cancillerías. .... Aladtes dr cuartel en las Chancillerías y Audiencias. - Aleahles-jueces te provincia.-Alcaldes do los llijos-dalgo en las Chameillerías.- Del Juez mayor de Vizaral. - - Alguaciles mayores. Oficiales de Chancillerias y Iudinomia. - Oficios anxiliares de la justicia.

\section{HEGCION}

.Turisdiccion eclesiástica. - Ite la Iglesia. - Jueces ordinarios. - Gerarquia. - Tribunal de la Ro!a. - Jurisdicciones exentas y privilegiadas. - Trihumales do la Inquisiejon. ... Consejo de las butenes.

\section{ISGCION $\pi$ it.}

Juicios. - Sumaria jelea solme estos puntos. - Constitucion del tribumal y su autorilad. - Procedimiento. Sentencias y modn de harerlas ejocular.

\section{HEGION}

Gobierno de ciudades y pueblos.-- Concejos y Ayuntamientos, - Tenientes y Alabldes mayores. - Alealles ordinarios. - Regidores. - oficiales. - Modos de elefcion y nombramionto. - Sus dorechos y sus cargos.-Términos. - Propins y allitrios. - Ahastos - Rógimen y polivia.

\section{HEGCION 78.}

Fstado social de las personas. - 1. Nalurales. - Firtranjeros. - Domicilialos, vecinos, moralores, trallsemutes. - : Clases soriales. - Señores. - Grandes. - 
Nolules. - Gaballeros. - Ilijos-dalgo. - Vilsallos. - Lihratores. - Menestrales. - Crialos. - Servicio milibar.

\section{HECGION 39.}

Estado civil. - 1. I a lamilia. - Su organizacion. Diferencia entre los que furron diversos reinos. - : L Lal propicdad. - Amortizacion. - Leyes reguladoras de su ahuisicion y trasmision.

\section{LEGCION 80}

Documentos. - Lecluna y exámen histórico-jurídico do documentos y puncesos.

Madrid - 1875.

El Catedrático re la asignatura,

SiNTOS IUE IsAsa. 


\section{Relación de méritos y servicios}

que presenta al concurso para proveer la plaza de Jefe de $3 \cdot{ }^{\text {er }}$ grado vacante en la sección de Museos, anunciado en la Gaceta de 6 de Marzo de 1884, el Oficial del Cuerpo facultativo de Archiveros, Bibliotecarios y Anticuarios y Catedrático, por oposición de la Escuela de Diplomática, D. Eduardo de Hinojosa.

Servicios ordinarios.

Véase la certificación adjunta, expedida conforme a lo prevenido en el art. ${ }^{0} 58$ del Reglamento vigente por el Jefe del Establecimiento en que sirve el interesado.

Servicios extraordinarios.

Comisionado por la Real Academia de la Historia en Diciembre de 1870 para auxiliar los trabajos del Anticuario en el arreglo y catalogación del Museo de Antigüedades de la Corporación, se ocupó durante más de cuatro años, sin retribución alguna, en esta tarea.

Comisionado en Agosto de 1878 por el Ministerio de Fomento para estudiar en Francia y Alemania las publicaciones hechas en ambos países sobre la historia y las antigüedades españolas, hizo el viaje y como fruto de él empezó a publicar en la Revista hispano-americana una serie de artículos, de que solo salió a luz el primero por haber cesado dicha Revista.

Juez de dos Tribunales de oposición a plazas de Aspirante del Cuerpo.

Juez de un Tribunal de oposición a cátedras de Instituto.

Juez y Secretario de un Tribunal de oposición a cátedras de Universidad.

Fundador y Director del Boletín Histórico. Revista especialmente dedicada al cultivo de los estudios propios del cuerpo.

Haber continuado asistiendo al Museo Arqueológico Nacional, después de haber sido nombrado Catedrático, y cuando por esta razón no estaba obligado a ello, a fin de auxiliar los trabajos relativos a la preparación de materiales para el Catálogo, como se consigna con elogio en la Memoria anual del Museo correspondiente a 1882, e inserta en el último Anuario del Cuerpo, pág. 367.

\section{Obras de Arqueología.}

Los Nuevos Bronces de Osuna. Monografía escrita en colaboración con D. Juan de Dios de la Rada y Delgado. Elogiáronla D. Manuel Rodríguez de Berlanga en la Revista de legislación y jurisprudencia y M. Giraud, Decano de la facultad de Derecho de París y miembro del Instituto, en su obra Les Bronzes d'Osuna, diciendo de ella este último que era un libro que "honraba a la erudición española". 
La colección de sellos romanos del Museo Arqueológico Nacional. Monografía del Museo Español de Antigüedades, en que el autor rectifica los errores cometidos por Hübner y otros, con especial relación al vol. II del Corpus inscriptionum latinarum.

Estudio sobre un vaso italo-griego del Museo Arqueológico Nacional. Monografía del Museo Español de Antigüedades.

La colección de terracotas del Museo Arqueológico Nacional. Monografía del Museo Español de Antigüedades.

"La estela de Mesa rey de Moab". Artículo publicado en el periódico La España.

"Inscripciones romanas de Galicia". Artículo de la Revista de Archivos, Bibliotecas y Museos.

"Un novísimo descubrimiento epigráfico". Artículo de La Ciencia Cristiana, en que se publica e ilustra por primera vez una importantísima inscripción romana descubierta en Córdoba.

"Examen de la obra sobre los Nuevos Bronces de Osuna, publicada por D. Manuel Rodríguez de Berlanga”. Dos artículos publicados en La Academia, donde se discuten algunas interesantes cuestiones relacionadas con la interpretación de los Bronces.

"La industria minera entre los Romanos". Comentario al notable monumento epigráfico intitulado La tabla de Aljustrel, a la sazón recientemente descubierto, publicado en La Academia.

"El culto de las divinidades orientales en la España romana". Estudio basado en las inscripciones romanas de la Península y publicado también en La Academia.

"Una rectificación epigráfica". Artículo del Boletín histórico, en que se desvanecen los errores en que incurrió la Revista de ciencias históricas de Barcelona al publicar una interesante inscripción de Tortosa.

"El régimen municipal romano en España". Dos artículos en la Revista hispanoamericana, fundados principalmente en el estudio de las inscripciones y de los monumentos.

"Publicaciones alemanas sobre la historia de España". Primer artículo. Comprende la reseña y examen de las relativas al periodo primitivo y se consagra la debida atención a las que conciernen a antigüedades. Salió a luz en la Revista hispano-americana.

"Revue des Revues et des publications d'Académie espagnoles, concernant l'antiquite classique. Tres artículos que contienen la reseña del movimiento literario de España en este orden, durante los años 1877, 78 y 79, escritos en francés y publicados en la Revue de philologie et d'histoire ancienne de París.

Siete artículos bibliográficos sobre publicaciones arqueológicas, en el periódico La España, y en La Ciencia Cristiana y el Boletín Histórico. 
Historia del Derecho Romano según las más recientes investigaciones. Vol. I, Madrid 1879. Del vol. II hay impresos ya siete pliegos que junto con el primero acompaño a esta relación. De esta obra, relacionada íntimamente por la materia sobre que versa con los estudios epigráficos y arqueológicos, y en que se trata repetida y ampliamente de este linaje de monumentos (véanse, en particular, las pág. 13-15, 188-192, 250-251, 256-258, 260, 262-266, y 294297 del vol. I) han hecho elogios, en artículos exclusivamente consagrados a examinarla, profesores extranjeros de competencia universalmente reconocida en los Studi e Documenti di storia e diritto de Roma, en la Revue générale de droit, la Nouvelle Revue historique du droit français et étranger y la Revue critique d'histoire et de litterature de Paris; la Revue de droit international et de législation comparée de Bruselas y el Literarisches Centralblatt de Leipzig. Elogianla asimismo Rivier, profesor de la Universidad de Bruselas, en la 2. ${ }^{a}$ edición de su Introduction historique a l'étude du droit romain y Misprulet, profesor de la Universidad de Paris en el prólogo a su obra Institutions politiques des Romains.

Otras publicaciones de carácter histórico.

"La Jurisdicción eclesiástica entre los visigodos". Dos artículos publicados en la Revista hispano americana.

"Félix Dahn y sus publicaciones sobre la historia de los pueblos germánicos". Artículo publicado en la misma Revista.

"Los orígenes históricos del Protestantismo". Dos artículos publicados en La Ciencia Cristiana.

"El Derecho internacional y el Cristianismo". Artículo en la misma Revista.

"La Ciencia católica en Alemania". Artículo publicado en la misma Revista.

"El método histórico en la Economía política". Artículo publicado en la Revista de legislación y jurisprudencia.

"Publicaciones alemanas sobre la historia del derecho visigótico". Artículo de la misma Revista.

"Instituciones mozárabes". Artículo publicado en la Revista de Madrid.

Veintinueve artículos bibliográficos sobre obras históricas publicados desde 1875 a 1882, en los periódicos La España y El Tiempo y en las Revistas Contemporánea, La Ciencia Cristiana y el Boletín Histórico.

Títulos académicos

Doctor en Derecho civil y canónico.

Doctor en Filosofía y Letras, con la calificación de Sobresaliente.

Archivero-Bibliotecario y Anticuario, con la calificación de Sobresaliente. 
Catedrático numerario, por oposición, de la Escuela superior de Diplomática. Auxiliar de la Comisión de Cortes de las Real Academia de la Historia desde 1874. Académico de número electo de la Real Academia de la Historia.

Académico Profesor de la Real Academia de Jurisprudencia y Legislación. Vocal de la Junta directiva de la misma Real Academia. 


\section{OBRAS INCLUIDAS COMO MÉRITOS}

Para comodidad del lector, en el presente listado ofrecemos las obras mencionadas por Hinojosa en su relación de méritos (1884). Están ordenadas alfabéticamente por la publicación periódica en la que aparecieron originalmente.

ACADEMIA, LA. REVISTA DE CULTURA HISPANO-PORTUGUESA (ACA, 1876-1890). Revista semanal.

La industria minera entre los romanos, ACA, T. IV, n. ${ }^{\circ} 2$ (julio 1878), p. 26.

El culto de las divinidades orientales en la España romana, ACA, T. IV, n. ${ }^{\circ} 3$ (julio 1878), p. 35 y 38.

ARCHIVO, EL. Revista publicada en Valencia por Roque Chabás, canónigo de la Catedral, quien se encargó de ordenar el archivo de la misma. Aprovechando su estancia en Valencia como gobernador, Hinojosa publicó allí un trabajo.

La privación de sepultura de los deudores. Estudio histórico-jurídico, El Archivo, T. VI (1882), p. 181-200.

BOLETÍN HISTÓRICO (BH, 1880-1886). Apareció en enero de 1880, publicado por los Sres. José Villa-Amil y Castro, Eduardo de Hinojosa, Ángel Allende Salazar y Marcelino Gesta y Leceta, individuos del Cuerpo Facultativo de Bibliotecarios, Archiveros y Anticuarios (a partir de 1881 no aparece su nombre en la mancheta). Allí publicó Hinojosa los siguientes trabajos, todos ellos reseñas bibliográficas.

Recensión de la obra El feudalismo y la servidumbre de la gleba en Cataluña, por José Coroleu e Inglada (Gerona, 1878), BH, T. I n. ${ }^{0}$ 1, (enero 1880) p. 13-14.

Recensión de la obra Deutsche Geschichte bis auf Karl der Grossen; Erster Band: Die Germanen der Urzeit [Historia alemana hasta Carlomagno; T. I: Los germanos primitivos], por Georg Kaufmann (Leipzig, 1880), BH, T. I, n. ${ }^{0} 6$ (junio 1880), p. 91-93.

Recensión de la obra El Colegio de Bolonia. Centón de noticias relativas a la fundación hispana de San Clemente, por Pedro Borrajo y Hermenegildo Giner de los Ríos (Madrid, 1880), BH, T. I, n. ${ }^{\circ} 8$ (agosto 1880), p. 127-128.

Recensión de la obra Der Spanische Cardinal Johann von Torquemada, sein Leben uns seine Schriften, por Stephan Lederer (Freiburg, 1879), BH, T. I, n. ${ }^{\circ} 10$ (octubre 1880), p. 159. 
Recensión de la obra Exempla scripturae visigoticae XL tabulis expressa..., por Paul Ewald y Gustav Loewe (Heidelberg, 1883), BH, T. IV, n. ${ }^{0} 1$ (enero 1883), p. 13-14.

CIENCIA CRISTIANA, LA (CC, 1877-1886). Revista fundada en 1877 por el catedrático de metafísica y académico Juan Manuel Ortí y Lara. Su intención declarada era defender la fe cristiana de las corrientes de pensamiento moderno que se abrían paso en Europa, como el krausismo, el positivismo y el evolucionismo, tendencias filosóficas que se proponía combatir con el neotomismo preconizado por León XIII en su encíclica "Aeterni Patris". Se le deben las siguientes colaboraciones.

Recensión de la obra Geschichte des deutschen Volkes seit dem Ausgang des Mittelalters, por Johann Janssen (Tomo I. Freiburg, 1876), CC, T. I (1877), p. 256261.

Recensión de la obra Geschichte des deutschen Volkes seit dem Ausgang des Mittelalters, por Johann Janssen (Partes IV y V. Freiburg, 1877), CC, T. V (1877), p. 357-360.

Recensión de la obra Tratado completo del derecho romano en cuadros sinópticos, por Manuel de Bofarull (Parte I. Barcelona, 1878), CC, T. VI (1878), p. 360362.

El derecho internacional y el cristianismo, CC, T. VI (1878), p. 511-519.

Recensión de la obra El comunismo, sus causas, efectos y remedios, traducida del italiano por Venancio de Minteguiaga, S. J. (Madrid, 1878), CC, T. VI (1878), p. 539-542.

Recensión de la obra Elogio del Cardenal Cisneros, por Hermenegildo Suaña (Madrid, 1878), CC, T. VII (1878), p. 65-68.

Las últimas elecciones en Alemania, CC, T. VII (1878), p. 525-532.

Recensión de la obra Catálogo de los manuscritos existentes en la Biblioteca del Noviciado de la Universidad Central, por José Villa-Samil y Castro (Madrid, 1878), CC, T. X (1879), p. 75-76.

Recensión de la obra La Edad de Piedra, por Juan Catalina García (Madrid, 1879), CC, T. X (1879), p. 180-181.

La ciencia católica en Alemania, CC, T. X (1879), p. 563-572. 
Recensión de la obra Deitania y su cátedra episcopal de Begastri, por Aureliano Fernández Guerra (Madrid, 1879), CC, T. XI (1879), p. 171-173.

Recensión de la obra El Gerundense y la España primitiva, por Fidel Fita (discurso de ingreso en la RAH, 1879), CC, T. XI (1879), p. 369-371.

Recensión de la obra Die Kirchlichen Reunionsbestrebungen während der Regierung Karls V, por Ludwig Pastor (Freiburg, 1879), CC, T. XIII (1880), p. 5963.

Los orígenes históricos del protestantismo, CC, T. XIII (1880), p. 204-213 y 306314 .

Recensión de la obra La secularización de la enseñanza, discurso del marques de Valle-Ameno (Valladolid, 1880), CC, T. XIV (1880), p. 53-56.

Recensión de la revista Historisches Jahrbuch (Münster, 1880), CC, T. XV (1880), p. 169-171.

Recensión de la revista Studi e documenti di storia e diritto (Roma, 1880), CC, T. XV (1880), p. 541-543.

Recensión de la obra Historia de los heterodoxos españoles, por Marcelino Menéndez Pelayo (Madrid, 1879-1880), CC, T. XVII (1881), p. 251-260 y 555-560.

Recensión de la obra Nomenclator literarius recentioris theologiae catholicae, theologos exhibens qui inde a Concilio Tridentino floruerunt..., por $\mathrm{H}$. Hurter, S. J. (Innsbruck, 1881-1882), CC, T. XXIII (1882), p. 165-167.

MUSEO ESPAÑOL DE ANTIGÜEDADES (MEA, 1872-1880). Esta revista, bellamente editada y de grandes proporciones, dirigida por Juan de Dios de la Rada y Delgado fue fundada en 1872; se centraba en el análisis de diversas piezas del Museo Arqueológico Nacional, y en ella colaboraron los más prestigiosos especialistas de la historia y la arqueología españolas. A Hinojosa se le deben los siguientes trabajos.

Sigilografía romana del Museo Arqueológico Nacional, MEA, t. VII (1876), p. 601-623.

Los nuevos bronces de Osuna (con Juan de Dios de la Rada Delgado), MEA, t. VIII (1877), p. 115-174.

Estatua romana en bronce que representa al emperador Geta, conservada en el Museo Arqueológico nacional, MEA, t. VIII (1877), p. 227-238. 
Gran vaso polícromo italo-griego de la colección que posee el Museo Arqueológico Nacional, MEA, t. IX (1878), p. 81-95.

Terras-cottas del Museo Arqueológico Nacional, MEA, t. IX (1878), p. 503-514.

REVISTA GENERAL DE LEGISLACIÓN Y JURISPRUDENCIA (RGLyJ). Publicación fundada en 1853 por José Reus García, es la revista jurídica decana de España e Hispanoamérica. Sus trabajos en esta revista son:

La escuela histórica en economía política, RGLyJ, T. LVIII (1881), p. 352-361.

Publicaciones alemanas sobre la historia del derecho visigodo, RGLyJ, T. LVIII (1881), p. 139-147.

La decadencia del Imperio Romano en sus relaciones con la historia del Derecho, RGLyJ, T. LX (1882), p. 108-123.

REVISTA HISPANO-AMERICANA (RHA, 1881-1882).

La jurisdicción eclesiástica entre los visigodos, RHA, T. I (1881), p. 193-202 y 510-521.

El régimen municipal romano en España, RHA, T. IV (1882), p. 183-200 y 528543 .

Félix Dahn y sus publicaciones sobre la historia de los pueblos germánicos, RHA, T. VI (1882), p. 513-527.

Publicaciones alemanas sobre historia de España, RHA, T VIII (1882), p. 599608.

REVISTA DE MADRID.

Instituciones mozárabes, en "Revista de Madrid”, T. IV (1882), p. 126-129. 


\section{REAL ACADEMIA}

DE

\section{CIENCIAS MORALES Y POLÍTICAS

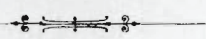

PROGRAMA

PARA LOS CONCURSOS ORDINARIOS DE 1888 Y 1889 OUE ABRE RUPA REAL ACADEMIA

EN CUMPLIMIENTO DE SUS ESTATUTOS

\section{CONCURSO PARA EL AÑO 1888}

TEMA PRIMERO

Examen histórico, económico y jurídico de la vagancia y de la mendicidad voluntaria, en el que se indiquen sus diferencias caracteristicas entre otras épocas y la actual; se determinen sus causas, sus efectos y sus remedios en lo que concierne á la economía politica; y se analice su naturaleza desde el punto de vista del Derecho para deducir si deben ser respetadas por la tolerancia de la autoridad, ó sometidas á la vigilancia de la policía ó á preceptos del Código penal.

\section{TEMA SEGUNDO}

Medidas cuya adopción contribuiria á evitar que se finja la locura con el propósito de sustraerse á responsabilidades criminales, ó que se suponga con el fin de privar $\dot{a}$ un individuo de su libertad y de la gestión de sus bienes.

\section{CONCURSO PARA EL AÑO 1889}

\section{TEMA PRIMERO}

¿Deben sujetarse al mismo régimen municipal las grandes y muy populosas capitales, que los pueblos de mediano ó corto vecindario? Los principios en que se funda la organización y la competencia de las Corporaciones municipales en general, ¿son "plicables, con beneficio de la Administración y de los intereses locales, á las ciudades de poủlación más numerosa? En caso de que no lo fuesen, ¿̇cuáles deberían ser las principales diferencias entre uno y otro régimen?

\section{TEMA SEGUNDO}

Influencia que tuvieron en el Derecho público de su patria, y singularmente en el Derecho penal, los filósofos y teólogos españoles anteriores á nuestro siglo. 
En estos concursos se observarán las reglas siguientes:

1. ${ }^{a}$ Los autores de las Memorias que resulten premiadas obtendrán una medalla de plata, dos mil quinientas pesetas en dinero y doscientos ejemplares de la edición académica de la obra.

2. ${ }^{a}$ La Academia podrá también conceder á cualquiera de los autores el título de Académico correspondiente, si hallare| en su obra mérito extraordinario.

$3 .^{a}$ La Academia, adjudique ó no el premio, se reserva declarar el accésit á favor de las obras que considere dignas de ello, cuyo accésit consistirá en un diploma, en la impresión de la Memoria y en la entrega al autor de doscientos ejemplares de ella.

Se reserva asimismo el derecho de imprimir las obras á que adjudique el premio ó accésit, aunque sus autores no se presenten ó los renuncien.

4. ${ }^{2}$ Las obras que hayan de optar al premio se señalarán con un lema y se remitirán al Secretario de la Academia, hasta las doce de la noche del 1. de Octubre del año á que corresponda. Su extensión no podrá exceder de la equivalente á un libro de 500 páginas, impresas en planas de 37 renglones de 22 cíceros, letra del cuerpo 10 en el texto y del 8 en las notas.

$5 .^{a}$ Los autores de las Memorias ú obras á que la Academia adjudique el premio ó accésit conservarán la propiedad de ellas.

No se devolverá en ningún caso el ejemplar de las Memorias presentadas á concurso, aunque no obtuvieren premio ni accésit.

$6{ }^{a}$ Cada autor remitirá con su trabajo un pliego cerrado, sen̂alado en la cubierta con el mismo lema de la Memoria respectiva, y que en la parte interior contenga su firma y la expresión de su residencia.

7. ${ }^{a}$ Adjudicado el premio ó accésit á cualquiera Memoria, se abrirá en Junta ordinaria el pliego cerrado á que corresponda; y los demás se inutilizarán en la Junta pública general en que se haga la solemne adjudicación.

8. ${ }^{\mathrm{a}}$ Á los autores, que no llenen las condiciones expresadas, y que en el pliego cerrado omitan su nombre ó pongan otro distinto, no se les otorgará premio ni accésit. Tampoco se les dará á los que quebranten el anónimo.

9. ${ }^{a}$ Los Académicos de número no pueden aspirar á ninguno de los premios.

Madrid $1 .^{\circ}$ de Marzo de 1887.

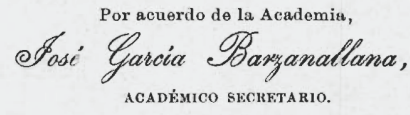

La Academia se halla establecida en la casa do los Jujanes,

Plaza de la Villa, número 2 , principal. 


\section{GACETA DE MADRID, 13 DE OCTUBRE DE 1889 \\ MINISTERIO DE FOMENTO \\ REAL ACADEMIA DE CIENCIAS MORALES Y POLÍTICAS}

Habiendo terminado a las doce de la noche de ayer e plazo señalado en el programa de 1 de marzo de 1887 para admitir al concurso ordinario del presente año, las Memorias escritas sobre los temas: $10^{\circ}$ ¿Deben sujetarse al mismo régimen municipal las grandes y muy populosas capitales que los pueblos de mediano o corto vecindario? Los principios en que se funda la organización y la competencia de las Corporaciones municipales en general, ¿son aplicables con beneficio de la Administración y de los intereses locales a las ciudades de población más numerosas? En caso de que no lo fuesen, ¿̇cuáles deberían ser las principales diferencias entre uno y otro régimen? Se anuncia el lema de la única Memoria que se ha presentado sobre dicho tema en 28 de septiembre último, el cual dice: Las instituciones locales son la escuela primaria del ciudadano, Ferrand.

Respecto al segundo tema, que es: "Influencia que tuvieron en el Derecho público de su patria, y singularmente en el Derecho penal, los filósofos y teólogos españoles anteriores a nuestro siglo", se publica también el lema de la única Memoria presentada sobre el mismo en $1 .^{\circ}$ del corriente, concebido en estos términos: "Durante el siglo de oro de nuestra literatura, predominó en España la doctrina de la escuela político religiosa, cuyos principales representantes fueron ciertamente el sabio Francisco de Vitoria, maestro de Melchor Cano; el insigne dominico Domingo de Soto, el jesuita Francisco Suárez, llamado el Doctor Eximio... Ella echó con Alfonso de Castro los cimientos de la ciencia del Derecho penal, y la del Derecho de gentes con Francisco de Vitoria y Baltasar de Ayala. Ella dio de sí innumerables tratados de derecho político, entre los cuales se cuentan muchos dignísimos de estima aun hoy en día... Ella será cuando profundamente llegue a estudiarse y conocerse del todo, el timbre mayor quizá del reinado de Felipe II, y uno de los mejores, sino el más celebrado fruto del talento español hasta ahora". Cánovas del Castillo, bosquejo histórico de la Casa de Austria en el Diccionario general de política y administración. Tomo I, Madrid, 1868, páginas 888 y 889.

La Academia examinará las expresadas Memorias y publicará el resultado del concurso.

Madrid, 2 de octubre de 1889.=El Académico Secretario, José G. Barzanallana. 
Carta de la RACM a Alejandro Pidal

Al Excmo. Sr. D. Alejandro Pidal

En 14 de octubre de 1889

E.S.

El Sr. Presidente de nuestra R. Academia, en uso de las atribuciones que le corresponden conforme al art. 18 de los Estatutos, ha nombrado a V.E. para que se sirva examinar y calificar la memoria presentada al Concurso ordinario del presente año sobre el tema $2 .^{\circ}$ : "Influencia que tuvieron en el Derecho público de su patria, y singularmente en el Derecho penal, los filósofos y teólogos españoles anteriores a nuestro siglo".

En su virtud, tengo la honra de remitir a V.E. la memoria que lleva el lema "Durante el siglo de oro de nuestra literatura, predominó en España la doctrina de nuestra Escuela político-religiosa, cuyos principales representantes fueron ciertamente el sabio Francisco de Vitoria, maestro de Melchor Cano; el insigne dominico Domingo de Soto; el jesuita Francisco Suárez, llamado el Doctor Eximio... Ella echó con Alfonso de Castro los cimientos de la ciencia del Derecho penal, y los del derecho de gentes con Francisco de Vitoria y Baltasar de Ayala. Ella dio de sí innumerables tratados de derecho político, entre los cuales se encuentran muchos dignísimos de estima aun hoy día... Ella será, cuando profundamente llegue a estudiarse y conocerse del todo, el timbre mayor quizá del reinado de Felipe II, y uno de los mejores, si no el más celebrado fruto del talento español hasta ahora", acompañada del Programa del concuro del año a que corresponde.

Dios, etc.

El Acadco. Scrio.

JGB (=José García Barzanallana) 
Dictamen del concurso de 1889, tema 2:

Influencia que tuvieron en el derecho público de su patria y singularmente en el penal los filósofos y teólogos españoles anteriores a nuestro siglo.

Leído en la sesión del 11 de febrero de 1890; se discutirá en 25 de febrero.

Encargado el que suscribe por oficio de 14 de octubre de 1889 del examen y calificación de la Memoria presentada al concurso ordinario de dicho año sobre el tema segundo, a saber "Influencia que tuvieron en el derecho público de su patria y singularmente en el penal los filósofos y teólogos españoles anteriores a nuestro siglo", tiene el honor de exponer a la consideración de la Academia, después de detenido estudio, detallado examen y menuda comprobación de citas y textos, que dicha memoria, o sea la que lleva por lema las palabras del "Bosquejo histórico de la Casa de Austria" del Sr. Cánovas del Castillo que empiezan Durante el siglo de oro de nuestra literatura y acaba ...sino el más celebrado fruto del talento español hasta ahora (única memoria presentada al concurso), llena cumplidamente, a su juicio, cuantas condiciones requiere el programa para la concesión del correspondiente premio.

Con efecto basta la rápida lectura general del citado estudio para echar de ver enseguida lo familiares que le son al autor la lengua latina, los monumentos teológicos y jurídicos de nuestra patria, las doctrinas científicas de nuestros teólogos y filósofos y el desarrollo propio de nuestra civilización en todo el curso de nuestra historia. Su estilo llano y claro, los juicios más analíticos que sintéticos, su erudición de fuentes y orígenes directa y de primera mano, su conocimiento profundo del movimiento científico contemporáneo, tanto nacional como extranjero respecto a estas materias, y su sobriedad excesiva a punto de generalizaciones y descripciones, ponen de manifiesto la modestia a la vez que prudencia y templanza del escritor; el carácter serio, sólido, práctico, concienzudo y hasta cierto punto tímido del pensador y del crítico.

No es esta por tanto una brillante disertación sistemática, hipotética y conceptual sobre los caracteres generales del tema, sino una sencilla exposición, nutrida de datos, de cuanto arrojan de sí, con relación al mismo, el estudio de los autores y de las doctrinas de nuestros pensadores más profundos y el examen de nuestros monumentos legales. Más que una fábrica aparatosa y aérea es un ordenado depósito de sólidos materiales con los que sin caer en una naturaleza retórica (que el cielo no sé si piadoso o ceñudo ha negado evidentemente al autor), construir un acabadísimo edificio, sin que esto sea por otra parte insinuar que faltan en este estudio aquellas conjeturas probables, aquellas inducciones y deducciones lógicas, aquellas consideraciones de carácter general necesarias para formar un 
ensayo de doctrina con relación a uno de los aspectos más importantes del desarrollo de la civilización española.

La introducción en que acertadamente se exponen el alcance y el sentido del tema, las condiciones científicas presupuestas o necesarias para desenvolverle, la bibliografía de trabajos sobre las fuentes para estudiarle, la división cronológica en sus tres distintos y principales periodos, demuestra desde el primer momento que si el autor no lograra dar cumplidamente cima a su empresa, no sería por desconocimiento de las dificultades que presenta ni de los medios que se requieren para llevarla a cabo.

El cuerpo de la obra que como se echa de ver por el índice apenas deja ningún autor, monumento legal o libro que no engarce según su época o su importancia en el lugar que le corresponde, no contiene extracto más sucinto que el texto, ni enumeración más completa que el sumario. Por el último podrá juzgar la Academia la importancia de las cuestiones que tiene. El primero es indispensable para apreciar lo cumplidamente que las resuelve. Sobresale en él, sobre todo, a nuestro parecer, el capítulo tercero destinado a exponer las causas de la influencia de nuestros teólogos en las ciencias políticas sociales, exposición llevada a cabo con sumo acierto, y con notable exactitud del mérito e importancia de cada uno de ellos, creciendo ya desde aquí, sin parar hasta el fin el interés, casi por decirlo así, "de actualidad" de la Memoria.

Ninguna de las graves y transcendentales cuestiones que fueron objeto de controversia o de consulta en aquellos siglos de tan honda y encarnizada lucha intelectual como física desde el origen de la sociedad y del poder hasta el de las formas del gobierno, desde la venta de los oficios públicos hasta la potestad de los reyes cristianos sobre la hacienda de los judíos y sarracenos, la intervención del pueblo en la redacción de las leyes y en la imposición de los tributos, la resistencia al poder público y el tiranicidio, la potestad del Papa en materias temporales, las exenciones e inmunidades del clero y su interacción en la gobernación del estado, los bienes de la Iglesia, las distintas teorías regalistas que predominaron ya en la Casa de Austria ya en la de Borbón, la herejía, considerada como delito civil, el tormento, la usura, la esclavitud, en suma, cuanto forma el fondo de aquella ardiente polémica que poniendo a contribución la ciencia profana y las Sagradas Escrituras, la filosofía, la teología, la política, la economía y el derecho, demostró lo sólido y lo grandioso de una civilización que depuraba las escorias de la barbarie en que se engendró, por el calor y la vida que fermentaba en su seno, todo encuentra allí, a su debido tiempo y vez, la consideración y el esclarecimiento que por su naturaleza requieren dado el punto de vista forjado de la cuestión impuesto por las exigencias del tema.

No es esto decir ni mucho menos que carezca en absoluto de lunares este trabajo. Aparte de lo que indicamos al principio echamos de menos algunas con- 
sideraciones cuya omisión puede fácilmente inducir a error, si no se llaman sobre ellas la atención del autor para corregirlas. Tal acontece, por ejemplo, en el capítulo $44^{\circ}$, donde convendría advertir a los lectores que al exponer nuestros teólogos la teoría de que el poder social deriva inmediatamente de la sociedad y de que interviene un pacto tácito o expreso entre el representante del poder y la sociedad, tratan siempre la cuestión en abstracto, siguiendo el método escolástico, por virtud del cual, así como en el ente físico, contemplan primero la materia y después la forma, sin que eso arguya sucesión de tiempo en la existencia del principio material y formal; del mismo modo cuando tratan de la sociedad la descomponen en su mente y contemplan primero el pueblo, principio material, y después la autoridad, principio formal, apareciendo en el proceso de la razón que esta es posterior a aquel, como la propiedad esencial al sujeto en que radica. Pero bien se echa de ver que no hay en esto sucesión de tiempo, sino solo de naturaleza y que tan imposible era para ellos una sociedad concreta sin autoridad como un ente sin forma.

Los teólogos que hablan del poder delegado por el pueblo como si interviniese pacto social y consignan que el soberano es solo depositario de la autoridad del pueblo, usan estas voces en el mismo sentido que algunos Santos Padres cuando tronaban contra la codicia de los ricos, usaban otras semejantes, relativas a la propiedad y al uso de las riquezas como cuando les decían que más que propietarios eran usufructuarios o administradores de los bienes de Dios. Ni unos ni otros pudieron sospechar jamás que de aquellos principios se pretendería deducir el derecho a la revolución, ni el comunismo.

En la página 140 se atribuye a Soto la opinión, calificada de errónea, de que el príncipe tiene derecho a privar de sus bienes a sarracenos y judíos. A mi juicio, por excepción, no debió entender o interpretar exactamente el texto de Soto que conforme a los teólogos y canonistas de su tiempo establecía que los judíos y sarracenos, una vez admitidos a una nación cristiana, tenían derechos civiles y no era lícito expulsarlos, a no ser en el caso de que maquinasen la perdición de la república.

Algún que otro error se podrá acaso señalar por el estilo en la interpretación del alcance de ciertas y determinadas doctrinas, pero aparte de que son contadísimas en número y no grandes en importancia, cabe la duda casi siempre de si fue error la omisión del copista, que está muy lejos por cierto de emular al autor en el desempeño de su cargo.

Por estas razones, atendida la dificultad natural de estos estudios, su utilidad e importancia, las evidentes condiciones del autor para esta clase de trabajos y el acertado desempeño de su obra, el que suscribe propone sin vacilar a la Academia que otorgue el premio correspondiente a la memoria de que se trata, seguro de que la publicación de un trabajo tan excelente estimulará a los que se dedican a 
este género de estudios a profundizar más y más en una investigación tan interesante como poner de manifiesto en la historia el lazo invisible a veces, pero no por eso menos real, que une el desarrollo de las ideas con el progreso o decadencia de las instituciones.

La Academia sin embargo resolverá como siempre lo más conveniente.

Madrid

Alejandro Pidal 


\section{GACETA DE MADRID, 3 DE MARZO DE 1890 MINISTERIO DE FOMENTO REAL ACADEMIA DE CIENCIAS MORALES Y POLÍTICAS}

Examinada por esta Real Academia la única Memoria presentada al concurso ordinario de 1889, sobre el segundo tema, que dice: "Influencia que tuvieron en el Derecho público de su patria, y singularmente en el Derecho penal, los filósofos y teólogos españoles anteriores a nuestro siglo", ha declarado el premio ofrecido en la regla $1 .^{a}$ de programa de 1 de marzo de 1887 , a dicha Memoria, que lleva el lema siguiente: "Durante el siglo de oro de nuestra literatura, predominó en España la doctrina de la escuela político religiosa, cuyos principales representantes fueron ciertamente el sabio Francisco de Vitoria, maestro de Melchor Cano; el insigne dominico Domingo de Soto, el jesuita Francisco Suárez, llamado el Doctor Eximio... Ella echó con Alfonso de Castro los cimientos de la ciencia del Derecho penal, y la del Derecho de gentes con Francisco de Vitoria y Baltasar de Ayala. Ella dio de sí innumerables tratados de derecho político, entre los cuales se cuentan muchos dignísimos de estima aun hoy en día... Ella será cuando profundamente llegue a estudiarse y conocerse del todo, el timbre mayor quizá del reinado de Felipe II, y uno de los mejores, sino el más celebrado fruto del talento español hasta ahora" [Cánovas del Castillo, bosquejo histórico de la Casa de Austria en el Diccionario general de política y administración. Tomo I, Madrid, 1868, páginas 888 y 889$]$.

Abierto el pliego que acompañaba a esta Memoria, ha resultado ser su autor el Sr. D. Eduardo de Hinojosa, residente en Madrid.

Lo que por acuerdo de la Academia se pone en conocimiento del público.

Madrid, 26 de febrero de 1890.=El Académico Secretario perpetuo, José G. Barzanallana. 
Carta de la Academia a Hinojosa

Al Sr. D. Eduardo de Hinojosa

En 4 de junio de 1890

Esta Real Academia ha acordado que la solemne adjudicación del premio que declaró a la Memoria presentada por V.S., sobre el $2 .^{\circ}$ tema del concurso ordinario de 1889 , tenga lugar en la junta pública que celebrará el día 8 de corriente a las dos de la tarde en su local de la casa de los Lujanes.

Lo que tengo el gusto de participar a V.S. a fin de que se sirva asistir a recoger en dicha acta el diploma y medalla que le corresponden; y al propio tiempo le incluyo las adjuntas esquelas de invitación para asistir al mismo.

Dios, etc...

El académico secretario perpetuo,

JGB (=José García Barzanallana) 
INFLUENCIA QUE TUVIERON

EN EL

\title{
DERECHO PUBLICO DE SU PATRIA
}

\author{
Y SINGULARMENTE \\ EN EL DERECHO PENAL \\ LOS FILÓSOFOS Y TEÓLOGOS ESPAÑOLES \\ ANTERIORES A NUESTRO SIGLO
}

POR EDUARDO DE HINOJOSA

Catedrático de la Escuela superior

de Diplomática, Individuo de número de la Real Academia de la Historia.

\begin{abstract}
MEMORIA
PREMIADA POR LA REAL ACADEMIA DE CIENCIAS MORALES Y POLÍTICAS EN EL CONCURSO DEL AÑO 1889
\end{abstract}

MADRID

TIPOGRAFÍA DE LOS HUÉRFANOS

Calle de Juan Bravo, núm. 5 .

1890 


\section{LEMA}

"Durante el siglo de oro de nuestra literatura, predominó en España la doctrina de la Escuela político-religiosa, cuyos principales representantes fueron ciertamente el sabio Francisco de Vitoria, maestro de Melchor Cano; el insigne dominico Domingo de Soto; el jesuita Francisco Suárez, llamado el doctor Eximio... Ella echó con Alfonso de Castro los cimientos de la ciencia del Derecho penal y la del Derecho de gentes con Francisco de Vitoria y Baltasar de Ayala. Ella dio de sí innumerables tratados de Derecho político, entre los cuales se cuentan muchos dignísimos de estima aun hoy día... Ella será, cuando profundamente llegue a estudiarse y conocerse del todo, el timbre mayor quizá del reinado de Felipe II, y uno de los mejores, si no el más celebrado fruto, del talento español hasta ahora" ${ }^{\text {. }}$

1 Cánovas del Castillo, Bosquejo histórico de la Casa de Austria, en el Diccionario general de política y administración, tomo I, Madrid, 1868, páginas 888-889. 
HINOJOSA EN LA RACMYP

\section{A LA MEMORIA}

de mi querido y malogrado amigo

\section{ENRIQUE PÉREZ-HERNÁNDEZ}




\section{INTRODUCCIÓN}

Entre los asuntos que más vivamente solicitan y atraen al que atentamente considera el desenvolvimiento de la historia y del derecho patrios, muy pocos logran despertar su interés en tan alto grado como el estudio del lazo, unas veces ostensible, velado y escondido otras, que une la historia de las ideas con la historia de las instituciones. La Real Academia de Ciencias Morales y Políticas ha dado elocuente muestra de su celo en promover las investigaciones sobre este aspecto interesantísimo de la vida nacional, eligiendo para sus concursos temas como el presente, cuya sola enunciación basta a dar idea de su importancia y trascendencia.

Al proponerme disertar sobre él, llevado más de afición que de confianza en mis fuerzas para tratarlo convenientemente, he empezado por determinar, con la precisión posible, el estadio cronológico que debo recorrer. De los términos mismos en que se halla redactado el tema, paréceme inferirse con evidencia que la exposición ha de arrancar de allí donde comienza a ser perceptible la influencia de las especulaciones filosóficas y teológicas sobre las instituciones políticas y penales de nuestro pueblo; y por tanto, que el punto de partida debe ser el período visigótico. Antes de él, sólo hay un filósofo español cuyas teorías se relacionen con las instituciones de que se trata, singularmente con el Derecho penal. Este filósofo es Séneca; mas, por causas que vamos a exponer brevemente, ninguna influencia ejerció en el desenvolvimiento del Derecho público español. Los principios de la filosofía estoica, brillantemente defendidos por el sabio cordobés, sin que por lo demás ofrezcan en sus obras caracteres esencialmente distintos de los que presentan en otros pensadores de la misma escuela, nada influyeron para modificar el Derecho público y penal de Roma, ni mostraron su virtualidad sino respecto del Derecho civil o privado, y especialmente de alguna institución como la esclavitud, preparando el camino a la influencia más directa y ostensible del Cristianismo. Por otra parte, España no gozaba entonces de verdadera autonomía en el orden político; no constituía un Estado independiente; como territorio sujeto a Roma, se gobernaba por las leyes de la metrópoli y su organización se diferenciaba muy poco de la que regía en las demás provincias del Imperio.

El período de agitación y de lucha que se extiende desde los orígenes del Cristianismo en España hasta la invasión de los pueblos del Norte, fue poco 
propicio al desarrollo de la ciencia teológica en nuestra patria. Los escasos cultivadores de estos estudios, atentos sólo a defender la pureza e integridad de la doctrina católica contra las nacientes herejías y a consolidar la disciplina, no abordaron en sus escritos los arduos problemas relacionados con el origen y constitución de las sociedades. Los cánones de los Concilios españoles anteriores a las Asambleas mixtas o Concilios nacionales de Toledo, en que podría reflejarse de algún modo la influencia de los teólogos en tal materia, carecen de importancia desde nuestro punto de vista; pues en la parte que dicen relación al Derecho público y al penal se limitan, ya como el Concilio Iliberitano a robustecer la pureza de la fe, prohibiendo a los cristianos que desempeñaban cargos públicos intervenir en las ceremonias paganas y mandando a los fieles que se abstuvieran de ciertos actos reprobados de trascendencia social, como los libelli famosi, ya como el Concilio de Lérida, celebrado en tiempo de Teudis, a vedar a los litigantes obligarse por juramento a no avenirse jamás con el adversario. Por lo demás, si bien las prescripciones de los Concilios en la época de que tratamos debieron ejercer cierta influencia en las costumbres, proporcionada al ascendiente que tenía a la sazón la Iglesia, y cuya extensión no podemos hoy precisar con exactitud, es indudable que por haberse celebrado el más importante de todos ellos antes de ser el Cristianismo religión del Estado, y otros cuando España, o no disfrutaba aún de autonomía política, o era gobernada por Monarcas arrianos, no pudieron reflejarse directamente su influencia en las instituciones jurídicas. La acción directa y eficaz de los teólogos presupone, además de un mayor grado de desarrollo de la ciencia teológica, un estado, no ya sólo de concordia, sino de estrecha alianza entre la Iglesia y el Estado, por virtud del cual este último, o venga a dar participación directa en las tareas legislativas a las personas eclesiásticas, o, además de sancionar con la fuerza de su autoridad los preceptos emanados de la Iglesia, se deje guiar, en más o en menos escala, de los principios consignados en las obras de los teólogos, considerándolos como expositores de la más sana y autorizada doctrina política e informando en ella las leyes civiles.

La influencia de los teólogos ha podido ejercerse, por tanto, y se ha ejercido de hecho bajo dos formas. La primera, y ciertamente la más directa y eficaz, ha sido la colaboración en el desempeño del poder legislativo. De ella nos ofrece singular ejemplo la historia de la dominación visigoda, durante la cual el clero no intervino en la formación de las leyes como uno solo de los varios brazos o estamentos, a semejanza de lo que sucedió en las Cortes de los reinos cristianos posteriores a la invasión árabe, sino con carácter preponde- 
rante y casi exclusivo. La segunda, cuando el Jefe del Estado, o acostumbra a asesorarse de personas doctas en materias teológicas respecto a la licitud y oportunidad de las disposiciones que se propone dictar, o, tanto él, como los funcionarios o corporaciones que intervienen en la redacción de las leyes, van a buscar en las obras de los teólogos, norma y guía a que atemperarse en el ejercicio de tan difícil o importante tarea. Esto último presupone, además de estrecha unión entre la Iglesia y el Estado, cierto progreso de los estudios teológicos, en cuya virtud sus cultivadores se dediquen a examinar los grandes problemas del Derecho público y la correlación y armonía entre la Teología y la Jurisprudencia, que se observan, por ejemplo, en Italia durante la Edad Media y en España, como herencia de la tradición medio-eval, durante el siglo XVI y el primer tercio del XVIII.

En cuanto a los filósofos, su influencia en el Derecho público de la $\mathrm{Pe}$ nínsula dista mucho de poderse comparar con la de los teólogos. La razón de esta diversidad se encuentra en que muy pocos de nuestros filósofos se dedicaron a tratar de propósito materias relacionadas con el Derecho público y penal, si se hace abstracción de los que fueron a un tiempo filósofos y teólogos, y que ejercieron principal o exclusivamente su influencia en este último concepto.

He procurado no perder de vista, al redactar la presente Memoria, que ni la influencia de la Religión, ni la de la Iglesia, representada por su Jefe visible o por sus Asambleas, los Concilios, ni la del Clero como clase social, son objeto propio de esta investigación, sino únicamente la de los teólogos de profesión, o sea de las personas consagradas al cultivo de la ciencia teológica. Por lo demás, he creído que debía consagrar igual atención que a las obras propiamente doctrinales, a los documentos redactados evidentemente por teólogos de profesión y en que éstos han expuesto su manera de ver respecto a los arduos problemas del gobierno de las sociedades. Juzgo, por tanto, no haber interpretado el tema en sentido demasiado lato y ajeno del propósito de la Academia al extender el estudio a documentos, como los preámbulos y los cánones de los Concilios de Toledo, en que las opiniones y la influencia teológicas se revelan de una manera ostensible. Teólogos eran sin duda alguna los Isidoros, Leandros, Julianes, Braulios e Ildefonsos, que tanta parte tuvieron en las leyes acordadas y promulgadas en los Concilios nacionales, y no debía prescindir del estudio de esos documentos redactados por ellos, suprimiendo uno de los aspectos en que más activa y eficaz se muestra la influencia teológica, singularmente en cuanto al Derecho público. 
¿Por ventura las consideraciones de índole doctrinal que se encuentran en los preámbulos de las Actas conciliares no reflejan con tanta claridad como los escritos teológicos de los siglos XVI y XVII, en su caso, las opiniones de los teólogos de la época bajo cuya inspiración se redactaron?

Otra cuestión previa, es la determinación del ámbito sistemático o materia que ha de ser objeto de las investigaciones exigidas por el tema; punto que, como el anterior, me parece desprenderse con entera claridad de los términos en que está redactado. Al establecer que la influencia de los teólogos y filósofos españoles ha de estudiarse con relación al Derecho público y especiad mente al penal, indica desde luego que no ha de tratarse solamente del Derecho público, en sentido estricto, o sea del Derecho político, sino también del Derecho público en el concepto más lato, o sea del político, del administrativo, del penal y procesal, así como del Derecho eclesiástico en lo concerniente a las relaciones entre la Iglesia y el Estado; sin que el incluir a este último dentro de los indicados límites arguya el desconocimiento de su carácter autónomo e independiente en términos generales. No me parece dudoso, por otra parte, que cae también en la esfera del tema el Derecho internacional público, o sean las normas a que se atemperaron las relaciones de España con otros Estados, así en tiempo de paz como en tiempo de guerra.

Fijada así, en términos que creo han de responder, en lo esencial, al propósito de la Academia, la inteligencia del tema, saltan desde luego a la vista las graves dificultades que ofrece el tratarlo convenientemente. Su presupuesto indispensable es el conocimiento más completo posible de los dos términos de la comparación: por una parte, el de las doctrinas sostenidas por los filósofos y teólogos españoles de las diversas épocas, en cuanto se han manifestado y pueden estudiarse en los monumentos legislativos redactados exclusiva o principalmente por ellos, y en los escritos de índole doctrinal que nos han legado; por otra, el de las normas del Derecho positivo patrio en las diversas ramas enumeradas anteriormente. Tarea larga y penosa, que sería imposible llevar a feliz término, dentro del plazo relativamente breve señalado por la Academia, a no contar con trabajos estimabilísimos que allanan y facilitan la investigación. Aun con el auxilio extraordinario que ellos prestan, queda todavía bastante que hacer al que se proponga estudiar la materia en su conjunto, emprendiendo trabajos de primera mano sobre autores e instituciones, además de acomodar a la índole peculiar del tema las publicaciones anteriores.

No creo ajena de este lugar la exposición del estado actual de los estudios acerca del particular, y la reseña de los trabajos cuya investigación ha servi- 
do de punto de partida a la presente Memoria. El examen de las doctrinas de los teólogos españoles de la Edad Media posteriores a la invasión árabe importantes para el Derecho público y el penal está todavía en mucha parte por hacer. No así las del período visigótico, estudiadas en su conexión con las instituciones políticas por D. Manuel Colmeiro en su Curso de Derecho político $^{2}$ y por D. Vicente de la Fuente en su Historia eclesiástica de España ${ }^{3}$. Otro tanto puede decirse de las instituciones políticas del mismo período, que han servido de materia a trabajos tan importantes como los ya citados de Colmeiro y La Fuente, Pidal (D. Pedro José) ${ }^{4}$ y Conde de Torreánaz ${ }^{5}$ entre los españoles, y de Guizot ${ }^{6}$ y Dahn ${ }^{7}$ entre los extranjeros. Menos fortuna han tenido las instituciones penales, acerca de las cuales apenas poseemos otras publicaciones dignas de mención que el trabajo fragmentario y superficial de Du-Boys ${ }^{8}$, el más completo, pero insuficiente también, de Gutiérrez (D. B.) en su Examen histórico del Derecho penal ${ }^{9}$, y sobre todo el de Dahn en sus Westgothische Studien ${ }^{10}$.

Las obras de los teólogos que florecieron en los reinos cristianos de la Reconquista, de escaso interés para el Derecho público y el penal, como consagradas las más de ellas casi exclusivamente al estudio de las graves cuestiones de organización eclesiástica agitadas en su tiempo, han ocupado menos la atención de los publicistas. Los mismos autores anteriormente citados, a excepción de Dahn, cuyas obras se limitan al período visigótico, permiten orientarse en el dédalo del Derecho público y penal de los reinos de León y Castilla. Acerca del vigente en los otros Estados cristianos de nuestra Península, me han servido de guía los Estudios sobre la Historia y el Derecho de Aragón ${ }^{11}$, de La Fuente, la monografía del Conde de Torreánaz sobre Los Consejos del Rey, los datos sueltos que sobre el Derecho público y penal de Navarra ofrece

2 Curso de Derecho político según la historia de León y Castilla. Madrid, 1873.

3 2. $^{\text {a }}$ edición. Madrid, 1873.

4 Lecciones sobre la Historia del Gobierno y Legislación de España. Obra póstuma dada a luz por su hijo el actual Marqués de Pidal. Madrid, 1880.

5 Los Consejos del Rey durante la Edad Media. Madrid, 1884.

6 Histoire de la Civilisation en Europe. París, 1849.

7 Die Verfassung der Westgothen. 2. ${ }^{a}$ edición. Leipzig, 1883.

8 Historia del Derecho penal de España. Traducción española. Madrid, 1872.

9 Madrid, 1886.

10 Würzburg, 1874.

$113 \cdot{ }^{\mathrm{a}}$ serie. Madrid, 1886. 
Yanguas en su Diccionario de antigüedades ${ }^{12}$, el estudio de los Sres. Coroleu y Pella sobre Las Cortes catalanas ${ }^{13}$ y el discurso de D. Bienvenido Oliver ver sobre La Nación y la Realeza en los Estados de la corona de Aragón ${ }^{14}$. Las obras de los antiguos comentaristas del Derecho de Aragón y Cataluña me han sido de escaso auxilio, por amenguar mucho su valor como fuente de conocimiento histórico, las más de las veces, la tendencia exageradamente romanista de sus autores.

En cuanto a los teólogos y filósofos españoles del período más importante a que ha de referirse la Memoria, poseemos las investigaciones de Balmes en los tomos III y IV de El Protestantismo comparado con el Catolicismo en sus relaciones con la historia de la civilización europea, la Defensa ${ }^{15}$ de Martínez Marina contra las censuras de que fueron objeto sus obras por parte de la Inquisición, el estudio de D. Antonio Cánovas del Castillo sobre Las ideas políticas de los españoles ${ }^{16}$ bajo la dominación de la casa de Austria y la monografía del P. Garzón sobre Mariana ${ }^{17}$. Las doctrinas de los teólogos españoles de los siglos XVI, XVII y XVIII acerca del Derecho penal no han sido, que yo sepa, materia de especial investigación, si se exceptúan las breves páginas que dedica Gutiérrez en la obra citada al más importante de ellos, Alfonso de Castro. El desenvolvimiento de las instituciones políticas y de las relaciones entre la Iglesia y el Estado en este período, puede estudiarse en las obras de Colmeiro y La Fuente, de que ya se ha hecho mérito, y en la monografía de este último escritor sobre la Retención de Bulas en España ${ }^{18}$, así como el de las instituciones penales en el Examen histórico de Gutiérrez.

He dividido la exposición en tres períodos, que me parecen indicados por la naturaleza misma del asunto. Comienza el primero con la abjuración del arrianismo por Recaredo, y termina con la invasión árabe y consiguiente ruina del imperio visigodo. El segundo, tras larga pausa, después del estancamiento de los estudios teológicos en los siglos posteriores a la Reconquista, tiene como punto de partida el renacimiento de la ciencia teológica y jurídica en el siglo XIII y llega hasta mediados del siglo XVI, en cuyo tiempo el método iniciado por Francisco de Vitoria y propagado por sus colegas y discípulos

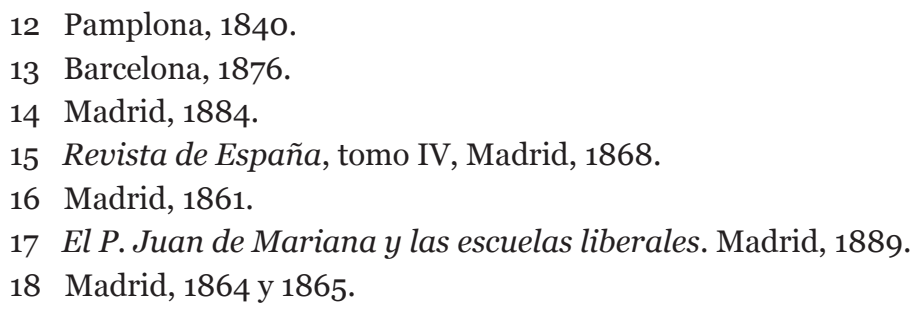


abre nueva y fecundísima era a las ciencias jurídicas y sociales. El tercero se extiende hasta mediados del siglo XVII, en armonía con los límites asignados a este trabajo por la Academia.

Me atrevo a esperar que, considerando tan docta Corporación las graves dificultades que ofrece tratar convenientemente el tema propuesto, se mostrará indulgente respecto a los vacíos y deficiencias de este trabajo. 


\section{CAPÍTULO PRIMERO}

La Iglesia y el Estado entre los Visigodos. - Fuentes a que debe acudirse para estudiar la influencia de los teólogos en las instituciones de este pueblo.- Vestigios de la influencia teológica en el Derecho público; limitaciones de la autoridad real; negación del carácter patrimonial de la Monarquía; textos de San Isidoro y San Braulio favorables a la Monarquía hereditaria; el derecho de indulto.- Insuficiencia de los datos que poseemos para apreciar la influencia de los teólogos visigodos en el Derecho penal.

Las relaciones entre la Iglesia católica y el Estado visigodo antes de la conversión de Recaredo no consintieron que ésta última, por medio de sus más autorizados representantes los Obispos, ejerciese influencia alguna en las leyes ni en las instituciones políticas. Perseguida por algunos Monarcas, especialmente por Eurico, tolerada por otros que, como Teudis, consintieron a los Prelados congregarse en Concilio para tratar en común de los asuntos concernientes al régimen interior de la Iglesia, careció, en el largo período que se extiende desde Ataúlfo hasta la muerte de Leovigildo, de los medios necesarios para modificar el modo de ser de aquella sociedad semi-romana y semi-bárbara. Pero desde el momento en que Recaredo con la mayoría de la nobleza visigoda, arrastrada por la fuerza y el ejemplo de la autoridad real, abjura la herejía arriana, llevando a cabo un acto en que tuvo quizá tanta parte como la convicción religiosa la razón del Estado, se inicia una era de alianza estrechísima entre la potestad civil y la eclesiástica, que ofreció al Episcopado ancha base para infiltrar su espíritu y traducir sus aspiraciones de una manera sensible en la legislación visigoda. La resistencia de la casi totalidad de los Prelados y de la población católica a los halagos y persecuciones de que se valió Leovigildo para sumirlos el arrianismo, habían puesto elocuentemente en relieve la fuerza incontrastable del Episcopado católico y su inmenso ascendiente sobre los pueblos. El divorcio entre la Monarquía y el Clero católico, factor tan importante y elemento tan valioso en la vida social del pueblo visigótico, sobre todo después de la incorporación del reino de los Suevos, convertido más de medio siglo antes al Catolicismo, podía ser en extremo peligroso a la integridad y aun a la existencia del Reino visigodo en lucha con enemigos tan poderosos como los Francos y Bizantinos, católicos en religión. Unos y otros podían explotar en provecho propio el desvío y el encono entre los monarcas y la mayoría de la nación, apegada a las creencias católicas, y profesadas no sólo por los súbditos hispano-romanos, sino tam- 
bién por una parte de la raza conquistadora. De aquí que Recaredo, de la sinceridad de cuya conversión no hay por otra parte motivo alguno para dudar, creyese con razón obrar como hábil político al emprender camino opuesto y más llano y seguro que el seguido por su padre, para realizar la misma aspiración que éste en lo esencial, o sea la unificación religiosa de su reino, como base y coronamiento de la unificación política. Contaba a la sazón el Clero católico con hombres eminentes por su virtud y por su ciencia como los Isidoros, Leandros, Masonas y Juanes de Biclara, a quienes el Monarca visigodo debió considerar como valiosos auxiliares en la ardua tarea de organizar y gobernar una nación compuesta de elementos heterogéneos en tradiciones y costumbres, y a quienes ningún otro vínculo podía ligar tan eficazmente como la comunidad de ideas religiosas, atenuando las diferencias de nacionalidad y de cualquier otro género que separaban a vencedores y vencidos. No es, pues, de extrañar que Recaredo llamase a los Obispos a tomar asiento en las Asambleas legislativas y a los Consejos del Trono, donde por la superioridad de su cultura ejercieron una influencia considerable y a veces preponderante y decisiva.

Como consecuencia de esta íntima alianza, entre el Clero católico, la Monarquía y los Concilios procuran realzar y acrecentar a los ojos de los fieles la autoridad y el prestigio de los Jefes del Estado, quienes a su vez robustecen y extienden la influencia de los Obispos, sancionan los derechos de la Iglesia, le otorgan nuevos privilegios y agregan la sanción civil a los Cánones de los Concilios nacionales. Es, por lo demás, una verdad innegable que la tradición romana de los últimos tiempos respecto al poder casi ilimitado de los Emperadores, así en lo temporal como en lo espiritual, contribuyó eficazmente al desarrollo de la potestad de los Reyes visigodos en materias eclesiásticas; y que, andando el tiempo, semejante compenetración de la Iglesia y el Estado trajo consigo muchas y grandes desventajas para la primera, que vio coartada frecuentemente por el poder civil la libertad de que ha menester para el cumplimiento de su elevada misión. No fue ciertamente el menor de los males consiguientes a ella que la influencia del Cristianismo en la vida social fuese meramente exterior, perseverando viva en realidad la idea pagana de la omnipotencia del Estado y teniendo que sufrir la Iglesia frecuentes y excesivas intrusiones del Estado en el terreno puramente eclesiástico.

Algunos de los Prelados visigodos que intervinieron en la redacción de las leyes formadas en los Concilios nacionales y en otras que aparecen como obra exclusiva de la autoridad real, eran teólogos consumados en el sentido estric- 
to de esta palabra, es decir, hombres dedicados al cultivo y a la difusión de la ciencia teológica por medio de sus escritos, como San Isidoro, San Leandro, San Braulio, San Ildefonso y Tajón. Aunque sólo se nos hayan conservado obras del primero, como son las Etimologías y los Libri sententiarum que traten exprofeso de materias de Derecho, nos creemos autorizados para suponer que las consideraciones teológico-políticas de que acompañan a los monumentos legislativos en que tan activamente colaboraron todos ellos (y cuya redacción debe atribuírseles con mucho mayor fundamento que a los seglares que se sentaban con ellos en los Concilios y en el Consejo Real), reflejan con exactitud sus ideas sobre muchos puntos del Derecho público y penal y permiten apreciar en alguna manera la influencia ejercida por ellos en estas materias.

Entre los teólogos españoles del período visigótico, el único que incluyó en la órbita de sus disquisiciones las ciencias jurídicas y sociales, discurriendo a veces sobre ellas por cuenta propia, fue San Isidoro. En sus Etimologías, que son ante todo vasta y metódica Enciclopedia de la erudición clásica en todos los ramos del saber, no se limitó siempre al oficio de hábil compilador, antes hay algunas materias, así en esta obra como en los Libri sententiarum ${ }^{19}$, en

19 Janet, Histoire de la science politique dans ses rapports avec la morale, 2. ${ }^{\mathrm{a}}$ edición, París, 1872, p. 346-347, muestra desconocer la importancia de San Isidoro bajo el aspecto de que tratamos al expresarse en los términos siguientes:

"Los siglos V al IX, y aun el mismo siglo XI, son un período de triste decadencia en que no debe esperarse encontrar huellas de filosofía moral... Los únicos nombres que merecen ser citados en este intervalo son los de Boecio e Isidoro de Sevilla, mucho menos aún por su propio valor (pues el uno no es más que un retórico elocuente, el otro un compilador), que por la autoridad de que gozaron en la Edad Media. Isidoro de Sevilla no hizo otra cosa sino transmitir algunas definiciones que había recogido y tomado de los autoresantiguos y particularmente de los jurisconsultos; letra muerta que sirvió únicamente para que pasaran de la antigüedad a los tiempos modernos ciertos principios que habían vivido y que debían renacer".

Este juicio, inexacto en los términos generales en que está formulado, aun respecto de las Etimologías, a cuya obra alude evidentemente Janet, no cabe aplicarlo en manera alguna a los Libri sententiarum, desconocidos, al parecer, del escritor francés, y no utilizados, que yo sepa, hasta ahora para el estudio de las ideas e instituciones visigodas, no obstante el extraordinario interés que ofrecen en este concepto. Aunque esta última obra no pueda considerarse como enteramente original, juzgo muy distante de la verdad la opinión de Ebert, Histoire genérale de la litterature au moyen âge, I, París, 1883, pág. 630, que la considera como mero repertorio de sentencias morales tomadas de otros escritores. En todo caso es indudable que, como reflejo de las opiniones políticas, originales o recibidas, 
que expuso su propio pensamiento, elevándose extraordinariamente, en alas de la ciencia teológica, sobre las ideas de la sabiduría antigua.

La historia acredita constantemente que toda doctrina política, formulada y propagada en momentos propicios para su desarrollo y aplicación, se apodera rápidamente de los ánimos, y no tarda en trascender a la práctica. Las doctrinas expuestas por persona tan conspicua y de tanta autoridad como el ilustre Arzobispo de Sevilla, precisamente al tiempo en que la conversión de Recaredo al Catolicismo tenía que dar por resultado una transformación radical en el orden político, no podían caer en tierra improductiva. Los Cánones conciliares y las prescripciones del Código visigótico no son en muchos puntos sino la aplicación de los principios fundamentales del Derecho político y penal expuestos por San Isidoro en sus escritos.

Formuló éste claramente el origen divino del poder, instituido por Dios para bien de los pueblos ${ }^{20}$, y encareció a los Príncipes la estrecha obligación de defender a la Iglesia como misión que Jesucristo les había confiado y de que habían de darle estrecha cuenta ${ }^{21}$.

Bien conocida es su hermosa definición de la ley², incluida a la letra en el

del insigne Prelado visigótico, merece más atención de la que se le ha prestado hasta ahora. Tampoco carece de valor como fuente de conocimiento de las costumbres de la época. El capítulo De iudicibus (52 del libro III), en que alude frecuentemente al deplorable estado de la administración de justicia entre los visigodos, proporciona materia para un trabajo análogo al reciente de Monod, Les moeurs judiciaires au VIII siécle d'aprés la Paroenoesis ad Judices de Theodulf, en los Mélanges Reniér, París, 1838, p. 193-215. Es de notar a este propósito que en la obra citada de Teodulfo se encuentran evidentes reminiscencias del capítulo De iudicibus de San Isidoro.

20 Lib. Sententiarum, III, 49. Dedit Deus principibus praesulatum pro regimine populorum, et illis eos praeesse voluit, cum quibus vna est eis nascendi moriendique conditio. Prodesse ergo debet populis principatus, non nocere: nec dominando premere, sed condescendendo consulere: vt veré sit vtile hoc potestatis insigne, et dono Dei pro tutione vtantur membrorum Christi. Membra quippe Christi fidelis sunt populi, quos dum ea potestate quam accipiunt optime regunt, bonam vtique vicissitudinem Deo largitori restituunt.

21 Lib. Sentent., III, 51. Cognoscant principes seculi Deo debere se rationem reddere propter Ecclesiam, quam a Christo tuendam suscipiunt. Nam siue augeatur pax, et disciplina Ecclesiae per fideles principes, sive solvatur: ille ab eis rationem exiget, qui eorum potestati suam Ecclesiam credidit.

22 Etymol., c. XXV: Qualis debeat fieri lex.- Erit autem lex honesta, iusta, possibilis, secundum naturam, secundum patriae consuetudinem, loco temporique conveniens, necessaria, utilis, manifesta quoque, ne aliquid per obscuritatem in captione contineat, nullo privato commodo, sed pro communi civium utilitate conscripta. 
Código visigótico y en el Decreto de Graciano, y que sirvió de punto de partida a las admirables lucubraciones de los teólogos y jurisconsultos católicos. San Isidoro proclamó explícitamente como condición indispensable de buen gobierno el procurar la felicidad de los súbditos ${ }^{23}$; declaró sujetos a los Príncipes, no sólo a las normas eternas de la moral y del derecho, sino aun a las mismas leyes dictadas por ellos ${ }^{24}$, y consignó el principio de que la potestad otorgada a los Príncipes algunas veces en materias eclesiásticas deben emplearla únicamente en defensa de la disciplina de la Iglesia ${ }^{25}$. En el libro IX de sus Etimologías se encuentra el célebre aforismo Rex eris si recte facias; si non facias, non eris, que, como su definición de la ley y algún otro pasaje de sus escritos, fue incluido a la letra en el Código visigótico.

Evidentísima es la influencia ejercida por las doctrinas del insigne Arzobispo de Sevilla en el Derecho público visigodo.

Basta leer en los Libros de las Sentencias de San Isidoro el capítulo De praebenda sacerdotali protectione in plebe ${ }^{26}$ para comprender la elevada idea que tenía el ilustre Doctor de la misión social del Prelado católico. Con cuánta energía y vehemencia increpa a los malos Pastores que, por miedo a las potestades de la tierra (metu potestatis) o por conveniencias meramente terrenas (amore rerum secularium ne amicitiam perdant et molestiam odiorum incurrant), se retraen de predicar la verdad, de corregir a los extraviados, de acudir en auxilio del pobre y del desvalido, oprimidos por el poderoso; cómo les recuerda la estrecha cuenta que han de dar de las ovejas confiadas a su cuidado y solicitud, y el deber que tienen de sacrificar su vida, si necesario fuese, para salvarlas! ${ }^{27}$

$¿$ ¿No es evidente la influencia de estas ideas de San Isidoro sobre los deberes del Episcopado, no ya sólo acerca del bien espiritual, sino del bien temporal de los fieles, en concepto de protector nato de los pobres y desvalidos, en las prescripciones del Derecho visigodo, que ya erigen a los Concilios provin-

23 Lib. Sentent., III, c. XLVIII... Tunc autem bene geritur (potestas), quando subicetis prodest, quibus terreno honore praefertur.

24 Ibid., c. XLIX: Principes legibus teneri suis, neque in se posse damnari jura, quae in subiectis constituunt.

25 Ibid. Principes saeculi nonnunquam intra Ecclesiam potestatis adeptae culminae tenent: ut per eamdem potestatem disciplinam ecclesiasticam muniant.

26 Lib. III, c. XLV.

27 Sicut pervigil pastor contra bestias, oves custodire solet; ita et Dei sacerdos super gregem Christi sollicitus esse debet, ne inimicua vastet, ne persecutor infestet, ne potentioris cuiusque cupiditas vitam pauperum inquietet. 
ciales en tribunal de alzada respecto a los abusos que cometieran los funcionarios públicos en el ejercicio de sus cargos ${ }^{28}$, ya encomiendan a los Obispos velar por la recta administración de justicia, denunciando al Soberano a los jueces injustos y prevaricadores ${ }^{29}$ y avocando a sí el conocimiento de los litigios en determinados casos ? $^{30}$ La intervención concedida a los Obispos en asuntos del orden civil, como la tutela y la apertura de los testamentos ${ }^{31}$, está en armonía con las doctrinas de San Isidoro y con el carácter del sacerdocio católico, esencialmente distinto del pagano ${ }^{32}$.

No sólo las líneas generales de la organización eclesiástica, o sean los grados fundamentales de la jerarquía, el episcopado, el presbiterado y el diaconado "son únicos en el mundo greco-romano y peculiares de las comunidades cristianas, sino que también fue exclusiva de ellas la formación de un estado eclesiástico distinto del seglar" 33 , cuyos individuos ostentando el carácter de mediadores entre Dios y el hombre, habilitados para el desempeño de su misión con la imposición de las manos, símbolo de la gracia divina, y derivando su cargo de la institución apostólica, hacen el oficio de jefes y funcionarios de las comunidades cristianas, cuidan de mantener la pureza de la doctrina religiosa y moral y ejercen sobre el individuo imponderable influencia.

En los tiempos calamitosos de la invasión de los Bárbaros, los prelados aparecen en España, como en Francia e Italia, con gran frecuencia cumpliendo su misión de paz, y haciendo en consonancia con ella el oficio de mediadores entre la población hispano-romana y los conquistadores germánicos. Alguno de ellos hizo el sacrificio de su vida en tan generosa empresa. El Cronicón de Idacio ofrece más de un ejemplo del celo apostólico que animaba en aquellas tristes circunstancias a algunos Prelados españoles ${ }^{34}$. Abandonados del poder central, impotente para acudir a todas partes y conjurar los peli-

28 Conc. Tolet., III, c. XVIII; IV, c. XXXII.- L. W., II, 1, 30, y XII, 1, 2.

29 Conc. Tolet., IV, c. III

30 L. W., VII, $1,1$.

31 L. W., II, 5, 11, y IV, 3, 3 y 4.

32 Sobre las diferencias esenciales entre el sacerdocio pagano y el cristiano, y la imposibilidad de considerar a este último como derivación del primero, puede consultarse con fruto, además del trabajo de Harnack, citado en el tomo I de mi Historia general del Derecho español, I, p. 813, n. 1, a E. Löning, Die Gemeinde-verfassung des Urchristenthums, Halle, 1889, p. 138-154.

33 E. Löning, Op. cit., p. 150-151.

34 Véanse a este propósito las oportunas consideraciones de D. Pedro José Pidal, Lecciones sobre la historia del Gobierno y legislación de España, p. 227-229 
gros que en todas partes le amenazaban, las poblaciones encontraron amparo y ayuda en los Prelados, que consideraban como propio de su ministerio el defender a los fieles confiados a su solicitud, y esta circunstancia debió contribuir necesariamente a acrecentar la autoridad y el prestigio de los Obispos, que además, por razón del estado social y económico, vivían en contacto muy inmediato con los pueblos. La autoridad y el prestigio del Obispo, fundados en el imperio que ejercía sobre las conciencias de los fieles y en la importancia consiguiente a su cualidad de gran propietario territorial, así como en la suma de atribuciones concernientes al orden político y administrativo que le otorgaban las leyes, eclipsaba por completo la autoridad y el prestigio de los condes y demás funcionarios del poder central dentro de su Diócesis. Basta recorrer las vidas de los Padres de Mérida y la Historia de Wamba para formar idea del papel importante de los Prelados en la sociedad visigoda.

La inspección encomendada a los Obispos sobre los funcionarios del orden judicial y del económico era una necesidad de la época. Presentábase como el único medio verdaderamente eficaz para poner coto en alguna manera a la inmoralidad administrativa y a la corrupción judicial, fatal legado de los últimos tiempos del Imperio. Creíase con razón que los Prelados, por su elevada autoridad moral, por estar dotados ordinariamente de inteligencia y probidad, no comunes en su tiempo, y que por hallarse en contacto inmediato con los pueblos, podían conocer mejor los males que les aquejaban y ponerles oportuno remedio, eran los naturalmente llamados a ejercer el cargo tan espinoso y difícil como meritorio de velar por los supremos intereses del Estado y ser amparadores y patrocinadores del débil y del oprimido.

No se puede explicar de otra suerte que, casi simultáneamente, el Estado acudiera a ellos para ejercer en pro del bien público las funciones de inspección o intervención a que antes hemos aludido, así en el imperio bizantino como entre los Francos y los Visigodos. Bajo Justiniano y Justino, la elección de los gobernadores de provincia (judices provinciarum) correspondía al Obispo, en unión de las personas más conspicuas del territorio. Incumbencia suya era denunciar al Emperador a los jueces que se negaran a administrar justicia; asociarse al juez, a quien uno de los litigantes consideraba parcial para dictar, en unión con él, la sentencia; decidir en las contiendas que suscitaran contra los gobernadores los súbditos que se creyesen perjudicados; intervenir en el nombramiento de los magistrados municipales, y recibir las cuentas que éstos debían dar a él y a las personas principales de la ciudad.

Justiniano hizo a la Iglesia estas concesiones, porque, dada la absoluta co- 
rrupción de la burocracia, había menester para inspeccionarla y moralizarla de un poder ajeno y superior a ella. "La Iglesia fue el único y último refugio para el imperio cuando éste, en su miseria, se encontró ya impotente para defenderse a sí propio" 35 .

Entre los Francos existía también el deber impuesto a los Obispos de inspeccionar a los jueces civiles y avocar a sí en determinados casos el conocimiento de los negocios ${ }^{36}$.

La influencia extraordinaria que el episcopado vino a ejercer en la sociedad visigoda fue parte para que los Reyes, interesados en servirse para los fines de su política de tan poderosos instrumentos, se esforzaran por incluir en el número de sus atribuciones la designación de los sujetos que habían de ocupar las Sedes episcopales. En un principio parece haberse conservado la antigua práctica en materia de elección de Obispos; pero casi a contar desde la conversión de Recaredo pueden seguirse paso a paso las vicisitudes del predominio de la Corona en esta importantísima esfera.

Contra la tradición cesarista del Derecho romano formularon los Padres del Concilio IV de Toledo, entre los cuales figuran teólogos tan insignes como San Isidoro y San Braulio, la doctrina isidoriana de la sumisión de la potestad civil a las leyes, conminando con la excomunión a los Príncipes que, creyéndose superiores a ellas, tiranizasen a los pueblos ${ }^{37}$. Pusieron dique, asimismo, los teólogos citados a la arbitrariedad y crueldad de los Príncipes, haciendo prevalecer en las leyes el principio de que no pudieran por su sola voluntad condenar a nadie a pena capital ni a confiscación de bienes ${ }^{38}$, si era ingenuo o miembro del oficio palatino, y estableciendo que en las causas que pudiesen dar lugar a la imposición de estas penas, se asesorase de los nobles y prelados que constituían el Consejo.

35 Hegel, Storia della costituzione dei municipii italiani, Milán, 1861, I, p. 100-103. Hartmann, Untersuchungen zur Geschichte der byzantinischen Verwaltung in Italien, Leipzig, 1889, p. 49-50.

36 Tardif, Histoire des institutions politiques de la France, I, p. 162.

37 Canon 75: "Sane de futuris regibus hanc sententiam promulgamus: ut si quis ex eis contra reverentiam legum superba dominatione et fastu regio, in flagitiis et facinore, sive cupiditate crudelissimam potestatem in populos exercuerit, anathematis sententia a Christo domino condemnetur..." La misma idea late en el fondo de la tan repetida frase del lib. I, título I, ley $1 .^{\text {a }}$ del Código visigodo: "Rex eris si recte facis..."

38 Conc. Tolet. IV, canon 75: "Nec quisquam vestrum solus in causis capitum aut rerum sententiam ferat, sed consessu publico cum rectoribus ex judicio manifesto deliquentium culpa patescat. 
En consonancia con las ideas que profesaban acerca del origen y carácter de la potestad civil, influidos por la tradición del Antiguo Testamento, se esforzaron por acrecentar el prestigio y la inviolabilidad del soberano por medio de la ceremonia de la unción, que, conforme a la doctrina de la Iglesia, atrae sobre el que la recibe gracias y disposiciones necesarias para el cumplimiento de la misión que le ha sido encomendada. Usada ya en el pueblo de Israel, la práctica de ungir a los Reyes, o sea, como se ha dicho con razón, la consagración litúrgica de la Monarquía, se introdujo en el imperio bizantino a mediados del siglo V; aclimatose más tarde entre los Visigodos, de quienes la tomaron verosímilmente casi un siglo después los Francos y los Anglo-sajones.

El primer Soberano en cuya coronación hay noticia de haber intervenido la Iglesia es el Emperador de Oriente León I, que fue ungido por el Patriarca de Constantinopla el año 457. Formaba parte del ceremonial de Constantinopla la imposición de la corona por el Patriarca, después de una invocación pronunciada sobre el Soberano ${ }^{39}$. De esta ceremonia se hace mérito en tiempo de Wamba, que fue ungido por el Obispo de Toledo, Quincio, en 672; pero ya las actas del Concilio VI de Toledo de 636 aluden a dicha práctica. De Ervigio se dice: regnandi per sacrosanctam unctionem accepit potestatem en el Concilio VII de Toledo de 681.

De un texto de San Isidoro ${ }^{40}$, en que no se ha parado la atención, que yo sepa, hasta ahora, me parece inferirse que la práctica de ungir a los Reyes existía ya entre los Visigodos en los tiempos del Santo Doctor, y que se introdujo quizá por su iniciativa.

La Iglesia prestaba su sanción al juramento de fidelidad del pueblo al Soberano y al que debía prestar este último, imponiendo penas canónicas a los transgresores ${ }^{41}$. No se mostró menor su solicitud en conminar con penas canónicas a los que atentasen contra el soberano o contra la vida y la hacienda de su viuda y descendientes, constantemente amenazados en la Monarquía visigoda por la barbarie de los grandes, como consecuencia de la terrible lu-

39 Duchesne, Le Liber Pontificalis, XCVIII, n. 34, t. II, p. 38.

40 De off. eccless., lib. II, cap. 25 ...postqnam dominus noster, verus rex et sacerdos aeternus, a Deo Patre coelesti mystico unguento est delibatus, iam non soli Pontifices et Reges, sed omnis Ecclesia unctione chrismatis consecratur, pro eo quod membrum est aeterni Sacerdotis et Regis.

41 Conc. Tolet., c. 75: Quicumque ... sacramentum fidei suae, quod pro patriae gentisque Gothorum status vel conservatione regire salutis pollicitus est, violaverit ... anathema sit. 
cha entablada entre el principio hereditario, y el electivo en orden a la sucesión de la Corona ${ }^{42}$.

Memorable también y de suma trascendencia para la Monarquía visigoda fue la influencia de los teólogos respecto a la separación entre la fortuna privada del soberano y el patrimonio de la Corona, principio bien ajeno de la tradición romana y de la práctica de los otros reinos germánicos ${ }^{43}$.

Comprendiendo que el sistema electivo para la provisión de la dignidad real, dando rienda suelta a la desapoderada ambición de los nobles y engendrando la serie de intrigas y rebeliones que llenan la historia de los Visigodos, era amenaza constante para el orden público y la consolidación de la Monarquía, algunos teólogos visigodos de los más conspicuos y autorizados mostraron claramente su predilección por el sistema hereditario y se esforzaron por hacer que prevaleciese en la práctica, siendo verosímilmente en este punto eco de la opinión general del Clero visigodo. Recuérdense si no las palabras con que termina San Isidoro su Historia de los Godos, después de reseñar la elevación de Suintila al trono:

"Su hijo Racimiro", dice, "que aun en la infancia resplandece por su excelente índole, hasta el punto de ser en su semblante y en sus virtudes vivo retrato de su progenitor, asociado al Trono, se regocija compartiendo el solio con él; por lo cual debemos implorar del cielo y del Rector del humano linaje que, así como actualmente ocupa el trono con su padre, tras largo reinado de éste, logre ser dignísimo sucesor suyo" 44 .

No menos explícito que este testimonio en pro de la Monarquía hereditaria es el que proporciona la Epístola dirigida por San Braulio y Eutropio en unión del Clero y pueblo de sus Diócesis y de un elevado funcionario al rey Chindasvinto, rogándole que asociase, como asoció en efecto, al Trono a su hijo Recesvinto, para que le sucediese en la dignidad real:

"Hemos resuelto acudir a tu piedad, dicen, pidiéndote, como lo más conveniente a tu tranquilidad y a nuestro bien, que en vida tuya y con tu beneplácito nos des por rey y señor a Recesvinto, el cual, hallándose en edad de

42 Véanse los cánones relativamente numerosos De munitione prolis regis en los Conc. Tolet. V , c. 2; VI, c. 11, 16 y 18; XIII, c.4; XVI, c.8.

43 Conc. Tolet. VIII.

44 España Sagrada, tomo VI, pág. 503: Hujus filius Racimirus in consortium regni assumptus, pari cum Patre solio conlaetatur, in cujus infantia ita sacrae indolis splendor emicat, ut in eo, et meritis et vultu paternarum virtutum efigies praenotetur. Pro quo exorandus est coeli atque humani generis rector, ut sicut extat consessu patrio socius, ita post longaevum parentis imperium sit et regni successione dignissimus. 
soportar las fatigas de la guerra, puede ser, con el auxilio de la gracia divina, nuestro señor y defensor y el descanso de vuestra serenidad...45"

Estos documentos demuestran no ser muy exacta la opinión que afirma resueltamente haber sido los Prelados visigodos favorables a la subsistencia del sistema electivo, porque teniendo, en virtud de él, participación directa y constante en la designación del Soberano, podían hacerla recaer en quien más dispuesto se mostrase a favorecer sus miras e intereses. Lo cual no habrían podido lograr vinculada la dignidad real en una dinastía, cuya política pudiera ser contraria a las aspiraciones del Clero, imposibilitado ya, en virtud del cambio de sistema, para deshacerse de ella cuando lo juzgase conveniente. Ciertamente que las prescripciones del Derecho escrito de los Visigodos, en que se consagró el predominio del principio electivo, conforme al Derecho consuetudinario de la gente goda, se adoptaron en los Concilios nacionales y por tanto con la anuencia del Episcopado. Pero tales acuerdos, más bien que obra de los Prelados, han de considerarse como transacción entre éstos y los nobles, quienes habiendo visto menoscabados sus derechos a la ocupación del Trono con el entronizamiento de Recesvinto, intentaron y consiguieron reivindicarlos y afianzarlos expresa y solemnemente, aprovechando quizá la circunstancia de que este Soberano, del cual se ignora que tuviese hijos, no tenía interés en contrariar las aspiraciones de la nobleza. Siendo más directo y ostensible el interés de los nobles que el de los Prelados en el mantenimiento del sistema electivo, hay mayor fundamento, conforme al conocido aforismo del cui prodest, para atribuir a los nobles godos la paternidad de dichas leyes.

La facultad del Monarca de indultar a los reos del todo o parte de la pena en que hubieran incurrido fue reconocida expresamente por el Derecho visigodo, conforme a la tradición romana; pero los ilustres teólogos de aquel tiempo, considerando peligroso que la ejerciera por sí solo el Soberano en determinados casos, restringieron sus facultades sobre el particular, estable-

45 España Sagrada, tomo XXX, pág. 374: "Suggerendum gloriossisimo Domino nostro, Chindasvinto regi, Braulio et Eutropius, episcopi servuli vestri, cum presbyteris, diaconibus, et omnibus plebibus a Deo sibi creditis, necnon et Celsus servus vester cum territoriis a clementia vestra sibi commisis. Ad tuam pietatem recurrere decrevimus, ut quia compendiosius nihil nec quieti vestrae, nec casibus nostris prospicimus, in vita tua, et te benevolente servum tuum Dominum Recesvintum, dominum nobis regem deposcimus, ut cujus aetatis est et belligerare, et bellorum sudorem sufferre, auxiliante superna gratia, et noster possit esse dominus et defensor et serenitatis vestrae refectio..." 
ciendo que hubiera de proceder de acuerdo con los miembros del Episcopado y del Oficio palatino si se trataba de delitos políticos ${ }^{46}$.

$\mathrm{Al}$ clasificar las leyes en permisivas, prohibitivas y penales, encarece San Isidoro la importancia de las penas, afirmando que el castigo y la recompensa son los dos grandes moderadores de la vida humana ${ }^{47}$. Considera como fin de las leyes penales la defensa social y la ejemplaridad ${ }^{48}$, sin desconocer que el juez debe atender también a la corrección del delincuente ${ }^{49}$.

El sistema de represión y castigo de los delitos religiosos por parte del Estado, vigente en Europa durante toda la Edad Media y los comienzos de la moderna se halla consagrado también por San Isidoro en un importante pasaje, donde creo descubrir los orígenes de la teoría de la relajación del hereje al brazo secular, para que éste le impusiese la pena corporal correspondiente, adoptada y practicada en el procedimiento inquisitorial ${ }^{5}$.

En todo caso, es indudable que las prescripciones del Código visigótico contra los herejes, blasfemos, apóstatas y los que se dedicaban a las artes mágicas son otras tantas aplicaciones de la doctrina mencionada. Lo mismo puede decirse de la penalidad impuesta a los judíos conversos que volvieran a su antigua religión ${ }^{51}$.

"Los Visigodos parecen haber sido los primeros en la reacción que se verifica en el derecho en pro de la personalidad de esclavo: en el orden civil, las leyes más antiguas conservan aún la noción tradicional, considerándolo

46 Conc. Tolet., VII, c. 1.- L. W., II, 1, 6 y 7; VI, 1 y 6.

47 Etymol., c. 19. Omnis autem lex aut permittit aliquid, ut vir fortis petat proemium: aut vetat, ut sacrarum virginum nuptias nulli petere liceat, aut punit, ut qui caedem fecerit capite plectatur: aut enim premio, aut poena vita moderatur humana.

48 Ibid., c. 20. Factae sunt leges, ut earum metu humana coerceatur audacia, tutaque sit inter improbos innocentia, et in ipsis improbis formidato supplicio, refrenetur nocendi facultas.

49 Lib. Sentent., III, 50. Plerumque princeps iustus etiam malorum errores dissimulare novit: non quod iniquitati eorum consentiat, sed quod aptum tempus correctionis expectet, quando eorum vitia vel emendare valeat, vel punire.

50 Lib. Sentent., III, 51. Saepe per regnum terrenum coeleste regnum proficit, ut qui intra Ecclesiam positi contra fidem et disciplinam Ecclesiae agunt, rigore principum conterantur: ipsamque disciplinam quam Ecclesiae humilitas exercere non praevalet, cervicibus superborum potestas principalis imponat: et ut venerationem mereatur virtute potestatis impertiat.

51 L.W., XII, 2 у 2; III, 1 y 2; III, 5, 2 y 3; III, 4 y 13; VI, 2, 1 y 4; XII, 2, 11, y 3, 1. Cf. sobre esta clase de delitos a Dahn, Westgothische Studien, p. 233-236. 
como cosa; no sucede así en el Derecho penal, el cual lo juzga susceptible de desviaciones, de las cuales le hace responsable" ${ }^{2}$.

El derecho visigodo, más humano y más progresivo en esta parte que las otras legislaciones germánicas ${ }^{53}$, como influido por los principios del Cristianismo, limitaba la potestad privada del dueño respecto a la vida del esclavo, prohibiendo darle muerte, y aun mutilarle ex auctoritate propria $y$ sin preceder formación de juicio. El siervo reo de un delito de los castigados con pena capital no podía ser privado de la vida por el señor (extra publicum judicium), sino después de sentenciado a esta pena por los jueces públicos ${ }^{54}$. El señor que mataba al esclavo sin sujeción a este trámite, y no afirmaba con su propio juramento o con el de sus siervos, haberlo verificado involuntariamente y en castigo de un crimen que mereciese la pena capital, incurría en multa y en infamia perpetua, a la cual iba anejo el no poder atestiguar en juicio. Prohibió asimismo, so pena de tres años de destierro, mutilar a los esclavos absque iudicis examinatione ${ }^{55}$. Bajo la influencia de la Iglesia se estableció el derecho de $a{ }^{1}{ }^{56}$, que libraba a quien a él se acogía de la pena de muerte y facilitaba en muchos casos la reconciliación entre el ofensor y la familia del ofendido.

52 Lesueur, Des consequences du délit de l'esclave dans les Leges Barbaromm et les Capitulaires, en la Nouvelle Revue historique de Droit français et étrangcr de 1889, p. 603-617, muestra cómo los principios del Derecho romano modifican la tradición germánica entre los Visigodos, atenuando la responsabilidad del dueño, sustituyendo a la pena pecuniaria que debía pagar éste (V, 4 y 11; VI, 4 y 4) la pena personal que, de ordinario, era la de azotes, y facultándole en otros casos para entregar al esclavo (servum tradire) a fin de librarse de pagar por él la composición (VIII, 1 y 12; VI, 5 y 10).

53 L. W., VI, 1 y 5. Dahn observa a este propósito que Egica, al promulgar de nuevo esta ley de Recesvinto, se dolía de que hubiera sido iniuste abrasam.

54 L. W., VI, 5, 1, 12 y 13. Estas normas de la legislación civil habían sido precedidas por otras análogas del Derecho eclesiástico:

El Conc. Agath. de 506, c. 62, imponía la excomunión o dos años de penitencia a los dueños que matasen a sus esclavos, sine conscientia judicis. Los Conc. Emerit. de 666, c. 15 y Conc. Tolet., XI, de 675, c. 6, castigan a los Prelados que tratasen cruelmente a los siervos de la Iglesia. Gfrorer, Zur Geschichte deutscher Volksrechte im Mittelatter, Schaffhausen 1865-1866, II, p. 12-17.

55 Sobre la influencia de la Iglesia en la mejora de la condición del esclavo, véase también a Dahn en sus Bausteine, VI, Berlín, 1884, especialmente, p. 10-14.

56 Wilda, Geschichte des deutschen Strafrechts, I, Halle, 1842, p. 537-543. L. W., VI, 5,18 . "Si contigerit eum ad altare confugere ... ne eum mortis poena condemnet... sed in potestate parentum tradendum est ut, excepto mortis periculo, quidquid de eo facere voluerint licentiam habeant”. 
La legislación visigoda consideró como fin de la pena la ejemplaridad, $u t$ eorum metu humana coerceatur improbitas ${ }^{57}$, formulando el principio de la proporcionalidad de las penas ${ }^{58}$ estableciendo que sólo el autor de un delito fuese responsable de él, nunca su familia, suprimiendo así la responsabilidad colectiva de ésta, rasgo peculiar del Derecho germánico ${ }^{59}$, y exigiendo la intención punible como requisito indispensable para la existencia del delito ${ }^{60}$. Favoreciendo la institución del sistema de las composiciones, como medio de transición entre el de la venganza privada, dominante hasta entonces, y el de la justicia social o del Estado ${ }^{61}$, y procurando, como ya hemos indicado, que se consignaran en las leyes prescripciones análogas a las de la legislación romana acerca del derecho de asilo, puso dique poderoso a la ferocidad de las gentes del Norte.

57 L. W., I, tít. II, ley $5 \cdot^{\text {a }}$. Cf. L. III, 2, 7 y tít. IV, 1, 13 y III, V, 2 y VI, 4, 3, IV , 5, 6.

58 L. W., VI, 4, 3: Saeva temeritas saevioribus paenis est legaliter ulciscenda.

59 L. W., VI, $1,7$.

60 L. W., VIII, $3,6$.

61 L. W., VI, 5, 20; VII, 1, 4. 


\section{CAPÍTULO II}

Persistencia de la tradición visigótica en las instituciones de León y Castilla durante los primeros siglos de la Edad Media.- Factores que determinan el cultivo de la ciencia política desde el siglo xII.- El Derecho romano y canónico y la tradición visigótica en el Código de las Siete Partidas.- Recepción de las prescripciones canónicas concernientes a los delitos religiosos y en especial a la herejía en las legislaciones de Castilla y Aragón.- Influencia de los jurisconsultos en los Consejos de la Corona.

La índole cantonal y autonómica del desenvolvimiento jurídico en la Edad Media fue necesariamente poco favorable a la influencia eclesiástica y menos aún a la teológica. Los órganos por donde esta influencia había de hacerse sentir, o no existían o habían perdido en mucha parte la eficacia que tuvieron en el período anterior, como consecuencia de las modificaciones esenciales del estado social y político por efecto de la invasión árabe. A la legislación común y general emanada del Jefe del Estado, ordinariamente con el concurso de los Concilios nacionales o del Consejo de la Corona, sucede la formación del Derecho, ya por las entidades corporativas como el municipio y el gremio, ya por las potestades señoriales, en quienes de hecho viene a recaer, más bien que de derecho, la autoridad legislativa, ejercida antes únicamente por iniciativa del Soberano. A la centralización del poder público, característica del período visigótico, cede el puesto el fraccionamiento de ese mismo poder, que obligado a atender preferente y casi exclusivamente a la defensa y a la reconquista del territorio nacional, tiene que consentir y aun autorizar y promover que los funcionarios y organismos políticos dependientes de él ejerzan, como por derecho propio, para procurar los fines sociales que no podía promover directamente el Soberano, casi todas las atribuciones peculiares de este último.

De aquí que sean escasísimos relativamente los monumentos legislativos de índole general emanados del poder real (ya exclusivamente, ya con intervención de los Concilios mixtos, que subsisten en los primeros siglos de este período), en comparación de los dictados por los mismos Reyes con especial aplicación a localidad determinada, o por las entidades corporativas y señoriales a que se ha hecho referencia.

Aunque la intervención del Clero en las Asambleas mixtas de los reinos de León y Castilla no es tan preponderante como en el período visigótico, antes bien parece equilibrada por la nobleza en los Concilios de León y Coyanza, sin embargo resalta de una manera evidente la influencia, ya que no de los 
teólogos, porque entonces no los había en el sentido estricto de la palabra, a lo menos de las doctrinas de los teólogos visigodos en algunas de las disposiciones de Derecho público y penal emanadas de aquellas Asambleas y favorables al robustecimiento de la autoridad pública y a los intereses de la Iglesia. Tal sucede con las encaminadas a vigorizar el poder real conforme a la tradición visigótica, estableciendo que en todas las ciudades y alfoces hubiese jueces elegidos por el $\mathrm{Rey}^{62}$, las dirigidas a restringir la venganza privada ${ }^{63}$ y las concernientes a la protección de las propiedades de la Iglesia ${ }^{64}$.

En las Asambleas peculiares del Clero, o sea en los Concilios provinciales, singularmente en el celebrado en Santiago durante el pontificado de Gelmírez el año $1113^{65}$, y en algunos de los celebrados posteriormente en Castilla, se encuentran huellas de la misma influencia. Refléjase claramente en la tendencia a vigorizar el poder real, a poner término a la anarquía reinante, por la introducción de la paz y la tregua de Dios, y en el amparo de los desvalidos y menesterosos. La proximidad a los territorios del imperio franco, donde surgió por primera vez la institución de la tregua de Dios, fue parte para que Cataluña precediese a todos los demás Estados de la España cristiana en la adopción de la tregua de Dios, extendida también en Aragón y Navarra ${ }^{66}$.

Fue necesaria la concurrencia de dos factores importantísimos, la mayor extensión y consolidación de las monarquías cristianas enfrente del poderío árabe y la importación y desarrollo en España de los principios del Derecho público romano favorables al prestigio y robustecimiento de la Monarquía, para que ésta intentase y consiguiese paulatinamente reivindicar la plenitud de los atributos de la soberanía, singularmente en el orden legislativo, haciéndola servil para el establecimiento de una legislación común, y ofreciendo base y ocasión para que de una manera más inmediata y activa se manifestase en las leyes la influencia del elemento teológico.

Yerran grandemente los que consideran al Código de las Siete Partidas como copia servil de las prescripciones del Derecho romano y canónico, sin

62 Concilio de León del año 1020, art. 18, en las Cortes de los antiguos reinos de León y Castilla, publicadas por la Real Academia de la Historia, t. I, Madrid, 1861, pág. 5 .

63 Concilio de Coyanza del año 1050, art. 12: Op. cit., págs. 34-25. Concilio de León del tiempo de Alfonso IX: Op. cit., págs. 39-42.

64 Concilio de León, arts. 2 a 5: Op. cit., págs. 2-3. Concilio de Coyanza arts. 3 y 9: Op. cit., págs. 22-24. Concilio de Palencia de 1129: Op. cit., págs. 36-38. Concilio de Benavente de 1202: Op. cit., páginas 43-44. Concilio de León de 1208: Op. cit., págs. 46-48.

65 Muñoz, Colección de fueros municipales. Madrid, 1847, p. 403-409.

66 La Fuente, Historia eclesiástica de España, 2. ${ }^{\mathrm{a}}$ edición. Madrid, 1873, tomo III. 
parar atención en ciertas desviaciones, algunas de verdadera entidad, que ofrece aquel Código respecto de los dos Derechos antes citados y de las opiniones científicas dominantes entre los jurisconsultos de la época. Es importantísima la relativa a una cuestión del Derecho público medioeval; la supremacía atribuida al Emperador de Alemania sobre todos los Monarcas del orbe cristiano. Separándose intencionalmente las Partidas de la opinión que pasaba como axiomática entre los jurisconsultos de la época, afirman la independencia absoluta del Rey de Castilla respecto al Emperador en los términos más explícitos ${ }^{67}$; dejándose ver en esto claramente que los jurisconsultos que intervinieron en la redacción de aquel Código no se dejaron influir por la materia jurídica que elaboraban en asunto de tamaña trascendencia.

La sumisión del Rey a las leyes se encuentra formulada en las Partidas ${ }^{68}$ con admirable claridad, en oposición a la teoría cesarista del Derecho romano y de conformidad con la doctrina de los teólogos visigodos. Contra los principios que dominaban a la sazón entre los jurisconsultos italianos, y de acuerdo asimismo con la tradición visigótica, que negaba al Rey el derecho de confiscar arbitrariamente los bienes de sus súbditos, reivindicaron para éstos el pleno dominio sobre sus propiedades, afirmando, al discurrir sobre los casos de expropiación por causa de utilidad pública, que "magüer los Romanos que antiguamente allegaron con su poder el sennorio del mundo, fiziessen Emperador, e le otorgassen todo el poder, o el sennorio que avian sobre las gentes para mantener e defender derecho al procomunal de todos, con todo esso non fue su entendimiento de fazerle sennor de las cosas de cada uno e que las pudiese tomar a su voluntad, sino tan solamente por alguna de las razones que de suso van dichas" ${ }^{69}$.

Las Partidas formularon ya la distinción esencial entre el Príncipe legítimo y el tirano (que se encuentra en casi todos los escritores políticos españoles de los siglos siguientes), incluyendo en esta última categoría no sólo a los que violentamente o contra derecho se apoderan de la potestad soberana, sino también al que "oviesse ganado señorío del reino por algunas de las derechas razones que diximos en la ley ante desta, que si él usasse mal de su poderío

67 Part. II, tít. I, ley V. Vicarios de Dios son los Reyes, cada uno en su reino, puestos sobre las gentes para mantenerlas en justicia et en verdad cuanto en lo temporal, bien así como el Emperador en su imperio.

68 Part. II, tít. I, ley 1. Guardar debe el Rey las leyes como a la honra e a su fechura, porque recibe poder e razón para facer justicia... E otro si, las debe guardar el pueblo como a su vida e su pro...

69 Part. II, tít. I, ley 2 
en las maneras que de suso diximos en esta ley, quel pueden decir las gentes tirano, e tomarse el señorío que era derecho en torticiero"7o. Inspiradas en la tradición romana, vincularon en el Rey la plenitud del poder legislativo, del modo más explícito y terminante, proclamando que las leyes no dictadas por él mismo o con su aprobación "non han nombre nin fuerza de leyes, nin deben valer en ningún tiempo" ${ }^{11}$; pero sentaron también el principio defendido por los teólogos visigodos de que el legislador debe conformarse a las normas eternas de la justicia ${ }^{72}$. Consideraron asimismo el derecho de indulto como atribución del Soberano, distinguiéndolo en general y particular y estableciendo en cuanto a sus causas, formas y efectos ciertas gradaciones ${ }^{73}$.

Es muy de notar que, tratando incidentalmente de la potestad del Papa en materias temporales; los compiladores de las Partidas no sólo afirman que una de las maneras de adquirir el título de Rey es la concesión del Papa, allí donde puede ejercer esta facultad ${ }^{74}$, aludiendo sin duda alguna a los reinos feudatarios de la Santa Sede, sino que aceptan plenamente las doctrinas más acreditadas a la sazón, reconociendo al Papa implícitamente el derecho de absolver a los súbditos en algunos casos del juramento de fidelidad 75 .

En este punto, como en todo lo relativo a las instituciones eclesiásticas, los compiladores de las Partidas aceptaron las normas del Derecho canónico vigente; mas en nada se atuvieron a ellas tan estrictamente como acerca de los delitos religiosos.

La séptima Partida, consagrada al Derecho penal, muestra bien claramente la influencia de los principios teológicos, al declarar suprimidas las penas de marcar en la cara, de cortar las narices y sacar los ojos, tan prodigadas por los fueros municipales, fundándose en que "la cara del hombre fizo Dios a su semejanza" ${ }^{6}$. Mitigó además la barbarie de la penalidad, prohibiendo en tér-

70 Part. II, tít. I, 1.10.

71 Part. I, tít. I, 1.12.

72 Part. I, tít. I, 1. 4.- La teoría del origen divino del poder, formulada claramente en las Partidas, se encuentra reproducida por los Procuradores de Cortes en las de Olmedo de 1445 y de Ocaña de 1469, usando las palabras mismas de San Pablo, que sirven comúnmente de base a los teólogos que escribieron de política para disertar sobre la materia.Partida II, tít. I, ley 5, y Cortes de los antiguos reinos de León y Castilla, tomo III, págs. 469 у 768.

73 Part. VII, tít. XXXII, ley 1-3; Part. II, tít. X, ley 2, y Part. III, tít. XXIV, ley 1.

74 Part. II, tít. I, ley 9.

75 Part. I, tít. V, ley 5.

76 Part. VII, tít. XXXI, ley 6. 
minos generales apedrear, despeñar y crucificar a los delincuentes; y si bien se mostró inconsecuente castigando por excepción ciertos delitos con penas de esta índole, siempre ha de considerarse como un progreso el protestar en general contra ellas y limitar su aplicación.

Antes de exponer en detalle las prescripciones de las Siete Partidas acerca de los delitos religiosos, debemos examinar sus antecedentes históricos, o sean las normas consignadas anteriormente sobre el particular en las fuentes generales del Derecho canónico y en las particulares del reino de Aragón, reproducidas sustancialmente en los Códigos de Alfonso el Sabio.

En pocas materias han sufrido con el transcurso de los tiempos tantas y tan rápidas transformaciones las opiniones de los hombres, como en orden al carácter de los delitos religiosos, dependiendo esto, no sólo del cambio de las ideas en materia de religión y moralidad, sino también y muy principalmente de la diversa situación del Estado respecto a la Iglesia y aun a la religión en general. Cuando el Estado adopta una religión y se considera obligado, en su virtud, a proteger el interés religioso como uno de los más caros de la sociedad, los delitos contra la religión vienen a tener el carácter de delitos políticos. Refléjase esto singularmente en las leyes de la Edad Media y de los primeros siglos de la moderna acerca de los delitos religiosos y especialmente de la herejía, considerada como el más grave de todos los de este género.

Castigada en un principio con penas meramente eclesiásticas, comienza a ser considerada como delito por las leyes civiles, merced a los esfuerzos de la Iglesia, desde fines del siglo XII. El Concilio de Tortosa de 1119, a que asistieron, juntamente con los de varias regiones de Francia, prelados españoles, exhortó ya a los Príncipes seculares para que usaran de su poder a fin de reducir a los herejes. Otros Concilios celebrados en Francia con posterioridad siguieron este ejemplo. Los Pontífices, por su parte, sobre todo a contar desde Inocencio III, dirigieron sus esfuerzos al mismo fin y el Concilio IV de Letrán, reunido bajo su pontificado, en 1215, condensando las normas vigentes hasta entonces en este punto, impuso a los herejes las penas de infamia, incapacidad civil y perdimiento de bienes, conminando con la deposición a los Príncipes que no expulsaran a los herejes de sus Estados ${ }^{77}$.

El reino de Aragón fue uno de los primeros que consignaron en sus leyes

77 Labbé, Concilia, XI, col. 148-150. Cf. Ficker en las Mittheilungen des Instituts für österreische Geschichtsforschung, I, Innsbruck 1879, p. 179-226, y Havet, L'hérésie et le bras séculier au moyen âge en la Bibliothéque de l'École des Chartes de 1830, p. 488-517 y $570-607$. 
la pena de hoguera contra los herejes. Por ley dictada en 1197 expulsó Pedro II de sus dominios a todos los herejes, dándoles plazo de algunos meses para trasladarse a otros países. Los que transcurrido este plazo quedaran aún en Aragón y Cataluña incurrían en la pena de hoguera y en perdimiento de todos sus bienes, dos terceras partes de los cuales debían aplicarse al Fisco y la otra tercera parte a la persona que los denunciase ${ }^{78}$. Facultábase además a todos los subditos para maltratar y despojar a dichos herejes, con tal de que no los mataran ni inutilizasen, sin incurrir en ningún género de responsabilidad, antes bien considerándose este acto como meritorio (gratum et acceptum).

En Castilla, la consignación en el Derecho escrito de penalidad especial para los herejes, y precisamente la de hoguera, usual a la sazón en los demás reinos cristianos, data del reinado de Alfonso el Sabio. Según el Fuero Real, el Rey podía hacer lo que quisiera así de la persona como de los bienes del hereje y de cuantos le amparasen u ocultaran. Imponíase a todos la obligación de denunciarlos, y se reconocía a los prelados el derecho exclusivo de entender en las causas de herejía. Los herejes y sus encubridores eran castigados con la pena de muerte, si no volvían al seno de la Iglesia. El apóstata era quemado vivo; y el judío que hacía apostatar a un cristiano incurría en la pena de muerte y perdimiento de bienes ${ }^{79}$.

Las Partidas consideraron asimismo como atribución privativa de los Obispos y de las personas en quienes éstos delegaron su jurisdicción el conocimiento de las causas de herejía, bajo cuya denominación comprende este Código, no sólo las sectas disidentes del Catolicismo, sino al ateísmo. Terminada la causa ante el tribunal eclesiástico, el reo debía ser relajado al brazo secular, quién le sentenciaba a ser quemado vivo, o solamente al destierro y confiscación de bienes, según la índole del delito. El hereje incurría en todo caso en la nota de infamia y en la más absoluta incapacidad política y civil ${ }^{80}$.

78 Marca Hispánica, col. 1384 ...et si post tempum praefixum aliqui in tota terra nostra eos invenerint, duabus partibus rerum suarum confiscatis, tertia sit inventoris, corpora eorum ignibus crementur.

79 Lib. IV, tít. I, ley $1 .^{\mathrm{a}}$, y tít. II, ley $2 .^{\mathrm{a}}$.

80 Partida VII, tít. XXVI, ley 1-6.- La confiscación de bienes a los herejes se halla también preceptuada en una ley de Enrique III incluida en la Novísima Recopilación, lib. XII, 1. 3.

En la Revista de Archivos, Bibliotecas y Museos, I, p. 93-94, se inserta un documento del cual resulta que, ya antes de establecerse la Inquisición en Castilla, cuatro vecinos de Llerena fueron procesados por el Alcalde mayor de aquella población como judaizantes y ensabanados, siendo sentenciados dos de ellos, que eran varones, a pena de hoguera, y las 
Incurrían también en la pena de muerte y perdimiento de bienes, si carecían de parientes dentro del décimo grado, los que apostataban de la fe católica; pero si manifestaban su propósito de volver al seno de la Iglesia se les hacía gracia de la vida, aunque sin levantarles la nota de infamia ${ }^{81}$.

La magia o nigromancia en el concepto de trato y comunicación con los espíritus malignos, fue castigada asimismo por las Partidas, que imponían a todos la obligación de denunciar a los autores de este delito ${ }^{82}$.

Expuestas ya las más importantes prescripciones de los Códigos de Aragón y de Castilla (pues en los de Navarra no hemos hallado disposiciones especiales sobre el particular) acerca de los delitos religiosos, como base y antecedente necesario para examinar las opiniones de nuestros teólogos del siglo de oro en tan importante materia, réstanos bosquejar los pasos que siguió la influencia de los jurisconsultos en los Consejos de la Corona y la recepción del Derecho romano.

En Castilla, ya desde el reinado de Don Juan I, considerado como el verdadero fundador del Consejo Real, y sobre todo, desde los tiempos de Don Enrique III ${ }^{83}$, figuran constantemente en el Consejo cierto número de Letrados o Doctores en leyes, a que se daba el nombre de "oidores del Consejo". En virtud de acuerdo tomado en Medina por la Reina y el Príncipe de Asturias durante el reinado de Don Juan II, a 9 de Junio de 1441, se dispuso que formasen parte del Consejo "quatro Doctores, los dos que residieran o continuaren en él por tiempo de un año entero, e los otros dos de seis en seis meses" ${ }^{44}$. Pero lo que señala el apogeo de la influencia de esta clase en los Consejos del Monarca son las Ordenanzas de 11 de Julio de 1480, en que se establece que los acuerdos del Consejo hayan de tomarlos un Prelado, tres Caballeros, y hasta ocho o nueve Letrados, siendo indispensable la asistencia de tres o cuatro de esta última clase ${ }^{85}$.

dos mujeres a ser penadas (despeñadas?) En un testimonio de dicho documento, que es de 1477, expedido algún tiempo después, se dice ser este "el primer proceso y execución de fuego que se hiço contra herejes en éstos reinos”.

81 Partida VII, tít. XXIV, 1. 7, y tít XXV, 1. 4-8.

82 Partida VII, tít. XXIII, 1. 1-3.

83 Véase al Conde de Torreánaz, Los Consejos del Rey durante la Edad Media, vol. I, págs. 143-145.

84 "Des que fueren ayuntados a lo menos un Perlado, e dos Caballeros, e dos Doctores puedan librar o desembargar las peticiones". Ordenanza de Enrique III, dada en Segovia a 15 de Septiembre de 1406.

85 Torreánaz, I, pág. 167. 
Como muestra del crédito que gozaba el Derecho romano en Cataluña, aun entre los jurisconsultos consagrados a estudiar y comentar el Derecho catalán, vemos a Monjuich declarar que los fallos del Tribunal Supremo de apelación habían de conformarse, a falta de prescripciones de los usos y costumbres patrios, a las leyes romanas en cuanto eran justas y equitativas. Los principios del Derecho romano fueron abriéndose paso poco a poco en la legislación catalana, sustituyendo en muchos puntos a los del Derecho nacional, y extendiendo cada vez más el ámbito de su aplicación.

La recepción del Derecho romano y la influencia de los jurisconsultos en Navarra fue menos intensa que en los otros reinos cristianos de la Península, pero siguió en general el mismo camino que en ellos hemos observado ${ }^{86}$.

Conocida es la oposición enérgica formulada en 1264 por los ricos hombres y caballeros aragoneses a que los jurisconsultos formasen parte del Consejo de la Corona. Pero desde el momento en que la Corona tiene fuerza bastante para contrarrestar la acción de los nobles, vemos ya preponderante la influencia de los jurisconsultos. Esta influencia se acentúa, sobre todo, a contar desde el reinado de Pedro IV, el cual estableció que además del Juez de Aragón, versado en el conocimiento de los fueros que, según antigua costumbre, había de acompañar al Rey constantemente, fuesen también de allí en adelante en su compañía dos milites y dos jurisperitos. Esta influencia llega a su apogeo y recibe más solemne consagración, al organizar Fernando el Católico con su Pragmática de 19 de Noviembre de 1494, con carácter ya permanente y definitivo, el Consejo Real de Aragón y establecer que celebrara sus sesiones con "idóneo y suficiente número de letrados" ${ }^{87}$.

En Aragón, la influencia de los jurisconsultos en la administración de justicia se manifiesta en el hecho de ser un jurisconsulto quien generalmente entendía como juez delegado de las apelaciones que se interponían ante la Corona de las sentencias dictadas por los tribunales de justicia. De ellos habían de asesorarse también los alcaldes o justicias de las ciudades al dar sus sentencias.

La influencia extraordinaria de esta clase y de los principios del Derecho romano favorables al robustecimiento del poder real, que con perseverante energía defendieron y propagaron los jurisconsultos, se manifiesta muy luego, singularmente en Aragón y Castilla desde mediados del siglo XIII, en

86 Yanguas, Diccionario de antigüedades del reino de Navarra, vol. I, Pamplona, 1840, págs. 220-221-271 y 273.

87 Torreánaz, I, p. 265-266. 
multitud de disposiciones (que no es de nuestro objeto examinar en detalle), en virtud de las cuales van reivindicando paulatinamente los Reyes sus mermadas prerrogativas, y llega a su más alto punto en tiempo de los Reyes Católicos.

Las Partidas atribuyeron al Rey la plenitud de la potestad legislativa, teoría sancionada por el Ordenamiento de Alcalá, cuando afirma que "al Rey pertenesce e ha poder de facer fueros, e leys, e de las interpretar, e declarar, e emendar do viese que cumple". "En esto se fundaron los procuradores a las Cortes celebradas en el real sobre Olmedo el año 1445, para suplicar a Juan II que revoque o declare o interprete ciertas leyes mal entendidas por los que desconocían su autoridad, usando de su poderío real absoluto. El Rey así lo otorgó, e hizo sobre ello ordenamiento" 88 .

En el reino de Castilla, Juan II "usó y abusó" de la frase "poderío real absoluto", y sus sucesores continuaron empleándola ${ }^{89}$. En el de Aragón, hallamos también empleadas en los documentos reales frases análogas, alusivas al poderío absoluto del Monarca ${ }^{90}$. En el de Navarra, la autoridad del Rey no reconocía otra limitación que la de no poder éste, según el Fuero General, hacer la guerra, ni otro granado fecho, ni ejercer el poder judicial, sino asesorándose de "doce ricos hombres ancianos o sabios de la tierra" 91.

Una de las consecuencias inmediatas de la recepción del Derecho romano fue, según hemos indicado en otro lugar, que los Soberanos se esforzasen y lograran al cabo paulatinamente reivindicar para sí la suprema potestad legislativa y judicial, tan menoscabadas por la organización feudal y corporativa de la Edad Media. El aforismo quod principi placuit legis habet vigorem, resucitado por los juristas, tuvo parte principalísima en esta transformación. Las Cortes se cuidaron bien poco de limitar las facultades del Monarca en cuanto a fijar por escrito el derecho vigente, preocupadas casi únicamente con lo relativo a sus intereses económicos y particulares. Y los Monarcas ab-

88 Part. I, tít. I, lib. XII: "Emperador o Rey puede facer leyes sobre las gentes de su señorío, et otro ninguno non ha poder de las facer en lo temporal, fueras ende si las feciese con otorgamiento dellos. Et las que de otra manera son fechas, non han nombre nin fuerza de leyes, nin deben valer en ningún tiempo".

89 Colmeiro, Curso de Derecho politico, p. 265-266.

90 En el privilegio confirmatorio del Estudio general de Valencia dado por Fernando $\mathrm{V}$ en Sevilla el año 1502, e inserto en el Aureum opus regalium privüegiorum civitatis et regni Valentiae, Valencia, 1515, fol. CCXXIII V ${ }^{\circ}$ se lee esta frase: Nos enim ... ex nostra regia potestate, legibus non astricta, volumus et decernimus...

91 Lib. I, tít. I, cap. I.- Yanguas, Op. cit., I, p. 274-277. 
solutos prescindieron de la representación nacional casi enteramente, mientras los jurisconsultos los proclamaban omnipotentes y absolutos, invocando el principio del Derecho romano princeps legibus solutus est.

Sabido es que, por el ordenamiento que otorgó Juan I en las Cortes de Briviesca de 1387 "quedaron los Reyes de León y Castilla privados de establecer y derogar las leyes a su albedrío, puesto que las dadas en Cortes no se podían revocar sin su consentimiento". Pero esta concesión teórica no fue respetada: los Monarcas posteriores derogaron cuando lo tuvieron a bien los acuerdos tomados en las Cortes del reino, sin que la actitud de éstas, enérgica unas veces, servil otras, modificase en lo más mínimo tal estado de cosas, que perseveró hasta la ruina definitiva de aquella institución ${ }^{92}$.

Estos gérmenes de ruina los llevaba en su seno la institución misma, no sólo en Castilla ${ }^{93}$, sino también, aunque en menos grado, en Aragón, Cataluña, Valencia ${ }^{94}$ y Navarra. Las Cortes de este último reino, que no aparecen con caracteres definidos hasta principios del siglo XIV, comienzan a otorgar el donativo desde 1385, llamando el Rey con este objeto a individuos de los tres brazos, a su arbitrio; si bien una vez concedido el privilegio de la representación en Cortes a las villas, no se revocaba sino con causa a contar desde $1519^{95}$.

92 Colmeiro, Curso de Derecho político, p. 334-348.

93 Cánovas del Castillo, Carlos V y las Cortes de Castilla en La España Moderna, Madrid, 1889, I, p. 73-115, prueba que la división en brazos, peculiar de las Cortes de Aragón, Cataluña y Valencia, fue ajena a las Cortes de Castilla, donde ni los nobles, ni el clero tuvieron representación propia, siendo, por tanto, equivocado que Carlos V excluyese de ella a los nobles en 1538 .

94 Oliver, La Nación y la Realeza en los Estados de la Corona de Aragón, p. 19.- La Fuente, Estudios críticos sobre la historia y el derecho de Aragón, II, p. 197 y 343-347.

95 Yanguas, I, p. 274-338. 


\section{CAPÍTULO III}

Carácter general de la literatura teológica-política en la Edad Media.- Producciones de la literatura teológica de la Edad Media española interesantes bajo algún aspecto para nuestro estudio: el tratado De planctu Ecclesiae de Alvaro Pelagio; el Crestía o libro del Regiment de Eximenes; el Derectorium de Eymerich; la Summa de Ecclesia de Torquemada; el tratado De optima poluta del Tostado; tratados de Sánchez de Arévalo; el libro De Republica de Castrillo.

En los primeros siglos de la Edad Media, la ciencia política no fue cultivada sino en escritos destinados a ofrecer a los Príncipes la instrucción necesaria para el buen desempeño de su oficio; y esto únicamente en Francia, que, gracias a la tranquilidad relativa de que gozó durante el siglo IX, fue la única nación de Europa propicia para el desarrollo de este género de literatura. La primera de sus producciones fue la Via regia del abad Smaragdo de Verdún, escrita en 813; seguida de allí a poco por el tratado De institutione regia de Jonás, Obispo de Orleans, dirigido a Pipino de Aquitania, hijo de Ludovico Pío, en el primer tercio del mismo siglo. Vienen luego las obras De comparatione regiminis ecclesiastici et politici de Abogardo de Lyon, el Liber institutionis de auctoribus christianis de Sedulio de Lieja y las obras De Regis persona et regio ministerio y De ordine Palatii de Hincmar de Reims. Esta última, además de exponer el cuadro de la organización palatina vigente a la sazón en Francia, enumerando los diversos cargos y sus atribuciones, da a conocer en un preámbulo de índole doctrinal, las ideas del autor sobre materias políticas. Rasgo común a todos estos escritos, es inspirarse en la doctrina de San Agustín y de San Isidoro al tratar del origen y el fin de la sociedad civil, de las obligaciones del soberano y de las relaciones entre la potestad civil y la eclesiástica. Su influencia en el desenvolvimiento de las instituciones políticas del reino franco fue extraordinaria, según han venido a demostrar recientes investigaciones ${ }^{96}$.

Más tarde, las luchas entre el sacerdocio y el imperio en tiempo de Gregorio VII y las empeñadas polémicas entre los partidarios del Papa y los del Emperador dan origen a numerosos escritos, en los cuales, con ocasión de examinar los fundamentos y títulos de ambas potestades con especial relación a las diferencias que entre ellas habían surgido, se investigan los problemas capitales de

96 Schrörs, Hinkmar Erzbischof von Reims, Friburgo, 1884, p. 381-388; Bourgeois, La Capitulaire de Kiersy-sur-Oise, París, 1885, p. 271-308; Prou, al frente de su edición del tratado De ordine Palatii, Paris, 1885, p. XXIII-XLI. 
la constitución y organización de la sociedad política. Mayor aún fue el impulso que recibió su estudio con motivo de las discordias entre Juan XXII y Luis el Bávaro, nuevo y trascendentalísimo episodio de la lucha entre el pontificado y el imperio, que llena la segunda mitad de la Edad Media y coincide con el admirable desarrollo de los estudios teológicos, filosóficos y jurídicos, consiguiente al estudio e interpretación de las obras de Aristóteles y del Corpus iuris civilis por la Escolástica y los Glosadores. Los escritos polémicos de este período reflejan claramente el progreso que se había verificado en tales estudios.

$\mathrm{Al}$ calor de este movimiento, surgieron también algunos escritos, cuyos autores, sin intervenir directamente en las controversias que a la sazón se agitaban, se aplicaron a discurrir en abstracto y fundamentalmente sobre los principios de la ciencia política. Entre los tratados de este género, descuellan las disquisiciones de Santo Tomás de Aquino en la Summa Teologica y en el tratado De regimine Principum ${ }^{97}$. "En los escritos de Santo Tomás de Aquino, no se encuentra huella alguna de los trascendentales sucesos y de las enconadas luchas que agitaron su época. Cierto que habla ocasionalmente en la Summa de diferencias entre la potestad civil y la eclesiástica; pero tan fría y tan brevemente, de un modo tan abstracto, como si el examen teórico de las razones en pro y en contra no fuese interrumpido nunca por el ruido de las armas, por salvajes violencias, por contiendas y excomuniones. Tampoco se le ocurrió nunca explicar las teorías por medio de los sucesos de su época o desenvolver los especiales problemas que éste le ofrecía. Y en esto radica ciertamente una de las mayores excelencias de su fecunda especulación. ¿Cómo hubiera podido ser Tomás de Aquino el maestro de los futuros siglos si sus ideas en puntos esenciales hubiesen sido influidas por las tendencias del siglo XIII, si hubiesen surgido como consecuencia natural de las circunstancias históricas de su época? Mas no debe creerse por esto que fuese propósito deliberado en él mantener alejada la investigación científica de la vida y de la actividad de su tiempo. Seguía en esto la práctica tradicional de la Escuela”98.

97 Entre los innumerables trabajos consagrados a exponer las doctrinas de Santo Tomás en materias políticas y sociales, debemos mencionar los Estudios sobre la Filosofía de Santo Tomás del P. Zeferino González, Manila, 1864; el Santo Tomás de Aquino de D. Alejandro Pidal y Mon, Madrid, 1875, y la Memoria de D. Francisco Fernández de Henestrosa, laureada por la Real Academia de Ciencias Morales y Políticas, Concepto del derecho según la doctrina de Santo Tomás: Influencia de esta doctrina en la constitución y desarrollo de la Ciencia del Derecho, Madrid, 1888.

98 v. Hertling, Der heilige Thomas von Aquin und die Probleme des Naturrechts en el Jahresbericht der Göirres-Gesellschaft, Colonia , 1884. 
Imitando el ejemplo de Santo Tomás, escribió otro tratado De regimine Principum Egidio Colona Romano ${ }^{99}$ obra que alcanzó en la Edad Media boga extraordinaria, y de la cual hizo una versión castellana en el siglo XIV Juan de Castrojeriz $^{100}$. La Ética y la Política de Aristóteles fueron conocidas ya por los compiladores de las Partidas ${ }^{101}$. Allanó el camino a la influencia del Estagirita en España la traducción de la Ética llevada a cabo por el Príncipe de Viana ${ }^{102}$.

Las relaciones entre la Iglesia y el Estado son el asunto predilecto de los escritos teológicos de la Edad Media. Es de notar a este propósito, que desde mediados del siglo XI van cayendo en desuso las expresiones relativas a la coordinación de ambas potestades, y son sustituidas por otras que consignan la supremacía de la eclesiástica sobre la civil, influyendo en esto las instituciones feudales vigentes en Francia y Borgoña, según las cuales todo vínculo de subordinación, así en el Estado como en la Iglesia, debía hacerse sensible por un signo exterior, por la entrega de objetos simbólicos que representaban la potestad otorgada. "Progresivamente se fue abriendo paso la idea de que la Iglesia, y en última instancia el Papa, había otorgado a los Soberanos la potestad temporal por medio de actos simbólicos. La superioridad de la Iglesia sobre el Estado se condensa en la proposición de que Cristo había confiado a San Pedro los jura coelestis et terrestris imperii o las dos espadas, una de

99 En el Rimado de Palacio (Biblioteca de Autores Españoles, t. LVII, Madrid, 1867, p. 444), se habla de la obra de Egidio en los términos siguientes:

625 "Qual regimiento deven los principes tener, Es escripto en los libros que solemos leer:

Egidio el Romano, omne de grant saber, In regimine principum lo fez bien componer.

626 Non curo de escrevirlo, pues y lo fallarás, Mejor que lo diria, ally lo tu verás:

Nobles ensennamientos, que placer tomarás.

Por onde de desirlo, escusado me averás".

100 Véase sobre ella a Cánovas del Castillo, De las ideas políticas en España cuando la Casa de Austria entró a reinar, en la Revista Contemporánea de 30 de Mayo de 1889, p. $337 \mathrm{y}$ siguientes.

101 Part. II, tít I, leyes 6 y 10.

102 Yanguas, Diccionario de antigüedades del reino de Navarra, t. I, páginas 186 a 192, publica una carta del Príncipe D. Carlos, relativa al proyecto que éste tuvo de escribir un extenso tratado de Moral y Política, cuyo plan, calcado sobre los tratados de Aristóteles, expone minuciosamente el documento en cuestión. Refiere el Príncipe, que el cansancio que le había causado la traducción de las Éticas fue causa de que desistiera de semejante propósito, el cual ruega tomen sobre sí "los valientes letrados de nuestra Spania”. 
las cuales había dado el Papa a los Soberanos temporales. La debilidad del Estado medioeval, manifestada especialmente en el hecho de verse obligado a consentir las guerras privadas, no podía menos de vigorizar la influencia política de la Iglesia, que se esforzó, como es sabido, desde mediados del siglo XI por poner dique al estado caótico de la sociedad con el establecimiento de la tregua de Dios $^{103}$.

Enfrente del concepto eclesiástico de la superioridad de la Iglesia respecto al Estado, subsistió o se mantuvo durante toda la Edad Media la opinión resueltamente laica, que pretendía derivar directamente de Dios la potestad civil y sostenía su absoluta independencia de la Iglesia. Los defensores de ambas opiniones se dejaron llevar a teorías extremas, como las que se encuentran por parte de los acérrimos regalistas en el Defensor pacis de Marsilio de Padua, y por parte de los campeones de la supremacía eclesiástica muestran su expresión más acentuada en los escritos de algunos curialistas decididos del siglo XIV, como Agustín Triunfo y Álvaro Pelagio”.

Por lo demás, la reflexión de la Edad Media sobre el Estado se consagró, no tanto a discurrir sobre las formas políticas o de gobierno, como acerca de los deberes peculiares del Príncipe, y entre ellos surge especialmente uno nuevo, desconocido de la antigüedad, el deber de proteger a la Iglesia, de amparar con mano fuerte los intereses morales y religiosos. Al tratar de la naturaleza y el fin de la sociedad política, en primer término, dedicó la atención a aquellos puntos en que la potestad eclesiástica y la civil se mostraban mutuamente hostiles en sus pretensiones.

En la lucha de Luis el Bávaro con el Papa Juan XXII, escribió el médico de cámara del Emperador, Marsilio de Padua, su Defensor pacis, sosteniendo que el Papa no era sino el Vicario del Emperador en Roma; todos los sacerdotes le igualan en dignidad; el Episcopado es de institución humana, y el Papa no tiene autoridad ninguna sobre los Obispos, ni es sucesor de Pedro. La Iglesia es la reunión de los fieles (congregatio populi): la elección de los sacerdotes toca a la autoridad civil, la cual puede obligarlos a administrar los Sacramentos: sólo al Príncipe toca castigar a los herejes y cismáticos. El Papa corona al Emperador sólo como delegado ad hoc por el pueblo romano. Los Reyes son Vicarios de Dios; tienen que gobernar según las leyes emanadas de la multitud, y si las violan, pueden ser depuestos por el pueblo. La elección de antipapa y la condenación de Juan XXII como hereje y reo de lesa majestad no fueron otra cosa sino aplicación práctica de estas teorías.

103 Grauert, Historisches Jahrbuch de 1888, IX, p. 141-142. 
Agustín Triunfo († 1328), por el contrario, enseñaba que, comparado con el de los Papas, el poder de los Emperadores y Reyes era subdelegado ${ }^{104}$; que el Emperador no podía dictar leyes sin la autoridad del Papa ${ }^{105}$; que el Papa es Señor del mundo, no sólo en lo espiritual, sino en lo temporal ${ }^{106}$; que, en este concepto, es el repartidor de los imperios, y que, conforme a esto, mediando causa razonable, puede deponer a unos Reyes y entronizar a otros. La donación de Constantino, inventada, según la opinión más autorizada ${ }^{107}$ a mediados del siglo IX en el monasterio francés de San Dionisio para legitimar el imperio de Occidente contra Bizancio, fue invocada frecuentemente en documentos pontificios y en los escritos de los defensores del Papado para justificar sus teorías.

Los errores de Marsilio, en especial el de que toda potestad, así eclesiástica como civil, emanaba del Emperador, fueron condenados en 1327 por Juan XXII; sobre todo la tesis "Quod ad imperatorem spectat Papam instituere et destituere at punire; et quod tota Ecclesia simul iuncta nullum hominem punire potest punitione coactiva nisi concedat hoc Imperator".

Relaciónase con estas polémicas la primera de las producciones de nuestra literatura teológico-política de este período.

El franciscano Álvaro Pelayo, obispo de Silves en Portugal, en su libro De planctu Ecclesiae, escrito, según opinión muy verosímil, por orden de Juan XXII para combatir las teorías hostiles al Pontificado expuestas por Marsilio de Padua y Juan de Jandun en el Defensor pacis $^{108}$, defiende la doctrina corriente entre los escolásticos de su tiempo acerca del origen de la sociedad y la transmisión del poder ${ }^{109}$. Deriva la primera, conforme a ellos, de la tendencia natural del hombre a la sociabilidad, y al mismo tiempo que sostiene el origen divino del poder, le hace radicar primeramente en el pueblo, el cual lo delega después a una o varias personas ${ }^{110}$. Declárase partidario de la monarquía

104 Summa, De potestate Ecclesiae, Venecia, 1483, q. I, art. I.

105 Ibid., q. 44, a. 1.

106 Ibid., q- 45, a.2.

107 Summa, De potestate Ecclesiae, Venecia, 1483, q. 46, a. 3.

108 Es digno de ser consultado el trabajo de Birck, Marsiglio von Padua und Alvaro Pelayo über Papst und Kaiser, Kirche und Staat, Mülheim, 1868, p. 16-22, y los más importantes de Riezler, Die literarischen Widersacher der Päpste zur Zeit Ludwigs der Bayern, Leipzig, 1874 , y Scaduto, Stato e Chiesa negli scritti politici del Medio Evo, Florencia, 1882.

109 Grauert en el Historisches Jahrbuch, IV, p. 674-680.

110 Lib. I, art. 52. 
templada, y reconoce con Santo Tomás ser el principal inconveniente de esta forma de gobierno, que el Príncipe degenere en tirano ${ }^{111}$. En este último caso, considera lícita la resistencia al poder, si bien únicamente bajo la forma de apelación contra el Príncipe secular que tiene superior jerárquico ${ }^{112}$.

$\mathrm{Su}$ teoría acerca de las relaciones entre la Iglesia y el Estado puede concretarse en los términos siguientes: Jesucristo transmitió a Pedro y sus sucesores la plenitud de la potestad sobre la tierra, y esta potestad sin número, peso, ni medida, no sólo abarca a los cristianos, sino también a los paganos y a los judíos. De aquí nace el supremo derecho de inspección que incumbe a los Pontífices sobre los Soberanos temporales, y la facultad de amonestarlos y aun privarlos de sus dominios si fuese necesario. De aquí también la obligación de la potestad civil de ponerse enteramente al servicio de la espiritual. El fuero de jurisdicción y la inmunidad de tributos del clero no emanan de privilegios de los Príncipes, sino que corresponden por derecho divino a los miembros del estado eclesiástico. Ninguna potestad temporal tiene legítimos títulos a la obediencia de sus súbditos, si no ha sido reconocida y confirmada por la Iglesia ${ }^{113}$.

La corona de Aragón puede gloriarse con justo título de haber surgido en sus dominios el fruto más sazonado de nuestra literatura teológico-política en la Edad Media; no inferior ciertamente en la doctrina a los mejores libros de índole análoga escritos en otros países, y superior a todos ellos por la grandiosidad del plan y su copiosa y escogida erudición. Nos referimos al Crestiá o Llibre de regiment de Princeps e de la cosa publica $^{114}$, del franciscano cata-

111 Lib. I, art. 62, fol. 52v. Magis esse expediens sub uno rege vivere quam multorum... Los electores deben considerar las cualidades de la persona de suerte que no sea probable degenere en tirano: Deinde sic disponenda est regni gubernatio ut, regi iam instituto, tyrannidis subtrahat occasio: sic eius temperet potestas ut de facili in tyrannidem declinare non possit.

112 Lib. I, art. 62, fol. 56v. Si autem alius non esset superior tyranno, invocandum esset Ecclesiae auxilium contra eum ... deficiente etiam humano auxilio recurrendum est ad Deum.

113 Alvari Pelagii, De planctu Ecclesiae, desideratissimi libri duo. Lyon, 1517. Edición dedicada por el Editor "Reverendo in Christo Patri vigilantissimoque Dertosanorum antistiti domino Hadriano Florentio Traiectensi”. Los capítulos 62 a 52 del libro primero de esta obra (fol. XXXIV v. ${ }^{\circ}$ a LVIII v ${ }^{\circ}$ de la ed. cit.) son los que ofrecen mayor interés para el estudio de las opiniones del Autor en la materia que nos ocupa.

114 La única edición que existe de la obra de Eximenes es la impresa en Valencia por el alemán Lamberto Palmart el año 1484. El ejemplar de ella que he consultado es el que posee la Biblioteca Nacional, procedente de la del Marqués de la Romana. 
lán Francisco Eximenes o Jiménez, Obispo de Elna y Patriarca de Alejandría, escrito en el año 1379, y calificado con razón por nuestro insigne bibliógrafo Nicolás Antonio de varium quidem opus et vastum theologico-politicum, vastum atque eruditum, et vere christianum ${ }^{115}$.

La segunda parte de El Crestiá de Fr. Francesch Eximenes intitulada "Llibre dels regiments de Princeps e de Comunitats" está dedicada "al molt alt e poderos senyor Namfós, marqués de Villena, conte de Denia e de Ribagorça, fill del molt alt senyor e de sancta memoria infant frare Pere Daragó del orden deis frares menors" y nieto del rey D. Jaime. En ella condensa el Autor, según declara al final de la dedicatoria, las sentencias "cullit ab gran mussa e affany dels dits e fets dels grans pares e dels nomenats senyors, philosophs, doctors, cavallers e sancts princeps passats".

Define Eximenes al gobierno o "regiment" "auctoritat e jurisdictio sobre alguns dada al president per lunyarlos de mal per grat o per forza e per promourelos a be ${ }^{116 ”}$. Discurriendo sobre las causas que movieron a los hombres a congregarse en sociedad, considera como una de las principales el deseo de refrenar mejor a los delincuentes por medio de las leyes "Las quals leys e penes" dice "fan molt refrenar les males cobejances. E maiorment quant aqui ja apparent los torments a hull axicom les forques e les costells e semblant coses; diu l'exemple que paor guarda la vinya"11.

Las sociedades fueron libres en un principio de elegir la forma de gobierno que más les acomodase, y "cascu pot presumir que cascuna comunitat feu ab sa propria senyoria pactes e convencions profitosas e honorables per simateixa principalment, e apres per aquell o per aquells a qui dona la potestat de sus regiments... car la comunitat no elegi senyoria per amor del regidor, mas elegi regidor per amor de simateixa". Pondera Eximenes la duración y prosperidad de los Estados regidos de esta suerte, y la instabilidad y miseria de los gobernados "per poder absolut e per propria volentat del regidor, e sens ley e pacte ab los vasalls"118.

De los supremos magistrados de la nación, o "presidents", como él los llama, dice, "que ells poden manar als altres e aells no mana sino la ley els pactes fets ab los vassalls, els mana encara la consciencia e Deu"; mas para conservar su autoridad "fa mester que non ischa fora los termens assignats al president

115 Bibliotheca hispana vetus, tomo II, p. 180, col. 1.

116 Parte IV, cap. 397.

117 Parte I, cap. 26.

118 Parte II, cap. 156. 
per la ley e pactes posats entre ell els vasalls", pues si los traspasa degenera en tirano y pierde el derecho a la autoridad ${ }^{119}$.

Al tratar del régimen municipal, se decide por que "tota la multitud se partescha en tres parts; coes en maiors, mitjans e menors e que de cascun siens elegits los millors per regiment de la comunitat" ${ }^{{ }^{20}}$; pondera los inconvenientes de que los magistrados municipales sean perpetuos ${ }^{121}$, pero defiende con buenas razones la opinión contraria respecto a los "regidors principals, axicom son los prínceps"122. Pesando a este propósito las ventajas de la monarquía hereditaria y de la electiva, afirma "que mes val lexar ho tot a Deu e que el do al regne aytal princep per natura com li placia, lexada tota electio, axi que lo princep sea perpetual en linatge et en regiment"123.

$\mathrm{Al}$ sostener la conveniencia de que las tres clases en que podía considerarse dividida la población interviniesen en el gobierno municipal, Eximenes no hacía sino defender el régimen vigente en Valencia, en cuya virtud el Consejo general funcionaba como asamblea consultiva y deliberante al lado de los jurados, en representación de las tres clases: caballeros, ciudadanos honrados y plebeyos, o sea de los mercaderes y menestrales. Estas tres clases también estuvieron representadas cada una por dos jurados desde 1278 a 1283, por privilegio de Pedro I ${ }^{124}$.

Eximenes alude al carácter de monarquía paccionada del reino de Valencia, sostenido por los jurisconsultos valencianos aun en los siglos XVI y XVII, y manifestado en la obligación del heredero del trono de prestar juramento para ser reconocido como soberano ${ }^{125}$.

Muéstrase enemigo acérrimo de las elecciones para todos los cargos públicos, excepto de los municipales, por ser tan ocasionadas a discordias, y

119 Parte II, cap. 154.

120 Parte IV, cap. 400.

121 Parte IV, cap. 401.

122 Parte IV, cap. 402.

123 Parte IV, cap. 403.

124 Aureum opus regalium privilegiorum civitatis et regni Valentiae, fol. 29. Se reconoce a los jurados el derecho a promulgar nuevos estatutos "ubi forum Valentiae non sufficiat", "ita tamen ut semper fiant consilio proborum hominum de manu maiori mediocri et minori”.

125 Privilegio de Alfonso de Aragón de 1329 en el Aureum opus regalium privilegiorum civitatis et regni Valentiae, fol. LXXXVI v ${ }^{\circ}$ dice que mientras el nuevo Rey no jurase respetar los fueros y libertades del reino, et juramentum pro ipsis servandis prestiterit non teneamini eum in regem vestrum aut dominum recipere nec sibi in aliquo respondere. 
preconiza las ventajas de la insaculación, sistema que sólo juzga defectuoso aplicado a los cargos eclesiásticos ${ }^{126}$.

Examinando las causas por que los Reyes pueden ser privados de la soberanía, sostiene que, si el Rey es hereje, debe acudirse al Papa para que desligue a los súbditos del juramento de fidelidad y dé el reino a otro Príncipe. Si degenera en tirano, y amonestado de personas graves o de los mayores de la tierra, no se enmienda, o si muestra su incapacidad para gobernar, "sia dat per enemich e sia absolt del regiment de son regne e sia fiet rey lo pus prohisme seu"127.

Dando pruebas de elevación y rectitud poco comunes en su tiempo, defiende resueltamente, que los judíos e infieles que habitan entre cristianos no son esclavos, antes bien tienen verdadero señorío sobre sus bienes ${ }^{128}$, y censura acerbamente a "aquells qui consellen los senyors del mon quis prenguen los bens dels jueus e dels altres infeels asicom a bens de lurs propris catius"129. $\mathrm{Al}$ tratar de materias eclesiásticas, afirma en redondo que el Papa es "general senyor e monarcha sobre tot lo mon e aso per dret divinal e temporal" ${ }^{130}$.

Tales son, en la parte relacionada con nuestro estudio, los conceptos fundamentales de la obra de Eximenes, en la cual abundan rasgos y noticias curiosas para conocer las aficiones del Autor y las costumbres de la época ${ }^{131}$.

El Directorium Inquisitorum ${ }^{132}$, compuesto a mediados del siglo XVI por el dominico gerundense e implacable enemigo de Raimundo Lulio ${ }^{133}$, Nicolás Eymerich, Inquisidor general del reino de Aragón, ofrece cierto interés bajo

126 Parte III, cap. 388.

127 Parte IV, cap. 411.

128 Parte II, cap. 166-168.

129 Parte II, cap. 169.

130 Parte IV, cap. 450-461.

131 Así, en el cap. 24 de la primera parte trae un paralelo entre Barcelona y Tarragona, de que sale muy mal parada esta última ciudad. Dice, por ejemplo: "Es aximateix Terragona mal poblada e de gent simpl e grossera. Mas Barcelona es dotada de gran seny e poblada de gent notabla e de gran pes e fort nodrida specialment en la gola," etc. En uno de los capítulos más curiosos e interesantes de la obra (parte III, cap. 384) afirma que la muchedumbre de los juristas es muy dañosa a la comunidad, y gran destrucción suya: otro tanto dice de los notarios, "picaplets", fiscales, etc. Parte III, cap. 385-387.

132 La edición de esta obra que he utilizado es la publicada con importantes ilustraciones y notas por el teólogo y jurisconsulto español del siglo XVI, Francisco Peña: Directorium Inquisitorum, R. P. F. Nicolai Eymerici, Ord. Praed. S. Theol. Mag., Inquisitoris hereticae pravitatis in regnis regis Aragonum... Roma, 1578

133 Menéndez y Pelayo, Historia de los heterodoxos españoles, I, Madrid, 1879, p. 527-530. 
el punto de vista de nuestro estudio. En la segunda de las tres partes de que consta la obra ${ }^{134}$, muéstrase Eymerich defensor acérrimo de la potestad pontificia, a la cual atribuye, en consonancia con las prácticas de entonces, la facultad de deponer a los Príncipes seculares que no se prestasen a extirpar los herejes de sus Estados. Defiende asimismo con vehemencia la legitimidad del procedimiento y de las penas empleadas a la sazón contra los prevaricadores de la fe católica.

Teólogo y jurisconsulto a la vez y hombre de gran vigor de entendimiento, Eymerich dio carácter científico en esta obra y condensó con extraordinario método y claridad las teorías y las prácticas del Santo Oficio ${ }^{135}$. De aquí que su libro viniera a ser en España y fuera de ella el Vademécum de los Inquisidores de la herética pravedad, a quienes ofrecía cuantas instrucciones habían menester para el cumplido desempeño de su cargo, ejerciendo por este concepto inmensa influencia en los tribunales eclesiásticos.

Es muy de notar la prolijidad y evidente predilección con que trata en la tercera y más extensa parte de su obra consagrada a la práctica judicial, de la cuestión del tormento, al cual juzga, apoyándose en su propia experiencia de Inquisidor, como el medio más eficaz para arrancar del reo la confesión de la verdad. Que, muy especialmente en lo que se refiere al tormento, la autoridad del libro de Eymerich no fue eclipsada por otro ninguno, lo demuestra la frecuencia con que invocan su testimonio los tratadistas de práctica criminal de los siglos XVI y XVII.

El famoso dominico y Cardenal Juan de Torquemada ${ }^{136}$, que tan activamente intervino en los sucesos y controversias relacionados con la gran crisis que sufrió la Iglesia en la primera mitad del siglo xv, acérrimo defensor de los Papas, hasta el punto de que algún escritor moderno le ha llamado con razón "el gran legitimista de la autoridad pontificia" ${ }^{37}$, consagró una parte de su Summa de Ecclesia al estudio de las relaciones entre la potestad eclesiástica y la civil. Sostiene que esta última depende de la primera como de su causa

134 "Nam in prima” dice el autor en la Epístola-Prólogo "agitur de fide catholica, ut plantetur, secunda de pravitate haeretica, ut vitetur; in tertia de officiis practica ut servetur".

135 Véase acerca de ella el juicio de Molinier, L'Inquisition dans le Midi de la France au XIII et XIV siècle, París, 1881, p. 221-226.

136 La vida y escritos de este ilustre español han sido estudiados no ha mucho por el alemán Lederer en su monografía Der spanische cardenal Johann von Torquemada. Sein Leben und seine Schriften. Friburgo, 1879.

137 Véase el libro de Hübler, Die Constanzer Reformation, Leipzig, 1867, p. 172. 
eficiente ${ }^{138}$ y atribuye al Papa amplísima potestad directiva y preceptiva sobre los Soberanos. En virtud de ella, dice, los Pontífices deben dictar a los Príncipes las normas a que han de conformarse en el ejercicio de su poder.

El célebre teólogo y escriturario Alfonso de Madrigal, Obispo de Ávila, más conocido por los sobrenombres de El Avilense y El Tostado, trató de propósito de materias políticas en su opúsculo intitulado De óptima politia ${ }^{139}$.

$\mathrm{Al}$ examinar las varias formas de gobierno y las reglas a que debe acomodarse la constitución de las sociedades, clasifica con Aristóteles las formas políticas en dos clases, buenas y malas, incluyendo en la primera categoría la monárquica, la aristocrática y la timocrática, y en la segunda la tiranía, la oligarquía y la democracia. Al caracterizar la monarquía, coincide con todos los tratadistas de la Edad Media. Respecto a la aristocracia, o gobierno de los mejores, sostiene que la nación es la que ha de designar los jefes, y que la participación de cada cual en el gobierno ha de ser proporcionada con el grado de virtud. El gobierno monárquico degenera en tiránico cuando el rey explota la potestad de que se halla investido en provecho propio y no en procurar el bien común, o cuando reina contra la voluntad de sus súbditos. La oligarquía es censurable porque consagra la dominación de unos cuantos, fundada exclusivamente en el poder o la riqueza. La democracia es el peor de todos; pues para nada tiene en cuenta el talento ni la virtud de los gobernantes. Entre todas las formas de gobierno, prefiere la monarquía, por ser menos ocasionado a discordias el régimen de uno sólo que el de varios. Pero en esta importante materia, dice, no ha de seguirse un criterio absoluto, sino que debe aceptarse la que más convenga a cada país, conforme a la regla trazada sabiamente por la naturaleza, según la cual debe ser distinto el régimen de los niños del de los adultos, el de los sanos del de los enfermos.

Hablando en los Commentaria in Exodum de los jueces de Israel, se expresa en estos términos: "En el pueblo, debe perseverar siempre el poder de elegir los Príncipes y el de corregirlos, pues no puede enajenarse enteramente sino aquello de que se es propietario, y la nación no es dueña del poder soberano, sino mera depositaría” 140 .

138 Lib. I. Patet quod potestas secularis in república christiana pendeat a potestate spirituale etiam in genere causae efficientis, quasi ab ea formata.

139 Hállase en el t. XXV de la edición de sus Obras completas, Venecia, 1728, p. 61-74.

140 Martínez Marina, Defensa contra las censuras dadas por el Tribunal de la Inquisición a sus obras, p. 36, 64, 85-86, 90-92, 101-102 y 120-121 cita los pasajes más importantes del Tostado acerca del particular. 
Defendió con crudeza la absurda opinión de que la monarquía del orbe reside únicamente en el Pontífice romano el célebre prelado español del siglo XV y adicto servidor de los Pontífices de su tiempo, Rodrigo Sánchez de Arévalo, consagrando un libro (que por desgracia no hemos podido consultar, pero cuyas tesis fundamentales nos son conocidas por haber transcrito íntegramente su título D. Nicolás Antonio) ${ }^{141}$, a propugnar y a combatir la que atribuía a los Emperadores jurisdicción universal y suprema sobre todas las naciones del mundo. Parece asentar a este propósito, de acuerdo con la doctrina consignada en las Partidas, que algunos reinos, en especial Francia y España, no dependían de los Emperadores, y vindica para los Pontífices romanos la facultad de castigar y aun de privar de sus tronos a los Soberanos temporales, negándosela en absoluto al pueblo y a la nobleza. De donde se infiere claramente ser nuestro Autor adversario resuelto de la doctrina sustentada ya por algunos teólogos y canonistas acerca del tiranicidio ${ }^{142}$.

El libro más curioso, ya que no el más importante (pues bajo ningún concepto puede compararse con el de Eximenes), de cuantos se escribieron en este período sobre materias políticas, es el Tratado de República del trinitario Alonso de Castrillo, que si bien pertenece al siglo XVI, no puede incluirse, ni por el fondo, ni por el método, entre las producciones de nuestra gran escuela teológico-política ${ }^{143}$.

141 El título exacto en el mss. 4.881 de la Biblioteca Vaticana (Bibliotheca hispana vetus, tomo II, Madrid, 1780, p. 299) es como sigue: Liber de monarchia orbis, et de origine et differentia cuiusvis principatus, tam imperialis quam regalis; et de antiquitate et iusticia utriusque, duobus libris. Primus agit de praedictis, et an Imperatores moderni iuste possint praetendere iurisdictionem universalem et supremam super omnes orbis nationes; et an aliqua regna provinciae, praesertim Francia et Hispania, sint de iure libera et exemta ab imperio. Ostenditur etiam veram orbis monarchiam solum residere in Romano Pontifice. Secundus liber agit, a quo, et ex quibus causis Reges et Principes orbis recognoscentes aut non recognoscentes superiorem in terris possint punire aut deponi. Ubi deducitur solum ad Romanos Pontifices spectare eamdem punitionem, et non ad populum, nec ad barones cuiusvis regni. Según Pastor, Geschichte der Päpste seit dem Ausgang des Mittelálters, Insbruck, 1890, p. 388, este libro está dedicado al Cardenal Rodrigo de Borja, más tarde Alejandro VI.

142 El Sr. D. Pascual de Gayangos posee un ejemplar de la obra citada de Sánchez de Arévalo, descrito por el Sr. Menéndez y Pelayo en los Apéndices del tomo IV, p. 1.563, del Ensayo de una Biblioteca española de libros raros y curiosos de Gallardo, Madrid, 1889. Por desgracia, esta noticia llegó a mis oídos ausente de Madrid el Sr. Gayangos, siéndome por tanto imposible acudir a la generosidad del distinguido bibliófilo para que me permitiese utilizarlo.

143 Tratado de República con otras hystorias y antigüedades. Intitulado al muy 
En el prólogo del Tratado de República ${ }^{144}$ dirigido al Provincial de su Orden en Castilla, alude Castrillo a los sucesos de las Comunidades atribuyendo los daños que de ellos se siguieron a "hombres peregrinos y extranjeros enemigos de nuestra República y de nuestro pueblo", y comparando este levantamiento con el de los gigantes de la fábula contra Júpiter. "Por los gigantes nascidos de la tierra y engendrados sin padres, entendemos la gente común de vaxos estados, de cuya generación ni parece fama, ni título, ni memoria, y por la conspiración y congregación de los gigantes contra el cielo y contra Júpiter, entendemos el concierto y la junta de las comunidades hechas contra la voluntad de su Rey a lo que parece...” Juzga Castrillo, por lo demás, que las aspiraciones de los Comuneros eran justas aunque no lo fuese el procedimiento que emplearon para alcanzarlas. "Ciertamente ningún justo ni sabio debe dudar que las gentes comunes en los principios pidiesen muy justa justitia, mas parece que se facen indignos de la justitia, rompiendo la orden y acatamiento con que se debe pedir la justitia..."145 Muy de cerca debió ver los sucesos de las Comunidades, si no es que anduvo algo mezclado en ellos, según se infiere de estas frases del mismo prólogo: "Si salud y tiempo me sobrara, como algo escribí de república, algo escribiera de las Comunidades, lo quel más por experiencia que por letras".

La obra está sembrada de sentencias de escritores antiguos, en especial de Platón, Aristóteles, Cicerón, San Agustín y San Isidoro, de las cuales toma pie el Autor para discurrir brevemente por cuenta propia, incurriendo en frecuentes contradicciones; pues a los pocos renglones de haber dicho que sin Rey "no ay república pacífica ni perfecta ni reyno bienaventurado", asiente a la opinión de que la obediencia "fue introducida mas por fuerça y por ley positiva que por natural justicia”" 146 .

Rdo. Sr. Fr. Diego de Gayangos ... nuevamente compuesto por el Rdo. P. Fr. Alonso de Castrillo, frayle de la misma Orden (de la Santísima Trinidad). Burgos, 1521.

144 La singularidad de algunas opiniones del Autor y la rareza del libro, que no se encuentra en las Bibliotecas públicas de Madrid, y del cual sólo sé que existan el ejemplar del Sr. Gayangos, citado por el Sr. Cánovas del Castillo en su trabajo sobre Las ideas políticas de los españoles, inserto en la Revista de España de 1868, y éste que yo he utilizado, propiedad de mi buen amigo D. José Sancho Bayón, me mueven a reproducir los pasajes más interesantes, en vez de limitarme a meras referencias.

145 Aij. V.

146 Cap. 6. En el cap. 22 vuelve a afirmar que "salva la obediencia de los hijos a los padres y el acatamiento de los menores a los mayores en edad, toda la otra obediencia es por natura injusta, porque todos nacimos iguales y libres”. 
Afirma que "después que se corrompió la inocencia del mundo, no poca necesidad ubo de guerra entre los hombres: que unos ubiesse superiores de otros y otros inferiores dellos: que unos mandasen y otros obedeciesen: porque donde ay mayor ay menor, y donde ay menor ay acatamiento, y donde acatamiento ay concierto, y donde ay concierto todas las cosas son bienaventuradas, mas donde todos son iguales todos son sin orden, y donde no ay orden, es infierno..."147. Deriva la sociedad civil, con Aristóteles, de la tendencia natural del hombre "que por natura todo hombre es deseoso de compañía y de cibdad" 148 .

Discurriendo sobre "si conviene ser perpetuos los governadores de la república" dice entre otras cosas, que "para ser mas segura la república, no conviene ser perpetuos los governadores della, porque quando goviernan por poco tiempo, entretanto que aprenden tiranizar, ya se les acaba el poder para ser tiranos"149. Este carácter amovible de la suprema magistratura de la nación "constituyó a los Romanos por señores del universo". Quiere Castrillo que el Jefe del Estado no sólo sea amovible, sino responsable: "paréceme", dice a este propósito, "que bien bastaría el agravio que a la naturaleza se haze de que un hombre obedezca y consienta ser governado de otro, sin que el governador haziendose obedecer por fuerza nunca se obligue a dar cuenta de como govierna, que ninguna cosa asi parece tan agraviada contra nuestra natura humana" ${ }^{150}$.

Aunque, a diferencia de casi todos los tratadistas españoles de política, así de los que le precedieron como de los que le siguieron, no trata Castrillo de propósito la cuestión del tiranicidio, puede inferirse de algunos pasajes de su obra, que entendía no ser obligatoria para los súbditos la obediencia al Monarca aun cuando degenerase en tirano ${ }^{151}$.

Considera Castrillo, siguiendo en este punto a Cicerón, como rasgo característico del ciudadano, la participación en el gobierno del Estado, y distingue, con San Agustín, a los habitantes de cada nación en tres clases: "nobles o caballeros", a quienes llama, también con Aristóteles, "defensores de

147 Cap. 8.

148 Cap. 9.

149 Cap. 22. Recalcando esta idea al principio del mismo capítulo, dice: "Cosa cierta es que el temor que todo governador tiene de ser presto subdito o governado, le hace más justo quando govierna".

150 Cap. 22.

151 Cap. 7. "La obediencia y el acatamiento que al estado real se debe, tanto parece derecho divino como humano, con tal quel servicio no se convierta en tiranía.” 
la república”, "mercaderes y oficiales”. Muéstrase a este propósito muy poco satisfecho de los nobles de su tiempo: "Ya en nuestro tiempo, dice, miramos destruyda y pervertida toda la orden de la nobleza ... porque los que habían de vivir de la justicia ya viven del interese, y los que habían de vivir de la paz, ya roban, y los que habían de robar no tanto lo dexan por temor como porque falta qué robar, y los caballeros que habían de vivir de la virtud, no tantas vences cabalgan sobre sus caballos como sobre su provecho"152.

Apoyándose en la autoridad de Aristóteles y extremando el pensamiento del filósofo, no quiere que los mercaderes ni los oficiales o artesanos intervengan en la gobernación del Estado: "pues como arriba declaramos, la cibdad es una compañía de hombres libres. Cómo se llamará cibdadano aquel que es esclavo de lo que tiene? Y es de saber que no todos son cibdadanos aquellos sin los cuales no puede ser la cibdad. Cierta cosa es que ninguna cibdad puede ser sin niños, mas por eso no se entiende que los niños son cibdadanos, y si cibdadanos son imperfectos son: y assi cierto es que la cibdad no puede ser sin mercaderes y officiales, mas no por esso son cibdadanos, y si cibdadanos son, imperfectos son" 153 .

No obstante esto, al discurrir sobre si la provisión de los cargos públicos ha de acomodarse al principio timocrático, o sea si conviene dar la preferencia a los más ricos, declara que sólo debe tenerse en cuenta la idoneidad de la persona ${ }^{154}$.

Las teorías de los teólogos españoles de este período no ejercieron, ni en realidad podían ejercer, influencia alguna sensible en el desenvolvimiento de las instituciones patrias. Y la razón se comprende fácilmente. Prescindiendo del libro extravagante de Castrillo, y exceptuando la obra de Eximenes, único ensayo de aplicación de los principios teológicos a los arduos problemas del gobierno de las sociedades, las demás obras que hemos analizado se limitan a tratar la cuestión, candente y palpitante durante toda la Edad Media, de las relaciones entre la potestad pontificia y la secular, con relación especial a las contiendas entre el sacerdocio y el imperio. Por otra parte, el oficio de consejeros y colaboradores de los Reyes en el ejercicio del poder legislativo y en la gobernación del Estado, que durante el período visigótico habían desempe-

152 Cap. 25.

153 Cap. 26.

154 Cap. 27. “Assi para proveer algún oficio de governación de república, no se debe considerar quan rico sea el hombre, salvo que tal sea el hombre”. 
ñado preferentemente los Obispos, vino a ser ejercido por los jurisconsultos en este de que ahora tratamos.

Mas ya que no en las leyes y en las instituciones, las doctrinas de nuestros teólogos acerca de la potestad del Papa en el orden temporal, doctrinas que por lo demás no eran peculiares suyas, sino comunes a casi todos los teólogos de su tiempo, trascendieron a nuestra historia política; manifestándose, ya en la sentencia de Martino IV, privando de la corona a Don Pedro de Aragón y haciendo donación de ella a los franceses, ya en la de Julio II, desposeyendo a la casa de Albret del reino de Navarra y concediéndolo a Femando el Católico. La fuerza de las armas que negó su sanción a la providencia de Martino IV, se la otorgó cumplidísima a la del Papa Julio, siendo de notar que Palacios Rubios, el jurisconsulto áulico de Don Fernando, en la obra De jure obtentionis et retentionis regni Navarrae, defendió en los términos más absolutos la autoridad de los Papas para dar y quitar coronas ${ }^{155}$.

Fernando el Católico fundó en esta facultad de los Pontífices su derecho a la posesión del reino de Navarra. Al dar noticia de la incorporación de este reino a la Corona de Castilla, en las Cortes de Burgos de 11 de Junio de 1515, decía a los Procuradores "que ya sabían cómo el Duque de Alba les había dicho de su parte, estando juntos en Cortes, que el Papa Julio, de buena memoria, le proveyó del reino de Navarra, por privación que del dicho reino $\mathrm{Su}$ Santidad hizo a los Reyes D. Juan de Labrit y Doña Catalina, su mujer, Rey y Reina que fueron del dicho reino de Navarra, que siguieron y ayudaron al dicho Rey Luis de Francia, que perseguía la Iglesia con armas y cisma, para que fuera de Su Alteza el dicho reino, e pudiere disponer del, en vida o en muerte a su voluntad" ${ }^{156}$.

155 Véase acerca del particular la notable monografía de D. Vicente de La Fuente sobre Palacios Rubios, en la Revista general de Legislación y Jurisprudencia de 1869.

156 Yanguas, Diccionario de antigüedades del reino de Navarra, tomo III, Pamplona, 1840, p. 260-267.

Palacios Rubios, que hizo valer este título en su citada obra De justitia et jure obtentionis Regni Navarrae, defendió la tesis siguiente: "Romanus Pontifex ... Reges et Principes, propter demerita, potest increpare, corrigere, castigare, et, si opus fueri, deponere, regnisque et dominiis privare”. 


\section{CAPÍTULO IV}

Importancia de la literatura teológico-política de nuestro siglo de oro.- Opiniones de los teólogos españoles del siglo XVI sobre la relación entre la Teología y el Derecho.- Razón de la extraordinaria influencia que ejercieron sus escritos.- Reseña de los que, así por este concepto, como por su valor intrínseco, han de ser objeto especial de nuestro examen: las Relectiones theologicae de Vitoria; el tratado De justitia et jure de Soto; obras de Castro y Simancas interesantes para el objeto; la Regalis institutio de Orozco; el libro De regis institutione de Osorio; el De justitia et jure de Molina; El Principe Cristiano de Rivadeneira; la Philosophia moral de Torres; el libro De rege de Mariana; obras de Suárez, Márquez y Santa María.- Escritos de Fox Morcillo y de Sepúlveda.

"La Teología, tal como se profesaba en los siglos XVI y XVII, no sólo era ciencia de Dios, sino ciencia de la razón y de la conciencia del hombre, y tanto entendían los que trataban de ella en la Sagrada Escritura, como en las leyes civiles, económicas o políticas, y aun en aquellas por las cuales o se regía o había de regirse en lo sucesivo el derecho de gentes; de manera que siendo los teólogos comúnmente filósofos y teólogos a la par en aquel tiempo, no puede negarse como tales muy particular atención a los españoles, ya que entre todos los del mundo predominaron, sin duda alguna, por la profundidad y extensión de su ingenio y doctrina"157. Nuestros teólogos del siglo de oro consideraban la teología a la manera que Cicerón la ciencia del derecho: como conocimiento de las cosas divinas y humanas y ciencia de lo justo y de lo injusto. De aquí la trascendencia de sus escritos bajo el aspecto que hemos de considerarlo y la huella imperecedera que han dejado en la historia de las ciencias jurídicas y sociales.

La misión y oficio de la teología son tan amplios, dice Francisco de Vitoria al comenzar su Relectio de potestate civili, que no hay asunto, investigación ni materia alguna que parezcan ajenos de la profesión y de la incumbencia del teólogo ${ }^{158}$. Al enumerar Melchor Cano, en su obra De locis theologicis, las ciencias auxiliares de la teología, encarece una y otra vez la importancia, no sólo del Derecho canónico, sino del civil, indicando de pasada la íntima

157 Cánovas del Castillo, De las ideas políticas de los españoles durante la Casa de Austria, en la Revista de España, IV, 1868, p. 500.

158 Relect. III, 1: Officium et munus theologi tam late patet, ut nullum argumentum, nulla disputatio, nullus locus alienus videatur a theologica professione et instituto. 
relación que existe entre el derecho y la filosofía ${ }^{159}$. Empleando términos análogos a los de Cano, vindica Domingo de Soto para el teólogo, en el Proemio de su tratado De justitia et jure, el derecho a disertar sobre materias jurídicas, fundándose en que la teología y la filosofía, ciencias familiares al teólogo de profesión, sirven de base al derecho canónico y al civil respectivamente ${ }^{160}$.

En consonancia con las ideas profesadas en este punto por tan ilustres hijos de la Orden de Santo Domingo, sostiene el franciscano Alfonso de Castro, que el investigar los fundamentos del derecho penal es incumbencia del teólogo tanto por lo menos como del jurisconsulto, y censura a los teólogos que, sin tomarse el trabajo de discurrir por cuenta propia en materias de esta índole, seguían ciegamente las opiniones de aquellos ${ }^{161}$.

Santiago de Simancas se esforzó por demostrar en un tratado ad hoc intitulado De episcopis iurisperitis la necesidad de que los Prelados uniesen los conocimientos jurídicos a los teológicos; y Mariana, abundando en esta misma idea, consideraba ser, sin duda alguna, aquellos que poseyeron ambas ciencias los más idóneos para el desempeño del cargo episcopal ${ }^{162}$.

Luis de Molina insiste muy especialmente sobre la conexión íntima entre el derecho y la teología al comienzo de su tratado De iustitia et iure ${ }^{163}$ y y el in-

159 Lib. X, cap. IX: ...Atque cum e sacra morum philosophia ius esse ortum civile constet, ut fontem, sic certe et rivulos theologus colet, ne parum sit in philosophiam ipsam religionis. Sane qui ius civile theologo negligendum putat, is bonam partem moralis philosophae revellit, cuius subsidium si quis illi neget de moribus disserenti, stultus esse videatur. Quia ergo saepe utitur theologos subsidio iuris in disputatione theologica, idcirco istam iuris scientiam theologiae tanquam ancillulam, pedisequamque adiuvari.

160 De pot. leg. poen., Proemiuin: Neque vero est, quod theologis vitio detur, hanc sibi assumere provinciam, quae iurisperitis accommodatior videri potest quando quidem canonica iura ex visceribus theologiae prodiere, civilia vero ex media morum philosophia Theologi ergo est iuris canonici decreta ad normam Evangelii exigere, philosophique ex principiis philosophicae examinare.

161 De potest. leg. poen., l. II cap. IX: Nostri theologi (ut quod de illis sentio candide loquar) iurisperitorum in hac parte sententiam legentes, illam sine ulla discussioue (ut ego suspicor) sunt sequti. Nam si rem hanc, quae ad illos, tamquam ad legis naturalis et divinae peritos, optimo jure spectabat, diligenter investigassent, et illius origines optime fuissent perscrutati, non dubito quin aliter sensissent.

162 De rege, lib. III, cap. II: Quod si cum iuris scientia theologiae cognitio conjungatur aut e contrario theologus ecclesiasticas leges teneat, ii maxime regendis ecclesiis idonei videntur, uti Abbas Panorniitanus cum aliis affirmat, et res ipsa nullo monstrante indicat.

163 "Cum enim theologi via et ratione, ex verisque principiis resintelligant, in quo longo intervallo iurisperitis superant, sane si eam Theologiae partem, quae de moribus 
mortal Suárez consagra enteramente el proemio de su obra De legibus et Deo legislatore a la demostración de esta misma tesis, encareciendo la competencia especialísima del teólogo para discurrir sobre materias jurídicas. "Nadie debe maravillarse" dice "de que los teólogos de profesión diserten sobre las leyes: pues la eminencia de la teología, derivada del sujeto eminentísimo sobre que versa, excluye todo motivo de admiración"164.

No cabe negar ciertamente la exactitud de las ideas de nuestros teólogos respecto a la misión y alcance de la teología y a su íntima conexión con la ciencia del derecho. Sólo quien considere como esferas independientes y autónomas la moral y el derecho, podrá sostener que los conceptos fundamentales del derecho y del Estado sean materias ajenas del dominio de la teología. Sólo quien rinda culto a esa tendencia, destructora de los fundamentos esenciales del orden social, podrá negar al teólogo y al filósofo el derecho a colaborar con el jurisconsulto de profesión en tan arduas y trascendentales investigaciones. No obstante las invasiones de las doctrinas positivistas en la ciencia del derecho y el favor de que tales doctrinas pueden ufanarse, especialmente entre muchos jurisconsultos contemporáneos dedicados al estudio de la ciencia penal, la inmensa mayoría de los hombres eminentes que cultivan la ciencia del derecho reconocen y proclaman la importancia capital del elemento ético en este orden y se muestran unánimes, a pesar de las diferencias esenciales que

disserit, copiose et pro dignitateet amplitudine obiecti, et facultatis theologiae tradiderimus ... nihil viro theologo deerit, quod ad Ecclesiae gubernationem et Reipublicae christianae utilitatem necessarium fuerit indicatum".

164 Nulli mirum videri debet, si homini theologiam profitenti leges incidant disputandae. Theologiae namque eminentia, ab eius subiecto eminentissimo derivata, omnem excludit rationem admirandi. Imo si res ipsa recta dispiciatur, palam erit, ita legum tractationem theologiae ambitu concludi, ut theologus subiectum eius exhaurire non valeat, nisi legibus considerandis immoretur... Theologia vero sub altiore ratione haec omnia complectitur; nam ius ipsum naturale con siderat, ut supernaturali ordini supponitur, et ab illo firmitatem maiorem accipit; leges vero civiles solum, vel ut de earum honestate ac rectitudine per altiores regulas diiudicet, vel ut obligationes conscientiae, quae ex illis oriuntur, iuxta principia fidei declaret: sacros autem canones, et Pontificum decreta, ut conscientiam ligant, et ad aeternam salutem dirigunt, tanquam sibi proprias recognoscit, et vindicat,. ac subinde in omnibus his legibus primariam originem, et ultimum finem sub divino lumine inquiret: quomodo scilicet a Deo ipso originem habeant, quatenus potest as ad illas ferendas in Deo primaria existit, et ab ipso ad homines aut naturali aut supernaturali via dimanet, et cum illis semper influat, et cooperetur. Ac denique declarat, quomodo leges omnes mensurae sint humanarum actionum in ordine ad conscientiam, et censequentur quantum ad meritum vel demeritum aeternae vitae conferant. 
en otras cuestiones los separan, en cuanto a la necesidad de informar en él los principios fundamentales de la ciencia de las leyes.

En una sociedad creyente, como lo era sin duda alguna, no obstante la laxitud de costumbres y su moral algo acomodaticia, la española de los siglos XVI y XVII, la teología tenía una importancia y trascendencia en la esfera política de que difícilmente podemos formar idea, por las radicales diferencias que de ella nos separan, en los tiempos actuales.

Diversas causas contribuyeron a que fuese más directa y eficaz la influencia de los teólogos en las esferas del gobierno y de la legislación. Por una parte, la costumbre de los Reyes de consultar a las personas más reputadas por su saber teológico todos los asuntos importantes cuya resolución podía implicar cargo de conciencia. Ejemplo de ello son, las hechas a Francisco de Vitoria sobre el bautismo de los indios, y a Melchor Cano, Domingo de Soto y otros sobre la guerra al Papa Paulo IV. Es de notar, además, que algunos de los teólogos más celebrados, desempeñaban, como Domingo de Soto respecto de Carlos V, el cargo de confesores de los Reyes, ejerciendo por este hecho influencia directa y constante sobre ellos. Conviene asimismo tener en cuenta, que muchas de las obras más importantes acerca del derecho público y del penal escritas por teólogos están dedicadas a los mismos Reyes; prueba evidente de que éstos miraban con interés tales publicaciones. Así el tratado De iusta haereticorum punitione de Alfonso de Castro está dedicada a Carlos V; el De iustitia et iure de Molina a Felipe III, y el De rege et Regis institutione de Mariana a este mismo Soberano. A él dirigió también su Tratado de Republica Fr. Juan de Santa María, y a Felipe II dedicaron sus obras Domingo de Soto, Alfonso Orozco y Simancas.

Manifiéstase la autoridad y el prestigio de los teólogos en el hecho de ser utilizados frecuentemente sus escritos y adoptadas de ordinario sus opiniones en las obras y comentarios de los jurisconsultos, quienes por razón de su oficio eran los que principal o exclusivamente entendían en la formación y aplicación de las leyes, viniendo los teólogos a ejercer de esta suerte una influencia mediata pero segura en las transformaciones del Derecho. Recuérdese, en confirmación de ello, el uso que hace Gregorio López, en su glosa a las Partidas, de las Relectiones de Vitoria, aun antes de ser vulgarizadas por la imprenta, las frecuentes referencias de Covarrubias y Vázquez Menchaca al tratado De iustitia et iure de Domingo de Soto, y las de los criminalistas a las obras de Castro y Simancas.

Al discurrir sobre el objeto de las normas jurídicas, nuestros teólogos ha- 
cían en algunos casos la crítica del derecho vigente, descubriendo sus defectos y preparando su reforma. El examen de la lex data les llevaba a disertar sobre la lex ferenda.

Una copiosísima erudición teológica, jurídica y clásica, fruto sazonado del estudio atento y asiduo de las fuentes de la erudición sagrada y profana, era patrimonio común de los teólogos y jurisconsultos de la época. Pasma verdaderamente el lujo de citas tomadas de los libros sagrados, de las leyes romanas y patrias, de los cánones conciliares y de las obras de los poetas y prosistas clásicos que esmaltan los escritos a que nos referimos. Es tal su riqueza en este punto, que, unida a las frecuentes referencias a opiniones de los teólogos y jurisconsultos de la Edad Media y de los comienzos de la moderna, convierte a veces sus escritos en un laberinto casi inextricable, a través del cual es en ocasiones difícil descubrir las opiniones personales del autor, entresacándolas del enorme fárrago de erudición en que se hallan envueltas.

La ciencia teológica y jurídica española de los siglos XVI y XVII se distingue además por su carácter esencialmente cosmopolita; así en el concepto de que sus cultivadores estuvieron abiertos a todas las corrientes de la vida intelectual de su época, como en el de que sus producciones eran leídas y utilizadas en todas partes, ejerciendo una influencia tan intensa como durable. Y esto no se explica solamente por el predominio político de España durante el primero de dichos siglos, bien que éste fuera, como ha sido siempre, auxiliar y vehículo poderoso para el caso. La asombrosa talla de nuestros teólogos, filósofos y jurisconsultos y la bondad intrínseca y superioridad incontestable de sus escritos nos dan la razón de esa prodigiosa influencia. ¿Qué nación podría presentar tantos y tan ilustres teólogos como Vitoria, los dos Sotos, Cano, Báñez, Suárez, Vázquez y Arriaga; canonistas como Antonio Agustín, Martín de Azpilcueta, Diego de Covarrubias, Barbosa, González Téllez y Sánchez; romanistas como Agustín y Covarrubias, Amaya, Retes y Ramos del Manzano?

Asombra verdaderamente la actividad científica de nuestros teólogos y jurisconsultos de los siglos XVI y XVII. Apenas se suscitaba una cuestión de importancia, acudían a tratarla con erudición y competencia, que aun hoy nos maravillan, hombres eminentes en considerable número. Alentábalos a ello la excelente costumbre de los Monarcas, a que antes hemos aludido, de asesorarse en los negocios graves de los sujetos más versados en la materia, a fin de autorizar su conducta con la aprobación de los doctos; prueba evidente de la gran estima en que era tenida la ciencia, así por las clases elevadas de la sociedad, como por los Monarcas y del deseo de acierto de estos últimos. 
¿Cuántas publicaciones, muchas de extraordinario valor científico, no suscitaron, por ejemplo, la cuestión del divorcio de Enrique VIII, consultada por Carlos V con las Universidades, la del derecho de los Reyes de España sobre los territorios descubiertos en América, y las controversias acerca del origen y las relaciones entre las potestades Pontificia y Episcopal?

Carácter común a todas las obras de los teólogos españoles de esta época, es servirles de punto de partida y de base en lo esencial la doctrina del Ángel de las Escuelas, restaurada y desarrollada en nuestras Universidades por la vigorosa y fecunda iniciativa de Francisco de Vitoria, a quien secundaron admirablemente en esta tarea no sólo sus colegas y discípulos de la Orden de Santo Domingo, sino también insignes teólogos de otras religiones, y sobre todo de la naciente Compañía de Jesús. Y en esto estriba precisamente una de las mayores excelencias de nuestra literatura teológico-política.

Séame lícito recordar a este propósito el homenaje de admiración recientemente tributado a la doctrina jurídica de Santo Tomás por el protestante Rodolfo de Jhering, uno de los más ilustres representantes de la ciencia jurídica contemporánea. Refiriéndose a un artículo publicado en la Revista católica el Indicador Bibliográfico sobre la primera edición de su obra El fin del Derecho, se expresa Jhering en los términos siguientes: "En el citado artículo se me demuestra con textos de Tomás de Aquino, que este poderoso entendimiento distinguió ya con toda exactitud, al tratar de la moral, el elemento práctico y realista y el elemento social. No puedo, en verdad, vindicarme de la nota de ignorancia que de aquí resulta contra mí, y que alcanza en grado incomparablemente mayor a los filósofos y teólogos protestantes modernos, que no se han cuidado de aprovechar en sus trabajos los grandiosos conceptos de aquel pensador. Discurriendo sobre esto, me pregunto con asombro: ¿Cómo es posible que tales verdades hayan pasado inadvertidas para nuestra ciencia protestante? (Jhering subraya estas palabras) iCuántos, extravíos habría evitado asimilándoselas! De mí puedo decir, que quizá no habría escrito este libro, a saber que las ideas fundamentales sobre que descansa habían sido ya formuladas en los términos más gráficos y con la mayor claridad por aquel genio poderoso. iOjalá que mi obra sirva para que la ciencia protestante utilice las enseñanzas que puede recibir de la teología católica; pues quien desaprovecha la que le proporciona su adversario a nadie perjudica más que a sí mismo! ${ }^{165}$

165 Jhering, Das Zweck im Recht, tom. II, 2. ${ }^{\text {a }}$ edición, Leipzig, 1886, pág. 161. Tomo la cita del Literarischer Handweiser de 1886. 
No incurrieron, por lo demás, nuestros teólogos del siglo de oro en el defecto, censurado con razón en la Escolástica decadente, de apego excesivo a la autoridad: nunca sacrificaron en sus aras los fueros de la propia razón. Vitoria, con ser tan entusiasta admirador del Ángel de las Escuelas, no vacila en separarse de él en más de una ocasión para sostener opiniones que considera más acertadas ${ }^{166}$; Melchor Cano encarece al teólogo que nunca se deje llevar ciegamente de la autoridad de los teólogos y filósofos cuyas obras estudia, pues que ninguno de ellos ha dejado de errar en algo ${ }^{167}$; y Alfonso de Castro combate en algunos puntos a San Agustín, expresándose respecto de él con un desenfado que raya en irrespetuoso ${ }^{168}$, y censura agriamente a los que seguían sin discernimiento las opiniones de Aristóteles.

Inaugura la serie de los escritos teológico-políticos de nuestro siglo de oro, que, así por su valor intrínseco, como por el prestigio de sus autores, son dignas de particular atención, las Relectiones theologicae ${ }^{169}$, de Francisco de Vitoria, obra de escasa mole, pero de precio inestimable, que señala el comienzo de una nueva era para los estudios de que tratamos. Pues, como reconocen todos sus contemporáneos, y este juicio lo confirma plenamente el examen de las Relectiones de Vitoria, de él data el renacimiento de dichos estudios en España, el favor general que alcanzaron, el método que en lo sucesivo se empleó en su exposición y enseñanza, y sobre todo la correlación entre los estudios teológicos y jurídicos, alianza feliz que tan favorable fue al progreso de la ciencia del derecho en Europa.

Mucho más comprensivo y no inferior en mérito a la obra de Vitoria es el libro De iustitia et iure ${ }^{170}$ de su compañero en el convento de San Esteban y en la Universidad de Salamanca, Domingo de Soto, dedicado al infeliz Principe Don Carlos; obra de sólida doctrina en que se hallan tratados fundamentalmente los más graves problemas del derecho y de la política.

Fueron tan grandes la autoridad y el prestigio de Soto y la estimación en

166 Relectio IX: Neque mihi per omnia placet etiam opinio S. Thomae recitata, neque possum ex sententia satisfacere dubiis emergentibus ex illa.

167 De locis theol., lib. X, cap. 5 .

168 De potest. leg. poen., lib. I, cap. 7.

169 Imprimiéronse por vez primera en Salamanca en 1550. La edición de que me he servido es la siguiente: Relectiones theologicae tredecim partibus per varias sectiones in duos libros divisa. Authore B. P. Francisco de Vitoria. Lyon, 1586.

170 Me he valido de la edición de Salamanca: Fratris Dominici Soto Segoviensis, theologi, ordinis Predicatorum, Cesareae Majestatis a sacris confessionibus, Salmantini professoris, De iustitia et iure libri decem. Salamanca, 1566. 
que lo tuvieron Carlos V, de quien fue confesor, y Felipe II, que no surgió en estos reinados cuestión importante de las que entonces se consideraban con razón, como de la competencia especial de los teólogos, que no le fuera consultada. La obra De iustitia et iure compartió con las Relectiones de Francisco de Vitoria el favor de los jurisconsultos de la época, en términos que apenas hay quien deje de utilizar ambas en sus escritos.

Para el estudio de las teorías cardinales del derecho penal, ofrecen extraordinaria importancia las obras De iusta haereticorum punitione (dedicada ésta al Emperador Carlos V) y De potestate legis poenalis ${ }^{171}$ del egregio franciscano y catedrático de Teología en Salamanca, Alfonso de Castro; de la primera de las cuales puede afirmarse sin exageración que forma época en los estudios a que se refiere.

Aparte del extraordinario interés que ofrecen desde nuestro punto de vista las dos citadas obras de Alfonso de Castro, lo tienen también muy grande para el estudio de la historia general de la época, por las noticias que proporcionan sobre muchos sucesos coetáneos y los pormenores interesantes acerca de la vida y escritos del Autor. Las frecuentes alusiones a opiniones y doctrinas contrarias a las sostenidas por él, y cuya refutación declara Castro haber sido una de las causas ocasionales de sus citados escritos, así como la predilección con que trata determinadas materias ${ }^{172}$, permiten conocer la existencia y la fuerza, que a no ser por esto no se sospecharían quizá, de doctrinas abiertamente contradictorias de las consignadas en las leyes y tan ardientemente propugnadas por Alfonso de Castro respecto a cuestión tan importante como la represión de la herejía y otras de este jaez. Su crítica, acertada por lo general, de las leyes y de las instituciones de España y de los Países Bajos, región esta última donde había residido bastante tiempo, es, a veces, sobremanera interesante e instructiva.

De gran importancia también, singularmente para el derecho penal y el

171 Imprimiéronse por vez primera en Salamanca en 1550 y 1556 respectivamente. La edición utilizada en esta Memoria es la incluida en el tomo II de sus Obras completas, Madrid, 1773, p. 1-458.

172 De justa haeretic. punit., lib. II, cap. 14: multos, variosque homines, qui se fideles Catholicos jactabant audivi, qui Caesarem ... improbe, atque irreligioso accusabant, dicentes rem minime christianam esse haereticos bello oppugnare; quia illi (ut dicebant) non armis, sed rationibus vincendi erant. Hac igitur occasione ego motus, decrevi hanc controversiam huic operae, quod jam ad umbilicum perduxeram, inserere, ut ostenderem toto (ut dicitur) errare coelo eos, qui ita sentiunt. 
eclesiástico, es el libro De catholicis institutionibus ${ }^{173}$ del prelado del siglo XVI, Santiago Simancas, teólogo y canonista muy familiar de Felipe II, de cuyo Consejo formó parte, a quien dedicó, tanto la obra mencionada, como otra intitulada De Republica ${ }^{174}$, publicada algunos años después. Aunque en esta última predomina el carácter compilatorio, deja conocer en algunos puntos las opiniones de Simancas, y en este concepto habremos de utilizarla en más de una ocasión. En la dedicatoria del libro De catholicis institutionibus, elogia Simancas el celo de Felipe II por extirpar a los herejes y dice que todos los Príncipes ortodoxos deberían imitar su conducta.

Carácter común a estos dos escritores, que imprime sello especial a sus obras, es haberse consagrado preferentemente a persuadir a nuestros Monarcas de que el castigo de los delitos contra la religión es el principal deber del Soberano.

El primero de los teólogos del período de que tratamos que, siguiendo la tradición de la Edad Media, escribió una obra especialmente dedicada a señalar al Príncipe los deberes propios de su oficio conforme a las normas de la moral cristiana, fue el religioso agustino Beato Alfonso Orozco, predicador de Felipe II y autor, entre otras varias, de la obra intitulada Regalis institutio ${ }^{175}$, repertorio de sentencias enlazadas por consideraciones originales de Orozco, las cuales dan a conocer sus ideas sobre la materia.

Digno de todo elogio y atención, por su originalidad, método y estilo, es el tratado de Jerónimo Osorio, Obispo de Silves, sobre la educación y deberes de los Reyes, dedicado al Rey Don Sebastián de Portugal ${ }^{176}$. Usa en él la forma

173 Jacobi Simancae Pacensis episcopi, De catholicis institutionibus liber, ad praecavendas et extirpandas haereses admodum necessarius. $2 .^{\mathrm{a}}$ ed. (la $1 .^{\mathrm{a}}$ es de 1552 ), Alcalá, 1569.

174 Jacobi Simancae Civitatensis Episcopi, iurisconsulti clarisimi. Collectaneorum de Republica libri novem. Opus studiosis omnibus utile, viris autem politicis necessarium. Valladolid, 1565 .

No hago mérito aquí de los Aphorismos sacados de los Anales de Tácito, por Arias Montano, obra de índole análoga a la de Simancas, porque más bien refleja las aficiones que las ideas propias del célebre escriturario, favorables al absolutismo monárquico. Véase sobre ella a Cánovas del Castillo, Ideas políticas, p. 544-546.

175 Regalis institutio ortodoxis omnibus, potissime Regibus et Principibus perutilis. Catholico regi Hispaniarum Philippo secundo dicata. Fratre Alphonso Orozco, Sancti doctoris Augustini instituto, Autore. Alcalá, 1565.

176 Hieronymi, Osorii, Lusitani, Episcopi Algarbensis, De regis institutione et disciplina libri octo. Colonia, 1574. 
dialogada; la acción se desarrolla en los huertos de Belém, cerca de Lisboa, y hacen oficio de interlocutores Lorenzo Pérez Tavora, Francisco Sala Meneses y Francisco Portugal.

La obra De iustitia et iure del jesuita Luis de Molina, cuyas dos primeras partes fueron impresas por primera vez en 1593 y la tercera en 1600, después de la muerte del Autor, ocurrida este último año, por el Colegio de Jesuitas de Madrid, consta de 760 disputationes o disertaciones sobre diversos asuntos de moral y de derecho. Según declara Molina, el estudio de Santo Tomás fue el que le animó, como a otros muchos, a tratar tales materias, considerándolas desde el punto de vista teológico y jurídico ${ }^{177}$.

Una de las cualidades que hacen a veces interesante y ameno el estudio de la obra, por otra parte farragosa e indigesta, de Molina, y que la distingue, como a las de Alfonso de Castro, respecto de casi todos los escritos de índole análoga, es la abundancia de referencias a las instituciones de España y Portugal, región esta última que le era también muy conocida, por haber residido allí, durante largos años, como catedrático de filosofía y de teología en Coimbra y Evora. De aquí la extraordinaria importancia del tratado de Molina como fuente de conocimiento de las ideas y de las costumbres españolas en la segunda mitad del siglo XVI. iCuánto detalle picante y curioso nos ofrecen los escritos de Alfonso de Castro y de Luis Molina sobre la sociedad española de aquel tiempo, que en vano se buscarían en otros lugares! ${ }^{178}$

El discípulo y compañero de San Ignacio de Loyola, Pedro de Rivadeneira, dedicó al "Príncipe de España Don Felipe nuestro Señor" (más tarde Felipe III) su "Tratado de la religión y virtudes que debe tener el Príncipe cristiano"179, sin disputa una de las más notables producciones de la literatura que nos ocupa, y que a pesar de su mérito no parece haber gozado entre los

177 Ludovici Molinae... De iustitia et iure, tomi sex. Anvers, 1615.

178 Es de advertir, por lo demás, que adolece de mucho desorden en la exposición. Así en la disp. 658 relativa, como todas las anteriores a contar desde la 576, a los mayorazgos, para resolver si los hijos del reo de lesa majestad deben ser excluidos de la sucesión del mayorazgo, pasando éste a los llamados por el fundador fuera de la línea directa diserta ampliamente sobre los delitos de lesa majestad y de herejía, exponiendo las doctrinas de Antonio Gómez, Julio Claro y Gregorio López y la legislación de Castilla y de Portugal acerca de la materia.

179 Tratado de la religión y virtudes que debe tener el Príncipe cristiano para governar y conservar sus Estados. Contra lo que Nicolás Maquiavelo y los políticos de este tiempo enseñan. Madrid, 1595. Incluyolo Don Vicente de Lafuente en las p. 449-587 del t. LX de la Bibl. de Aut. españoles. 
contemporáneos de mucha estimación. Merece ser notado, que, en la advertencia al "cristiano y piadoso lector", dice haberle puesto la pluma en la mano el afán por remediar los estragos causados por las obras de Maquiavelo, La Nue, Duplessis Mornay y Bodin, del último de los cuales, en especial, dice que sus libros gozaban de extraordinario favor entre nuestros hombres de Estado de aquel tiempo ${ }^{180}$.

Escasa atención merece, no obstante el favor verdaderamente extraordinario de que debió gozar en su tiempo, si ha de juzgarse por el número de las ediciones que llegó a tener en muy pocos años, la Philosophia moral de Principes del jesuita Fr. Juan de Torres, impresa en Madrid el año 1596 y dedicada al Marqués de Velada, ayo del Príncipe Don Felipe. Libro voluminoso y farragosísimo, de muy poca originalidad, serie interminable de máximas y avisos tomados de la Sagrada Escritura, de los Santos Padres y de los filósofos de la antigüedad, dirigido a inculcar en el ánimo de los Príncipes los deberes propios de su cargo.

La obra De Rege et Regis institutione ${ }^{181}$ del jesuita Juan de Mariana, dedicada a Felipe III, no obstante su escasa originalidad, pues el fondo esencial se encuentra en las producciones anteriores de este género, ha debido el ser la más conocida, así a la brillantez de su estilo como a la censura de que fue objeto su doctrina del tiranicidio por parte de la Sorbona, y en virtud de la cual fue quemado pública y solemnemente un ejemplar de ella en París de orden de Enrique IV.

Cierra la serie de los insignes teólogos españoles que consagraron preferente atención al estudio de los fundamentos de la moral y del derecho (pues los que vinieron después no pueden compararse en importancia con los citados hasta ahora), el genio asombroso a quien sus contemporáneos calificaron de "Doctor eximio" y sus adversarios protestantes de Papa Metaphysicorum et Anchora Papistarum. En el tratado De legibus et Deo legislatore ${ }^{182}$, legó

180 En el cap. 11 de la Vida del P. Pedro de Rivadeneira, de la Compañía de Jesús, escrita por él mismo y añadida por su compañero el Hermano Cristóbal López en el año 1612 (Mss. que me ha facilitado mi amigo Don José del Ojo) se dice: "El libro del Príncipe cristiano que escribió nunca tuvo tanta alabanza ni fue tan estimado como él merece: espanta a los mayores hombres de Estado lo que allí trata y cómo lo trata”.

181 Joannis Marianae Hispani, e Soc. Jesu, De Rege et Regis institutione, libri III. Toledo, 1599. Recientemente se ha enriquecido nuestra literatura con una buena monografía sobre las doctrinas políticas de Mariana: el libro del jesuita P. Garzón, intitulado El Padre Juan de Mariana y las Escuelas liberales. Madrid, 1889.

182 Tractatus de legibus ac Deo legislatore in decem libros distributus. Auctore 
Suárez a la posteridad un monumento grandioso ante el cual toda ponderación es mezquina o insuficiente. Aunque de menos importancia, su Defensio fidei catholicae ${ }^{183}$, es también de sumo interés para conocer las opiniones del incomparable jesuita granadino sobre algunas materias que han de ser objeto de nuestro estudio.

El Governador cristiano deducido de las vidas de Moisés y Josué184, publicado en 1612 por el fraile agustino Juan de Márquez, catedrático de vísperas de teología en Salamanca, es, como se ha dicho con acierto, "la expresión más exacta y completa que puede hallarse en cierta escuela templada o media, entre las extremas de los políticos castellanos de los siglos XVI y XVII ${ }^{185}$.

Escribió el P. Márquez este libro a ruego del duque de Feria, según consta en carta de este magnate, fechada en Mesina a 11 de Junio de 1604 y que antecede al Prólogo del Autor. "No fue el assumpto del duque" dice éste "mandarme escribir contra Machiabello; cosa que en esta edad han hecho tantos, y pudieran aver escusado algunos; porque, como el señor Condestable de Castilla dixo a la Santidad del Papa Clemente VIII, tomando tantas armas contra él, le han hecho más nombrado de lo que debieran".

Utilizando en gran escala los trabajos de sus predecesores, como lo demuestran las numerosas citas que acompañan a todos los capítulos de su obra, verdadera suma de la ciencia teológico-política del siglo XVI, meritoria en alto grado aún bajo este sólo concepto, supo además el P. Márquez ser original en algunos puntos y dar novedad e interés a muchas de las cuestiones, revelando al tratarlas serenidad y elevación que no eran ya comunes en su tiempo.

Es también estimable el tratado de República y Policía cristiana del fraile descalzo Fr. Juan de Santa María, dedicada a Felipe III, obra que, a pesar de

Francisco Suárez, e Societate Jesu, in Conimbricense Academia sacrae theologiae primario professore. Coimbra, 1613. - He utilizado la edición de Nápoles de 1872.

183 Defensio fidei catholicae et apostolicae adversus Anglicanae sectae errores. Coimbra, 1613 .

184 La edición de que me he servido es la siguiente: El Governador christiano deducido de las vidas de Moysen y Josué, príncipes del pueblo de Dios, por el Maestro Fr. Juan Márquez, de la orden de San Agustín, Predicador de la Majestad del Rey Don Felipe III, Catedrático de vísperas de theologia de la Universidad de Salamanca. Cuarta impression, aumentada en differentes partes con extensión de la doctrina y nuevas cuestiones. Madrid, 1640 .

185 Cánovas del Castillo, Op. cit., p. 554-555 y 561-566, donde nota la concordancia de Márquez con Soto y Suárez en las cuestiones fundamentales. 
lo general de su título, versa casi exclusivamente sobre las cualidades y deberes de los Reyes y sus ministros. En la importancia que da a la materia de los privados, dedicándole ocho nada menos de los treinta y ocho capítulos del libro, muéstrase bien a las claras la importancia e interés de actualidad del asunto $^{186}$.

Los únicos filósofos españoles de la época a que nos referimos que escribieron de propósito sobre materias de derecho público fueron el insigne sevillano comentador de Aristóteles y Platón, Sebastián Fox Morcillo, y el célebre humanista cordobés y furibundo aristotélico Juan Ginés de Sepúlveda. El libro De regni regisque institutione ${ }^{187}$ del primero, notable, no menos que por la elevación de las ideas, por la sobriedad y elegancia del estilo, es digno de especial y detenido estudio. En carta dedicatoria dirigida al duque de Medinaceli, expone Fox el plan de la obra ${ }^{188}$, haciendo de paso un gran elogio de Felipe II, a la sazón reinante. Figura el escrito de que tratamos un diálogo cuyos interlocutores son: Aurelio, defensor de la monarquía; Antonio, que lo es de la república, y Lucio, indiferente en materia de formas de gobierno, y que es quien ofrece a ambos ocasión de discutir.

Con verdad se ha dicho de Fox Morcillo que "no tuvo entre los filósofos españoles de su tiempo iguales, ni dejó tampoco quien siguiese su ejemplo en esto de aplicar el poder de la razón, fortificada por el estudio profundo de la madre de las ciencias, al análisis y exposición de las cuestiones políticas ${ }^{189}$.

El propósito de nuestro filósofo, claramente manifestado en el Prólogo, "fue exponer el ideal del Príncipe óptimo, y la manera cómo habían de gobernarse el Reino y el Rey, no siguiendo para esto a los escritores antiguos (que traen muchas cosas sobre el particular en que no debe pararse atención, como ajenas del uso común e incompatibles con nuestros tiempos), sino cual conviene a los presentes, a cuyo bien se enderezan nuestros estudios y desvelos".

No es esta obra la única en que pueden estudiarse las ideas de Fox Morcillo en orden al derecho y la política. Algún interés ofrece también bajo este aspecto su Tratado de Ética según las doctrinas de Platón, Aristóteles y otros filósofos, reflejo en muchos puntos de opiniones personales del Autor, y no

186 Tratado de República y Policía christiana para reyes y Príncipes, y para los que en el govierno tienen sus veces. Madrid, 1615.

187 Sebast. Foxii Morcilli, Hispalensis, De regni, regisque institutione, libri III. Ad illustrissimum Principem D. Joannem Cerdam, Metimne coeli ducem. Antuerpiae, MDLVI.

188 Haec omnia sic disseruntur, ut constituto Philippo rege, quem ego unum ex praestantissimis, quos vidit unquam Hispania, judico...

189 Cánovas del Castillo, op. cit., pág. 541. 
mera compilación de sentencias de otros, como podría quizá creerse por el título ${ }^{190}$.

Muy inferior a la obra primeramente citada de Fox Morcillo en originalidad, mérito y extensión, es el libro De regno et regis officio de Juan Ginés de Sepúlveda, dedicado a Felipe II. Además de exponer en él una y otra vez, casi siempre con evidente inoportunidad, sus teorías favoritas sobre la esclavitud natural según Aristóteles, diserta Sepúlveda sobre las formas de gobierno, siguiendo de ordinario a dicho filósofo, sobre la diferencia entre el Rey digno de tal nombre y el tirano, y la educación y deberes de los Príncipes ${ }^{191}$.

A contar desde mediados del siglo XVII, la decadencia de los estudios teológicos, el escaso favor de los teólogos de profesión en las altas esferas del gobierno y el divorcio entre la teología y la jurisprudencia, originan la decadencia de la literatura, cuyas producciones han de ser asunto preferente de nuestro examen.

190 Ethices. Philosophiae compendium, ex Platone, Aristotele, aliisque optimis quibusque auctoribus collectum a Sebastiano Foxo Morcillo, Hispalensi; Basilea, 1554.

191 La primera edición se hizo en Lérida en 1580. Al publicar la Real Academia de la Historia, a fines del siglo pasado, las obras completas de Sepúlveda, incluyó este tratado en el tom. IV, Madrid, 1780, páginas 97-161. 


\section{CAPÍTULO V}

Imposibilidad de reconstruir un sistema completo de Derecho público con los escritos teológicos y filosóficos de este periodo.- Teorías sobre el origen de la sociedad y del poder.- Las formas de gobierno.- Sucesión a la corona.- Oposición a la teoría cesarista del Princeps legibus solutus.- Subordinación del interés del Rey al de la nación.- Parecer de Vitoria contra la venta de los oficios públicos.- Opinión de Soto sobre la potestad de los Reyes cristianos en la hacienda de los judíos y sarracenos. - Intervención del pueblo en la redacción de las leyes y en la imposición de tributos.- El Consejo Real.- Teorías de nuestros teólogos acerca de la resistencia al poder público y al tiranicidio.- Opiniones de Márquez y Ginés de Sepúlveda sobre la materia.- Influencia ejercida por nuestros teólogos y filósofos en el orden político.

No esperemos reconstruir, con ayuda de los escritos de nuestros teólogos y filósofos, el cuadro completo del derecho público. Limítanse de ordinario a establecer los conceptos fundamentales sobre el origen de la sociedad y del poder, a fijar las normas esenciales e inmutables a que debe acomodarse el ejercicio de este último. Rara vez descienden a precisar cuáles deban ser la participación del pueblo en el gobierno, las instituciones más apropiadas a este fin, la esfera en que haya de moverse la acción del Estado; cuáles los objetivos de una política previsora y fecunda. La insuficiencia, unas veces, y otras la vaguedad de que adolecen en este punto hacen sobremanera difícil en muchos casos determinar la influencia que las teorías generales consignadas en sus escritos vinieron a ejercer, por vía de derivación o corolario, en las normas del derecho positivo. En este punto, habremos de limitarnos necesariamente a consignar el resultado esencial que se desprende del estudio comparativo de las instituciones políticas y de las opiniones defendidas por nuestros teólogos y filósofos en las cuestiones fundamentales.

Comencemos por bosquejar sus teorías acerca del origen de la sociedad política y del poder público.

La sociedad civil es el resultado necesario de la tendencia natural del hombre a la sociabilidad. Las agrupaciones humanas, consideradas, no como aglomeración mecánica de individuos, sino como cuerpos políticos, han menester de una autoridad que las dirija para la consecución del fin común; y esta autoridad, que procede de $\operatorname{Dios}^{192}$, radica originariamente por derecho

192 Véase sobre el particular la explicación magistral de Suárez, De legibus, l. III, c. III, n. 5: ...dico primo hanc potestatem dari a Deo per modum proprietatis consequentis 
natural en la sociedad misma o cuerpo político, el cual, no pudiendo ejercitarlo por sí, lo confiere a una o varias personas. La potestad política en concreto y la obediencia que le es debida tienen su fundamento en el acuerdo de la sociedad civil y no proceden inmediatamente de $\operatorname{Dios}^{193}$. Conforme a esto, no consideraban como legítimo otro poder sino el emanado del consentimiento tácito o expreso de la sociedad ${ }^{194}$, en quien originariamente radicó la potestad suprema ${ }^{195} \mathrm{y}$ la cual pudo elegir a su arbitrio la forma política con que quería gobernarse ${ }^{196}$. El pueblo, al transmitir la potestad, es enteramente libre para conferir la plenitud de ella o reservarse una parte de los derechos que la constituyen ${ }^{197}$.

Los dos factores esenciales de esta teoría ${ }^{198}$, el pueblo como primitivo depositario del poder emanado de Dios, y la transmisión de éste por el pueblo a la autoridad pública, proceden del derecho romano y fueron aceptados con algunas modificaciones por los publicistas de la Edad Media, así teólogos como jurisconsultos. Su punto de partida fue el tan conocido texto de Ulpiano ${ }^{199}$ : "quod principi placuit legis habet vigorem, utpote cum lege regia, quae de im-

naturam ... nimirum medio dictamine rationis naturalis ostendentis, Deum sufficienter providisse humano generi, et consequentur illi dedisse potestatem ad suam conservationem et convenientem gubernationem necessariam.

193 Defensio fidei, 1. III, c. II: ..."regium Principatum et obedientiam illi debitam fundamentum habere in pacto societatis humanae ...; non esse ex immediata institutione Dei...”

194 Vitoria, Relect., III, n. 7 y 8; Soto, I, q. 1 , a. 3 y IV, q. 4, a. 1; Molina, II, disp. 23; Suárez, De leg., III, c. IV.

195 Vitoria, Relect., III, n. 7; Molina, II, disp. 22; Suárez, III, c. 2 y 3.

196 Vitoria, Relect., III, n. 15; Soto, IV, q. 4, a. 1; Molina, II, disp. 23; Suárez, III, c. III, n. 8 y c. IV.

197 Tratan especialmente este punto Molina, II, disp. 23 y Suárez III, c. V, n. 5 y c. XIX, n. 6 y IV, c. XVII, n. 4. Suárez, a diferencia del primero, juzga más perfecta forma de gobierno aquella en que el Monarca no está obligado a dar intervención al pueblo en el ejercicio del poder legislativo.

198 Los fundamentos de ella son idénticos en todos los teólogos importantes del siglo XVI. Véase a Vitoria, Relect. I, q. 5, n. 8 y III passim; Castro, De potest. leg.poen. 1. 1; Soto, I, q. 1, a. 3 y IV, q. 4, a. 1 y 2; Suárez, III, c. I, n. 4; Mariana, De rege, I, c. X; Molina, II, disp. 21 a 31 que se limitaron en esta materia a exponer y desarrollar en algún punto la doctrina tomista. Basta para convencerse de ello comparar el bosquejo que damos en el texto con el magistral resumen de las teorías políticas del Ángel de las Escuelas en el Santo Tomás de Aquino de Alejandro Pidal, p. 159 y siguientes.

199 Instit. De Justiniano, I, 4, §1. 
perio ejus lata est, populus ei et in eum omne suum imperium et potestatem conferat". En virtud de la tendencia de la Edad Media a convertir en axiomas aplicables a todos los tiempos y naciones, teorías y hechos pertenecientes a otros períodos históricos, vino a convertirse el principio de derecho público romano consignado por Ulpiano en base de las teorías respecto al origen y transmisión del poder, con la sola modificación de considerarlo en su origen como emanado de Dios. Enlazose también con el texto citado de Ulpiano la controversia de si el pueblo, al transmitir el poder, lo había hecho de una manera irrevocable o si sólo lo había delegado y podía revocarlo a su arbitrio. Las opuestas soluciones que, andando el tiempo, vinieron a darse a la cuestión que nos ocupa engendraron, por una parte, las teorías absolutistas, que consideraban vinculado ya a perpetuidad y de una manera omnímoda el poder en la persona del Soberano, y, por otra, las teorías más o menos revolucionarias, que entendían haberse reservado el pueblo en todo caso la facultad de revocar los poderes conferidos al jefe del Estado y de modificar la forma de gobierno.

No obstante ciertas analogías aparentes, que engañan al que no va al fondo de las cosas, separan diferencias esenciales a los defensores de la teoría de la soberanía del pueblo y a nuestros teólogos en la materia de que tratamos. Para éstos, el poder procede de Dios, para aquéllos, de los hombres; según éstos, Dios lo transmite a la sociedad; según aquéllos, los hombres al asociarse voluntariamente convienen en crearlo; según éstos, la sociedad lo transmite al jefe del Estado necesariamente, por virtud de una ley natural y divina; según aquéllos, libremente, en virtud de un contrato. Del mismo modo que Aristóteles y los teólogos, Fox Morcillo deriva la sociedad civil de la natural tendencia del hombre a vivir en común con sus semejantes. De ella surgió también la idea de cierto orden necesario para la coexistencia social, que vino a concretarse en una organización política o forma de gobierno, la cual, ruda en sus comienzos, fue perfeccionándose paulatinamente, en armonía con las costumbres y el carácter de cada pueblo y territorio ${ }^{200}$.

$\mathrm{Al}$ discurrir sobre las formas de gobierno, el método seguido casi constantemente por nuestros tratadistas, así teólogos como filósofos, es exponer la división tradicional establecida por Aristóteles, a quien siguen también al reseñar las ventajas e inconvenientes de cada una, y decidirse al fin por la monarquía, no obstante reconocer que ésta es más ocasionada que las demás

200 De regni... lib. I.: "quod hominibus disociatis adhuc et vagis, atque unum in locum coeuntibus, appetitu societatis nativo ... iidem continuo aliquem ordinem, qui omnis est multitudinis necesarius, adhibendum cognovere ...” 
formas de gobierno a degenerar en tiranía. Es tal en lo que a estas materias se refiere la uniformidad que se observa en los escritos de nuestros teólogos y filósofos, que no he creído necesario reproducir sus opiniones; limitándome a mencionar las de Mariana y Fox Morcillo, que discrepan en puntos esenciales de la doctrina general y corriente.

Mostrose Mariana resuelto partidario de la monarquía, al exponer y quilatar con su habitual elocuencia las ventajas o inconvenientes de las diversas formas políticas ${ }^{201}$, pues aunque no se disimula los peligros inherentes a ella y especialmente el de que degenere en tiranía, hállalos compensados por mayores ventajas. Pero su ideal no es la monarquía absoluta ni la electiva, sino la representativa y hereditaria, mitigada, no sólo por el respeto a los eternos principios de la moral y del derecho, sino también por la intervención directa y eficaz del pueblo en la gobernación del Estado, manifestada en la institución de las Cortes y en la facultad inalienable que les reconoce de compartir con el Soberano el ejercicio del poder legislativo y de ser exclusiva competencia de ellas la determinación de los impuestos.

Fox Morcillo, que después de discurrir ampliamente sobre las diversas formas de gobierno en el tratado De regni regisque institutione, declara su preferencia por la monarquía hereditaria ${ }^{202}$, manifiesta cierta indiferencia sobre el particular en el capítulo de la Ethices relativo al asunto ${ }^{203}$. Observa a este propósito que, así como los pueblos atrasados se avienen bien con la forma monárquica, los más civilizados, por el contrario, prefieren la oligárquica o democrática, citando como ejemplos de lo primero a los indios, persas egipcios, y de lo segundo a los griegos y romanos. Lo esencial, dice en otro lugar, es la bondad y prudencia de los magistrados; pues el ser más perfecta una república no estriba en el número de sus gobernantes, sino en la manera de gobernar ${ }^{204}$.

Que las opiniones favorables a la República, en consonancia con las ideas defendidas por el agustino Castrillo, no eran tan peregrinas como pudiera creerse entre los españoles del siglo XVI, se infiere a mi ver con evidencia, así de la misma predilección con que la mayoría de los tratadistas de política

201 De rege, l. I, c. II a XI ...: "unius principatum caeteris omnibus reipublicae formis esse praeferendum..."

202 L. III Aa. 2 v. ${ }^{0}$

203 Ethices, lib. III, c. IX, p. 126-127: ...esse autem debere ver regem vel senatum vel populum, eum qui huius rei curam gerat, adhuc in dubitationem cadit.

204 Etices, l. III, c. IX. 
se aplican a tratar de las excelencias de la monarquía, comparándola con las demás formas de gobierno, como de las alusiones que a veces se encuentran entre ellos a la existencia de contrarias opiniones a las suyas en este punto. No debió contribuir poco a hacerlas germinar en algunos, la consideración del alto grado de prosperidad que habían alcanzado en la Edad Media y alcanzaban aún algunas Repúblicas, como las de Génova y Venecia, y el haber visto funcionar de cerca las instituciones republicanas en algunos de estos Estados, por efecto del cosmopolitismo característico de los españoles de aquella edad $^{205}$.

El único de nuestros teólogos que encuentro haber tratado exprofeso de la sucesión a la corona, que es el P. Márquez, aunque pondera los inconvenientes que suelen seguirse de que las mujeres ocupen el trono, declara que debía reconocérseles este derecho allí donde había sido consignado en las leyes ${ }^{206}$. No se disimula, por lo demás, este grave y juicioso escritor los obstáculos que la debilidad del sexo y la consiguiente imposibilidad de ejercer por sí mismas algunos de los oficios propios de la potestad real oponen de ordinario a las Reinas, según acredita la historia.

Es muy de notar, por su singularidad, la opinión de Fox Morcillo favorable a la deposición del Soberano por causa de incapacidad. Si el Príncipe carece de entendimiento, de juicio y de las demás dotes de prudencia necesarias para el buen desempeño de su oficio, nada impide privarle de la soberanía por inútil a sí mismo y a la república, del mismo modo que las leyes romanas quitaban al particular demente el gobierno de su casa y familia ${ }^{207}$. No desciende, sin embargo, nuestro filósofo a la cuestión del modo y forma como había de ser privado del trono el Rey incapaz.

Mientras el absolutismo monárquico hallaba en Francia, bajo el reinado de Francisco I, ardientes defensores en los escritos de Feraud y Grassailles, eco fiel de las doctrinas dominantes en la Universidad de París, y en las altas

205 A esta última causa atribuye Fox Morcillo, en el libro I de su tratado De regni..., la predilección de Aurelio por la República.

206 L. I, c. XXXII: "me parece que pudieron ser excluidas de los Reynos con mayor fundamento que de otras cosas ... 'por más que' no se puede negar que ha avido mugeres tan valerosas, que han mostrado con el hecho que no son incapaces de govierno, sino muy bastantes para él”. Cita en confirmación de esto a la Reina Católica.

207 De regni..., lib. II: "Si ingenium, si iudicium, si cetera naturae ornamenta prudentiae necessaria principi desint, nihil obstat, quominus idem publica cura privetur, tanquam inutilis sibi et reipublicae: cum rei quaque domesticae procuratio privato homini, ob insaniam, legibus Romanorum adimatur”. 
esferas de la magistratura ${ }^{208}$, y, bajo Enrique IV, privaba aún la doctrina de la no sujeción del Príncipe a las leyes ${ }^{209}$, en España prevalecía casi sin contradicción el principio aceptado por el derecho canónico, Principes tenentur et ipsi vivere legibus suis, formulado ya tan explícitamente por San Isidoro, en oposición directa con el concepto absolutista del derecho romano, Princeps legibus solutus. Nuestros teólogos y juristas más ilustres, de acuerdo con el derecho canónico, defendieron la subordinación del Príncipe a las leyes.

Así, Vitoria sostiene resueltamente ser más cierta y probable la opinión según la cual las leyes civiles obligan a los legisladores y en especial a los Reyes, que la opinión contraria, defendiendo su tesis con eficacísimos argumentos $^{210}$. Considera el ilustre dominico, que el legislador injuria a la república y a los demás ciudadanos si, siendo como es miembro de la misma república, no tiene también su parte de carga, bien que conforme a la calidad y dignidad de su persona. Las leyes dictadas por el Rey, añade, tienen la misma eficacia que si se dictaran por toda la república, y así como estas últimas obligan a todos los ciudadanos, así las dictadas por el Rey obligan también a éste. Como en el gobierno aristocrático los senadoconsultos obligan a los mismos senadores, autores de ellos, y en el gobierno democrático los plebiscitos obligan al pueblo que los dicta, del mismo modo las leyes reales obligan al mismo Rey, y aunque sea potestativo en éste el dictar la ley, no lo es el obligarse o no a cumplirla. Sucede en esto como en los pactos: las partes son libres de pactar o no; pero una vez hecho el pacto, quedan obligadas.

Osorio hace estribar la diferencia entre el Rey verdaderamente digno de este nombre y el tirano, en que el primero se reconoce ligado a las leyes, y el segundo desligado de ellas ${ }^{211} ;$ y juzga más estrecha que la que incumbe a los demás ciudadanos, la obligación del soberano de cumplir las leyes.

Con enérgica elocuencia truena Mariana contra la teoría cesarista del Princeps legibus solutus y sus abyectos defensores, afirmando en los térmi-

208 Hanotaux, Études historiques sur le XVI et le XVII ${ }^{e}$ siècle en France, París, 1886, p. 9-11.

209 Ibid., p. 141.

210 Vitoria. Relect. II, 8. "Quaeritur tandem an leges civiles obligent legislatores et maxime reges. Videtur enim aliquibus quod non, cum sit supra totam Rempublicam, et nullus possit obligari nisi a superiori; sed certius et probabilius est, quod obligentur".

211 De regno, p. 85. "Ne legibus quidem se solutus existimabit: imo multo arctioribus vinculis quam ceteros se alligatum reputabit ... Hoc enim etiam non mediocre discrimen est inter Regem atque tyrannum; quod Rex se devinctum esse legibus profitetur: Tyrannus vero in interitu legum omnem dignitatem suam collocandam existimat”. 
nos más explícitos la obligación común a Príncipes y pueblos de respetar las normas del derecho natural, así como las consignadas en las leyes fundamentales del Estado ${ }^{212}$.

Conformes de todo punto con esta doctrina, nuestros más ilustres jurisconsultos del siglo XVI, así canonistas como civilistas, ponen como límite a la autoridad legislativa del Soberano las normas inmutables del derecho natural y lo sujetan a las leyes positivas ${ }^{213}$.

Quevedo formula también con claridad el principio de la sumisión de los Reyes a los preceptos del derecho positivo ${ }^{214}$. Igualmente explícito se muestra en este punto el filósofo Fox Morcillo: "No es dudoso" dice "que el Rey está obligado a la observancia de las leyes como todos los demás ciudadanos". Pues, aun cuando, en cierto sentido, prosigue poco después: "en cuanto dicta, sanciona y robustece con su autoridad las leyes se diga que es superior a ellas como su autory defensor, en cuanto está obligado a conformarse a lo que preceptúan, está sujeto a ellas y les es inferior" ${ }^{215}$.

Nuestros teólogos sostienen unánimemente que la ley humana debe conformarse a la divina y a la natural, cuyos preceptos inmutables son pauta y límite a un tiempo del derecho humano positivo ${ }^{216}$. Alfonso de Castro impug-

212 De rege, l. II, c. 11, y en otro lugar dice: "Constricto legibus principatu nihil est melius; soluto milla pestis es gravior. Quidam consulti legi subiectum principem negant quod ejus arbitrio, authoritateque leges ferantur: eum tamen secundum leges vivere volunt. Servari a principe leges debere, constat jam aeque apud omnes; esse vero ipsum tum legem superiorem, tum inferiorem, sic est intelligendum, ut eo, quod leges ferat sanciat, et authoritate sua firmet, inferior eis dicatur tanquam earum author, et vindex: eo tamen, quod ex earumdem praescripto vivat, subiectus sit atque inferior”. Cf. Santa María, c. I.

213 Véase, en confirmación de ello, al grave Covarrubias, I, c. 1 y 4: "id quod contra rationem naturalem statutum est, non potest firmum esse nec validum, etiamsi a príncipe supremo statuatur"; y especialmente a Vázquez Menchaca, caps. 4 y 5, 18, 21, 26 y 45. Este último no sólo combatió acérrimamente el aforismo cesarista, Princeps legibus solutus est, sino que sostenía estar ligado el Príncipe no sólo por la ley natural, sino también por la civil.

214 Política de Dios y Gobierno de Cristo, edición publicada por D. Aureliano Fernández Guerra. Parte II. Madrid, 1868, cap. XVI, pág. 222: Obedecer deben los Reyes a las obligaciones de su oficio, a la razón, a las leyes, a los consejos, y han de ser inobedientes a la maña, a la ambición, a la ira, a los vicios.

215 De regni, etc., II: Legum observationem ad regem pertinere sicuti ad reliquos item cives, dubium non est. Cf. Suárez, De leg., III, 35.

216 Vitoria. Relect. II, 7; Soto I, q. 5 y IV, q. 3, a. 1; Castro, De potest. leg. poen., l. I, c. V; Molina, tract. V, disp. 47 y 69; Suárez, De leg., l. I-II y III, 34; Quevedo, Política de Dios. Parte II, cap. VI. 
nó directa y enérgicamente el aforismo cesarista, sosteniendo que sólo las leyes justas obligan en conciencia ${ }^{217}$. En términos análogos se expresa Suárez, al discurrir sobre las normas a que debe acomodarse el ejercicio del poder legislativo ${ }^{218}$.

La subordinación del interés particular del Rey, o mejor dicho, de la potestad política, sea cualquiera la forma en que se concrete o actúe, al interés general, formulada ya por el Escolasticismo de la Edad Media en la frase Regnum non est propter Regem, sed Rex propter Regnum ${ }^{219}$ se encuentra consignada en todos nuestros escritores, así teólogos como filósofos, contestes en considerar la desviación de este principio como rasgo que diferencia esencialmente el gobierno legítimo de la tiranía ${ }^{220}$. Declaración que tenía su mérito y su importancia, por más que hoy nos parezca encerrar una verdad axiomática, si se considera que hacia el mismo tiempo defendían escritores extranjeros la tesis contraria. Fox Morcillo juzga que el Soberano debe subordinarlo todo al bien del Estado, entendiendo que no ejercita el poder por derecho propio, sino en concepto de administrador o delegado: $y$ formulando más en concreto la idea, dice que "los Reyes no son señores o poseedores de los reinos, sino como clientes y súbditos de la República" ${ }^{21}$. Con vigor y elocuencia dignos de encomio, impugna el ilustre filósofo sevillano el carácter patrimonial atribuido a la monarquía por algunos escritores.

En su Parecer sobre si los Señores podían vender o arrendar las escribanías y alguacilazgos, sostiene Vitoria que el Rey no tiene derecho para poner en almoneda los cargos, ni oficios públicos, pues, siendo obligación suya nombrar personas idóneas para que desempeñen tales cargos, no debe exigir por ello derecho ni emolumento alguno, fuera de los que le corresponden por

217 De potest. leg. poen., l. I, c. V.: "Quod autem dicitur in C. I. ff. Constitutionibus Principum, quod Principi placuit, legis habet vigorem intelligendum est, et justa adsit voluntatis causa; alias sola voluntas Principis sine causa legitima non poterit aliquem in conscientia obligare".

218 De leg., l. III, c. XXXIV, y I, c. IX.

219 Santo Tomás, De regim. Princ., l. III, c. II.-Cf. Aristóteles, Pol., l. V. c. 11.

220 Suárez, De leg., l. I, c. VII: in hoc differt tyraunum a Rege, quod ille propriam, hic communem utilitatem in suo regimine quaerit.-Cf. Mariana, De mut. mon., c. I.

221 De regni..., l. I. "Itaque quoniam ipse (Princeps) personam communitatis sustinet, atque ad ejusdem utilitatem honestatemque, quod est reipublicae finis, referre omnia debet, sic se comparabit, ut e reipublicae commodo vivat, cum sui ipse iuris non sit, sed quasi administer quidam civitatis. Reges enim non sunt regnorum domini aut possessores, sed velut clientes ac subditi universae reipublicae". 
el señorío y gobierno. "Demandar más, sería evidente injusticia y querer ser pagado dos veces. Aparte de que pedir estipendio a los oficiales a cargo de los emolumentos que han de percibir, es defraudarles lo suyo, pues que el cargo lo desempeñan ellos y no el Príncipe ni el señor. Allégase a esto, dice Vitoria, que de la tal vendición de oficios se seguirían graves inconvenientes para la policía humana, que los pobres temerosos de Dios doctos y hábiles serían excluidos de ellos, por no tener con qué comprarlos, y quedarían ociosos los talentos que Dios les dio, mientras los inhábiles e insuficientes y menos temerosos de Dios serían instituidos y preferidos contra lo que exige el bien público. Lo cual, añade, es contra la condición del buen principado que ha de mirar más y procurar el bien de la República que el suyo propio, al revés de lo que hace el tirano, que atiende únicamente a su conveniencia y provecho".

En carta dirigida por Francisco de Vitoria a Fr. Bartolomé de Miranda ${ }^{222}$ contestando a cierta consulta que éste le hizo sobre la materia de que se trata, se encuentran datos muy curiosos para juzgar de las grandes proporciones que tenía a la sazón esta plaga. Da también a conocer los temperamentos de prudencia con que, en sentir de Vitoria, debía mitigarse en la práctica el rigor de los principios teológicos en este punto. Afirma, pues, contra el parecer de su compañero de religión Fr. Pedro de Contreras, que aunque se debían condenar de ordinario estas compras y ventas, había algunas respecto a las cuales sería muy duro proceder así. La generalidad del mal le movía a aconsejar que se transigiese con los que tenían algún cargo como merced perpetua de la Corona, consintiéndoles que lo arrendaran ${ }^{223}$.

Criticando otra institución de la época, perjudicial por el mismo concepto que la venta de oficios a los intereses sociales, Fox Morcillo se declara enemigo de la perpetuidad de los cargos públicos, estimando más conveniente para el Estado que sean temporales, a causa de la propensión natural de los hombres a abusar, con daño del bien común, de las facultades de que no temen ser privados ${ }^{224}$.

No tratan nuestros Autores ex-professo de las atribuciones peculiares de la dignidad real sino en cuanto se relaciona con el ejercicio del poder legislativo, materia que por su importancia habremos de tratar separadamente. En

222 Mss. de la Biblioteca Nacional procedente de la del Marqués de la Romana. El Sr. Menéndez y Pelayo cree ser este religioso el célebre Arzobispo de Toledo, Fr. Bartolomé Carranza de Miranda.

223 ¿Hémoslos todos de dar al diablo? exclama con este motivo.

224 De regni, l. II. 
Domingo de Soto hallamos una opinión digna de ser consignada, bien que no le sea peculiar, pues se encuentra ya patrocinada por muchos canonistas de la Edad Media ${ }^{225}$. Atribuye a los Príncipes cristianos, fundado en las Decretales, el derecho de privar de sus bienes a los sarracenos y judíos que moran en sus dominios $^{226}$, cohonestando indirectamente de esta suerte la forma con que se llevó a cabo la expulsión de los judíos y moriscos de nuestro suelo.

¿Tuvo quizá alguna parte en esta última la opinión del ilustre dominico?

Nuestros más insignes teólogos, aunque amantes del robustecimiento del poder real, no solamente se esforzaron por contrarrestar el deplorable influjo de las ideas cesaristas, señalando unánimemente como límite a la potestad legislativa las normas del derecho divino y natural, y defendiendo la sujeción del Soberano, no sólo a estas mismas normas, sino también a las del derecho positivo, según hemos indicado, sino que sostuvieron algunos de ellos la necesidad o la conveniencia de reconocer al pueblo cierta intervención en el ejercicio de la potestad legislativa y en la imposición de tributos.

Mariana declara, que la potestad del Soberano, superior a la de la nación en cuanto a las cosas que son de su competencia conforme al derecho constituido escrito o consuetudinario, citando como ejemplos a este propósito la declaración de guerra y la elección de los funcionarios públicos, es inferior a la de la nación en orden a ciertas materias respecto a las cuales ésta se reservó la facultad de intervenir o resolver, y en todo caso acerca de la imposición de tributos y la modificación de leyes fundamentales, por ejemplo la concerniente a la sucesión de la Corona. Respecto a las leyes emanadas de la autoridad del pueblo, tiene por indudable que los Reyes no pueden modificarlas sino con aprobación de la Representación nacional, o sea de las Cortes ${ }^{227}$.

"Nuestros mayores, como tan prudentes", dice Mariana, "tomaron muchas y sabias disposiciones para que, contenidos los Reyes en los términos de la moderación y de la justicia, no ejerciesen nunca una autoridad excesiva con perjuicio de la república. Cuidaron para esto, en primer lugar, de que los Príncipes no pudieran decidir los asuntos de más importancia sin anuencia

225 Véase, entre otros, al valenciano Pedro Belluga, Speculum Principum, Venecia, 1560, Rubr. 29, n. 3: Princeps potest auferre bona Iudaeornm, quia illi habent ut peculium.

226 V. q. 2. a 5: "Quídam enim sunt qui iure et facto suo ditione christianorum Principum vitam degunt, quales olim erant in Hispania sarraceni, et hebraei, et nunc in Italia et Germania perseverant iudaeit. Et de istos nemini in dubium venit, quin valeant christiani Principes lege in eos agere, suisque adeo privare bonis... His proxime accedun: heretici, qui ex nobis, uti ait loannes, exierunt”.

227 De rege, l. II, c. 11. 
y consentimiento del pueblo y de la nobleza. Debían, pues, ser convocados con este objeto a las Cortes del reino representantes de todas las clases sociales, Prelados con plena jurisdicción, próceres y procuradores de las ciudades. Esta costumbre se observa todavía en Aragón y en otros reinos, y yo desearía que fuere restablecida también por nuestros Príncipes. ¿Por qué han excluido éstos de nuestras Cortes a los próceres y los Prelados, sino porque sin contar con su consentimiento, del cual depende la felicidad de la república, pueden manejar los intereses públicos y privados a su arbitrio y favorecer la codicia de un corto número de personas?”228.

Para Márquez, la potestad legislativa radica en el Príncipe, siempre que las leyes fundamentales no hubieran dado participación en su ejercicio al pueblo bajo una u otra forma ${ }^{229}$.

Oigámosle sobre esto:

"Algunos doctores han querido decir que no tendría fuerza la ley si el pueblo no la reciviesse, pero éstos hablan después de promulgada, y aun en este caso tengo lo contrario por más cierto; pero que para hacer leyes tenga necesidad el Rey de consentimiento del pueblo nadie lo ha dicho, sino en caso que fuesse eligido con esa condición expresamente, o desde el principio no se le huviesse dado suma autoridad que oy tienen los Reyes soberanos" ${ }^{230}$.

Alfonso de Castro me parece expresar esta misma idea, bien que en términos vagos y un tanto oscuros. La potestad legislativa, que radicaba, como la potestad pública en toda su plenitud, originariamente en la sociedad, consérvala ésta, por derecho natural, en cuanto a las leyes que no contradicen o repugnan al veto y legítimo dominio del superior o soberano ${ }^{231}$.

Veamos ahora sus opiniones acerca de la intervención del pueblo en la imposición de tributos.

228 De rege, l. I, c. 9.

229 Lib. I, c. XVI. Cf. Molina, II, disp. 23, n. 6 y V 46, 3.

230 L. I, c. 16.

231 Castro, De potest. leg. poen., l. I, c. 1.: "Est alia potestas laica, cuius hic solus est finis, ut populum in pace custodiat: et haec potestas licet sit semper a Deo, non tamen immediate, sed saepe per populi consensum, a quo primum, Deo annuente aut permitiente, illam accepit; nec maiorem quam illae populus ab initio concessit. Et qui talem populi regendi curam dedit, eo ipso dedit potestatem eas condendi leges, sine quibus populus bene regi non posset. Constat enim potestatem legem statuendi jure naturae populo concessam esse, praesertim ad eas leges sibi condendas, quae superioris sui veto et legitimo dominio nequaquam repugnant." Vitoria, Rel. III, n. 15 y 21 y Soto, I, q. 7, a. 2. 
Rivadeneira $^{232}$ combate a los cesaristas que atribuían al Rey poder sobre la hacienda de sus súbditos, afirmando "que si el dominio y propiedad de las haciendas de los súbditos fuese de los Reyes, y el uso y posesión solamente de los que las poseen, no habría para qué juntarse como se juntan en las Cortes de los Reinos para tratar de las necesidades de los Reyes, y buscar nuevos modos y formas para servirles, ni lo que se les diese en ellas se llamaría servicio, subsidio o donativo, y con otros nombres que muestran que lo que se hace es servicio voluntario, y no obligatorio".

Examinando muy detenidamente la cuestión, dice Márquez: "o se ha de resolver, atento sólo el derecho divino y natural, o considerando también el humano, que consiste en las leyes de los Reinos, y el título que estos pueden aver adquirido contra sus Reyes, hora por contrato, hora por prescripción de costumbre inmemorial. Y considerando esto segundo, no recibe duda, que no podrá el Príncipe, por sola su autoridad, imponer el nuevo servicio contra la voluntad del Reyno, que por cualquiera de las razones alegadas hubiere adquirido derecho contra él, como tengo por cierto del de Castilla” ${ }^{233}$.

Siguiendo las huellas de Mariana, prosigue Márquez²34: "aun los tributos necessarios, afirman hombres de buenas letras, que no los podría imponer de nuevo el Príncipe sin consentimiento del Reyno; porque dicen, que no siendo (como no lo es) señor de las haziendas, tampoco podrá servirse de ellas sin la voluntad de los que se las han de dar. Y en esta costumbre están de grande tiempo acá los Reyes de Castilla, en que por leyes reales, no se reparte nuevo servicio, sin que primero vengan en ellas Cortes, y aun después de la resolución, se vuelve a votar en las ciudades, y hasta que venga la mayor parte dellas, no piensa el Príncipe qué ha obtenido en la pretensión”.

En cuanto a Mariana, resulta con evidencia del texto citado anteriormente al tratar de la intervención del pueblo en la redacción de las leyes, que juzgaba imprescindible la intervención de las Cortes en esta materia.

Las opiniones de nuestros teólogos no encontraron eco en las esferas gubernamentales. Desde que Fernando IV otorgó a las Cortes de Valladolid de 1307 que en lo sucesivo no echaría ningún pecho sin pedirlo a la Representación nacional, los monarcas castellanos hasta Felipe II se atuvieron a esta norma generalmente. Pero, a contar desde el reinado de este Monarca, se prescindió con frecuencia del acuerdo de las Cortes, y no obstante hallarse

232 El Príncipe cristiano, 1. II, c. 9.

233 El Governador cristiano, l. I, c. 16. Cf. Suárez, De leg., l. V, c. 17.

234 L. I, c. 16. 
expresamente consignada en el derecho escrito la norma arriba indicada, acabaron aquéllas por perder en el reinado de Felipe IV tan valiosa prerrogativa.

Nadie, por lo demás, culpará seguramente a nuestros teólogos y filósofos de haber contribuido a la ruina de las Cortes. Ninguno se pronunció contra ellas, y algunos abogaron expresa y enérgicamente por que fueran reintegradas en la plenitud de sus antiguas atribuciones. Causas de muy diversa índole, expuestas en detalle por el historiador de las instituciones de León y Casti$1 \mathrm{l}^{235}$, habíanla condenado ya a inevitable ruina.

La importancia que perdieron las Cortes vino a refluir y concentrarse desde principios del siglo xv en los Consejos de la Corona. "El Monarca, en los primeros siglos de la Edad Media, celebraba consejos, pero no tenía un Consejo permanente para resolver las dificultades de la gobernación. Después puso a su lado una Junta formada de los hombres más poderosos o de los más entendidos, que, antes de adquirir estabilidad, pasó por singulares vicisitudes. Cuando se aproxima la Edad Moderna, esta Junta legisla, administra y falla, sin reconocer otro superior que el Jefe del Estado, y es el centro a que convergen todas las autoridades y jurisdicciones. - La diversa importancia que gozan entonces la Representación nacional y el Consejo del Rey nace de varias causas, y una de ellas nos parece la que sigue: La Representación nacional, por lo común se reúne de tarde en tarde, y al disolverse cae la ejecución de sus acuerdos en manos del Monarca, que a veces no desea o no puede cumplirlos. El Consejo funciona diariamente, pesa a todas horas sobre la voluntad del Monarca, y dispone de medios eficaces para ejecutar por sí mismo lo que decide. Bajo tal aspecto, no suponían menos que las Asambleas de la nación los Consejos de la Corona”" ${ }^{236}$.

No descendieron nuestros teólogos a tratar en detalle de esta institución, de importancia tan capital en el antiguo régimen. Fue, por lo demás, objeto de especial atención para los políticos de la época y dio origen a un género de literatura, cuya más valiosa producción es el tratado de la institución del Príncipe, del publicista valenciano Furio Ceriol ${ }^{237}$.

235 Colmeiro, Curso de Derecho politico, p. 322-331.

236 Torreánaz, Op. cit., I, p. V-VI. Es muy de desear, que el Autor de esta notable monografía se decida a publicar en breve el tomo II, terminado ya según mis noticias, que abarca el período más interesante y fecundo de la historia de dicha institución. Sobre la importancia capital de los Consejos en nuestro organismo político de los siglos XVI a XVIII, véanse también las luminosas consideraciones de D. Joaquín Sánchez de Toca en su reciente obra, Del Gobierno en el régimen antiguo y el parlamentario, I, Madrid, 1890, p. 68-73 y 169-197.

237 Cánovas del Castillo, De las ideas políticas, etc., p. 527-529. 
El Rey, según Fox Morcillo, no debe gobernar por su solo arbitrio, sino con el consejo de varones prudentes ${ }^{238}$. Como filósofo de profesión, piensa que los filósofos, como son tan peritos en la ciencia del hombre y del mundo, deberían tener asiento en los Consejos de los Príncipes con preferencia a los jurisconsultos y a los teólogos ${ }^{239}$. Sepúlveda, aleccionado por la triste experiencia de los reinados de Juan II y Enrique IV, encarece la conveniencia de que los Reyes, en vez de entregarse al capricho de un privado, se rodeen de un Consejo de personas graves y prudentes y consulten con él los arduos negocios de la gobernación del Estado ${ }^{240}$.

Vitoria $^{241}$ y los demás publicistas de nuestra Escuela teológico-política concuerdan en cuanto a negar carácter absoluto e irresponsable a la autoridad del Jefe del Estado, y en dejar abierto el camino, aunque con importantes restricciones, al derecho de insurrección. Soto ${ }^{242}$ reconoce a la nación el derecho a deponer al Rey cuando degenera en tirano, pero se abstiene de indicar el procedimiento que había de seguirse en este caso.

La doctrina del tiranicidio, expuesta ya por Cicerón, exhumada por vez primera en la Edad Media en su Policraticus por Juan de Salisbury ${ }^{243}$ e indicada por Santo Tomás en un pasaje más bien narrativo que afirmativo ${ }^{244}$ toma cuerpo en los escritos de la segunda mitad de la Edad Media y sobre todo en los escritores políticos del siglo XVI.

238 Ethices, l. III, c. 9, p. 127: Nam et rex non suo, sed prudentiorum etiam consilio debet cuncta administrare.

239 De regni etc., l. I, c. 7.

240 De regno, l. III, C. 6: illud talibus regibus etiam atque etiam cavendum est, ne se unius etiam ingenium et rerum periti consilio voluntatique addicant; sed complurium gravium sapientiumque virorum prudentia...

241 Relect., III, n. 15 .

242 I. q. 7, a. 2 y IV, q. 1: per rempublicam rex non potest jure expoliari, nisi fuerit in tyrannidem corruptus.

243 Sobre la doctrina de Santo Tomás acerca de la resistencia al poder y al tiranicidio, véase al P. Zeferino González, Estudios sobre la filosofía de Santo Tomás, Manila, 1864, tomo III, p. 452-475, en especial las págs. 470-471, en que condensa con su habitual lucidez las teorías de Santo Doctor sobre la materia. Cf. Balmes, El Protestantismo comparado con el Catolicismo, cap. 54 a 56, y el estudio de Sanseverino, La doctrina de Santo Tomás de Aquino y el supuesto derecho de resistencia en La Ciudad de Dios, III, Madrid, 1870.

244 Janet, Histoire de la Science politique dans ses rapports avec la morale, $2 .^{\mathrm{a}}$ edición, París. 1872, I, p. 370-373. 
Molina ${ }^{245}$, después de aceptar la distinción corriente entre el tirano de derecho y de administración, afirma que al primero puede darle muerte lícitamente cualquier ciudadano, mas no al segundo si no fuera en propia defensa. Cuando el Rey legítimo degenera en tirano, piensa que pueden reunirse las personas más conspicuas del Estado (designadas con la vaga denominación de capita), para resistirle, dictar la sentencia de deposición, si fuese necesario, e imponerle el castigo que merezca.

Los fundamentos de la doctrina de Mariana acerca del tiranicidio y del regicidio se encuentran principalmente en Molina; si bien es fuerza reconocer, y esto no cede ciertamente en pro del jesuita talaverano, que éste le dio un desarrollo más grave y peligroso, al declarar en términos vagos que, si advertido el tirano de hecho por personas graves para que se enmiende persevera en la tiranía, la nación puede declararle la guerra y aun darle muerte, usando del derecho de legítima defensa. Completa la teoría con la peligrosa afirmación de que, si la nación no puede congregarse para juzgar al tirano, cualquier ciudadano puede matarlo lícitamente ${ }^{246}$.

Suárez la trató muy de propósito en su obra De legibus ${ }^{247}$ y más especialmente en la Defensio catholicae et apostolicae fidei ${ }^{248}$ defendiendo conforme a la doctrina tradicional ser lícito dar muerte al tirano quoad titulum, en el caso de que la sociedad manifieste evidentemente la voluntad de resistirle y no haya ningún otro medio de deshacerse de él; pero cuidó de establecer al efecto condiciones y limitaciones que hacen muy difícil la aplicación de esta doctrina. En cuanto al Rey legítimo que gobierna tiránicamente, o sea al tirano quoad administrationem, no considera justa la resistencia, sino en el caso de que, depuesto y excomulgado por el Pontífice, se empeñase en conservar la corona. Con admirable serenidad de juicio, examina el agustino Márquez los argumentos aducidos en pro y en contra de la licitud del tiranicidio, y no

245 Tract. III. disp 6, n. 2: “...Posset item respnblica ipsa” añade, “quoad capita convenire, eique resistere, lataque sententia, deponere illum ab administratione, si id ita excessus illius, communeque bonum efflagitarent atque illum depositum punire”. Cf. Tract. II, disp. 23, n. 8-10, y el V, disp. III, n. 2.

246 Merece consultarse el extenso capítulo que dedica el P. Garzón al examen de las doctrinas de Mariana sobre el particular, en su ya citada monografía. Como no podía menos de suceder, el P. Garzón reconoce lo peligroso de tales teorías, condenadas también recientemente por otro hermano de Orden de Mariana, el P. Cathrein, en el artículo Absetzung del Staatslexikon, de Bruder, Friburgo, 1889, col. 39-47.

247 Lib. III, c. 4.

248 Lib. III, c. 3 y 6 
vacila en declarar que, si hay derecho para privar de la vida al que, sin justo título, pretende alzarse con la dignidad suprema, no lo puede haber jamás para quitársela al Príncipe legítimo, aunque degenere en verdadero tirano, por ser grandísimos los daños que necesariamente habían de seguirse a la nación de prevalecer la doctrina contraria ${ }^{249}$.

Sepúlveda había defendido ya la misma opinión, negando en absoluto a los súbditos el derecho, no sólo a dar muerte, sino a resistir bajo cualquier forma al Rey legítimo, aun en el caso de que degenere en tirano ${ }^{250}$.

Discurriendo Vitoria sobre la importantísima cuestión de la validez de las leyes emanadas de los gobiernos de hecho (que no encuentro tratada en ningún otro autor de la época, fuera de Suárez) ${ }^{251}$, la resuelve con su habitual discreción y acierto: "Si las leyes dadas por el tirano", dice, "son convenientes para el Estado, es innegable que obligan a los subditos, no ciertamente por razón de la autoridad de donde emanan, sino por ser mejor para la república que se observen estas leyes que si no se observan ningunas; pues redundaría evidentemente en perjuicio del Estado el que no hubiese tribunales, ni juicios, ni pudieran ser castigados o cohibidos los malhechores, etc."

La singular predilección con que trataron nuestros teólogos de los siglos XVI y XVII la materia del tiranicidio, muy especialmente Suárez, al impugnar las teorías crudamente cesaristas del rey Jacobo I de Inglaterra, se explica, según la acertada observación de uno de los publicistas que han estudiado más a fondo las doctrinas políticas de los escritores españoles de la época, por razones circunstanciales ${ }^{25}$. Preocupados ante todo del interés religioso, y considerando como uno de los mayores peligros para el Catolicismo el principio cuius regio illius est religio, defendido y aplicado por los soberanos protestantes, se aplicaron a combatirlo con empeño, valiéndose al efecto de las armas que les ofrecía la ciencia política medioeval y llegando alguno de ellos, como Mariana, a conclusiones tan absurdas como peligrosas.

249 L. V, c. 3.

250 L. I, n. 11-12.

251 Suárez, De legibus et Deo legislatore, l. III, c. 10, n. 8, sostiene en el fondo la misma doctrina, afirmando que en tales casos reipublicae consensus supplet defectum potestatis tyranni.

252 Cánovas del Castillo, De las ideas políticas, etc., p. 560. "Lo que a los teólogos de la escuela de Suárez les importaba no era salvar entonces la Monarquía, sino la libertad humana, para que los súbditos pudieran permanecer fieles al Catolicismo, a pesar de sus Reyes”. Cf. Sánchez de Toca, Del Gobierno en el régimen antiguo y el parlamentario, I, p. 49-53. 
Si nos preguntamos ahora cuál fue la influencia de nuestros teólogos y filósofos de los siglos XVI y XVII en las instituciones políticas, muy difícil de precisar por las razones indicadas al principio de este capítulo, habremos de reconocer como su mérito principal el haberse esforzado por que prevaleciesen contra las tendencias cesaristas, tan en boga a la sazón, dos importantísimos principios: la limitación del poder legislativo por las normas inmutables del derecho divino y natural y la sujeción del Monarca a las leyes del Esta$\mathrm{do}^{253}$. Merced a esto, el absolutismo de los Reyes de la Casa de Austria no llegó a tener nunca el carácter personal y depresivo de la dignidad humana que alcanzó en las naciones protestantes y en la Francia de Luis XIV. Los esfuerzos de algunos de nuestros teólogos, y en especial de Rivadeneira, Mariana y Márquez, en pro de la autoridad de las Cortes fueron una tentativa generosa, necesariamente ineficaz a causa de los gérmenes de decadencia y ruina de esta institución, singularmente en Castilla ${ }^{254}$.

La historia hace hoy justicia a Felipe II, reconociendo que dejó subsistir en su forma antigua las Cortes de Navarra y Aragón. De las de este último reino en la Edad Media, dice un profundo conocedor de su historia y su derecho, que "no solamente no modificaron ni reformaron (los abusos de gobierno), sino que los aumentaron casi siempre, y a veces los produjeron, sirviendo para sancionar la tiranía en perjuicio de la verdadera libertad, y la anarquía en perjuicio del orden"; más adelante añade "que a mediados del siglo XVI estaban completamente desacreditadas por sus abusos" 255 . Juzgando el mismo escritor la conducta de Felipe II respecto a las Cortes aragonesas, se expresa en los términos siguientes: "Se ha hecho creer al vulgo que Felipe II, al decapitar al Justicia de Aragón, mató con él los fueros, libertades, Cortes y el justiciado. Es falso: siguieron los fueros como estaban y durante el siglo XVII hubo varias Cortes y en ellas se modificaron, reformaron o añadieron, según convenía. Los que mataron los fueros de Aragón fueron los afrancesados de Felipe V y los revolvedores de Zaragoza. Felipe II tuvo Cortes en Tarazona, en que se dieron fueros nuevos y cortaron abusos y se ratificaron las libertades aragonesas, prohibiendo el tormento, las confiscaciones, las sisas y la pena de

253 Sánchez de Toca, Op. cit., I, p. 152-158 y 189-197.

254 Balmes, El Protestantismo comparado con el Catolicismo, IV, c. 66. Sánchez de Toca, Op. cit., I, p. 63-68, 168-169 y 179-181.

255 La Fuente. Estudios críticos sobre la historia y el derecho de Aragón, tercera serie, p. 343 . 
galeras, sino contra los ladrones..." ${ }^{256}$. Un historiador protestante de nuestros días, que ha hecho asunto especial de sus investigaciones la política de Felipe II en los Países Bajos, no vacila en elogiar el respeto de este soberano a la legalidad constitucional en aquel país ${ }^{257}$.

Con el advenimiento al trono de la dinastía de Borbón, las teorías acreditadas en Francia por Bodin, Barclay, Buchanam y tantos otros acerca del absolutismo personal de los Reyes, toman carta de naturaleza entre nosotros y trascienden muy luego a la práctica, manifestándose no sólo en el orden eclesiástico, como veremos después, sino también en el político, aun en los menores detalles.

Harto conocida es, para que necesite insistir aquí sobre ella, la negativa de Felipe $\mathrm{V}$ a reunir las Cortes de Castilla, que, con excelente acuerdo, intentaban restaurar entonces algunos buenos españoles ${ }^{258}$. Muestra también de su extraordinaria suspicacia en este punto, es el encargo que dio a Salazar y Castro de refutar la pretensión del Consejo de Castilla de entender en determinados asuntos ${ }^{259}$. En la ley sobre sucesión a la Corona se encuentra ya la frase, "que así es mi voluntad" traducción de la fórmula despótica "car tel est notre plaisir" usada por los Reyes de Francia desde hacía mucho tiempo en los documentos emanados de su cancillería. A contar desde Felipe V, el aforismo cesarista Princeps legibus solutus imperó hasta principios del siglo actual en las esferas del gobierno y dejó huella indeleble en los monumentos legislativos.

Terminaremos recordando un episodio bastante conocido del tiempo de Felipe II, que, relacionado con las ideas políticas de Luis XIV, me parece caracterizar gráficamente la diferencia esencial entre el absolutismo austríaco y el borbónico.

Bajo el reinado de Felipe II, como un predicador afirmase desde el púlpito a presencia del Soberano "que los Reyes tenían poder absoluto sobre las personas de sus vasallos y sobre sus bienes" fue procesado por la Inquisición y obligado a retractarse en el mismo púlpito, siendo calificada aquella proposición de errónea y obligándosele a declarar, conforme a la instrucción literal del Santo Oficio “que los Reyes no tienen más poder sobre sus vasallos

256 La Fuente, Op. cit., p. 358-359.

257 Treitschke, Histor. und polit. Aufsätze, II, 5. ${ }^{\mathrm{a}}$ ed,. p. 425.

258 Colmeiro, Curso de Derecho político, p. 346.

259 Véanse sobre el particular los interesantes datos que ofrece el Conde de Torreánaz en su Historia de los Consejos del Rey, I, p. 78-80. 
del que les permite el derecho divino y humano; y no por su libre y absoluta voluntad" ${ }^{260}$. Es circunstancia digna verdaderamente de ser notada, que la segunda parte de la mencionada proposición es antitética de otra expuesta por Luis XIV en sus Memorias y en la Instrucción a su nieto Felipe $V^{261}$.

Tarea ajena de la presente Memoria, y digna por si sola de especial y detenido estudio, es la comparación entre las doctrinas políticas de nuestros teólogos y filósofos y las que hacia el mismo tiempo sostenían los publicistas extranjeros coetáneos suyos, así católicos como protestantes; pero, aun sin entrar en ella, puede asegurarse, de acuerdo con las mayores autoridades en la materia, que el parangón no cedería en desprestigio de la ciencia españo$\mathrm{la}^{262}$.

260 Balmes, El Protestantismo comparado con el Catolicismo, $3 .^{\text {a }}$ ed., II, p. 368-469, cita este hecho tomándolo de las Relaciones de Antonio Pérez, donde se halla relatado con minuciosidad.

261 "Les rois sont seigneurs absolus et ont naturellement la disposition pleine et libre de tous les biens, tant des séculiers que des ecclésiastiques, pour en user, comme des sages économes, c'est-á-diré selon les besoins de leur Etat". Mémoires, ed. de Dreyss, I, p. 209, citada por Koser, Die Epochen der absoluten Monarchie in der neueren Geschichte, en la Historische Zeitschrift de Sybel, LXI, 1889, p. 270, n. 1.

262 El más conspicuo representante del absolutismo político, el primero que formuló sin rebozo y defendió en toda su desnudez el concepto pagano del Estado, fue Maquiavelo en su libro Del Príncipe, donde aparece el poder del Estado concentrado en manos de un monarca absoluto como fin supremo y casi único de la sociedad civil. El derecho y la moral, la religión y la virtud son simples medios de gobierno, que pueden, cuando la necesidad lo exija, ser sustituidos por sus contrarios. El individuo pierde todo valor ante la autoridad y la fuerza del Estado. En formas aún más crudas, defendieron el absolutismo Guillermo Barclay (que además de considerar al Rey como fuente de todo derecho y desligado de todo vínculo, atribuyó a los Príncipes el derecho absoluto sobre las personas y bienes de sus súbditos), Alberico Gentili, Claudio Buchanan, Salmasio y Hobbes en el siglo XVII.

Véase especialmente sobre la exposición y crítica de las teorías políticas de los siglos XVI y XVII la obra de Bandrillart, J. Bodin et son temps, París, 1853, especialmente p. 16-45; Janet Histoire de la science politique, 2. ${ }^{\mathrm{a}}$ ed., II, p. 3-218; Bluntschli, Geschichte des allgemeinen Staatsrecht und der Politik, 2. ${ }^{a}$ ed., Munich, 1867, p. 1-63; Cánovas del Castillo, Las ideas políticas etc., en los tomos IV y VI de la Revista de España; Gierke, Johannes Althusius und die Entwickelung der naturrechtlichen Staatstheorien, Breslau 1880; v. Hertling, artículo Absolutismus en el Staatslexikon de Bruder, I, fol. 47-68 y a Sánchez de Toca, Del Gobierno en el antiguo régimen y en el parlamentarismo, I, p. 98130, y el Apéndice sobre La Soberanía del Estado en su libro Felipe IV y Sor María de Agreda, Madrid 1887, p. 343-393, en el cual dedica especial atención a la teoría del pacto como medio de constituirse la autoridad política, sostenida por nuestros teólogos. 
Comparando las teorías políticas de nuestros teólogos con las de los protestantes del siglo XVI, dice un ilustre escritor alemán: "La Reforma dio nueva vida al concepto teocrático. No obstante la variedad de matices que entre ellos se observa, Lutero, Melanchthon, Zuinglio y Calvino concuerdan en proclamar el derecho divino de la autoridad. Sometiendo más o menos resueltamente la esfera eclesiástica al Estado, y haciendo depender la legitimidad de éste del cumplimiento de su deber religioso, prestaron a la sentencia de San Pablo "todo poder procede de Dios" un alcance hasta entonces desconoci$\mathrm{do}^{263}$. Los más acérrimos enemigos de la Reforma, en especial los dominicos y los jesuitas, trabajaron con todas las fuerzas de su entendimiento porque prevaleciese el concepto puramente racional del Estado y del Soberano. Hicieron esto, a la verdad, para contraponer el Estado a la Iglesia, o inferir de esta contraposición entre obra humana o institución divina la subordinación de la potestad temporal a la espiritual. Pero en aquellos puntos en que las relaciones del Estado con la Iglesia quedaban fuera de juego, desarrollaron la doctrina del Estado sobre fundamentos enteramente filosóficos y abstraída de todo presupuesto dogmático. Los grandes teóricos de esta tendencia están unánimes en que la sociedad política radica en el derecho natural y en que, por virtud de este mismo derecho, corresponde a la sociedad la soberanía sobre sus miembros y todo poder emana de la voluntad social, sin abandonar por esto la teoría de que el Estado se funda en la voluntad divina y el poder emana de Dios ${ }^{264}$.

Las teorías de Melanchthon acerca de las relaciones entre el derecho natural y el positivo, sobre el origen divino del poder, el fin de la sociedad civil, los deberes del Estado en el orden religioso y la resistencia al tirano ${ }^{265}$, concuerdan en lo esencial con las de nuestros teólogos, y el expositor de sus ideas en este punto ha podido afirmar que el criterio de Melanchthon en todas estas cuestiones es el de la Escolástica, no obstante su aversión a ella ${ }^{266}$.

263 Roscher, Geschichte der National-Oekonomie in Deutschland, Munich, 1874, p. 66. Die Reformation hat bekanntlich in allen den Ländern, wo die Fürsten sich ihrer annahmen, zur Verstärkung der fürstlichen Machi (Roscher subraya estas palabras) ungemein beigetiagen ... So ist denn auch Luther einer der bedentendsten Vorläufer der absoluten Monarchie, welche die beiden folgenden Jahrhunderte beherrscht...

264 Gierke, profesor de Derecho público en la Universidad de Berlín, en su magistral monografía Iohannes Althusius, p. 64-65.

265 Haenel, Melanchthon der Jurist en la Zeitschrift für Rechtsgeschichte, VIII, Weimar, 1869, p. 249-270, especialmente p. 257-262 y 265-267.

266 Ibid., p. 269: "Sein Standpunkt ist, trost aller Abneinung gegen dieselbe, der der 
Scholastik". Cf. Stintzing, Geschichte der deutschen Rechtswissenschaft, I, Munich, 1880, p. 283-287, el cual, conviniendo en lo esencial con Haenel, afirma, sin embargo, y en esto muestra un absoluto desconocimiento de la doctrina escolástica, que Melanchthon se eleva sobre ella, sobre todo por considerar que el Estado es de ordenación divina: "vor allen die Anerkennung dieses letzteren (des Staats) als einer ebenfalls göttlichen Ordnung, führt ihn über die Scholastik hinaus".

Juan de Valdés, el único protestante español que trató, aun cuando solo incidentalmente, de materias políticas en su Diálogo de la lengua, concuerda en lo esencial con los teólogos católicos compatriotas y contemporáneos suyos, como observó ya acertadamente Menéndez y Pelayo, Historia de los heterodoxos españoles, II, Madrid, 188o, p. 149-151. Basta, para convencerse de ello, comparar sus teorías sobre el pacto como medio de transmisión del poder, la subordinación del interés del Soberano al del Estado y otros puntos con las de los teólogos aludidos. 


\section{CAPÍTULO VI}

Actitud de nuestros teólogos respecto a las polémicas sostenidas en la Edad Media sobre la potestad del Papa en materias temporales. - Sus opiniones acerca de las exenciones e inmunidades del Clero.- Autoridad que atribuyen al Jefe del Estado en esta materia.Resistencia al Papa, aun en las cosas que atañen exclusivamente a la administración de la Iglesia, cuando ceden evidentemente en grave daño de esta última.- Opiniones extremas de Simancas en este punto.- Teoría de Mariana sobre la intervención del Clero en la gobernación del Estado.- Deberes del Príncipe en el orden religioso, según Rivadeneira.- Defensa de la necesidad de autorización del Papa para disponer de los bienes de la Iglesia. - Las teorías regalistas a fines del siglo XVI y principios del XVII: diferencias entre el regalismo austríaco y el borbónico.- Influencia de los teólogos en este orden.

Combatieron acérrimamente todos nuestros teólogos de los siglos XVI y XVII la teoría de la potestad directa del Papa en materias temporales, defendida durante la Edad Media por Enrique de Segusia, cardenal obispo de Ostia, Agustín Triunfo, Álvaro Pelagio, Juan de Salisbury, Egidio Colona y otros, y cuyos fundamentos, que hemos expuesto en otro lugar, conviene recordar al presente. Según ella, Dios otorgó a San Pedro y sus sucesores de una manera ilimitada la potestad de atar y desatar, así en lo espiritual como en lo temporal, y los Pontífices romanos poseen esta potestad temporal absoluta sobre todo el universo, aun sobre los pueblos paganos. Conforme a esto, los Papas tienen que gobernar al mundo, así en las cosas temporales como en la espirituales, ejerciendo esta última potestad inmediatamente por sí, y confiando la temporal a los Príncipes y Reyes, los cuales son meros servidores de la Iglesia, pues que de ella reciben la potestad, tienen que darle cuenta de su ejercicio y son reconocidos o depuestos por los Pontífices.

Discurriendo sobre las polémicas suscitadas entre los acérrimos defensores de la potestad pontificia y secular, afanados respectivamente por realzar los fueros de cada cual de ellas con menoscabo de la otra ${ }^{267}$, Vitoria defiende el justo medio entre tan encontradas opiniones, y al mismo tiempo que refu-

267 Relect. de pot. Eccl., n. 1: Utrum scilicet Papa sit superior potestate civili iurisdictione et aucthoritate. Et quidem sunt qui, tanto studio et favore Pontificum feruntur, ut putent Reges et alios Principes temporales non esse nisi vicarios aut legatos Romani Pontificis ut ministros potestatis papalis, et quod innixa potestas temporalis derivetur a Romano Pontifice. Alii, e contrario, ita eximunt Principes a potestate ecclesiastica, ut nihil pene integrum relinquant ecclesiasticae potestati, sed omnes causas etiam spirituales velint deferri ad iudicium civile, et illic terminari. 
ta magistralmente la opinión que atribuía al Papa el señorío del universo, le reconoce potestad indirecta en las cosas temporales. La teoría de Vitoria y de los demás teólogos del siglo XVI y principios del XVII acerca de las relaciones entre la Iglesia y el Estado es, en suma, la unión y coordinación de ambas potestades, conservando su independencia mutua en las cosas que atañen al fin peculiar de cada una ${ }^{268}$. Idéntica opinión emite en este punto con su precisión habitual Alfonso de Castro ${ }^{269}$.

Según Vitoria, los Soberanos temporales no dependen del Papa, a la manera que algunos Reyes del Emperador, si bien todos están sujetos a aquél en cuanto se relaciona con el fin espiritual. Por este concepto, el Papa tiene potestad tan amplia respecto a los Soberanos temporales, que alcanza no sólo a derogar las leyes civiles contrarias a la religión, cuando el Soberano, amonestado al efecto por el Pontífice no las deroga por sí mismo, sino también a prohibir las guerras que redunden en perjuicio de los intereses religiosos, y aun a deponer a los mismos Soberanos si necesario fuese. Es atribución privativa del Papa apreciar dicha necesidad, pues sólo él puede juzgar acertadamente de la relación entre el orden temporal y el espiritual. Si el Papa dice que una ley civil es contraria al bien temporal de la sociedad, invade una esfera distinta de la suya y no hay obligación de aceptar su juicio: lo contrario sucede en el caso de declarar que tal ley cede en detrimento de la salud espiritual. Niega por tanto Vitoria, que la potestad temporal dependa de la espiritual, como

268 Relect. cit., n. 10: Sed potestates distinguuntur ex fine sicut potentiae per obiectum si ergo non potest humana societas sine utraque vita manere, necessaria est duplex potestas ad conservationem iustitiae: una quae praesit terrenis ad ordinandum vitam terrenam: alia quae praesit spiritualibus ad componendam vitam spiritualem. Praeterea non ex aequo se habent, sed certo modo una potestas ad alia ordinatur ... Non oportet imaginare, quod potestas civilis et spiritualis sint sicut sunt duae republicae disparatae et difierentes, ut Gallorum et Anglorum. Cf. Molina, Tract. II, disp. 21., n. 1, y Suárez, De leg., 1., IV, c. 9.

269 De pot. leg. poen., III, 10: Tamen circa alias res mere laicas et mere saeculares, quae nullnm ad rem ecelesiasticam respectum habent, Papa non potest condere leges, quae omnes obligent, sed illas solum, qui in oppidis, aut villis eiusdem Summi Pontificis vivunt. Potest quidem Papa prohibere Hispanorum aut Gallorum Reges, no aliqua civili lege utantur; propterea quod constat, illam legi naturali aut divinae contvadicere, sed non potest illos ad aliquum civilem lege cogere, quae non necessario ex lege divina aut naturali deducatur. Sunt enim hae duae potestates, Pontificalis videlicet et Regalis, hac ratione divisae, quod altera in spiritualibus, altera in corporalibus praeest, ut dicit ipse Summus Pontifex Innocentius tertius in cap. Solitae de maioritate et obedientia... Cf. Suárez, De leg. 1. IV, c. 6. n. 3 . 
aseguraban los partidarios de la potestad directa, al modo que una facultad inferior depende de la superior, y que haya de considerarse la primera como mero instrumento de la segunda.

Concuerdan evidentemente en estos puntos nuestros teólogos con la doctrina de Santo Tomás ${ }^{270}$, si bien se encuentran en ellos desarrollos y aplicaciones que no hallamos en el Ángel de las Escuelas.

Examinando con serenidad y elevación verdaderamente extraordinarias la cuestión de las exenciones e inmunidades del Clero, asienta Francisco de Vitoria que, si bien los clérigos están exentos de la potestad civil en las causas civiles y gozan de inmunidad de tributos, no todas estas exenciones son de derecho divino, pues la de tributos, por ejemplo, según Santo Tomás, a quien sigue nuestro teólogo, es de derecho humano, como fundada en privilegios de los Príncipes. La exención de los clérigos respecto de la potestad secular en las causas meramente eclesiásticas, es de derecho divino. En cuanto a la de no ser juzgados y castigados por los jueces seculares, créela muy conforme al derecho divino y natural, y afirma que, proceda o no del derecho divino, no puede ser derogada por la mera voluntad de los Príncipes.

Si estos últimos tienen alguna facultad en orden a la administración de las cosas eclesiásticas, como elegir Obispos o presentar personas para las dignidades o beneficios eclesiásticos, "hoc totum habent privilegio et indulgentia Ecclesiae, non ratione suae dignitatis" ${ }^{271}$.

Los clérigos no están, por derecho divino ni humano, exentos de la potestad civil, antes bien tienen obligación de conciencia de cumplir las leyes civiles concernientes al gobierno y administración temporal del Estado, cuando no son contrarias al régimen de la Iglesia ${ }^{272}$. Reconoce Vitoria a la potestad temporal la facultad de limitar o suprimir las inmunidades de los clérigos cuando ceden en daño manifiesto de la república, si el Pontífice se niega a hacerlo con

270 De regimine Princ, I: In tantum saecularis potestas est sub spirituali, in quantum est a Deo supposita, scilicet in his, quae ad salutem pertinent. Et ideo in his est magis obediendum potestati spirituali quam temporali. In his autem quae ad bonum civile pertinent, est magis obediendum potestati saeculari secundum Matheum: Reddite quae sunt Caesaris Caesari. Cf. Molina, II, disp. 28-30 y Suárez, Defensio, 1, III, c. 6.

271 Relect. cit., n. 3: Itaque non est dubitandum quin Principes non habeant aliquod iudicium nec administrationem, nec de iure divino, nec a republica, in rebus spiritualibus; et si quid iuris habent totum est ab Ecclesia.

272 Relect. de pot. Eccl. n. 4: ...in his quae expectant ad gubernationem et administrationem temporalem civitatis, et non impediunt administrationem ecclesiasticam, et pecant facientes contra legem. 
su autoridad. Aduce como argumento irrefragable a este propósito el derecho de legítima defensa que, en orden a su conservación, poseen las naciones del mismo modo que los individuos ${ }^{273}$. Recuerda, pareciendo asentir a ella, la opinión del célebre cardenal Cayetano, según el cual los Príncipes temporales pueden resistir al Papa, aun en lo que atañe a la administración de las cosas eclesiásticas, cuando éste obra con daño manifiesto de la Iglesia, como es procediendo desacertadamente o con simonía en la concesión de beneficios ${ }^{274}$. En este caso, según Cayetano, puede el Príncipe negarse a dar posesión a los agraciados por el Pontífice, al cual no se ha de obedecer en las cosas malas.

La opinión de que los Príncipes seculares pueden resistir al Papa en determinados casos, por ejemplo, cuando dicta leyes disciplinarias injustas, cuando se apodera violentamente de lo que no le pertenece, o conduce a la Iglesia a su ruina, se encuentra consignada también en las obras de Soto ${ }^{275}$, y Molina $^{276}$. Simancas afirma que si el Papa diera algún decreto en detrimento del Tribunal de la Inquisición, debía pedírsele que lo reformase o suspendiese, y negándose a ello, no se le debía obedecer en manera alguna. Tanto en este caso, con en el de dictar los Pontífices alguna otra providencia "contra la utilidad pública", por ejemplo, contra el derecho de patronato de los seglares y el de elegir para los beneficios o capellanías patrimoniales, "el Rey debe resistirle en virtud del derecho natural de legítima defensa y para que no redunde en daño notorio de la paz pública y del bien común ${ }^{277}$. La misma idea expresaba en el fondo el batallador Arzobispo de Granada Pedro Guerrero,

273 Relect. cit. II, n. 8: Nihilominus si libertas clericorum esset in manifestam reipublicae perniciem, ita ut ecclesiastici impune baccarentur in cedem laicorum, et Pontifices nollent admitere remedium, possent Principes consulere suis civibus, non obstante privilegio clericorum, Probatur: Quia (ut supra dictum est) respublica civilis est perfecta, et sibi sufficiens: ergo potest se defendere, et servare ab iniuria cuiuscumque propria authoritate, et super hoc leges convenientes ferre. Et confirmatur: Nam possunt Principes servare proprias respublicas ab iniuriis aliarum rerum publicarum, non solum per modum defensionis sed authoritatis, ut supra ostensum est: ergo etiam ab iniuriis clericorum.

274 Relect. cit., II, n. 3: Circa quod nota quod Dominus Cajetauus, concedit lib. de Potestate Papae, cap. XXVII, quod etiam circa administrationem ecclcsiasticam possunt Principes resistere Papae, si manifeste dissipet Ecclesiam; ut, si pernicioso provideat vel simonice det beneficios, non est danda possessio illis nec obediendum in malis.

275 Soto, l. IV, dist. 3, y l. III, q. 13 y sig.

276 Molina, Tract., II, disp. 31, n. 4 y 5.

277 De cathol. inst., tit. XLV, n. 34 y 35, p. 211: ...id manu regia retineri et impediri solent, quia regum officium est, ab huiuscemodi iniuriis populos sibi subiectos liberare; et, iure naturalis defensionis, licet Principibus secularibus etc. 
al decir en 1560 a Felipe II "que los Reyes habían de rendir cuenta a Dios de la Iglesia que estaban llamados a amparar y reparar", afirmando al mismo tiempo, con evidente injusticia: que "todos los daños y censuras de la Iglesia habían venido del sacerdocio, y todo el remedio y quietud del gobierno y brazo temporal" 278 .

Mariana defiende la estrecha unión entre la potestad eclesiástica y la civil, y desea que el Clero intervenga directa y eficazmente en la gobernación del Estado. Pide, a este efecto, que los Prelados tengan asiento en las Cortes por derecho propio y gocen, como en lo antiguo, de los privilegios jurisdiccionales de los Señores, y encarece la conveniencia de que se les confíen los más elevados cargos en la gobernación del Estado ${ }^{279}$. Rivadeneira, aunque asienta que el Príncipe no tiene facultades para entender en las cosas eclesiásticas, "sostiene que está obligado a apoyar lo que por los Prelados fuese establecido y favorecerlo y mandarlo guardar so graves penas y castigar severamente a los que no obedecen" 280 , y defiende resueltamente, contra Bodin, que los Príncipes tienen obligación de perseguir y castigar a los herejes ${ }^{281}$.

Fue doctrina común de nuestros teólogos, contra la tradición acreditada en estos reinos ${ }^{282}$ y la opinión de muchos jurisconsultos, ser necesaria la autorización del Papa para enajenar o disponer en alguna manera el Estado de los bienes eclesiásticos. Rivadeneira afirmaba no ser lícito prescindir de ella, y Mariana se expresaba en los términos siguientes: "No consienta el Rey, no debe consentir se prive a las Iglesias y a los Obispos de los pueblos y fortalezas que poseen, con las cuales podrá el sacerdote defender la religión de la impiedad de los innovadores, entre quienes pudieran encontrarse con el tiempo los mismos Soberanos...” Los bienes de las Iglesias, añadía, constituyen un depósito sagrado al que en ocasiones críticas puede acudir el Estado, pues para las guerras en defensa de la religión es lícito echar mano de ellos.

278 Citado por Cánovas del Castillo. Bosquejo histórico de la Casa de Austria, p. 12.

Refléjanse las ideas expuestas en el texto, en los Pareceres dados a Felipe II por algunos de los hombres más eminentes de su tiempo sobre la guerra al Papa Paulo IV y los cuales extracta y analiza Cánovas del Castillo en las páginas 16 a 36 de su trabajo Roma y España a mediados del siglo XVI, inserto en el tomo IV de la Revista de España, singularmente en el tan conocido de Melchor Cano.

279 De Rege, III, 2.

280 El Príncipe cristiano, lib. I, cap. 22.

281 Ibid., lib. I, cap. 26.

282 Colmeiro, Curso de Derecho político, págs. 448-454.- Cárdenas, Ensayo sobre la historia de la propiedad territorial en España, Madrid, 1873, II, p. 429-497. 
Si comparamos ahora los principios defendidos por nuestros teólogos acerca de las relaciones entre la potestad eclesiástica y la civil con las normas y prácticas vigentes en la materia durante el período que nos ocupa, salta, desde luego, a la vista la perfecta consonancia entre unas y otras. Los medios excogitados por el poder civil para impedir el libre ejercicio de la autoridad eclesiástica (y que constituyen un verdadero atentado a la independencia de que ésta debe gozar por institución divina), a saber, los recursos de fuerza y la revisión de los documentos pontificios o retención de bulas, son meras aplicaciones de las teorías sustentadas por algunos teólogos de este período. Por lo demás, es evidente que no fueron la autoridad y el prestigio de dichos teólogos la causa de que tales recursos, inoportuna y abusivamente empleados, se consignaran en nuestras leyes: ambos datan del tiempo de los Reyes Católicos ${ }^{283}$. Pero sí parece innegable, que el mayor desarrollo que adquirió su empleo, sobre todo a contar desde el reinado de Felipe $\mathrm{II}^{284}$, se debió en mucha parte a las teorías acreditadas a la sazón entre teólogos y jurisconsultos, extremadas con ocasión de las desavenencias entre Urbano VIII y Felipe IV, en la literatura regalista ${ }^{285}$, cuyas principales producciones son las obras De tertiis debitis catholicis Regibus Hispaniae, de Castillo Sotomayor y las De regia protectione y De supplicatione ad Sanctissimum, de Salgado de Somoza.

¿Cómo no hallar cierta conexión, entre la facultad atribuida a los Reyes por Simancas de impedir la ejecución de los Breves pontificios contrarios al

283 Nueva Recopil., lib. II, tit. 5, 1. 86.

284 Véase el trabajo de Philippson, Felipe II y el Pontificado, en los Estudios sobre Felipe II, traducidos por R. de Hinojosa, Madrid, 1888. Con razón se decía a este propósito en la Scrittura sopra l'autoritá ecclesiastica data al Ré Filippo da Mgr. Acquaviva en 2 Mayo 1568 (Cod. Corsin. 504, fol. 42, sq.): “...il sindicare le Bolle apostoliche che si fa ogni giorno nelli Consigli e Cancellerie regie, gl'impedimenti che si danno in tanti modi alle provisioni et exsentioni che vengono dalla Corte Romana, il mettere le mani per diverse vie e sotto pretesto di giustizia nelle cause ecclesiastiche, commandare alli Prelati e Giudici e Clerice che escommunichino et asolvano come pare al Consiglio et alle Cancellerie, il vedere le corti secolari continuamente piene di Clerici e Frati, et in somma tante usurpatione della giurisdittione spirituale che sono in questi Regni, non e altro senza dubbio se non a poco a poco attribuire al Re anche alli suoi Ministri sotto certi colorí, e con una certa destrezza potestà ecclesiastica ...” y Baronio Epistola ser. ad Cofess. Philippi II. Reg. Hispan. (ex. Cod. Vallicell. Q. 47, fol. 185) calificaba estas prácticas de "eresia coperta, che regna ne'regni del Re Cattolico". Tomo estas dos citas de las Institutionen des katholischen Kirchenrechts de Lämmer, Friburgo, 1886, p. 319.

285 Trata ex-professo de ella La Fuente, La Retención de Bulas, I, páginas 27-59. 
tribunal de la Inquisición y la Pragmática de Felipe II encomendando al Consejo Real la revisión de los documentos emanados de los Papas y relativos a aquel célebre tribunal?286

Diferencias esenciales separan, sin embargo, el regalismo de la Casa de Austria del regalismo borbónico. El primero no consideró nunca extensiva la aplicación del Placet a los documentos de carácter dogmático, sino únicamente a los de índole beneficial y jurisdiccional. El regalismo borbónico, informado por las ideas galicanas y enciclopedistas, lo estableció también para los concernientes al dogma ${ }^{287}$.

"La opinión que los teólogos tenían por más segura, la de que no debía tocarse a los bienes eclesiásticos, sino en necesidad extrema y con autorización previa del Pontífice, es la que oficialmente prevaleció, por lo menos hasta fines del siglo XVIII, a pesar de los regalistas y de los filósofos, que deseaban con afán el empobrecimiento de la Iglesia. Macanaz, invocando el derecho y ejemplos antiguos, propuso al Consejo en 1718, que para las urgencias de la guerra de sucesión, aún no concluida entonces, se exigiera a los Prelados y a las Iglesias el derecho de lanza sobre sus Estados y rentas y se comprendiera a los eclesiásticos en los repartimientos; y que si esto no bastase, y sin acudir al Papa, se utilizara la plata de los templos; mas fue oído con escándalo y no se adoptó su propuesta ${ }^{288}$.

286 Salgado, Tract. de supplic., II, p. 462-463.

287 Veáse el texto de la Pragmática y la Cédula de Carlos III de 1768 en la citada obra de La Fuente, I, p. 150-155.

288 Cárdenas, Op. cit., t. II, p. 496. 


\section{CAPÍTULO VII}

La Teología y el Derecho penal.- La doctrina de Santo Tomás, base de la de nuestros teólogos en esta materia.- El derecho de penar, función privativa del poder público.- Del fin de la pena.- División de las leyes penales. - Variabilidad de sus normas. - Proporcionalidad entre el delito y la pena.- Reglas para la aplicación de las leyes penales.- La pena de muerte.- Opiniones de nuestros teólogos acerca de los delitos religiosos, y especialmente acerca de la herejía y su penalidad.- La magia.- Opiniones contradictorias de Orozco y Soto sobre la usura.- Factores que influyen en el desarrollo de esta rama del derecho en el siglo XVI.- Concordancia de los teólogos con los jurisconsultos respecto a las demás clases de delitos y al procedimiento en general.- Opiniones de Chaves, Soto y Simancas sobre si el Rey puede sentenciar sin formación de proceso.- El tormento y Luis Vives. - El derecho de indulto.- Influencia de los teólogos en el derecho penal y procesal.

La filosofía del derecho, que investiga el concepto del delito, el fundamento del derecho de penar y el fin de la pena, es parte siempre de un sistema filosófico, reflejo fidelísimo de una determinada concepción científica del mundo y del hombre. Las ideas de derecho, culpa, delito, expiación, libre albedrío, responsabilidad, conciencia, tan importantes y transcendentales para el derecho penal, son del dominio mixto de la teología moral y de la filosofía. De aquí que acaso ninguna otra rama del derecho positivo haya sentido tanto la influencia de la teología y de la filosofía como el derecho penal.

Las doctrinas fundamentales de nuestros teólogos en materia de derecho penal están calcadas en lo esencial, como en materia de derecho político, sobre Santo Tomás. Distinguió éste oportunamente el derecho de la moral, al establecer que la ley humana no pueda castigar todos los pecados, como la divina $^{289}$. Discurriendo sobre el ámbito de la ley penal, sostuvo que ésta no debe prohibir toda injusticia, sino sólo las más graves, en especial aquellas quae sunt in nocumentum aliorum, sine quorum prohibitione societas humana conservan non posset ${ }^{290}$. Y en otro lugar añade: sufficit, ut prohibeat ea, quae destruunt humanum convictum ${ }^{291}$. Consideró como fin de la pena, no sólo la enmienda del culpable, sino también y más principalmente la defensa social,

289 Summa Theol., II, 1, q. 90, 91, 95, a. 1: quia dum auferre vellet omnia mala, sequeretur quod etiam multa bona tollerentur et impedirentur. Sobre las teorías de Santo Tomás acerca del derecho penal, véase a V. Bar, Handbuch des deutschen Strafrechts,I, Berlín, 1880, p. 215-227.

290 Summa Theol., I, 2, q. 96, a. 2.

291 Summa Theol., II, 2, q. 77, a. 1. 
y vindicó para la autoridad pública el derecho exclusivo de castigar a los delincuentes ${ }^{292}$.

La abolición del derecho de venganza privada, y su sustitución por el derecho exclusivo del Estado a castigar a los delincuentes, se debe a la influencia bienhechora del Cristianismo; no, como se ha sostenido por algunos, a la tendencia humanitaria de los tiempos modernos. Los Padres y Doctores de la Iglesia condenaron siempre la venganza privada y reconocieron únicamente a la autoridad pública el derecho de penar ${ }^{293}$. De acuerdo con esto, Santo Tomás de Aquino ${ }^{294}$ enseña que "el dar muerte a los delincuentes es lícito, en cuanto se ordena a la salud del cuerpo social, y que, por tanto, es incumbencia exclusiva de aquel a quien está encomendado el cuidado de dicho cuerpo, como pertenece cortar el miembro podrido al médico a quien se ha encargado cuidar de la salud de todo el cuerpo. Ahora bien: el cuidado del bien común está encomendado a los Príncipes, que tienen autoridad pública, y por tanto sólo a ellos, no a los particulares, corresponde el dar muerte a los malhechores".

"El premio y la pena ${ }^{295}$ ", dice Soto, "son dos astros divinos que gobiernan el universo ${ }^{296}$ ". Fin principal de la pena es la defensa de la sociedad, que no podría subsistir si los crímenes quedaran impunes. La comparación de la pena capital impuesta al delincuente con el acto de cortar el miembro podrido para salvar el cuerpo humano, se encuentra a cada paso en los escritores de que tratamos. No solamente los teólogos, sino también los filósofos representados por Fox Morcillo, concuerdan en asignar a la pena el fin arriba indicado ${ }^{297}$.

292 Summa Theol., II, 1, q. 17, a. 3 y 4.

293 Véase a este propósito los textos aducidos por Kohler, Blutrache und staatliches Strafrecht der den christlichen Kirchenrätern, en su estudio Zur Lehre von der Blutrache, Wurzburgo, 1885, p. 25-31, el cual, aunque hace mérito de las opiniones de algunos teólogos posteriores a la Edad Media, como San Alfonso de Ligorio y el jesuita contemporáneo P. Lehmkuhl, no menciona a ninguno de los teólogos españoles que trataron esta materia.

294 Summa Theol., II, 2, q. 64, a. 3. Copiamos sólo este pasaje, que es el más característico: ...cura autem communis boni commissa est principibus habentibus publicam auctoritatem; et ideo eis solum licet malefactores occidere, non autem privatis personis.

295 Soto, De iust. et iure, I, q. 2, a. 2, apropiándose el dicho atribuido a Solón y Demócrates: Duo divina lumina cuneta gubernant; praemium scilicet et poena. Y el texto de San Isidro citado en la p. 38 , n. 2.

296 Orozco, Tract. III, p. 51 p. y 52 vo: Sane, ut membrum putridum mérito a corpore separatur, ne omnia membra contaminare possit, ita eos regno, civitate recte jura disponant ut flagitiosi occidantur. Ne forte respublica impiis impune agentibus, magnam subeat iacturam et pereat.

297 Foxo Morcillo. De regni etc., 1. I: ...quam sit Reipublicae utile, hominum laxum 
Además de la defensa social, consideran nuestros teólogos como fin de la pena la corrección o enmienda del delincuente ${ }^{298}$. No consideraron, sin embargo, con los defensores de alguna de las novísimas teorías penales que deba atribuirse a la corrección el carácter de fin exclusivo de la pena ${ }^{299}$; antes bien, cuidan muy especialmente de señalar que este fin debe subordinarse en todo caso al primero. Molina dice terminantemente, que "el poder público, en la imposición de las penas, no ha de mirar o atender tanto al bien del delincuente, como al bien común del Estado"30o. Es muy de notar, que Castro juzga que puede agravarse la pena para procurar la enmienda del delincuente y contener a los que pudieran contagiarse con su ejemplo ${ }^{301}$.

Todos nuestros escritores, así teólogos como filósofos, están contestes en negar al particular el derecho a tomar venganza por sí mismo de las ofensas recibidas, y en atribuir esta facultad única y exclusivamente al poder público. No pueden ser más terminantes en este punto los textos de Vitoria ${ }^{302}$, Soto, Molina, Suárez y Fox Morcillo. La facultad de imponer penas es privativa de las personas o corporaciones que tienen potestad para obligar a sus súbditos con fuerza coactiva, a fin de conservar el orden ${ }^{303}$. Sólo a la potestad pública civil y eclesiástica reconocen Castro ${ }^{304}$ y Soto el derecho a encarcelar o privar

legibus coercere, cum pleraeque Reipublicae studiose, caverint, ne corruptis civibus, una pereat quoque Respublica.

298 Castro, De iusta haeretic. punit., l. II: Duplicem constat esse causam, qua vehementer urget, ut malefactores iuxta variam suorum criminum qualitatem puniantur. Prima causa est ipsius malefactoris correctio et emendatio.

299 Aludimos a la llamada del derecho a la pena defendida por Krause, Röder y Ahrens y aceptada por algunos criminalistas españoles contemporáneos

300 Tract. III, Disp. 5., n. 6: ...potestas publica in puniendo, non tam respicit bonum ejus qui punitur, quam commune Reipublicae bonum.

301 De pot. leg. poen., l. II: ...quando autem poena ultra mensuram delicti augetur, tunc poena non habet solam punitionis rationem, sed etiam ad medicinam ipsius delinquenti, et aliis qui illus exemplo peccare possent...

302 Vitoria. Rel. de homicidio, n. 19: Octavo dico: quod tale homicidium solum de iure naturali et divino est commissum Reipublicae aut publicis magistratibus et principatibus, qui habent curam Reipublicae...

303 Vitoria. Relectio cit: Ea autem quae necessaria sunt ad gubernationem et conservationem orbis, sunt de iure naturali: nec alia ratione, probari potest quod Respublica iure naturali habeat auctoritatem afficiendi supplicio et poenis cives suos, qui Reipublicae sunt perniciosi.

304 De iusta haeretic. punit., lib. II: Omnis persona aut Respublica habens potestatem coactivam, potest subditos suos obligare ad ea, quae ad pacis et tranquilitatis obser- 
de la libertad ${ }^{305}$. No difiere la opinión de Fox Morcillo de la de los teólogos respecto a que solamente a la autoridad pública, y nunca a los particulares, corresponde el castigo de los delincuentes, y que, así como la venganza privada es injusta y perjudicial a la República, la pública, o sea la ejercida en nombre de la sociedad, es útil y necesaria ${ }^{306}$.

Alfonso de Castro divide las leyes en puramente penales, que son las que castigan determinados actos u omisiones, sin mandar ni prohibir cosa alguna; y penales mixtas, que son las que mandan o prohiben ciertos actos, conminando expresamente con alguna pena a los que infringen el precepto en ellas establecido ${ }^{307}$. En su opinión, sólo las de esta segunda clase obligan en conciencia a sus transgresores a la pena consiguiente, aun sin mediar sentencia del juez ${ }^{308}$.

La variedad de las normas del derecho penal, en armonía con el grado de cultura y estado social de los pueblos, se encuentra bellamente expresada por Molina, al afirmar que, así como el derecho de penar tiene su fundamento en la ley natural, la determinación de las penas es materia del derecho positivo $^{309}$. Oigamos sobre este punto a Alfonso de Castro: "La penalidad en concreto depende más del arbitrio que de la razón; de aquí la diversidad de las penas con que se castiga un mismo crimen en los varios reinos cristianos; pues aunque la razón natural, que es la misma siempre, muestra qué críme-

vationem sunt necessaria. Si quis autem illa praetermittens, pacem turbaverit, iuste potest illum iuxta criminis qualitaten punire.

305 L. V, q. 2, a. 3: Publicae potestati, eidemque soli, fas est, subditos in carcerem occludere, sive ecclesiastica sit, sive civilis.

306 Fox Morcillo. De regni., lib. II: Vindicatio autem est vel illatae iniuriae vel damni accepti compensatio: eademque aut privata, aut publica existit: privata, ut cum quis factam ab alio injuriam ulciscitur; publica, ea quo et Princeps et magistratus Reipublicae totius nomine utitur: illa injusta et perniciosa, haec utilis et necessaria est.

307 De potest. leg. poen., 1. I, c. 9: Lex pure poenalis est illa, quae nihil facere praecipit, aut prohibet: sed tantum imponit poenam illi, qui aut aliquid fecerit, aut facere omiserit. Lex poenalis mixta est, quae aliquid fieri praecipit, aut prohibet, et insuper verbis expressis statuit poenam contra eiusdem legis transgresorem, quocumque modo illa statuatur.

308 Ibid: ...omnem legem poenalem, quae sententiam continet ab ipsa latam, obligare in conscientia illius transgressorem ad poenam in illa statutam, absque aliqua alia judicis sententia.

309 Tract. 3, disp. n. 4: Deo relinquente rebus ipsis publicis, potestatibusque a rebus publicis ad leges condendas constitutis, arbitramentum ac determinationem in particulari poenarum iustarum pro unoquoque delicto, ut viderint expedire pro temporum et nationum varietate, spectatisque reliquis circunstantiis concurrentibus...; Esta misma doctrina había sido formulada ya por Santo Tomás. 
nes son dignos de castigo, no declara las penas que han de imponerse a los delincuentes. Lo cual queda al arbitrio humano, que es variable, y como consecuencia de esto, lo son también las penas dictadas por él. De donde también se sigue, que el argumento de semejanza o identidad no sea valedero respecto de las leyes penales" ${ }^{10}$.

Castro recomienda que la penalidad impuesta por las leyes sea proporcionada a la gravedad de los delitos ${ }^{311}, \mathrm{y}$ aconseja al legislador que cuide, en todo caso, de que la pena no sea demasiado atroz, ni cruel en relación con la culpa, antes sea siempre menor que ésta ${ }^{312}$. Dice asimismo, que la ley penal no ha de extenderse o aplicarse nunca más que al delito, persona o caso expreso en la ley, sin que, por razón de analogía, o por existir la misma razón, haya de aplicarse a otros casos, como es lícito hacer tratándose de otra clase de leyes ${ }^{313}$.

La cuestión de si las leyes penales deben o no tener efecto retroactivo, la resuelve Castro negativamente ${ }^{314}$.

Suárez cree que el arbitrio del juez pueda agravar la pena señalada por la ley, mediante ciertas circunstancias que hagan al delito atroz o gravísimo, pues "la ley, dice, habla sólo del delito ordinario y no excluye el proveer al bien común” ${ }^{115}$. Examinando el mismo Suárez la cuestión de la territorialidad

310 De potest. leg. poen. 1. I, c. 7: Et quia saepe poena ex arbitrio, potius quam ex ratione pendet, evenit, ut idem crimen in diversis orbis christiani provinciis diversa poena puniatur. Quia licet ratio naturalis, quae eadem est apud omnes, ostendat crimina esse punienda, qua tamen poena punienda sint, non perinde declarat ratio naturalis, et ideo voluntatis arbitrium accedere oportet, quo una potius quam altera poena eligatur. Et hinc evenire necesse est, ut quia humanum arbitrium non est idem apud omnes, poena etiam per legem decreta non sit eadem apud omnes. Et inde ulterius sequitur, ut argumentum a similibus, aut ab identitate rationis, sit in lege poenalis prorsus invalidum.

311 De iusta haeretic. punit., l. II: ...iuxta criminis qualitatem.

312 De potest. leg. poen. l. I, c. 6: Cum igitur legislator poenalem aliquam legem condere voluerit, summo studio cavere debet, ne poena per legem imponenda sit nimium atrox et crudelis, et quae culpa gravitatem trascendant; sed poena sit semper minor culpa.

313 De pot., I, 6: Lex poenalis numquam extendenda est ultra criminem aut personam, aut denique ultra casum in lege expressum: quamvis in aliis criminibus, aut in aliis casibus eadem ratio inveniatur, quae invenitur in casu per legem expresso. Et hinc est, quod in legis poenalis interpretatione, non licet arguere per argumentum a simili. quod alias non parvam vim apud iurisperitos habere solet. Hoc documentum de sola lege poenali intelligendum esse volo, et illi soli est peculiare: in aliis autem legibus aliquando contrarium agere licet.

314 De pot. leg., poen., l. I, c. 6.

315 De leg., 1. III, c. 8: Non tollitur quominus si delictum habuerit extraordinarias cir- 
de las leyes penales, asienta que las peculiares de cada país obligan, no sólo a los naturales, sino también a los extranjeros, en términos que pueden ser penados a causa de su transgresión por los jueces y conforme a las leyes del territorio en que delinquen ${ }^{316}$. Fúndase principalmente, en que la potestad del Jefe de cada Estado debe ser tan amplia como lo requieren la conservación del orden y de las buenas costumbres, de la cual son correlativas las de dictar leyes obligatorias para todos los habitantes del territorio y castigar a los extranjeros que en él residen cuando cometen algún delito.

Nuestros teólogos dedican especial atención a la cuestión de la licitud y necesidad de la pena de muerte, agitada ya entre los escolásticos de la Edad Media, alguno de los cuales, como Escoto, sostuvo no ser lícito a las potestades temporales aplicarla sino en los casos consignados en el Antiguo Testamento. Vitoria ${ }^{317}$, Soto ${ }^{318}$ y Alfonso de Castro ${ }^{319}$ combaten resueltamente la opinión de Escoto, y defienden que, no solamente en estos casos, sino también en todos aquellos en que lo exija la gravedad del delito, debe imponerse a los delincuentes la pena capital. Alfonso de Castro, que es entre todos ellos quien más de propósito discurre sobre el particular, dice que las leyes humanas puedan establecerla con plena justicia respecto a aquellos delitos para los cuales la pida la razón natural, insistiendo en que el error contrario, sobre ser opuesto a la Sagrada Escritura rectamente interpretada, es perniciosísimo a la sociedad ${ }^{320}$. Piensa, por lo demás, que debe emplearse la pena de muerte con sobriedad, no imponiéndola sino a los delitos muy graves, y recordando a

cunstantias, quae illud atrox vel gravissimum reddant, possit iudex prudenti arbitrio illas specialiter punire, quia dignae sunt speciali poena, et hoc non excluditur per legem, quae loquitur de delicto ut ordinarie committi solet, et non excludit providentiam ad bonum commune.

316 De leg., l. II, c. 6: Unusquisque gubernator reipublicae habet potestatem necessariam ad conservationem suae reipublicae, et ad eius bonos mores tuendos; ergo habet potestatem ad ferendas leges, quas omnes ibi morantes servare tenentur. Hac enim ratione habet potestatem puniendi advenas ibi delinquentes.

317 Relect. de homicidio, n. 20.

318 L. V, q. 1, n. 2.

319 De potest. leg. poen., l. I, c. 6: convincitur posse iuste leges humanas statui de poena mortis pro aliquibus criminibus inferenda, si ex iudicio naturalis rationis illam inferendam esse constiterit, quamvis in lege Mosaica similis poena non fuerit pro tali crimine expressa.

320 De iusta haeretic. punit., l. II, c. 12: Talis enim error, praeter hoc quod sacris repugnat litteris, humanum tollit convictum, pacem totius reipublicae perturbat, et omnem prorsus honestam pervertit politiam. 
este propósito, como en otros muchos lugares, la necesidad de que la mayor o menor gravedad de las penas se acomode a la de los delitos ${ }^{321}$.

Vitoria impugna resueltamente la opinión de aquellos que interpretaban el precepto non occides en términos absolutos, suponiéndolo regla general de que sólo por ley divina se exceptúan algunos casos, y que no estando entre estos el de la adúltera y el ladrón, no debía castigarse a éstos con dicha pena ${ }^{322}$.

Molina $^{323}$, siguiendo las huellas de Vitoria y Castro, diserta también ampliamente sobre este punto, valiéndose de la comparación usual de la sociedad civil con el cuerpo humano, e insistiendo en la necesidad de amputar el miembro podrido, cuando este sacrificio es necesario para conservar la salud general.

La severidad en la persecución y castigo de los herejes se consideraba generalmente en los tiempos de que tratamos como el único medio verdaderamente eficaz para contener la propagación de los errores contrarios al Catolicismo. Y no era de escaso valor el argumento que sacaban en favor de su tesis los propugnadores de dicho sistema, comparando la difusión que alcanzaban en otros países con la escasísima que habían tenido en España, gracias a los rigores de la Inquisición ${ }^{324}$. Infiérese, por lo demás, claramente de algunos

321 De potest. leg. poen., l. I, c. 6; Poena mortis nonnisi pro valde gravi delicto, et quod vehementer, reipublicae nocere possit, statuenda est. Aliae etiam poenae semper juxta delicti mensuram, quae potissimum est proximi nocumento aut publicae pacis turbatione capietur, sunt infligendae. Qualiter autem poenarum diversitas statuenda sit, congrua, et aptissima similitudine a corpore humano sumpta optime doceri potest.

322 Vitoria, Relectio de homicidio, n. 18: ex intencione licitum est, stando iu iure divino solum et naturali, occidere hominem nocivum, socium Reipublicae, quia homo est membrum communitatis, et ideo sicut licitum est abscindere membrum corruptum nocivum toti corporis, ita est licitum in iure divino et naturali hominem perniciosum et bonis communis corruptorem interficere, etiam si hoc numquam fuerit expressum in iure divino scripto: quia hoc est notum in lumine naturali, quod maius bonum debet preferri minori bono et privato bono publicum bonum.

323 Tract. III, disp. 1 y 8: ita quando bono communi reipublicae, illius pacis securitati ac conservatione, expedit, ut corrupti quoque moribus omnino abscindantur plectendos illos morte, quam in poenam justam ob sua flagitia commerentur, ut timore tantae poenae homines similia flagitia committere in ea non audeant, fas est reipublicae ipsa ministrisve publicis ad id ab ea deputatis, morte illos punire eos, a república abscindendo.

324 Castro, De iusta haeretic. punit., 1. II, c. 4: Hoc enim manifesta experientia compertum est, provincias illas, in quibus severa contra haereticos viget iustitia, multo plus ab haeretibus esse purgatas, quam illae, in quibus effraenata est omnibus concessa licentia docendi et praedicandi quidquid libuerit. Huius rei testis fidelissimus est nostra Hispania, 
pasajes de las obras de Alfonso de Castro no ser tan corriente, como podría creerse, dado el espíritu de la época, la opinión de que los herejes debían ser castigados por las leyes civiles; antes parece evidente, que, en sentir de algunos, el poder público debía abstenerse en absoluto de proceder contra aquellos ${ }^{325}$.

El objeto de la obra De iusta haereticorum punitione fue persuadir bien a los Príncipes cristianos de que debían emplear, sin contemplación alguna, contra los herejes pertinaces y obstinados todas las penas consignadas en las leyes, a fin de poner coto a la propaganda de sus errores y obligarles a abjurar de ellos ${ }^{326}$. En su exceso de celo contra los herejes, sostuvo una y otra vez ${ }^{327}$ Alfonso de Castro estar aquellos obligados en conciencia a entregar al Fisco los bienes que poseían, sin que mediara sentencia de los tribunales imponiéndoles esta pena; opinión que, según él mismo declara, fue impugnada por doctos teólogos de su tiempo ${ }^{328}$.

Ni Alfonso de Castro, ni los demás teólogos de los siglos XVI y XVII que trataron esta cuestión, preconizaron la institución de un nuevo procedimiento, ni de una nueva penalidad contra los herejes; pero consagraron todo su vigor dialéctico y toda su pasmosa erudición sagrada y profana a defender la licitud y oportunidad del procedimiento y de la penalidad vigentes a la sazón,

ad quam, propter acerbum disciplinae rigorem in ea adversus haereticos vigentem, vix ullus est ausus accedere ad Lutheranam sectain praedicandam, aut docendam: quamvis multi ex hac pestifera factione per reliquas fere omnes Christiani orbis provincias pervagentur.

325 Así resulta, entre otros varios, del pasaje citado en la nota 172 y del de De iusta haeretic. punit., 1. II, c. 3: Quamvis haereseos crimen sit adeo pestilens, et intractabile, ut inter omnia humana scelera nullum sit, quod toti Christianae reipublicae magis nocere possit, et cui minus medicare valeat, non defuere tamen haereticorum patroni, qui pro illorum impunitate contendant, dicentes haereticos non esse ob haereseos crimen puniendos, sed divino iudicio relinquendos.

326 Epístola dedicatoria que precede a la obra: ut Principes chriastiani, de haereticorum punitione bene persuasi, nullam illarum poenarum, quas iura contra haereticos decernunt praetermitti patiantur quin illam pertinacibus quibuscumque haereticis, et obstinatis infligere iubeant, ut poenarum metu illi coerceantur, ne similes novitates, et insanias effutire audeant, et sic tándem a suis erroribus resipiscant.

327 De iusta haeretic. punit., l. II, c. 6 y De potest. leg. poen., l. II, c. 9.

328 De potest. leg. poen., l. II, c. 9: haereticum esse in conscientia obligatum ad reddendum ad fiscum bona quibus est ipso iure privatus, aliqui docti viri in variis Hispaniae scholis Theologiam publice profitentes (ut ab iis, qui audierunt, mihi relatum est) hanc meam sententiam publice reiecerunt, et illi non esse ullatenus acquiescendum auditores suos docuerunt. 
conforme a las normas del derecho canónico y del civil, y sobre todo encarecieron a los Príncipes con vehemencia y tenacidad incansables la estrecha obligación en que estaban de consagrar sus esfuerzos a la persecución y castigo de los herejes ${ }^{329}$. Fuerza es reconocer, por lo demás, que esta semilla caía en tierra bien preparada para recibirla. La pena de muerte, como único castigo digno de los herejes obstinados, la confiscación de bienes ${ }^{330}$, la infamia (con todas sus terribles consecuencias en aquellos tiempos), transmisible a la posteridad del hereje ${ }^{331}$, la privación de la patria potestad ${ }^{332}$, encontraron en Alfonso de Castro el más acérrimo y vigoroso defensor. Sostuvo resueltamente la opinión corriente a la sazón entre los teólogos y canonistas, de que el hijo del hereje estaba obligado en conciencia a denunciar a su padre, sin que ni la voz de la sangre, ni la consideración de los males que atraía sobre sí mismo (la infamia y la confiscación) debieran retraerle del cumplimiento de este deber. No tuvo tampoco reparo alguno en declarar que, en el confesonario, se había esforzado, bien que infructuosamente, por conseguir este sacrificio de uno de sus hijos de penitencia ${ }^{333}$.

329 Castro, De iusta haeretic. punit., l. II, c. 12. Haec causa est (la ejemplaridad) quae iustificat leges quae praecipiunt occidere fures, pyratas, sicarios, homicidas, et alios eiusdem notae homines. Si haec iusta est causa, ut homo sceleratus e vita tollatur, consequens est, ut iustum etiam sit haereticum incorregibilem e vita tollere: quia si superstes esset, aliis Catholicis vehementer nocere poterit.

330 De iusta haeretic. punit., l. II, c. 5: iuste tamen omnium bonorum proscriptione punientur... quia haeresis (ut supra ostendimus) gravissimun est crimen, in eo puniatur quod acerbisime omnes fere homines affligere creditur; et ut talis poenas metu in crimen haeresis labiformident. Et si huius poenae terrore haeresim non fugerint, iustum est, ut eam ipsam poenam quam pro haeresis amore neglexerunt patiantur.

331 De iusta haeretic. punit., 1. II, c. 9.

332 De iusta haeretic. punit., l. II, c. 8. Iustum igitur fuit, et necessarium, a parentibus haereticis patriam omnes aufferre potestatem, et filius sui iuris suique arbitrii facere, ne parentes, sua auctoritate suoque exemplo, filios in eadem haeresim traherent, et filii, iuris auctoritate fulti, possent, si voluerint, parentibus resistere, tamquam qui iam sunt ipso iure ab illorum potestate liberati.

333 Op. cit., l. II, c. 26: nitebatur eumdem filium, ut patris crimen quamlibet occultum, Inquisitoribus revelaret, et, quamvis id necessario est faciendum multis evidentibus rationibus convincerem, numquam tamen ut id facere vellet, illi persuadere potui. Nam hoc scuto se tuebatur, quod non erat decens, neque ratio naturalis patiebatur, ut filius patrem ad mortem duceret. Deinde semetipsi nocere dicebat, si patris crimen revelasset, quia non poterat (ut dicebat) patris crimen revelare, quin sibi ipsi injuriam inferre, et sui suo gladio transfodere. 
Por grande que sea la eficacia de la palabra hablada, no puede compararse en manera alguna con la influencia persistente de la palabra escrita. iCon cuánta verdad y vehemencia expresa esta idea ${ }^{334}$ Alfonso de Castro, para inferir de aquí el esmero y diligencia con que ha de prohibirse la circulación de los malos libros y la severidad con que han de ser castigados sus autoresy propagadores! Nuestro Autor censura con este motivo ${ }^{335}$ la negligencia de algunos jueces y la codicia de otros, causas frecuentemente de que, en vez de ser destruídos por el fuego los libros heréticos, fueran vendidos a todo el que quería comprarlos y corriesen libremente de mano en mano; y elogia la providencia del Consejo de Castilla prohibiendo los libros escritos en lengua vulgar contra los herejes, y conminando con graves penas a los que se dedicasen a vender anteriormente los publicados ${ }^{336}$.

En la segunda mitad de la Edad Media, la superstición bajo sus diversas formas creció grandemente, no contribuyendo poco a ello el contacto con Árabes y Judíos, asiduos cultivadores de la astrología y nigromancia. Los Concilios condenaron la magia y todo género de supersticiones, a pesar de lo cual esta mala hierba llegó a tomar grandes proporciones. Gerson y la mayoría de los teólogos parisienses pensaban que muchas de las cosas atribuidas a la influencia demoniaca eran de origen natural; pero reconocían la posibilidad de la magia debida a la influencia satánica y condenaban la opinión de que no era idolatría tratar con el diablo. La Facultad de Teología de París había censurado proposiciones y escritos sobre magia en 1398, 1431, 1466 y 1493. En suma, fue condenada por los teólogos como delito afín de la herejía, y en este concepto sujeto a la jurisdicción eclesiástica, y castigada por las leyes civiles con penas severísimas.

334 De iusta haeret. punit., l. II, c. 14: Habet adhuc aliquid peculiare scriptura, per quod multo latius nocere potest, quam oratio prolata: quamvis illa sit tam anxie praecogitata, ut in qualibet illius junctura millies orator caput scalpserit, otosque desoserit ungues. Nam verbum semel ore prolatum, irrevocabile volat. Quo fit, ut nulla in posterum sit potestas illius; quia, ut semel ab ore fuerit emissum, nemini praeter illos, qui tunc audierunt, se solo prodesse, aut obesse poterit. Ea vero quae scripta sunt, per multa saecula servantur.

335 De iusta haeret. punit., l. II, c. 18: Non semper haereticorum libri (ut necessario faciendum esse in praecedenti capite docuimus) comburuntur, immo aliquando, propter iudicum ad quos spectat negligentiam, aliquando propter negotiorum pessimam avaritiam, passim omne emere volenti venales exhibentur, ut quisquis voluerit eos legere possit.

336 De iusta haeret. punit., l. I, c. 2. 
Nuestros teólogos, a contar desde Vitoria, dedicaban especial atención a la magia, examinando los fenómenos comprendidos bajo esta denominación y conviniendo en que, aun cuando muchos de ellos eran ficticios, había otros indudablemente verdaderos y cuya explicación no podía encontrarse sin admitir la intervención del demonio ${ }^{337}$. Entre las obras teológicas dedicadas al examen de la magia, ninguna alcanzó tanto crédito, ni tanta difusión, dentro ni fuera de España, como los Disquisitionum magicarum libri sex ${ }^{338}$ del jesuita Martín del Río, obra que vino a ser considerada clásica en la materia, y cuya boga atestiguan, así las numerosas ediciones que de ella se hicieron, no obstante su desmesurada extensión, como la frecuencia con que se encuentra citada en las obras teológicas y jurídicas del siglo XVII. Contrastan con la prudencia y sobriedad de Vitoria al tratar este asunto, la excesiva credulidad y falta de crítica de Martín del Río, defectos que recientemente ha reconocido en él un ilustre teólogo contemporáneo, hermano de hábito del Autor339. Tanto se sutilizó y desatinó al tratar de la magia, que hubo autor como Torreblanca ${ }^{340}$, el cual, dándose a investigar el carácter jurídico del pacto con el diablo, sostuvo ser un contrato innominado, Do ut facias, en cuya virtud adquiría el diablo el derecho a ejercitar la acción praescriptis verbis contra su contratante, sin que éste pudiera intentar acción alguna contra el diablo; porque, "no siendo éste pura criatura, no podía contraer una obligación natural”.

La usura, castigada por el derecho romano en cuanto excedía de la tasa legal, prohibida luego por la Iglesia en absoluto, penada severamente durante la Edad Media y los comienzos de la moderna por las leyes civiles, borrada del catálogo de los delitos por los esfuerzos unidos de la filosofía racionalista y de la Economía política del siglo XVIII, vuelve en nuestros días, según la opinión de criminalistas eminentes y la legislación de Alemania, a ser considerada como delito, en el sentido que lo fue por los Romanos.

337 Relect. de magia, 3: Eorum quae a Magis fiunt, licet nonnulla fiant solum per illusionem et prestigia sensum, quaedam tamen in re et secundum existentiam fiunt.

338 Maguncia, 1593. Véase sobre toda esta materia el excelente capítulo IV del tomo II de la Historia de los heterodoxos españoles de Menéndez y Pelayo, p. 646-568.

339 Hurter, Nomenclator literarius theologicae catholicae. I, Insbruck, 1876, p. 352: "refert facta mira atque stupenda, sed plura tamen dubia atque incerta, ita ut merito sagacior artis criticae desideretur usus".

340 Orozco, Tract. III: ...usura et suo vocabulo detestanda est, eo quod rapinam indicat ... Caveat maxime Rex, ne tam nefandi criminis eum noxa involvat, deinde solerti cura invigilet, ne pestis haec lethalis civitatem vel regnum inficiet. 
Difieren nuestros teólogos en cuanto a calificar a la usura de delito que deba ser penado por las leyes civiles. Algunos, como Orozco, la califican de rapiña y de crimen nefando, y exhortan al Soberano para que cuide de que tan mortífera peste no inficione a la sociedad ${ }^{341}$. Soto cree que las leyes civiles pueden no imponer castigo a los usureros, del mismo modo que omiten el castigar a las prostitutas; comparación poco lisonjera para los que se dedican a semejantes granjerías ${ }^{342}$.

Durante el siglo XVI, se consolida en materia de derecho penal una evolución iniciada en los últimos tiempos de la Edad Media, no por obra de los Soberanos, sino por el trabajo lento o incesante de la práctica y de la jurisprudencia, influidas por las doctrinas jurídicas del derecho romano. "Sus principales promovedores fueron las que podríamos llamar clases ilustradas de la época, las más imbuidas en la corriente de las ideas modernas de su tiempo; en una palabra, los legistas".

Observando los rasgos fundamentales de esta transformación, vemos que, al carácter local y autónomo que ofrece el derecho penal de los tiempos anteriores, por virtud del cual, así el cuadro de los delitos como el de las penas, variaba a veces extraordinariamente de una ciudad a otra, sustituyen doctrinas y prácticas comunes en lo esencial, iniciándose de esta suerte la que con exactitud ha podido calificarse de era del derecho penal europeo. Durante ella, la doctrina reina como soberana absoluta sobre la jurisprudencia práctica. Los jueces y tribunales no acuden en busca de reglas de conducta y de la instrucción necesaria para el buen desempeño de su oficio a los antiguos Fueros y Ordenanzas, sino a los escritos de los criminalistas, sobre todo a los de los comentadores italianos. El derecho penal romano, desarrollado por los jurisconsultos italianos de la Edad Media, influyó más bien en la práctica que en la teoría. La serie de los delitos o actos punibles no se modificó esencialmente, si se exceptúan los delitos de lesa majestad, desconocidos del antiguo derecho germánico en la extensión que les dio el romano: y las terribles penas usadas en la Edad Media germánica no cedieron el puesto a las más humanas del derecho romano.

341 Demonologia sive Magia naturalis, Maguncia, 1623.

342 De iustitia et iure, VI, q. 1, a. 1: Quod autem usurarii civilibus poenis non subiaceant, non est contra fidem; sicuti neque id quod meretrices nullo afficiantur supplicio; y la razón la indica poco antes, abundando en las ideas de Santo Tomás respecto al ámbito de la ley penal. Nam Principes illa tantum ulciscuntur, quae paci et quietudini reipublicae officiunt, praesertim per vim... 
Respecto a los delitos contra las personas y los bienes, siguen todos nuestros teólogos en general las opiniones corrientes entre los jurisconsultos de su tiempo, en especial las consignadas en las Sententiarum receptarum libri $V$, seu Practica criminalis, de Julio Claro, italiano de nacimiento al servicio de Felipe II, que murió en Zaragoza el año 1575 (cuya autoridad no fue eclipsada por otro alguno hasta la aparición de su compatriota Farinacio) y en la del príncipe de nuestros criminalistas del siglo XVI, Antonio Gómez; razón por la cual, debemos considerarnos dispensados de exponer sus ideas acerca de la materia.

Los teólogos que tratan ex professo del procedimiento se limitan por lo general a exponer las normas del derecho canónico y civil y las opiniones de los jurisconsultos prácticos de la época sobre este particular ${ }^{343}$. De aquí que debamos prescindir también de la reseña circunstanciada de sus doctrinas en lo que a esto se refiere, concretándonos a indicar algunas teorías que les son peculiares acerca de la potestad de los Príncipes en sus relaciones con el derecho procesal. Singularísima entre los teólogos españoles, en cuanto se me alcanza, fue la sostenida en este punto por Fray Diego de Chaves, confesor de Felipe II; el cual no vaciló en afirmar que el Rey estaba facultado para condenar a muerte a Escobedo sin formación de proceso. "El Príncipe seglar", decía, "que tiene poder sobre la vida de sus súbditos y vasallos, como se la puede quitar por justa causa y por juicio formado, lo puede hacer sin él, teniendo testigos"344. Pero tan absurda y peligrosa doctrina, corriente, por lo demás, entre los principales jurisconsultos de la época respecto a los delitos de lesa majestad, fue enérgicamente combatida por Domingo de Soto y Santiago Simancas.

Examinando Soto si es lícito al particular dar muerte al malhechor, afirma resueltamente, que esta facultad solamente la tienen la República y el Príncipe o magistrado público ${ }^{345}$; y al dilucidar la cuestión de si puede el Sobera-

343 Basta, para convencerse de ello, recorrer la pars posterior del t. III de la obra de Molina que trata de delictis et quasi delictis, en especial las disputationes 680 a 696, dedicadas principalmente al hurto, la rapiña y el damnum datum. Otro tanto puede decirse del procedimiento, descrito en los tratados 1-10 del libro v de la misma obra.

344 Véase la carta de Antonio Pérez inserta por el Marqués de Pidal en su Historia de las alteraciones de Aragón, tomo I, Madrid, p. 295, y las consideraciones de Cánovas del Castillo, Las ideas políticas etc., p. 506, que recuerda la condenación de esta doctrina por Saavedra Fajardo en su Empresa 22, cuando dice: "El que hace la justicia a escondidas, más parece asesino que Príncipe".

345 L. VI, q. 4, a 3: soli Reipublicae, Principique, ac publico magistrato licitum est maleficos occidere. 
no otorgarla a los particulares, contesta en términos generales que no debe hacerlo sino con ciertas limitaciones; que nunca puede otorgarla a todos los súbditos, para vengar mutuamente sus injurias, y en ningún caso sin preceder sentencia condenatoria; que, mediante esta sentencia, puede concederla para matar a los ladrones públicos y enemigos declarados de la República, a quienes no se pueda prender, bien que sólo en casos rarísimos. Declara, por lo demás, resueltamente, a este propósito, ser contra el derecho natural condenar al reo sin formación de proceso, considerando el derecho de defensa patrimonio sagrado aun de los mayores criminales ${ }^{346}$. No es menos explícito Santiago Simancas, al asentar que, por manifiesto que sea un delito, nunca se debe prescindir para imponer la pena, de la formación de causa ni de la sentencia del juez competente, ni se ha de negar al reo el derecho de defensa ${ }^{347}$. Tal era la opinión de los dos ilustres teólogos mencionados, mientras entre los criminalistas de toda Europa prevalecía la de Fr. Diego de Chaves.

El tormento, muy usado entre los Visigodos, que lo tomaron de los Romanos, desconocido de los Fueros municipales, vuelve a tomar carta de naturaleza en España en la segunda mitad de la Edad Media, como consecuencia de la recepción del derecho romano, no sólo en Castilla, sino también en Aragón ${ }^{348}$ y Navarra ${ }^{349}$, para no desaparecer hasta principios del siglo actual; bien que habiéndose mitigado mucho su aplicación desde fines del XVII y ya en completo desuso el XVIII. No fue, por lo demás, como es bien sabido, peculiar de nuestra España tan absurda práctica judicial, ni se prolongó su uso entre nosotros mucho más que en los restantes países de Europa.

La conveniencia del empleo de la tortura para arrancar al reo la confesión de su delito, hasta tal punto se había arraigado en las costumbres, que no hay publicista alguno de los siglos XVI y XVII, así teólogo como jurisconsulto, que, al tratar incidentalmente de esta práctica judicial, no la tenga por buena y conducente a su objeto. Aun el doctísimo Antonio Agustín, al comentar la Epístola del Papa Nicolás a los Búlgaros, en que algunos creían encontrar

346 L. VI, q. 7, a.3.

347 De cathol. Instit., tit. 9, n. 166: ...nullo iure aut evidente ratione probatur, quinimo crimines manifestissime egent causa cognitione atque sententia judicis competentis; neque tam evidens potest esse delictum, quod aliqua justa defensione in toto, aut in parte defendí aut excusare non queat.

348 Véase sobre la práctica del tormento en estos dos reinos, a Acevedo, Ensayo acerca de la tortura, Madrid, 1817, p. 26-51.

349 Yanguas, Diccionario de antigüedades del reino de Navarra, t. III, páginas 374-375. 
una censura de semejante práctica, se declara partidario de ella y pretende demostrar que el mencionado documento no contiene tal condenación. La única voz discordante en el general concierto de alabanzas a la tortura es la del insigne Luis Vives, quien al comentar cierto pasaje de los sermones de San Agustín, en que este Doctor de la Iglesia alude a la crueldad y falibilidad del tormento, se pronuncia resueltamente contra él. "Verdaderamente, dice, fue invención de Tarquino o de algún otro tirano, aún más cruel, la idea de averiguar la verdad por medio de los tormentos; pues el dolor obliga a mentir aun a los inocentes. Me admira que los cristianos conserven con tenacidad, como si se tratara de cosas religiosas, prácticas gentílicas, contrarias no sólo a la caridad y mansedumbre cristianas, sino a todo sentimiento de humanidad. Dice San Agustín, que se empleaban los tormentos por obligar a ello la sociedad humana: ¿pero quién no repara que habla con los gentiles? ¿qué necesidad tan intolerable es esta, que ni es útil y puede abolirse sin daño público? ¿Cómo viven sin el tormento tantas naciones, aun las calificadas de bárbaras por los griegos y los latinos, las cuales juzgaban fiero y cruel atormentar a un hombre de cuyo delito se duda? Nosotros, hombres dotados de sentimientos de humanidad, atormentamos a nuestros semejantes para que no mueran inocentes. De esta suerte causan más compasión que si se les quitase la vida, pues a veces los tormentos son más crueles que la muerte. Por ventura, ¿̇no vemos con frecuencia y diariamente que hay quien prefiere morir a sufrir los tormentos, y, seguro de ser ajusticiado, confiesa el delito que no ha cometido? Tenemos a la verdad almas de verdugos; pues podemos sufrir los lamentos y llantos arrancados por el dolor a hombres cuya culpabilidad ignoramos" 350 .

El derecho del Soberano de indultar a los reos del todo o parte de la pena, así como el de conceder amnistía general en algunos casos, fue reconocido por el derecho romano y practicado frecuentemente bajo el Imperio. El derecho visigodo y las leyes de Partida lo aceptaron, como consecuencia de la recepción del derecho romano, y muy luego vino a tomar carta de naturaleza en todos los países. El primer escritor que formuló científicamente la teoría del indulto, fijando su concepto y límites, no bien determinados hasta entonces, fue Julio Claro, considerándolo como atribución exclusiva del Príncipe, la cual, sin embargo, podían ejercer por costumbre otros señores jurisdiccionales, y presuponía en todo caso el consentimiento del ofendido. Los teólogos españoles que tratan esta cuestión la resuelven difiriendo esen-

350 Pasaje citado por Acevedo, p. 75-76. 
cialmente respecto a ella. Así, Suárez no duda en reconocer al Soberano la facultad, que niega a los jueces, de rebajar al delincuente la pena que se le hubiere impuesto, fuera de los casos en que la ley lo mande expresamente o lo exija la equidad ${ }^{351}$. En cambio, Soto, después de afirmar y demostrar que el poder público tiene facultad derivada del deber de conservación para castigar a los malhechores aun con pena de la vida si es necesario ${ }^{352}$, declara que el Príncipe no está facultado para indultarlos, porque esto redundaría en daño de la República. Y no lo juzga lícito ni aun en en el caso que, conservando la vida a los delincuentes, se supiera que habían de enmendarse y salvarse, y de que constara por revelación que, dándoles muerte, habían de condenarse. "Pues la pena impuesta por el poder público", dice, "no se endereza a procurar la enmienda ni el bien del culpable, sino el bien público, atemorizando a los demás".

En resolución, la influencia de los teólogos españoles en el derecho penal y procesal me parece haber consistido, más bien que en introducir y acreditar instituciones nuevas, de lo cual no podría encontrarse quizá ni un solo ejemplo, en haber contribuido a consolidar y arraigar los procedentes del derecho romano y canónico, aclimatadas en nuestro suelo merced a la acción más directa y eficaz de los jurisconsultos, especialmente de los italianos, comentadores de las fuentes del derecho justinianeo.

Mérito suyo indiscutible, es haber vindicado constantemente para la autoridad pública el derecho de penar, mientras jurisconsultos tan eminentes como Grocio consideraban lícito en algunos casos el ejercicio de la venganza privada; haber precisado el ámbito en que ha de moverse la ley penal, y haber fijado los conceptos fundamentales de la ciencia del derecho penal, sostenien-

351 Suárez, De legibus, t. II, p. 52. At vero princeps habet supremam potestatem, et ad interpretandam legem, et ad dispensandum, quotiescumque prudenter iudicarent, causam esse sufficientem, vel rationabilem. Unde sicut Pontifex saepe censetur iuste indulgentiam concedere ob similem causam... item potest facere remissionem in gratiam alterius principis id postulantes: nam haec beneficentia mutua necessaria est, et redundat etiam in bonum commune. Item propter utilitatem personae, quae delinquit, vel propter priora obsequia, potest interdum iuste eum in poena dispensare.

352 L. VI, q. 5, a. 2. Quo enim se quisque jure tueri potest, cum hostis interimere, et quo potest sibi membrum amputare ut ipsi sit super, potest Respublica se incolumen percivis sciem servare.

Ibid.: Et ratio est, quod punitio publica non refertur in emendam, neque in bonum ipsius qui punitur, sed in bonum publicum... 
do acerca de la pena y las normas para su aplicación doctrinas tan sólidas como elevadas ${ }^{353}$.

En algunos puntos en que hubieran debido ser atendidas sus excitaciones y aplicadas sus doctrinas, como en lo relativo a la proporción de las penas con los delitos, tan recomendada por Alfonso de Castro, no encontraron eco en el poder legislativo. Si no puede atribuírseles la gloria de haberse adelantado a su tiempo, iniciando la reforma del sistema penal y procesal consagrado por la tradición, justo será reconocerles la de haber abogado por una aplicación menos severa de las penas; de haber robustecido la autoridad y eficacia de las leyes penales presentando la sumisión a como un deber de conciencia y de no haberse opuesto a que se tradujeran en las leyes ideas más humanitarias, traídas por ajenas corrientes, cuando la influencia del Tratado de los delitos y de las penas de Beccaria vino a impulsar entre nosotros la reforma de la legislación criminal.

Por lo demás, si el haber sido el primero que, en un tratado escrito $e x$ professo discurrió acerca del derecho natural y de gentes (pues que el fondo de su doctrina en lo que tiene de más sólido y acertado pueden reivindicarlo nuestros teólogos), se ha atribuido a Grocio la gloria de fundador de esta disciplina, con el mismo fundamento puede atribuirse a Alfonso de Castro la de fundador de la ciencia del derecho penal, título que justifican además la importancia intrínseca de su obra, donde se plantean y resuelven con novedad y amplitud algunos problemas cardinales de aquella ciencia.

Las ideas de nuestros teólogos respecto a la penalidad que debía imponerse a los delitos religiosos, singularmente a la herejía y la magia, que tanto chocan con los dominantes en el día, no eran, por otra parte, exclusivas de los teólogos católicos, sino propias también de los protestantes de su época. Lutero y Melanchthon defendían en forma mitigada la persecución de los disidentes, consignada merced a ellos en los Códigos de los Estados luteranos, y esta misma doctrina fue defendida también y practicada con formas más crudas y violentas por Calvino y Teodoro Beza ${ }^{354}$. Basta recor-

353 Sin desconocer la importancia capital de la obra de Beccaria, debe tenerse como muy distante de la verdad el juicio que formula Cantú, Beccaria et le droit penal, París 1887, p. 283, sobre las teorías penales anteriores al criminalista italiano: "Antes de Beccaria”, dice, "no se había encontrado, ni se había buscado siquiera, una teoría jurídica o científica del derecho de penar; o bien sólo se paraba atención en la ejemplaridad. Beccaria hizo sentir la necesidad de fundar este derecho sobre principios que demostrasen su justicia, enlazándole con los orígenes del derecho natural”.

354 Janet., Op. cit., II, p. 38 y sig.- V. Bar, Handbuch des deutschen Strafrechts. I, p. 
dar a este propósito el proceso y la muerte de nuestro compatriota el antitrinitario Servet.

"La Reforma", dice el ilustre criminalista protestante Wachter355, "no modificó en lo mas mínimo las ideas dominantes con anterioridad respecto a la hechicería. Los reformadores, especialmente Lutero, estaban íntimamente penetrados de ellas, y la Iglesia protestante no quiso ser menos celosa que la católica en punto a anatematizar los pactos con el diablo. Las Disquisiciones mágicas de Martín del Río adquirieron muy luego gran autoridad entre los protestantes alemanes".

El príncipe de los criminalistas protestantes en el siglo XVII, Benito Carpzov, en su Practica rerum criminalium, se apoyó en la autoridad de nuestro jesuita del Río para sostener la realidad de los pactos con el diablo; defendió, como él, la imposición de la pena de muerte a los reos de este delito, y se hizo famoso, entre otras cosas, por haber sentenciado a la hoguera más de un centenar de brujos ${ }^{356}$.

130, recuerda a este propósito la condenación de Servet y observa que Beza, en el tratado De haereticis a civili magistratu puniendis expone la misma doctrina de los teólogos católicos sobre la persecución de los herejes.

355 Beiträge zur deutschen Geschichte, Tubinga, 1845, p. 216.

356 Wächter, Beiträge, p. 282-292 


\section{CAPÍTULO VIII}

Importancia capital de los escritos de nuestros teólogos en la historia del derecho internacional.- Ocasión de dedicarse con especialidad al estudio de esta rama del derecho.Polémicas entre Las Casas y Sepúlveda.- Vitoria trata el primero científicamente estas cuestiones.- Resumen de sus opiniones en materia de derecho internacional.- La cuestión de la esclavitud: soluciones encontradas de Sepúlveda, por una parte, y de Vitoria y la generalidad de los teólogos por otra.- Declaración pontificia sobre el particular.- Influencia que ejercieron estas controversias en las leyes de Indias, y las teorías de nuestros teólogos en el desenvolvimiento científico del derecho internacional.

La gloria más indiscutible y más universalmente reconocida de nuestros teólogos es su influencia en las teorías fundamentales del derecho internacional ${ }^{357}$.

El descubrimiento del Nuevo Mundo, y las polémicas que muy luego se suscitaron sobre la conducta de los Españoles con los indígenas, dieron ocasión para que se investigase el título en virtud del cual los monarcas de España se enseñorearon de ellos y los derechos que habían adquirido por este concepto. De aquí surgió una copiosa literatura, en cuyas producciones se examinan, a veces serena e imparcialmente, pero las más con apasionamiento y encono, los arduos e importantes problemas que había venido a plantear por primera vez a la ciencia del derecho internacional aquel trascendentalísimo suceso. No es de este lugar la exposición detallada de los orígenes y vicisitudes del movimiento científico relacionado con esta cuestión: nos limitaremos, por tanto, a indicar sus principales etapas y sus resultados esenciales.

Inició la serie de importantes publicaciones sobre la materia, el Diálogo del célebre humanista cordobés Juan Ginés de Sepúlveda, titulado De honestate rei militaris, qui inscribitur Democrates, seu de convenientia disciplinae militaris cum christiana religione, impreso en Roma en 1535, origen de empeñada polémica con el famoso obispo de Chiapa, Fr. Bartolomé de las Casas, la cual vinieron a avivar y enconar muy luego el tratado De iustis belli causis contra Indios suscepti sive Democrates, y la Apologia pro libro de iustis belli causis contra Indios suscepti del primero, que fue impresa en Roma en 1550, y las réplicas de Las Casas a Sepúlveda. Además del número considerable de escritos en que se tratan de propósito estas gravísimas cuestiones,

357 Sirve de base al presente capítulo mi discurso sobre Francisco de Vitoria, Madrid, 1889 p. 38-50. 
apenas hay obra importante de teología o derecho de las publicadas en el siglo XVI, donde no se discurra también sobre ellas, a lo menos incidentalmente. Debióse esto, no sólo a la importancia capital del asunto y a su íntima relación con las dos indicadas disciplinas, sino también y muy principalmente al ardor de la polémica empeñada, y al afán verdaderamente extraordinario con que los partidarios de las diversas opiniones se esforzaron por allegar adhesiones de los hombres más eminentes de la época.

Entre las publicaciones a que nos referimos, descuellan por su importancia, y forman época en cierto modo, las dos Relectiones que Vitoria dedica a tan importante materia.

$\mathrm{Al}$ examinar los títulos en que pudo fundarse la dominación de los españoles en el nuevo Continente, asienta Vitoria ser derecho de cada nación respecto de las demás, inclusas las salvajes, mantener relaciones comerciales y comunicarles la verdadera religión, sin usar de medios violentos. De aquí puede surgir la dominación de un Estado sobre otro, bien por la sumisión voluntaria de los naturales, ya por la necesidad de defenderlos contra sus antiguos señores, si éstos los tiranizasen, ya por derecho de conquista, cuando, resistiéndose el pueblo en cuestión a sostener las indicadas relaciones, proporcionara causa justa para declararle la guerra. Las teorías de Vitoria sobre el derecho de la guerra son desarrollo de las sentadas por el derecho canónico.

La Iglesia, bien que, como poder esencialmente moral, no pudiera hacer desaparecer por completo los restos de la antigua barbarie, ni arrancar de raíz los gérmenes de mal existentes en el fondo de la naturaleza humana degenerada, hizo esfuerzos gigantescos por atajar y atenuar en lo posible estos males, ya formulando de una manera explícita los principios de justicia que deben regular las relaciones de unos pueblos con otros; ya prohibiendo las guerras injustas; ya atenuando los terribles efectos de la guerra con la prohibición de hacer daño a las personas inofensivas, e inculcando el respeto a la propiedad privada; ya, finalmente, aboliendo la esclavitud de los prisioneros de guerra y prohibiendo el uso de armas demasiado ofensivas; en una palabra, iniciando todos los principios de humanidad y de justicia que, aunque tardía e incompletamente, han llegado a prevalecer en el derecho internacional moderno.

Aceptando y fundiendo armónicamente principios proclamados por la jurisprudencia romana y por los Santos Padres, el derecho canónico consideraba la guerra como una calamidad, fuente de innumerables males; pero convencido de la imposibilidad de suprimirla por completo, la juzgaba necesaria para defender la independencia nacional, para castigar a los malos y 
defender a los buenos ${ }^{35^{8}}$. Tenía por injusta y criminal la hecha por ambición, por crueldad o por deseo de conquista ${ }^{359}, \mathrm{y}$, al que la emprendía llevado de estos móviles, le obligaba a reparar los daños causados. No reputaba lícita más que la guerra defensiva y la que se hacía para castigar graves ofensas, $o$ para recobrar lo injusta y violentamente arrebatado ${ }^{360}$. Prohibía, bajo severas penas, que se hiciera daño alguno a las personas que, por razón de su estado, sexo o edad no tomaban parte en la guerra, así como el que se robara o destruyera la propiedad privada ${ }^{361}$. Mandaba cumplir lo pactado con el enemigo ${ }^{362}$, prohibía el uso de armas demasiado homicidas, recomendaba la misericordia con el vencido ${ }^{363}$, y finalmente, por medio de sabias disposiciones, logró abolir paulatinamente la esclavitud de los prisioneros de guerra ${ }^{364}$. Entre las disposiciones dictadas por los Papas y los Concilios para disminuir los terribles efectos de la guerra, es digna de mención especial la prohibición de usar balistas y flechas, dictada por uno de los Pontífices más ilustres que ha tenido la Iglesia, el gran Inocencio III ${ }^{365}$.

No menos eficaz y saludable fue la influencia de la Iglesia para moderar y restringir, hasta abolirlas por completo, las guerras privadas, tan frecuentes en la Edad Media, y cuyos estragos se dejaron sentir en toda Europa, inclusa nuestra España, donde la necesidad de atender a la incesante lucha con los moros, parece que hubiera debido preservarnos de esta plaga ${ }^{366}$. El Concilio

358 C. 6 , c. XXIII, q. 1.: Apud veros Dei cultores, etiam ipsa bella pacata sunt; dum non cupiditate, aut crudelitate, sed pacis studio geruntur, ut mali coerceantur et boni subleventur.

359 C. 4, c. XXXIII, q. 1.: Nocendi cupiditas, ulciscendi crudelitas, impacatus atque implacabilis animus, feritas rebellandi, libido dominandi et quae similia, haec sunt quae in belli jure culpantur.

360 C. 1, c. XXIII, q. 2.: Iustum est bellum quod ex edicto geritur de rebus repetendis, aut propulsandorum hostium causa.

361 Du Boys De l’influence sociale des Conciles, París, 1869, p. 128 y 134-5.

362 C. 3 , c. XXIII, q. 1.: Fides quando promittitur, etiam hosti servanda est, contra quem bellum geritur.

363 L. c.: Sicut rebellanti et resistenti violentia redditur, ita, victo et capto, misericordia iam debetur, maxime in quo pacis perturbatio tenetur.

364 Die Sklaverei der Besiegten war unten den Einfluss der christlichen Kirche in Europa schön in Mittelalter abgeschafft worden. Holtzendorff, Eroberung und Eroberungsrecht, Berlín, 1872, p. 15.

365 Cap. un. X de Sagittariis: Artem illam mortiferam et odibilem ballistariorum et sagittariorum adversus Christianos et catholicos de caetero sub anatemathe prohibemus.

366 Puede consultarse sobre esta materia la obra antes citada de Du Boys, que en los 
de Jaca, celebrado a mediados del siglo XI, la Asamblea que convocó por el mismo tiempo en Barcelona Ramón Berenguer y los Concilios de Santiago y Palencia de principios del XII atestiguan los esfuerzos hechos en España para remediar los males de las guerras privadas.

Una de las conquistas de que más se gloría el moderno derecho de gentes, la prohibición de usar en la guerra proyectiles explosivos, acordada hace pocos años a propuesta de Rusia, consiste, como observa agudamente el canonista protestante Hinschius, profesor en la Universidad de Berlín, en haber aplicado a nuestra época la prohibición de Inocencio III anteriormente mencionada $^{367}$.

En la Relectio secunda de Indis, dedicada a tratar del derecho de la guerra, defiende Vitoria la licitud de ésta, en consonancia con los principios del derecho canónico; considera atribución exclusiva del poder público el declararla; afirma no ser lícita sin justa causa, y, negando que pueda serlo en ningún caso la conveniencia particular del Soberano o de la nación, ni la diferencia de religión, ni los atentados a la ley natural, juzga único motivo suficiente la injuria grave inferida por otra nación y no reparada debidamente.

$\mathrm{Al}$ final de esta misma Relectio $^{368}$, formula nuestro dominico con acierto y sobriedad los principios esenciales que deben informar el derecho de la guerra, y puede asegurarse que todas las nociones humanitarias que hoy prevalecen en este orden se hallan, cuando menos en germen, en esta breve disertación.

Supuesto que el Príncipe tenga autoridad para hacer la guerra, debe procurar en primer término no buscar ocasión, ni motivo para declararla; antes ha de esforzarse por vivir en paz, si fuere posible, con todos los demás Estados; mas si, a pesar de esto, se ve obligado, con justa causa, a hacer la guerra contra su voluntad, no debe excusarla. Empezada ya la guerra, conviene proceder en ella, no con ánimo de dañar al enemigo, sino únicamente con el de obtener satisfacción del derecho violado y defender la patria, a fin de alcanzar, mediante la guerra, la paz y la seguridad propias.

capítulos VI, VII y VIII del libro II hace un excelente resumen de las principales disposiciones dictadas por los Papas y los Concilios respecto de las guerras privadas. Este punto ha sido tratado con más extención en algunas obras especiales, entre las cuales merecen especial mención la de Sémichon, Paix et Tréves de Dieu, París, 1857, y la de Kluckhohn, Geschichte des Gottesfrieden, Leipzig, 1857.

367 Encyklopaedie der Rechtswissenschaft in systhematischer Bearbeitung, herausgegeben ... von Dr. Franz von Holtzendorff, Leipzig, 1877, p. 152.

368 Relectio II de Indis, n. 60. 
"Terminada la guerra y obtenido el triunfo, conviene aprovecharse de él con modestia cristiana, y que el vencedor se considere como juez entre dos Estados, de los cuales uno ha sido perjudicado por otro, a fin de que, procediendo como tal y no como vencedor, dicte sentencia bastante a reparar el daño causado. Al hacerlo, debe cuidar de que esta reparación se verifique con el menor perjuicio posible del Estado agresor, sin dejar por esto de imponer el merecido castigo a los autores del daño. Y esto con tanta más razón, cuanto que entre cristianos, las más veces tienen los Reyes la culpa de todo y los súbditos combaten por ellos de buena fe y sería soberanamente inicuo que se verificase lo que dice el Poeta:

Quicquid delirant Reges, plectuntur Achivi"369.

Según nuestro dominico, el derecho de gentes no deriva sólo su fuerza o eficacia de los pactos celebrados entre los hombres, sino que, bajo otro concepto, tiene también fuerza de ley. "No es dudoso", dice a este propósito ${ }^{370}$, "que el orbe entero, que es en cierto modo una república, tiene la facultad de dictar leyes equitativas y convenientes para todos sus miembros, como las que constituyen el derecho de gentes. De aquí que pecan mortalmente los violadores del derecho de gentes, así en la paz como en la guerra; y que, en materias importantes, como la inviolabilidad de los legados, no es lícito a ninguna nación negarse a observar el derecho de gentes" 371 .

Al tratar de la servidumbre, Vitoria, apartándose de la interpretación más exacta de la doctrina de Aristóteles, afirma que éste "no entendió jamás que las gentes de rudo entendimiento han de ser de derecho ajeno y carecer de dominio sobre su persona y sus bienes propios" ${ }^{372} \mathrm{e}$ impugna briosamente la

369 Las teorías de Soto, Comment. in IV Sent., dist. 5, q. 1, a. 10, así como las de Suárez, De tripl. virt. Theol., disp. 13, sobre el derecho de la guerra, concuerdan sustancialmente con las de Vitoria.

370 El concepto del derecho internacional de Suárez, De leg. 1. II, C. XIX, n. 9, calificado de grandioso por Heffter, no es sino desarrollo del formulado por Vitoria; filiación en que nadie, que yo sepa, ha parado atención hasta ahora, por hallarse el texto aludido de Vitoria, no en las Relectiones de Indis, consultadas por los escritores de derecho internacional, sino en la De potestate civili, n. 22.

371 Lorimer, Principes de droit international, trad. por Nyss, Bruselas, 1885, refiriéndose a las doctrinas de Vitoria, Soto y Suárez en materia de derecho internacional, atribuye a este último la prioridad respecto de los primeros, fundándose en la teoría relativa a los fundamentos del derecho internacional, que no es, como indicamos, sino mero desarrollo de la asentada antes por Vitoria.

372 Relectio prior de Indis, n. 23: Certe Aristoteles non intellexit, quod tales, qui pa- 
teoría defendida a la sazón en este punto, con tenacidad y erudición dignas de mejor causa, por el humanista Juan Ginés de Sepúlveda.

En armonía con este principio, no vacila Vitoria en reconocer a los Indios el derecho de propiedad y el de gobernarse por sus propias leyes e instituciones, bajo la obediencia de sus antiguos señores; mientras el moralista y filólogo cordobés los juzgaba condenados, por razón de la imbecilidad natural que les atribuía, a vivir en servidumbre perpetua. No discordan menos las opiniones de ambos respecto a las causas legítimas de la guerra y su aplicación al caso concreto de la conquista de América por los españoles. Sepúlveda, precursor en esto de Grocio, juzga que los pecados contra la ley natural atribuidos a los Indios eran motivo suficiente para declararles la guerra y privarlos enteramente de su independencia. Por el contrario, según nuestro dominico ${ }^{373}$, los paganos gozan de la plenitud de la potestad temporal y civil, y niega que se les pueda declarar la guerra por cometer pecados contra la ley natural. Siguiéronle en esto todos los teólogos de su tiempo que trataron la cuestión, como observa el jesuita Acosta ${ }^{374}$, uno de los que discurrieron sobre ella más de propósito.

La cuestión del título que autorizó a los Reyes de España para la conquista del Nuevo Mundo, suscitada por nuestros teólogos con motivo del descubrimiento de América, y asunto predilecto de sus disquisiciones, ha preocupado también a los Autores de derecho internacional de nuestros días, sin que hayan logrado hasta ahora encontrar una solución definitiva y uniforme. Al discurrir sobre si los Estados civilizados pueden emplear la fuerza para obligar a los pueblos salvajes a abrir sus fronteras y sus puertos a las relaciones exteriores, mientras unos resuelven la cuestión negativamente, fundándose en que, entre las naciones civilizadas y las bárbaras, no hay vínculo ninguno

rum valent ingenio, sint natura alieni iuris, et non habeant dominium sui et aliarum rerum ... sed vult docere, quod a natura est in illis necessitas, propter quam indigent ab aliis regi et gubernari...

373 Rel. de potest. eccl, q. 1, a. 8.

374 Acosta, De procuranda Indorum salute, 1, II, c. 4. Quamobrem preclarissima et suis ordinis et nostri temporis lumina, quae in causam Indorum proprie inciderunt, eiusmodi belli suscipiendi consilium, idque iuris gravissime cum disputationibus suis, tum etiam scriptis de industria libris improbarunt Quorum sententia iam dudum apud omnes obtinuit, Salmantino et Complutensi illustribus gymnasiis damnantibus, ut audio, atque explodentibus scriptum cuiusdam librum contra causam Indorum, atque ipso Catholici Regis senatu longe aliam rationem in expeditionibus indicis praecipiente, cuius aequitatem oportune exponemus. 
de comunidad, y no puede haber derechos y deberes mutuos respecto a la comunicación internacional, otros, como nuestros teólogos, la resuelven en sentido afirmativo, recomendando que no se apele a la violencia si no es motivada por la conducta de los salvajes ${ }^{375}$. Es de esperar, por lo demás, que no llegará a tomar nunca carta de naturaleza en el orden científico la teoría del profesor alemán ${ }^{376}$ que, proclamando como suprema ratio de la colonización el derecho del más fuerte, ha afirmado recientemente que "no puede menos de estar reservado a un futuro desarrollo del derecho internacional, hacer que prevalezca esta tesis, importante para la política colonial alemana; que el título jurídico de más peso para la adquisición de colonias no es la toma de posesión simbólica de las mismas enarbolando la bandera nacional o dictando proclamas, sino la voluntad y la capacidad de llevar la cultura a las partes lejanas del mundo y de trabajar por la civilización de los hijos desheredados de nuestro globo".

Bien que no entre en los límites de este trabajo examinar en detalle hasta qué punto se reflejaron en las leyes de Indias las polémicas referidas, asunto no tratado aún con la amplitud que merece, indicaremos que, si bien prevaleció generalmente en esas leyes la tendencia humanitaria y verdaderamente cristiana de que fue brioso paladín el infatigable Las Casas, y principal representante Vitoria en el terreno científico, en la práctica la conducta de los funcionarios españoles, y singularmente la de los aventureros militares que pululaban en el Nuevo Mundo, se acomodó, más frecuentemente que a la ley escrita, a las teorías defendidas por Sepúlveda, las cuales debieron contribuir alguna parte a este resultado, no obstante la afirmación contraria del sabio humanista.

Por lo demás, para juzgar imparcialmente de la conducta de los españoles

375 Ch. Salomón, De l'occupation des territoires sans maitre, tesis de doctorado de la Universidad de París, París, 1889, p. 43-57, examinando las teorías de Vitoria sobre el particular en un análisis detenido y exacto de las Relectiones de Indis, bien distinta de las generalizaciones vagas en que incurren, copiándose unos a otros, la mayoría de los tratadistas de derecho internacional, califica las ideas de nuestro dominico de "doctrine généreuse dont les États du XIX siècle pourraient faire, sur bien des points, leur profit, bien qu'elle soit la conception d'un théologien espagnol du XVI siècle”.

376 Miaskowski, a la sazón profesor de Economía política en la Universidad de Breslau, actualmente en la de Viena, Zur heutigen Kolonialpolitik der Gegenwart en el Jahrbuch für Gesetzgebung Verwaltung und Volkswirtschaft im deutschen Reich, de Schmoller, IX, 1, p. 271-283 y 282. Es el discurso leído el 15 de Noviembre de 1884 en una de las secciones de la Sociedad colonial alemana. 
con los indígenas de América, conviene tener presente, que "la historia de las colonias ha comenzado siempre por la violencia, la injusticia y el derramamiento de sangre, y su resultado ha sido el mismo en todas partes: la desaparición de las razas salvajes al contacto de las civilizadas. Esto, que ha sido obra de algunos años en las colonias portuguesas y españolas, necesitó algún más tiempo en las colonias inglesas. En todas partes, salvo en las Indias (y podría haber añadido en Filipinas), en Nueva Inglaterra como en Australia, en Van Diemen como en Nueva Zelanda, la raza anglo-sajona, llamada por Sir Carlos Dilke la única raza exterminadora, ha hecho desaparecer lenta y metódicamente, por decirlo así, las razas indígenas. Ningún pueblo puede acusar a los demás en este punto; las intenciones han podido ser mejores aquí o allí; los procedimientos de unos menos repugnantes que los empleados por otros; pero todos tienen yerros que reconocer, crímenes que deplorar, resoluciones generosas que adoptar para lo porvenir"377.

La Santa Sede dictó su fallo en la cuestión de la servidumbre de los Indios, colocándose resueltamente del lado de la justicia. Paulo III publicó el Breve Pastorale officium dirigido al Arzobispo de Toledo con fecha 29 de Mayo de 1537, y en él se refiere a la declaración en favor de la libertad de los indígenas, hecha ya en 1531 por el emperador Carlos $\mathrm{V}^{378}$.

Esta importante resolución pontificia fue debida en parte a los esfuerzos del religioso dominico Garcés, obispo de Tlascala; el cual, en vista de la ineficacia de sus esfuerzos cerca del Consejo de Indias para que hiciese cumplir la ley de 1531 prohibiendo en absoluto la esclavitud, se dirigió en 1536 al Papa Paulo III, instándole para que interpusiese su autoridad en favor de los desgraciados indígenas, y protestando enérgicamente contra la diabólica aserción de los opresores de los Indios, quienes no vacilaban en afirmar ser tales la imbecilidad natural y el embrutecimiento de estos últimos, que debía considerárseles como irracionales incapaces de sacramentos ${ }^{379}$.

377 Salomón, Op. cit., p. 68-69.

378 Nos igitur attendentes Indos ipsos, licet extra gremium Ecclesiae existant, non tamen sua libertate, aut rerum suarum dominio privatos, vel privandos esse, cum homines, ideoque fidei et salutis capaces sint, non servitute delendos, sed praedicationibus et exemplis ad vitam imitandos fore, ac praeterea Nos talium impiorum tam nefarios ausus reprimere, et ne iniuriis et damnis exasperati, ad Christi fidem amplectemdam, duriores efficiantur, providere cupientes ... y prohibe bajo pena de excomunión, reservada a la Santa Sede, ne praefatos Indos quomodolibet in servitutem redigere, aut eos bonis suis expoliare quoquomodo praesumant.

379 Insértala Lorenzana, Concilios celebrados en México, tomo I, p. 19; Nullam ergo 
Las leyes promulgadas en 1542, consecuencia de la bula de Paulo III y de los esfuerzos incesantes de Las Casas y de sus compañeros de Orden, forman época en la historia de nuestra política colonial ${ }^{380}$. Por virtud de ellas, se declaró, una vez más, libres a los Indios y se prohibió incondicionalmente reducirlos a esclavitud bajo ninguna forma ni pretexto. Es verdad que subsistieron las encomiendas; pero no fueron tratados ya como esclavos los Indios sujetos a ellas, y tomando esta institución el carácter, que conservó hasta su supresión por Carlos III en 1778, de "derecho concedido por merced real a los conquistadores de las Indias para percibir y cobrar para sí los tributos de los Indios que se les encomendaron por su vida y la de sus herederos conforme a la ley de sucesión, con cargo de cuidar del bien de los Indios en lo espiritual y lo temporal" 381 .

En el orden de estudios de que ahora tratamos, nuestros teólogos representan un progreso con respecto a sus predecesores, por el hecho de haber ampliado los horizontes de la ciencia, comprendiendo en el círculo de sus investigaciones problemas no examinados anteriormente, así como por haber sido los primeros en formular conceptos generosos y fecundísimos. Sus obras inician en el método y la doctrina una nueva fase en el cultivo científico del derecho internacional, de la cual no son más que continuación los escritos de Gentili y de Grocio, considerados generalmente como verdaderos fundadores de esta ciencia. Hay que tener presente, sin embargo, que en la ciencia del derecho internacional, como sucede en toda suerte de estudios y disciplinas, el progreso no es siempre constante. Gentili y Grocio, por ejemplo, cuyas teorías acerca del derecho de la guerra, aunque desarrollo en lo esencial de las sentadas por Vitoria, superan a veces a las del dominico español; muestran, en ocasiones, un retroceso con relación a él. Puntos hay, como la teoría de la ocupación y las causas de la guerra, en que la ciencia moderna acepta las teorías de Vitoria con preferencia a las de los dos sabios indicados. No es, por lo tanto, justo ni exacto afirmar, que la constitución del derecho internacional como ciencia autónoma data de las obras de Gentili y de Grocio. Ni uno ni otro se comprenden sin Vitoria, Suárez y Ayala, ni éstos, a su vez, sin la enorme labor acumulada en los siglos anteriores por los teólogos escolásticos, singularmente por Santo Tomás, y por los canonistas y civilistas bajo la influencia del derecho romano.

retrahat quaeso ab hoc opere, falsa talium assertio, qui, diabolicis instigati suggestionibus, incapaces religionis nostrae asserunt Indos istos.- Cf. Acosta, op. cit. l. I.

380 Herrera. Décadas, VII, l. VI, c. X.

381 Solorzano, Política indiana, l. III, c. III, n. 1. 
Nuestro insigne Vitoria es el centro alrededor del cual giran las teorías de la escuela teológica española acerca de la ciencia que nos ocupa, en términos que, expuestas las ideas capitales de aquél sobre tan importante materia, nos son conocidas en sus fundamentos las de casi todos nuestros teólogos contemporáneos y posteriores ${ }^{382}$. Con plena justicia ha podido resumir, no hace muchos años, el ilustre jurisconsulto italiano Alejandro de Giorgi el juicio comparativo entre Vitoria y Gentili, calificando a nuestro compatriota de padre de la ciencia del derecho internacional y afirmando, que, si bien no discurrió sobre ella con toda amplitud, "ma posse ordinatamente le basi; fissó i cardini della scienza; diede l'esempio del método conveniente; e tutto questo e ció che sopratutto importa" 383 .

Si se considera que las Relectiones de Vitoria no son fruto de trabajos elaborados lentamente y destinados a la publicidad, como las obras de Gentili y Grocio, que le aventajaban además en ser juristas de profesión, sino escritos de circunstancias, sube de punto la admiración que inspira el insigne dominico español y hace pensar en lo que habría sido una obra suya extensa y meditada de propósito sobre materias tan difíciles, las cuales apenas le consintió más que desflorar la índole de sus escritos.

$\mathrm{Al}$ dar por terminado mi trabajo, disto mucho de creer que pueda considerarse, bajo ningún concepto, como una obra definitiva. Me atrevo a esperar, sin embargo, que juzgándolo con benevolencia, se hallará que ofrece datos e indicaciones útiles para la demostración de la tesis consignada en el lema; y que los materiales aquí reunidos, a costa de no escasa fatiga, allanarán el camino al que, con mejor preparación y más holgura, emprenda esa obra que tanto habrá de enaltecer la historia de nuestra cultura.

Complemento de la presente Memoria, circunscrita a exponer, en armonía con el tema, la influencia que tuvieron en el derecho público de su patria y singularmente en el derecho penal los filósofos y teólogos españoles anteriores a nuestro siglo, sería el estudio de la que ejercieron en el desenvolvimiento

382 Menéndez y Pelayo, Discurso leído ante la Academia de la Historia, Madrid 1879, p. 85-89. Véanse la comparación de las teorías de Las Casas, Vitoria, Soto, Córdoba y Acosta en la biografía del primero escrita por D. Antonio Fabié, Madrid, 1879, p. 245278, y las Disertaciones jurídicas del mismo Autor, Madrid, 1885, p. 57-61.

383 Della vita e delle opere d'Alberico Gentili, Parma, 1876, p. 82. 
científico del derecho político e internacional europeo, mediante la recepción de sus doctrinas en las obras de los escritores extranjeros, sobre todo en las de Gentili, Grocio y Conring. La reseña de esta influencia constituirá seguramente uno de los más interesantes capítulos de la historia de la ciencia española. Aún ahora, sin que este trabajo exista, la importancia de nuestra gran escuela teológico-política en este concepto es universalmente reconocida por todos los eruditos extranjeros, así católicos como protestantes, conocedores del desenvolvimiento científico de la Europa moderna. Baste recordar a este propósito los nombres de Mackintosh, Wheaton, Cauchy, Pradier Foderé, Holland, De Giorgi, Gierke y Holtzendorf, por no citar sino a los más importantes. Séame lícito dar fin a este trabajo, agregando a estos testimonios otros no menos explícitos y valiosos de escritores alemanes contemporáneos, en los cuales hallará indicaciones del mayor interés quien se proponga estudiar la influencia de nuestra patria en el desenvolvimiento político e intelectual de la Europa moderna.

"En el siglo XVI", exclama el actual profesor de Economía política en la Universidad de Leipzig, "la cultura española alcanza transitoriamente el primer lugar en la vida intelectual de Europa. Es el apogeo de la historia de España. No debe admirar por tanto que el mundo entero tome a España por modelo. Sus instituciones son imitadas: no sólo su ejército y su organización administrativa, sino también ciertas instituciones económico-jurídicas, como los fideicomisos familiares; $y$, así como la infantería española imprime el sello a los ejércitos de la época, así también la política monopolizadora de España en el orden económico sirve de norma a las demás naciones" ${ }^{384}$.

"A mediados del siglo XVIII", dice el profesor de Historia en la Universidad de Berlín, Enrique de Treitschke, "se ensalzaba y veneraba a Suárez, el Papa de los metafísicos, en las cátedras sajonas, ni más ni menos que en las Escuelas de los jesuitas. Escobar, Mariana y todos los demás teólogos españoles e italianos que pusieron las armas contra la herejía en manos de los Habsburgos eran considerados por el Luteranismo decadente como columnas de la Iglesia reformada" 385 .

El literato e historiador Carlos Hillebrand se expresa en estos términos: "Nuestra época, algo inclinada a rebajar el papel de España en la historia de

384 Brentano, Über eine zukünftige Handelspolitik des deutschen Reiches, discurso leído el 20 de Noviembre de 1884 en la Universidad de Estrasburgo e impreso en el Jahrbuch de Schmoller, IX, 1, Leipzig, 1885, p. 7-9.

385 Preussische Jahrbücher de 1875, vol. XXXV, p. 621. 
la civilización europea, debe reconocer que, no sólo fue obra exclusivamente suya la reorganización de la Iglesia, sino también la monarquía de derecho divino tal como floreció en el siglo XVII”. Después de reseñar la influencia de España en la literatura y el arte, añade: "Mayor aún fue la que tuvo en el desenvolvimiento filosófico de Europa... No quiere decir esto que la filosofía de Molina y de Suárez informase por completo la vida intelectual de la época; pero es indudable que a España se debe el restablecimiento del principio de autoridad en todos los órdenes, que puso un dique, a veces beneficioso, al desarrollo de la especulación filosófica en la Europa continental..." ${ }^{86}$.

386 Zeitschrift für allgemeine Geschichte de 1885, p. 100-101. 


\section{DISCURSOS}

DE RECEPCIÓN DEL

EXCMO. SR. D. EDUARDO DE HINOJOSA

Y DE CONTESTACIÓN DEL

EXMO. SR. D. LUIS PIDAL Y MON, MARQUÉS DE PIDAL

Leídos en la Junta pública del 26 de Mayo de 1907

\section{TESIS:}

La condición civil de la mujer en el Derecho español antiguo y moderno 


\section{SEÑORES ACADÉMICOS:}

Insigne es el honor que me habéis otorgado, elevándome al puesto que ocupó entre vosotros el reputado jurisconsulto D. Feliciano Ramírez de Arellano, Marqués de la Fuensanta del Valle, cuyos méritos como fundador de la Colección de libros españoles raros o curiosos, y continuador de la Colección de documentos inéditos para la historia de España, le aseguran honroso lugar entre los promovedores de los estudios históricos. No hay palabras con que expresaros debidamente mi gratitud, tanto más viva y profunda, cuanto que vuestra benevolencia para conmigo no puede considerarse como premio de servicios prestados a la ciencia, sino como muestra de la estima en que tenéis el estudio de la historia del derecho, objeto preferente de mis trabajos.

Esta ilustre Academia se ha esforzado constantemente por estimular y favorecer tan importante estudio, ya llamando a su seno a los cultivadores de nuestra historia jurídica, ya promoviendo concursos relativos al origen y vicisitudes de nuestras instituciones políticas y civiles y su persistencia hasta nuestros días bajo la forma de derecho consuetudinario. Su acción en este orden ha sido fecundísima. Gracias a ella, se han publicado, siguiendo el ejemplo de la magistral monografía de D. Joaquín Costa sobre el derecho consuetudinario del Alto Aragón, trabajos interesantes, ricos en materiales preciosos para el jurisconsulto y el historiador.

A la investigación de nuestro pasado jurídico pertenece también el tema del presente discurso, en el cual me propongo estudiar cuál ha sido, cuál es y cuál debiera ser la condición de la mujer casada en la esfera del derecho civil. Aunque mi trabajo se contraerá especialmente a España, no habré de limitarme al derecho español, convencido como estoy de la necesidad del método comparativo para resolver satisfactoriamente, así los problemas de la historia del derecho, como los del derecho actual.

La reseña de las vicisitudes de la condición de la mujer no es sólo un capítulo importantísimo de la historia del derecho, sino uno de los capítulos más interesantes y atractivos de la historia general de la civilización. En ningún otro aspecto de la vida de los pueblos se manifiesta quizá con tanto relieve la influencia de las ideas religiosas y morales, de las circunstancias sociales, políticas y económicas. Desde este punto de vista complejo y amplio debe estudiarse el asunto, no considerando sólo la situación de derecho, sino la situación de hecho, pues sabida es la diferencia y, a veces, la oposición que entre ellas existe, más que en otras esferas, en la del derecho de familia, por 
el predominio del carácter ético sobre el jurídico en este orden de relaciones, según observó ya con su profundidad habitual el ilustre fundador de la Escuela histórica. Sólo abarcando ambos aspectos de la condición de la mujer puede considerarse exacta, en general, la afirmación de Sumner Maine de que "una sociedad da la medida de sus progresos en la civilización en la suma de independencia personal y de capacidad real que reconoce a la mujer". Naciones en el apogeo de la cultura intelectual y material, como Grecia y la Roma republicana en la Edad Antigua, Inglaterra y Suiza en la Moderna, han mantenido en una situación de inferioridad a la mujer en el orden jurídico. Pero esta inferioridad puede armonizarse, y se ha armonizado, con una situación de hecho digna y respetada en la familia y en la sociedad. Así sucedió en Roma bajo la República; así, entre los Germanos, "la mujer, súbdita en la esfera del derecho, fue señora en la esfera de la costumbre"; y esta misma observación es aplicable a la mujer inglesa de la primera mitad del siglo XIX ${ }^{1}$.

Carecemos de elementos para reconstruir el cuadro de la situación de la mujer ibérica antes del triunfo definitivo de la dominación y de la cultura romanas en nuestro suelo. No creo que pueda llenarse este vacío, suponiendo existentes en la España primitiva instituciones, como la promiscuidad sexual, el matrimonio por grupos y el matriarcado, que, según algunos etnólogos, historiadores, jurisconsultos y economistas, han debido darse en todas las sociedades humanas ${ }^{2}$.

1 Ihering, L'esprit du droit romain, trad. de O. Meulaneere, tomo II (Paris, 1884), págs. 200-205.- Sohm, Die Stellung der Frau im deutschen Recht en la Deutsche Rundschau de Enero de 1878, página 102.- Stuart Mill, L'assujetissement des femmes, trad. de E. Cazelles, 2. ${ }^{\mathrm{a}}$ ed. (Paris, 1876), págs. 79-80.

2 La teoría de la "evolución unilinear y necesaria" de las instituciones sociales, impugnada ya vigorosamente por Tarde en su obra Les transformations du droit (traducida al español por A. Posada, Madrid, 1892), apenas cuenta hoy partidarios entre los historiadores y jurisconsultos, aun en los países anglosajones, donde estuvo más en boga algún tiempo. Howard, A History of matrimonial institutions, tomo I (Chicago, 1904), pág. 9, pondera el gran quebranto de la fe en esta teoría, desde que la crítica se ha ejercitado en las obras de los principales constructores de sistemas sobre el origen y desarrollo de la familia. "The criticism, specially, to which the writings of Bachofen, Maine, Morgan and Mc. Lennan have given rise, has greatly weakened the faith of scholars in the doctrine of universal stages of evolution through which all mankind has run”. Pollock, Notes on Maine's Ancient Law en The Law Quarterly Review, tomo XXI (Londres, 1905), pág. 287, cita, haciéndolas suyas, las palabras en que el ilustre profesor de Cambridge, Maitland, recientemente arrebatado a la ciencia, califica de "vano y anticientífico" el intento de trazar un cuadro uniforme de desenvolvimiento aplicable a todas las agrupaciones humanas: 
Cierto que la historia comparada da a conocer tipos de instituciones sociales que se encuentran en pueblos no ligados entre sí por conexiones históricas; pero no debe inferirse de aquí, generalizando excesivamente, que se hayan dado en todos ellos, ni según una misma gradación. La variedad de formas sociales producto de la inventiva humana no es inagotable; tiene por presupuesto y límite realidades permanentes de la naturaleza y de la vida; y las identidades y semejanzas de que se trata se explican como resultante, ya del fondo común humano, ya de la igualdad de condiciones morales y económicas, íntimamente enlazadas con las jurídicas.

Si aun en territorios sujetos a una misma soberanía, y que se encuentran en un mismo grado de cultura, se han dado simultáneamente en el trascurso de los tiempos, y se dan aún en la actualidad, como sucede en España y Suiza, y antes en Francia y Alemania, diferencias fundamentales acerca de la situación jurídica de la mujer casada, ya en las relaciones personales, ya en las patrimoniales, ¿̇no hemos de admitir que debió suceder otro tanto, con más razón, en los tiempos primitivos? Aun en las sociedades menos adelantadas en el camino de la civilización, la situación de la mujer en la familia y en la sociedad dista mucho de ser uniforme. Como ha dicho, a este propósito, uno de los más diligentes investigadores de la historia de la familia, hay datos importantes, plenamente comprobados, que deponen contra la tesis más en boga, que considera como miserable y depresiva la condición de la mujer en estas sociedades. Reuniéndolos y estudiándolos atentamente, se ve que no es el menosprecio hacia la mujer la causa de las penalidades y trabajos a que está sujeta, sino las circunstancias económicas en que se desarrolla su existencia; y que las penosas cargas que pesan sobre ella son "frecuentemente compensadas por derechos que realzan su situación, y gracias a los cuales desempeña, bajo ciertos aspectos, un papel preponderante ${ }^{3}$.

Las únicas noticias positivas que tenemos acerca de la condición jurídica de la mujer ibera son: un texto de Estrabón sobre el derecho regional de la Cantabria y otro de Séneca sobre el derecho local de los cordobeses.

Refiere el primero que, entre los Cántabros, las hijas heredaban a los pa-

\footnotetext{
"We are learning that the attempt to construct a normal programme for all portions of mankind is idle und unscientific".

3 Westermarck, The position of woman in early civilisation, en la publicación de la Sociedad sociológica inglesa Sociological Papers (Londres, 1895), págs. 147-160.- Véase también a Grosse, Die Formen der familia und die Formen der Wirtschaft (Friburgo, 1896), pág. 176.
} 
dres con exclusión de los hijos varones, y casaban y dotaban a sus hermanos, y que los hombres llevaban la dote a sus mujeres, en vez de éstas a los maridos $^{4}$. Alude, verosímilmente, a la sucesión del primogénito sin distinción de sexos y a la condición del marido que casa con heredera, según el derecho de algunas regiones pirenaicas de España y de Francia.

"Nuestros cordobeses - dice Séneca- tuvieron en tanta estima las nupcias, que privaban del derecho de herencia a los que se unían sin celebrarlas, y aun después de pactadas, no consentían que los contrayentes se dieran el osculo sino después de sacrificar y de cantar himnos en honor de Ceres. Si alguno contravenía a este precepto y besaba a la novia, sin que estuvieran presentes al acto ocho parientes o vecinos, aunque tenía derecho a llevarla consigo, podía ser castigado privando el padre a la hija de la tercera parte de

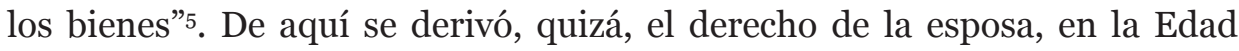
Media española, a la mitad de la donación que le hacía el esposo, cuando, después de besarla éste, no se verificaba el matrimonio.

El derecho romano vigente bajo los Emperadores, influido por las ideas cristianas, y el germánico, modificado en parte por las circunstancias políticas y económicas de los tiempos posteriores a la invasión, son los factores que principalmente informan el desarrollo de las instituciones relativas a la condición de la mujer en la Edad Media, en España como en todos los Estados europeos.

¿Cuáles eran los caracteres fundamentales de cada uno de estos sistemas?

En el primitivo derecho romano $^{6}$, la mujer estaba sometida a perpetua

4 Estrabón, III, 4, 18.- El primero que creyó ver una supervivencia de esta institución de los Cántabros en el derecho de primogenitura, sin distinción de varón ni hembra, existente en las regiones del Pirineo francés, fue Cordier, Le droit de famille aux Pyrénées en la Revue Historique de Droit français et étranger, de 1859, págs. 257-300 y 353-393. La opinión de Cordier es aceptada plenamente por Bachofen, Das Muterrecht, 2. ${ }^{\mathrm{a}}$ ed. (Basilea, 1897), págs. 415-420.

5 Fragmentum ex libro de matrimonio, en la edición de Haase, tomo III, pág. 434. Véase sobre este pasaje a Dirksen, Die Wirksamkeit der Ehegelöbnisse nach den Bestimmungen einzelner Ortsrechte im Bereiche der römischen Herrschaft en sus Hinterlassene Schriften, I (Leipzig, 1871), págs. 329-334, la monografía de Tamassia, Osculum interveniens, Contributo alla storia dei riti nuziali (Turín, 1885), y los trabajos más antiguos de Spangenberg y Wolff allí citados.

6 Gide, Étude sur la condition privée de la femme, 2. ${ }^{\mathrm{a}}$ ed., por A. Esmein (Paris, 1885), págs. 87-163.- Mitteis, Reichsrecht und Volksrecht in den Östlichen Provinzen des römischen Reiches (Leipzig, 1891), págs. 218-312.- Karlowa, Römische Rechtsgeschichte, 
sujeción (manus). Ejercíala el padre, o los parientes más próximos por la línea paterna, sobre la soltera, y el marido, o el que tenía la potestad sobre este, respecto de la casada. Como la mujer era incapaz de propiedad, los bienes que aportaba al matrimonio, o adquiría durante él por cualquier título, se fundían con los del marido, que era dueño absoluto de ellos, sin que la mujer tuviese en compensación de esto otro derecho que heredar del marido la misma porción que los hijos. Para garantizar la conservación de la dote, se vedó al marido disponer de ella sin intervención de la mujer. La situación de hecho de la mujer romana, ya en los últimos tiempos de la República, fue muy superior a su condición jurídica. Sometida enteramente al marido en el orden del derecho estricto, era considerada en realidad como su asociada en la gestión de los asuntos domésticos y gozaba de gran consideración social.

Bajo el Imperio, la legislación atenuó el rigor de la primitiva condición de la mujer casada. Las mejoras más importantes se derivaron de la institución del matrimonio sine manu, o sea sin la estricta sujeción personal y económica de la mujer a la potestad del marido, característica del derecho antiguo. En este régimen, la mujer es administradora y dueña absoluta de sus bienes propios, excepto la dote, cuyas rentas no se aplican a las necesidades de la familia, por ser privativo del marido el deber de sufragarlas. La dote se consideró como propiedad de la mujer, no correspondiendo a aquél más que el derecho de usufructo, con la obligación impuesta a él o a sus herederos de devolverla a la mujer o a los suyos, al disolverse el vínculo conyugal. Este movimiento tuvo, sin embargo, su contrapeso en otro que, mirando también al interés de la mujer, vino a restringir notablemente su capacidad. La idea que informa el derecho en este período es la de la debilidad (fragilitas) y frivolidad (levitas animi) del sexo femenino, que se traduce y refleja en las disposiciones encaminadas a prevenir y remediar el mal uso que la mujer pudiera hacer de sus bienes y a garantir la conservación de estos. Se vedó al marido devolver la dote antes de disolverse el vínculo conyugal; se declararon ilícitas las donaciones entre marido y mujer y, por el Senadoconsulto Veleyano, se la prohibió salir fiadora de obligaciones contraídas por el marido o por otras personas. Este era el estado de la legislación cuando apareció el Cristianismo.

El Cristianismo no trajo al mundo un nuevo sistema de derecho, pero sí ideas y tendencias nuevas, gérmenes fecundos de renovación individual y so-

tomo II (Leipzig, 1901), págs. 73-309, y 1105-1199.- Lefebvre, Leçons d’introdution générale à l'histoire du droit matrimonial français (Paris, 1900), págs. 44-260 
cial que, fructificando con el transcurso del tiempo, habían de trascender a la esfera del derecho ${ }^{7}$.

Elevando el valor del individuo humano en concepto de tal, considerando a todos los hombres, sin distinción de sexo, nacionalidad, clase ni jerarquía, como iguales ante Dios y dotados de un fin propio, no como medios los unos respecto de los otros, asignó a la mujer su lugar propio en la familia y en la sociedad. Según la doctrina evangélica, ni la diferencia del sexo ni las desigualdades sociales trascienden a la esfera de la moral. Hombres y mujeres, nobles y plebeyos, libres y siervos están sujetos a los mismos deberes. San Jerónimo combate las doctrinas y las prácticas inmorales del paganismo que toleraban la disolución con las esclavas. "Entre nosotros - dice-, lo que no es lícito al hombre no lo es tampoco a la mujer, y lo que no es lícito al libre no lo es tampoco al esclavo". Esta doctrina, difundida por los Padres de la Iglesia, fue sancionada por los Concilios. Esforzándose por infundir esta verdad en el fondo de las conciencias como norma de vida, el Cristianismo transformó y elevó la condición de la mujer. Ha dicho a este propósito el ilustre jurisconsulto alemán Rodolfo de Ihering: "El Cristianismo, al proclamar la igualdad del hombre y de la mujer en orden a la fidelidad conyugal, doctrina desconocida del mundo oriental y de la antigüedad clásica, vino a inaugurar una nueva era, y con la lucha que inició contra la esclavitud, causa principal de la laxitud de costumbres en el mundo pagano, allanó el camino al triunfo de la moralidad en la esfera de la familia".

En armonía con el principio cristiano de la equiparación de los cónyuges en el orden moral, la legislación de los Emperadores cristianos se esfuerza por limitar el concubinato, dicta disposiciones restrictivas del repudio y del

7 Gabba, Della condizione giuridica delle donne, 2. ${ }^{\mathrm{a}}$ ed. (Turín, 1880), págs. 495506.- Gide, Étude sur la condition privée de la femme, 2. ${ }^{\text {a }}$ ed., págs. 169-195.- Lefebvre, Leçons d'introduction générale à l'histoire du droit matrimonial français, págs. 178-244 y $456-497$

8 Entwicklungsgeschichte des römischen Rechts (Leipzig, 1894), págs. 75-76. Sirve de ilustración a esta idea justa de Ihering el canon del Concilio de Iliberis, relativo a las mujeres que, movidas por los celos, herían mortalmente a sus esclavas. Conc. Eliberitanum, c. v.: Si domina per zelum ancillam occident. Si qua femina, furore zeli accensa, flagris verberaverit ancillam suam ita ut intra tertium diem animam cum cruciatu effundat, eo quod incertum sit voluntate an casu occiderit; si voluntate, post septem annos, si casu, post quinquennii tempora, acta legitima poenitentia ad communionem placuit admiti; quod si infra tempora constituta fuerit infirmata, accipiat communionem.-Collectio canonum Eclesiae Hispanae (Madrid, 1808), pág. 283. 
divorcio, equiparando en este punto al marido y a la mujer, exige que la donación propter nuptias del marido sea de la misma cuantía que la dote de la mujer, y que los lucra nuptialia, o ganancias pactadas para el cónyuge sobreviviente, sean también iguales para uno y otro cónyuges. Novedades importantes, que reflejan también la influencia de las ideas cristianas, fueron el derecho de sucesión ab intestato de la viuda pobre, y el castigo impuesto al marido de pérdida de la cuarta parte de los bienes en provecho de la mujer pobre repudiada sin motivos. La madre y la abuela se vieron admitidas a la tutela legítima de los hijos y nietos.

No sólo en las leyes, sino también en las prácticas jurídicas, se manifiesta la virtualidad de las ideas cristianas acerca del matrimonio. En armonía con el carácter de jefe de la unión conyugal que atribuía al marido la nueva doctrina, se generaliza la costumbre de confiar la mujer al marido, en virtud de mandato, su representación en juicio y la administración de los bienes parafernales; y hay indicios de la acción común de los cónyuges en el orden de las relaciones patrimoniales. Las donaciones recíprocas entre esposos para después de su muerte entran en las costumbres y obtienen al fin validez legal. La institución de heredero hecha por el marido a favor de la mujer, a veces en unión con los hijos, ya puramente, ya como fiduciaria, y el legado de usufructo, a veces vitalicio, a veces por cierto tiempo, hasta la mayor edad de aquellos, acostumbrada ya en tiempo de los Emperadores paganos, son más frecuentes bajo los Emperadores cristianos. Manifiéstase en esto claramente la tendencia del marido a mantener después de su muerte a los hijos unidos a la madre, a conservar el organismo familiar. La trascendencia del concepto cristiano de la intimidad de la unión conyugal al orden de las relaciones patrimoniales se revela muy particularmente en los testamentos en que marido y mujer se instituyen mutuamente herederos para el caso de no tener hijos.

La tendencia favorable a la separación de bienes de los cónyuges y la desfavorable a la capacidad de la mujer persistieron, sin embargo, en la legislación.

Justiniano instituyó la hipoteca privilegiada de la mujer sobre los bienes del marido para seguridad de la dote; extendiendo el alcance del Senadoconsulto Veleyano, declaró inalienable la dote, aun mediando la voluntad de la mujer, y derogó la ley de Augusto, que la facultaba para donarla al marido. De esta suerte, los bienes de los cónyuges vinieron a quedar enteramente separados; no fue lícito a uno de ellos enriquecerse a costa del otro, por estar vedadas las donaciones entre ambos, ni pudo sufrir menoscabo la dote de la mujer, garantida como estaba su restitución por la hipoteca dotal. El marido 
sólo tenía el usufructo de la dote, intangible para ambos cónyuges mientras duraba el matrimonio. La mujer podía disponer libremente de los bienes parafernales, pero nunca en provecho del marido.

Entre los Germanos 9 , la mujer vivía constantemente bajo la potestad del padre 0 , a falta de éste, de los parientes más cercanos, cuando era soltera $o$ viuda, y, por virtud del matrimonio, pasaba a la del marido. Éste podía repudiarla, empeñarla y aun venderla en caso de necesidad, castigarla corporalmente y hasta darle muerte, mediando justa causa. No obstante su postergación en el orden jurídico, disfrutaba de gran consideración en el seno de la familia como partícipe de los afanes y riesgos del marido, a quien solía acompañar en las expediciones guerreras. Tácito consigna como rasgo característico de los Germanos primitivos el respeto y la estimación de la mujer, a la cual dice que atribuían algo de santo y de profético. De aquí la creencia de que los secretos del porvenir, inaccesibles a la mirada escrutadora del hombre, se descubrían a la de la mujer. Estas ideas se reflejan admirablemente en los antiguos poemas de la raza germánica.

Constituían la fortuna de la mujer casada, por una parte, la dote, que era el precio pagado antiguamente por el marido a los padres o parientes de la mujer por la transmisión de la potestad sobre ella; el don de la mañana (morgengabe), que, en reconocimiento de la virginidad, la otorgaba el marido después del casamiento, y las ropas, vestidos, alhajas y enseres que ella aportaba, cuya importancia fue muy escasa en los primeros tiempos, cuando estaba excluida de heredar bienes inmuebles; de aquí la poca atención que dedican a estas aportaciones los Códigos germánicos. Como consecuencia natural de la absoluta sujeción de la mujer a la potestad del marido, éste concentraba en su mano todos los bienes de aquella, así muebles como inmuebles, los cuales administraba y usufructuaba, pudiendo disponer por sí solo de los primeros, mas no de los segundos sin el consentimiento de la mujer. Al disolverse el matrimonio, la mujer recobraba los bienes que había aportado y, a veces, la dote y el don de la mañana; pero había legislaciones que no le otorgaban sino el usufructo vitalicio de los bienes recibidos del marido, que al morir la mujer recaían en los herederos de aquél. No se reconocía a los cónyuges el derecho a heredarse.

La organización de la familia germana concordaba, pues, con la de la familia romana de los primeros tiempos, en cuanto al carácter ilimitado de la

9 Brunner, Deutsche Rechtsgeschichte, tomo I (Leipzig, 1887), págs. 70-81 y 8991.- Viollet, Histoire du droit civil français, $3 \cdot^{\mathrm{a}}$ edición (París, 1905), págs. 312-322. 
autoridad del jefe de ella, padre o marido, sobre los individuos pertenecientes a la comunidad doméstica. La palabra munt, con que se la designaba, es igual en su origen etimológico a la de manus. El rasgo diferencial entre la potestad del jefe de familia germánico y la del romano consistía en que, mientras esta última abarcaba la personalidad de los individuos sujetos a ella en todas sus relaciones, aun las meramente patrimoniales, en términos que el pater familias disponía a su antojo de cuanto poseían, entre los Germanos no era dueño absoluto de los bienes familiares, sino mero administrador de los inmuebles, los cuales no podía enajenar sin consentimiento de la mujer y de los hijos, por estimarse como patrimonio común de la familia. La diferencia esencial entre la mujer romana y la germana, con relación a los bienes, estribaba en que, mientras, según el derecho romano de los últimos tiempos, los bienes de ambos cónyuges permanecían separados constantemente, conforme al derecho germánico, los de la mujer se fundían durante el matrimonio con los del marido. La libertad de la mujer romana respecto de sus bienes propios contrastaba con la incapacidad absoluta de disponer de los suyos la mujer germana.

En el derecho germánico, la capacidad civil y política se enlazaba íntimamente con la aptitud para el servicio militar. Entre los Germanos, sólo el que podía empuñar las armas poseía íntegramente la capacidad jurídica. La libertad individual en su más amplio sentido, el derecho a intervenir en la vida pública, en suma, el pleno goce de los derechos civiles eran inseparables de la posibilidad y del deber de defender la patria. Sólo el hombre, y el hombre apto para el servicio militar, tomaba parte en las asambleas políticas, que eran al mismo tiempo asambleas militares. El incapaz de derechos políticos veía mermada considerablemente su capacidad en cuanto a los derechos civiles, singularmente al de propiedad, y había de estar sujeto en cierta medida a la potestad ajena. El menor, el anciano, el impedido física o moralmente, la mujer, vivían bajo la tutela de otro. La tutela de la mujer era perpetua, por ser constante su causa.

En su afán por favorecer la cohesión de la sociedad familiar, el derecho germánico cohibía de varios modos la personalidad del individuo en interés de la colectividad. Refléjase esta tendencia, tanto en las disposiciones encaminadas a conservar en las familias los bienes patrimoniales, como en las que, no atribuyendo valor alguno a la voluntad de la mujer en el matrimonio, sólo atendían a la de los padres o parientes. Así se explica que la personalidad de la mujer se encontrase, no sólo menoscabada, sino casi enteramente absorbida en la del jefe de la familia. 
Bajo la dominación visigótica, se encontraron en presencia el derecho romano, tal como se revela en los monumentos jurídicos anteriores a Justiniano, y singularmente en la Lex romana Visigothorum, vigente entre los súbditos de raza romana de las Galias y de España, y el visigodo, informado en los principios comunes a los pueblos germánicos ${ }^{10}$.

La dote, constituida por el marido a la mujer, como entre los Germanos del tiempo de Tácito, era designada entre los Visigodos indistintamente con los nombres de dos y de pretium, denominación esta última que refleja la idea, visible también en otros textos de la época, de considerar el matrimonio como una especie de contrato de compra ${ }^{11}$.

La práctica de comprar el marido a la mujer, mediante un precio convenido con el padre, con los parientes y a veces con ella misma, fue conocida de muchos pueblos de la antigüedad; se encuentran vestigios y reminiscencias de ella en la Edad Media, y se observa aun en pueblos de cultura rudimen-

10 Dahn, Westgothische Studien (Wurzburgo, 1874), págs. 116-118 y 122 127.- London, Quaestiones de historia iuris familiae quod in Lege Visigothorum inest (Königsberg, 1875).- Zeumer, Geschichte der westgothischen Gesetzgebung, III, en el Neues Archiv der Gesellschaft fur ältere deutsche Geschichtskunde tomo XXIV, págs. 584-588, y tomo XXVI, págs. 122-124,135-136 y 138-146.- Ficker, Untersuchungen sur Erbenfolge der ostgermanischen Rechte, tomo IV (Insbruk, 1899), págs. 313-332.

11 Del uso del nombre de pretium en las leyes para designar la dote y de la comparación del matrimonio con la compra en una de las fórmulas (Form. 19: in quantum maritandis ordinibus erit comparanda mercatio), no se infiere sino que los Visigodos consideraban el matrimonio como un contrato remuneratorio; en manera alguna que fuese para ellos la dote el precio real de la venta de la mujer, y esta como una mercancía. Deponen contra semejante idea las fórmulas de dote y las de consagración religiosa del matrimonio, que muestran la estimación y el respeto hacia la mujer y la consideración de las facultades del padre sobre la hija y del marido sobre la mujer en el derecho visigodo. Como observa Huber, Die Bedeutung der Gewere im deutschen Sachenrecht (Berna, 1894), págs. 77-78, entre los Germanos, la entrega de una cosa o de una persona, como modo de transmisión del derecho sobre ellas, mediante el pago de un precio, fue calificada de compra, sin tener en consideración la diversidad de los motivos, elementos y fines de las varias clases de contratos de este género. "No parece que pueda dudarse, por lo demás - añade- que, aun en tiempo de Tácito, se sabía distinguir ya bien entre la compra de un caballo y la celebración del matrimonio”. Análoga es la opinión de V. Amira, Nordgermanisches Obligationenrecht, tomo II (Leipzig, 1895), pág. 285, acerca del matrimonio por compra en Noruega e Islandia. Aun entre los pueblos salvajes, según Westermarck, The position of woman in early civilisation, págs. 155-156, esta forma de matrimonio no implica la carencia de derechos de la mujer, ni la desconsideración hacia ella. El precio de compra tiene el carácter de compensación del valor económico de la hija y de indemnización de los gastos de los padres en su crianza y educación. 
taria. Existía entre los Hebreos de la época de los patriarcas; fue general en la Grecia homérica y en la Roma de los primeros siglos, entre los Germanos primitivos y en algunos de los reinos fundados por ellos; en Irlanda, en Tracia, Armenia, la India y la Arabia. En nuestros días subsiste aún en China, en Cambodge y entre los Ossetes del Cáucaso. Según puede inferirse de los datos, frecuentemente poco precisos, relativos al matrimonio por compra, al principio el precio pertenecía generalmente al padre o parientes de la mujer, y más tarde vino a ser propiedad de ésta.

Era la dote, entre los Visigodos, requisito necesario en los matrimonios nobles, calificación que se aplicaba a las uniones bendecidas por la Iglesia, para diferenciarlas de las puramente civiles. Aunque se consideraba como propiedad de la esposa, solía entregarse a los padres, que tenían el usufructo vitalicio de los bienes en que consistía, sin otra limitación que atender al sostenimiento de la hija en caso necesario. A la muerte de los padres, entraba esta en posesión de la dote, pudiendo disponer de toda ella libremente cuando carecía de hijos, y sólo de la cuarta parte si los tenía. Correlativa del usufructo de los padres sobre la dote de la hija era la obligación de pagar al esposo el cuádruplo de los bienes dotales, cuando por culpa de ellos dejaba de celebrarse el matrimonio. La dote visigoda, como la donación ante nuptias del derecho romano, tenía por principal objeto crear a la mujer una masa de bienes para atender a su manutención y a la de sus hijos después de viuda.

Hasta el reinado de Chindasvinto no parece que hubo precepto legal sobre la cuantía de la dote. Así se infiere de la referencia que hace este monarca a los altercados que se suscitaban sobre el particular, y a los cuales quiso poner término, estableciendo un máximo que sirviera de dique a la vanidad y a la codicia. En algunas regiones, el marido acostumbró a dar en dote a la mujer la mitad de sus bienes presentes y futuros. Chindasvinto estableció, pues, que no excediera en ningún caso de la décima parte de los bienes del esposo; permitiendo, además, a los nobles hacer una donación consistente en diez siervos, diez siervas, veinte caballos y mil sueldos en ropas (la morgengabe del derecho germánico). Cuando, por muerte del esposo, o por otra causa, no llegaba a verificarse el matrimonio, la dote entraba en el pleno dominio de la esposa si los esponsales se habían celebrado osculo interveniente. El marido o sus herederos la recobraban cuando la mujer moría sin dejar hijos, y cuando se disolvía el vínculo conyugal por culpa de ella. La mujer podía hacer donaciones al marido de cuantía igual a la dote que de aquel hubiera recibido, pasado un año después de celebrado el matrimonio. 
La idea de que todos los acrecentamientos que experimenta la fortuna de los cónyuges durante el matrimonio son debidos a la colaboración de ambos, y deben distribuirse entre ellos al cesar la sociedad, se encuentra, aunque de un modo imperfecto, en una ley de Recesvinto, según la cual los bienes adquiridos por marido y mujer durante el matrimonio habían de dividirse, al disolverse el vínculo, en la proporción correspondiente a sus aportaciones respectivas, y si era muy escasa la diferencia entre la cuantía de ellas, por partes iguales. Parece que ésta hubo de ser, ya antes de Recesvinto, la regla general para la división de las ganancias de la sociedad conyugal, sin tener en cuenta la diversa cuantía de los bienes que respectivamente habían llevado al matrimonio. Era requisito indispensable que marido y mujer hiciesen vida común, según lo expresa la frase de pariter viventes. Dividíanse entre los cónyuges los bienes adquiridos por uno de ellos separadamente, o por ambos mientras duraba el matrimonio, excepto los ganados por el marido en la guerra y los que cada cual adquiría por donación del Rey, del patrono o de otras personas. Las ganancias obtenidas con el trabajo de los siervos pertenecientes a la mujer eran del marido, en compensación de las responsabilidades a que estaba sujeto por los daños que aquellos pudieran causar.

El sistema de los gananciales parece haberse derivado de la costumbre de dar el marido a la mujer como dote la mitad de sus bienes, no sólo presentes, sino futuros. Al hacer esto, la asociaba a sus ganancias, se obligaba a compartir con ella los acrecentamientos que tuviera su fortuna durante el matrimonio. De aquí surgió, probablemente, la intervención de la mujer en las adquisiciones y las enajenaciones de inmuebles hechas por el marido. La dote de la mujer recaía, pues, sobre la mitad de todos los bienes del marido al verificarse el matrimonio y de todos los aumentos del caudal de este, fuese cualquiera su procedencia; lo que restringió después Recesvinto, al mismo tiempo que establecía la división de las ganancias en proporción de las aportaciones de los cónyuges, excluyendo a la mujer de las adquisiciones hechas por el marido con el trabajo de los siervos de aquella e in expeditione publica, es decir, con el botín de guerra. Esta disposición parece formar sistema con la ley de Chindasvinto sobre el diezmo, pues ambas se encaminan a restringir las liberalidades a favor de la mujer, unificando las variedades del derecho consuetudinario. No se ha conservado documento alguno de donde pueda resultar clara la reciprocidad entre ella y el marido, cuando este la asociaba a las ganancias; pero es de creer que la habría, como en el caso de dejarse mutuamente por herederos.

La existencia del régimen de la comunidad universal en todos los Estados 
cristianos de la Reconquista induce a creer que existió ya, como consuetudinario, en el período visigótico.

Tomándolo del derecho romano, facultó el visigodo a los cónyuges para instituirse mutuamente herederos universales cuando no tenían hijos. Chindasvinto estableció que sólo pudieran dejarse, ya uno a otro cónyuge, ya cualquiera de ellos a personas extrañas, la quinta parte de sus bienes propios cuando tuvieran descendencia, entendiendo por propria técnicamente los bienes heredados, no los adquiridos. Preceptuó asimismo que las donaciones de lo adquirido entre cónyuges fuesen válidas, mas no las de los bienes propios si llegaban a tener hijos.

A diferencia de las otras legislaciones germánicas, en que existía la tutela del sexo y era atribución exclusiva del padre autorizar el casamiento de la hija, la visigoda considera esta autorización como incumbencia común del padre y de la madre. La viuda podía casarse sin el consentimiento de los parientes exigido por los otros Códigos germánicos.

El derecho visigodo, como el borgoñón, influido quizá por el romano, estableció que, a la muerte del padre, recayesen los hijos en la potestad de la madre, que sólo la perdía en el caso de pasar a segundas nupcias. Reconocía por igual al padre y a la madre el derecho de corregir y aun de castigar corporalmente a los hijos menores de edad.

Aunque estaba prohibido a la mujer comparecer en juicio como representante de otra persona, se la facultaba para actuar ante los tribunales en asuntos propios. El marido no podía representarla si ella no le autorizaba para este fin.

Si consideramos la influencia que tuvieron en la condición de la mujer los varios factores del desenvolvimiento jurídico entre los visigodos, es fácil observar que la acción concordante del derecho romano y del Cristianismo se manifiesta especialmente en la equiparación de los dos sexos en materia de derecho de sucesión, en la potestad de la madre sobre los hijos y en la situación independiente de la viuda. Hay instituciones, como la subordinación de la mujer al marido y la exigencia de la dote para la solemnidad del matrimonio, cuya derivación de los principios del Cristianismo y de la influencia de la Iglesia o, cuando menos, su apoyo en ellos es evidente. La dote ofrecida por el marido a la mujer es genuinamente germánica. El régimen de gananciales nace como institución enteramente nueva, no conocida del derecho romano ni del germánico ${ }^{12}$.

12 El problema de los orígenes de la comunidad de bienes entre cónyuges es uno de 
Hasta principios del siglo XIII, en que se verifica la recepción del derecho romano, predomina en todos los Estados de la España cristiana el derecho germánico en cuanto a las relaciones personales y patrimoniales entre los cónyuges. Desde este siglo, aunque en grado muy diverso, según los países, comienzan a transformarse bajo la influencia del derecho romano justinianeo, elaborado y modificado por los glosadores y postglosadores, radicalmente en Cataluña, menos, aunque bastante también, en León y Castilla, en menor grado aún en Aragón. Su influencia es apenas perceptible en Portugal, Navarra y Vizcaya.

En León y Castilla ${ }^{13}$, a diferencia de lo que se observa en el período visigó-

los más difíciles de la historia del derecho medioeval. La opinión dominante, sostenida ya por Olivecrona, Précis historique de la communauté de biens entre époux (Paris, 1865), es que surgió bajo la influencia de las costumbres germánicas, como desarrollo del derecho de la mujer a una parte de las adquisiciones hechas durante el matrimonio, de la acción común de los cónyuges en la administración de los bienes de ambos y de la obligación de reservar del sobreviviente cuando había descendencia. Se hallará una extensa exposición de sus fundamentos en Masse, Du caractère juridique de la communauté entre époux dans ses précédents historiques, (Paris, 1902). Lefebvre, en la obra citada en la nota 7 , combate esta opinión por no tener en cuenta suficientemente, a su juicio, la parte principalísima que corresponde en el nacimiento y arraigo de esta institución a la dirección que imprimió a las ideas y las costumbres de la sociedad romana de los últimos tiempos del Imperio la doctrina evangélica acerca del matrimonio. Typaldo-Bassia, La communauté de biens conjugale dans l'ancien droit français (Paris, 1903), reproduce en lo esencial la tesis de Lefebvre. Beauchet, en su introducción a esta obra, cree descubrir el origen de la comunidad en las costumbres germánicas del tiempo de Tácito; considera como factores que contribuyeron a su desenvolvimiento la copropiedad familiar y el Cristianismo, y estima como argumento decisivo, en pro del origen germánico, el encontrarse esta institución en los Códigos escandinavos del siglo XIII, que, según él, reflejan fielmente el derecho germánico primitivo. Es indudable que el régimen de la comunidad se aviene mejor que el de la separación con la intimidad y perpetuidad de la unión conyugal proclamadas por el Cristianismo; pero esto mismo puede decirse de la cualidad de compañera y asociada del marido, que era, según Tácito, característica de la mujer germánica. Cuando varios factores concurren al mismo resultado es frecuentemente difícil determinar con exactitud la parte que corresponde a cada cual en el origen y desarrollo de una institución, como sucede en el caso de que tratamos.

13 Martínez Marina, Ensayo histórico crítico sobre la antigua legislación y principales Cuerpos legales de los reynos de León y Castilla (Madrid, 1803), págs. 195-198, 205-210 y 215 220.-Cárdenas, Ensayo histórico sobre la dote, arras y donaciones esponsalicias desde el origen de la legislación española hasta nuestros días, en sus Estudios jurídicos, tomo II (Madrid, 1884), págs. 5-62, y Ensayo histórico sobre las leyes y doctrinas 
tico, encontramos la tutela del sexo, no ya sólo con relación a la mujer casada, sino respecto de la soltera mayor de edad y aun de la viuda, en los tiempos posteriores a la invasión árabe. Si consideramos los riesgos que asediaban constantemente a la mujer, de los cuales permite formar alguna idea la mención frecuentísima del rapto en los Fueros municipales, se comprenderá que la tutela del sexo era una necesidad de los tiempos.

La estrecha sujeción de las mujeres a la autoridad doméstica en los primeros siglos de la Edad Media se explica en parte por las costumbres rudas y semibárbaras de aquellos tiempos y por la falta de un poder público fuerte y vigoroso que amparase la persona y bienes de los súbditos. En tales circunstancias, la mujer no podía ejercitar sus derechos eficazmente por sí misma; necesitaba ser representada y protegida por el jefe de la familia. Su personalidad quedaba absorbida por el padre o, en su defecto, por los más próximos parientes, si era soltera o viuda; por el marido, si casada; y esta situación, lejos de serle desventajosa, era para ella un bien positivo.

A pesar de la prohibición de Chindasvinto, subsistió en Asturias y León la antigua costumbre visigoda, según la cual, consistía la dote, llamada ahora arras, frecuentemente, en la mitad de los bienes del marido ${ }^{14}$ : una de tantas muestras de la inobservancia del derecho escrito cuando contradecía prácticas arraigadas entre los Visigodos. Mientras que en Toledo, donde la conservaron los mozárabes, pues no hay que pensar que la llevara de León Alfonso VI, se guardó la tasa del diezmo, y lo mismo se observa en Galicia y Portugal

que tratan de los bienes gananciales en el matrimonio, en los mismos Estudios, tomo II, págs. 63-116.

14 1092. Ego Didago Odariz tibi coniugi mea Maria Martiniz... nomino tibi villas pernominatas propter honorem virginitatis et pulcritudinis tue... quos vulgi vocitant dotis... id sunt in Vinari mea divisa... et de omnem omnino rem meam quod habeo vel quod adhuc amodo et deinceps augmentare vel ganare potuero, medietatem tibi volo esse donata atque concessa, et quicquid tibi extiterit voluntas licenciam habeas facere inde.- Documento particular del Monasterio de Sahagún num. 21. Archivo Histórico Nacional.-1155. Ego Didacus Pelaiz a tibi sponse mee Maria Pelaiz... do et dono a tibi per titulum dotis... de villas que abeo... in terra Asturias... medietatem ex integrum... et iterum adicio tibi de alias meas hereditates per ubi illas potueris invenire medietatem... et de mia criatione medietatem ex integrum, et de omni rem meam qui in iuri meo promansit medietatem ex integrum et... de quantum potuero ganare habeas tu medietatem per donum... ad pro abendum faciendi quod volueris liberam in Dei nomine abeas potestatem, et post obitum tuum ubi volumptas tua fuerit.- Vigil, Asturias monumental, epigráfica y diplomática (Oviedo, 1889), págs. 237-238. 
en los primeros siglos de la Reconquista, más tarde los Fueros municipales redujeron a cantidades relativamente pequeñas el importe de la dote.

En Galicia y Portugal, donde se conservó más pura y por más tiempo la tradición visigótica, perseveraba todavía en los siglos XIII y XIV la idea del matrimonio por compra, revelada en algunas frases de las cartas dotales ${ }^{15}$.

La práctica relativa a la división de los gananciales por mitad entre marido y mujer sin relación a la diversa cuantía de sus aportaciones fue derecho común en León y Castilla, como lo prueban los documentos de los primeros siglos de la Reconquista, en que se hace mérito de la sociedad de gananciales entre personas pertenecientes a las diversas clases sociales ${ }^{16}$. El no mencionar algunos Fueros municipales esta institución, nada dice contra su universalidad, dado que no se conoce hasta ahora Fuero alguno que contenga disposiciones contrarias a ella. Por otra parte, no siendo los Fueros códigos completos, su silencio se explica porque supone como derecho común el visigótico escrito o consuetudinario. El Fuero Viejo y el Fuero Real consagraron el carácter legal del régimen de los gananciales.

15 Santa Rosa de Viterbo, Elucidario (Lisboa, 1798), artículos Compra do corpo y Marido conoçudo, y Lévy María Jordao, Le morgengabe portugais, en la Revue Historique de Droit français et étranger, tomo V (Paris, 1859), págs. 101-120, citan varios documentos portugueses de los siglos XIII al XV en que se encuentran las frases pro compara corporis, por arras e por compra do meu corpo, refiriéndose a la dote del marido a la mujer.- 1321. Venta de una heredad por María López al Prior del Monasterio de Riveiro, en Galicia: "todo o erdamento que a min dara meu marido Meen Zan qo dito tina na vila de Lamas por arras e por compra de meu corpo". Boletín de la Comisión Provincial de Monumentos Históricos y Artísticos de Orense, tomo I, 1898, pág. 35.

16 1034. Ego Asuri Gomiz... tivi Momadona... dono... in titulo dotis puero ad puela, kavalo... cum sela argentea et freno argentio, e villas que abeo de pater meo Gomice Nuniz, medietate in Sancti Martine, et medietate in Vilella, cum suas adiacencias, et una pele alfaneque et alia delgata... et pro titulo dotis post obitum meo x. ${ }^{\mathrm{a}}$ portione tivi concedo secundum in lege contine, et post odie die vel tempore quanto in uno potuerimus ganare vel argomentare medietate abeas inde ex integra, et post obitum nostro que derelinquamus ad filios nostros que de nostro coniugio natos fuerint.- Escalona, Historia del Real Monasterio de Sahagún (Madrid, 1782), escritura LXXXIII, págs. 451-452. 1303. Haec est chartula dotis, quam fieri praecepi ego Johannes Aldefonsis... tibi dilectae sponse mea Agnes Aldefonsis... Ego amore tui et ob gratiam procreandam prolis do tibi in munus Alolla, et Alguelela... decimam partem omnium rerum mearum quas modo habeo, et a die nostre benedictionis in antea quantum nobis Deus in lucro dederit, qualibuscumque modis, inter nos per medium habeatur.-Memorias de Don Fernando IV de Castilla, tomo II (Madrid, 1860), Colección diplomática, número CCXLVII, pág. 373. 
Las Partidas presuponen vigente el sistema de los gananciales, al establecer que los conciertos hechos por marido y mujer antes o después del matrimonio respecto a los bienes, conforme a la ley o costumbre del lugar en que los otorgaron, se tuvieran por válidos, aunque trasladasen después su domicilio, o fallecieran en sitios donde rigieran normas diferentes; y que, a falta de pacto expreso, se aplicase el derecho del lugar en que se celebró el matrimonio. Según ellas, no eran gananciales los productos de la dote y de las arras, sino propiedad del marido; pero esta doctrina, o no rigió jamás, o rigió únicamente allí donde no existían costumbres en contrario. Prueba de la inobservancia de estas novedades de las Partidas respecto a los bienes gananciales es que la última de las disposiciones dictadas sobre esta materia en la Edad Media, la de las Cortes de Santa María de Nieva, no menciona siquiera dicho Código, sino el Fuero Real y Leyes del Estilo, únicas vigentes sobre el particular. Se estableció en las citadas Cortes, como regla general, que los bienes adquiridos a título singular por cada uno de los cónyuges fuesen de su propiedad exclusiva, y que sólo los productos de ellos engrosaran la masa de los gananciales, que habían de dividirse por mitad entre marido y mujer. Determinóse, además, el caso en que la mujer perdía tales bienes.

Es dudoso si se consideraban como bienes gananciales, además de los adquiridos por ambos cónyuges de consuno por compra o donación, como fruto de su industria durante el matrimonio y aumento del capital aportado, los que procedían de donación hecha exclusivamente en el mismo tiempo a uno solo de ellos. Los bienes raíces procedentes de cambio por otros privativos de uno de los cónyuges, o comprados con el producto de la venta de tales bienes, no pertenecían al fondo común de la sociedad conyugal.

El marido administra por sí solo los bienes de la comunidad, dispone inter vivos de los muebles y rentas y de los gananciales inmuebles; pero algunos Fueros limitan sus facultades a su parte de gananciales. La costumbre establece la acción común para disponer de lo adquirido por los cónyuges durante el matrimonio. En todo caso, era de rigor la intervención de la mujer para disponer de los propios suyos, y a veces también de los del marido, por razón del derecho a la viudedad.

El marido no debía disponer de los bienes propios de la mujer sin consentimiento de esta; si lo hacía, no podía la mujer impugnar la validez del acto; mas, al disolverse el matrimonio, estaban facultados ella o sus herederos para reivindicar los bienes así enajenados del que los hubiese adquirido. De los bienes gananciales disponía en absoluto, sin que su derecho en este punto es- 
tuviese limitado por el de la mujer. Si el marido contraía deudas para subvenir a los gastos comunes, éstas gravaban sobre los bienes de ambos cónyuges en proporción al capital respectivo.

La mujer casada no podía ser obligada a comparecer en juicio ausente su marido. Sin consentimiento de este, no le era lícito vender ni empeñar sus bienes muebles ni inmuebles, ni salir fiadora de otras personas. Igual prohibición tenían las solteras, aunque no estuvieran sujetas a la patria potestad, y las viudas cuando vivían con alguno de sus parientes; este debía prestarles el consentimiento para dichos actos. Se encuentra mención de tales autorizaciones en los documentos relativos a contratos verificados por esta clase de personas. Consecuencia de la incapacidad civil de la mujer era que las deudas contraídas por ella no pudieran ser exigidas, según algunos Fueros, sino en el caso de no exceder de cinco sueldos o un maravedí, a menos de que se dedicaran al comercio. No se permitía al acreedor reclamar el pago de las deudas de la mujer casada en vida del marido; pero, muerto este, tenía derecho a exigirlo de la mujer o de sus herederos.

Según los Fueros generales y algunos municipales, ni las arras ni la parte de los gananciales pertenecientes a la mujer respondían de las penas pecuniarias en que incurriese el marido. No era responsable tampoco con sus bienes propios de las deudas de este, si no se había impuesto semejante obligación en la escritura constitutiva del crédito. Cuando esto sucedía, su responsabilidad era solidaria de la del marido.

La recepción del derecho romano vino a introducir en los sistemas de bienes de la sociedad conyugal vigentes en Castilla la inalienabilidad de la dote, la hipoteca legal sobre los bienes inmuebles del marido para asegurarla, y las incapacidades impuestas a la mujer por el Senadoconsulto Veleyano y la Auténtica Si qua mulier. Las Partidas, como el Código de Justiniano, atribuyeron a la mujer la administración de los parafernales cuando no los entrega al marido con este objeto. Consignaron también la incapacidad de la mujer para ser fiadora, conforme a lo preceptuado por el Senadoconsulto Veleyano, con las excepciones introducidas por los glosadores. Las Leyes de Toro armonizaron el sistema de los gananciales con el régimen dotal; establecieron que en caso de ausencia o de negativa del marido, el juez pudiese autorizarla, y mantuvieron la prohibición del citado Senadoconsulto en la misma forma que la legislación de Justiniano, reconociéndole eficacia en muchos casos si se trataba de otras personas que el marido, y nunca si se trataba de este.

Los cónyuges celebraban a veces un contrato, en cuya virtud el que sobre- 
viviera debía tener el usufructo de todos los bienes de ambos hasta su fallecimiento, a menos que contrajese nuevo matrimonio, sin que los herederos del cónyuge difunto pudieran reclamarle alguna parte de ellos. Este contrato, llamado unidad y hermandad, no fue una innovación introducida por los Fueros municipales de Alfonso VIII y Alfonso IX, en que le encontramos regulado; hay documentos de los siglos X y XI que acreditan la antigüedad de esta institución ${ }^{17}$. Su trascendencia para los herederos, respecto a los cuales aplazaba, quizá por largo tiempo, la posesión de los bienes que habían de recaer en ellos, fue causa de que algunos Fueros municipales requiriesen su previa aprobación para la validez de dicho contrato, al cual se rodeó, además, de las mayores garantías de publicidad, exigiendo que se hiciese ante el Concejo en que se hallaban empadronados los cónyuges. El Fuero Real, al adoptar la institución de los contratos de hermandad, tan arraigada en León y Castilla, restringió la libertad de que hasta entonces habían gozado en este punto los cónyuges, no consintiéndoles celebrarlos sino después de transcurrido un año de matrimonio, y solamente cuando carecían de hijos legítimos. Estableció, además, que, caso de tenerlos después de verificado el contrato, se tuviese éste por nulo y de ningún valor. Las Partidas consignan también

17 959. Ego Rudericus et uxor mea nomine Gilvira, dum in coniugio positi fuissemus, et filios nobis non essent, communi consensu pariter tractantes... eligimus, ut invicem nobis cartula donationis conscribere deberemus, ut unusquisque ex nobis qui alios supervixerit ab integrum omnem paupertatis nostre quod habemus, vel quod adhuc cum Dei adiutorio adquirere potuerimus securus debeat possidere... tamen ratione servata si nobis dominus filios dederit ipsi nobis sint heredes. - López Ferreiro, Historia de la Santa A. M. Iglesia de Santiago de Compostela, tomo II (Santiago, 1899), Apénd. LXXIII, págs. 169-170. - 1055. Nos coniunti in unum... Garcia... et Leonina... ex eo quod abuimus nos filios natos et sunt migrati a seculo et devenimus sine filios in hoc mundo... facimus inter nos unitas perfecta... de omni re nostra... tam de hereditates quam etiam et de omnia nostra re... quantum ganamus et opulentamus vel ganaverimus usque ad exitum mortis nostre.- Cartulario del Monasterio de Eslonza (Madrid, 1884), número XXXVI, págs. 65-67. En documentos de los siglos XIV y XV se emplean juntamente, para designar este contrato, las palabras "unidad" y "hermandad". 1307 ... Yo, Arias Gonzalez de Cisneros, y yo, Doña Mencia su mujer, amos en vno hacemos carta de hermandat $y$ de unidad de todo quanto que oy havemos y haviemos cab adelante, también de muebles, como de raiz, et todo lo al que oy havemos y havremos cap adelante, también mueble, como raiz, per o quier que lo ovieremos y haver devemos, que finque todo a qualquier de nos amos que fincare sivo, libre y quito, y que lo aya de derecho heredamiento, y que faga de todo a su guisa en vida, y en muerte, asi como de sus cosas proprias.- Salazar y Castro, Historia de la casa de Lara (Madrid, 1694), tomo IV, pág. 674. 
la licitud del referido pacto y, de acuerdo con el Código antes mencionado, preceptúan que cuando la costumbre local establecía que el marido heredase la dote y donaciones de la mujer difunta, y ésta otros bienes del marido en su caso, se tuviese por válida y eficaz.

La potestad sobre los hijos se ejercía en común por ambos cónyuges, si bien, como en nuestros días, según parece, con predominio de la paterna en caso de discordancia, aunque no se prevea ni resuelva este caso. A la muerte del padre, pasaba a la madre en toda plenitud. Los derechos como las responsabilidades del padre y de la madre respecto de los hijos eran idénticos, como lo es la situación del hijo y de la hija generalmente entre los Visigodos.

En los Estados y territorios que tuvieron legislación especial propia, distinta de la de Castilla, y la conservan aún después de la promulgación del Código civil, la exposición histórica se confunde frecuentemente con la del derecho vigente.

Constituían la dote aportada por la mujer en Aragón ${ }^{18}$ los bienes inmuebles o que como tales llevaba al matrimonio (axovar), dados por los padres si casa con su consentimiento, de los pertenecientes a la sociedad, y si no los hubiese, de los propios de los cónyuges. Si hay hijos, éstos heredan la dote; si no los hay, o si los hijos mueren sin testamento ni descendencia, vuelve a los parientes de quien procede.

La donación del marido a la mujer al verificarse el matrimonio se denomina firma de dote, y es obligatoria cuando la mujer llevó dote o prometió la firma el marido; si no, voluntaria. La propiedad es de la mujer, que puede donarla al marido. Suele convenirse que la hereden los hijos, y, a falta de ellos, que sea la mitad del marido o de los herederos. Consistía antiguamente, si el marido era infanzón o caballero que casaba con mujer de su misma condición, en tres castillos, villas o lugares con vasallos, y si la mujer era de condición inferior, en tres villas, campos o casas, dos o una. De ordinario, la cuantía de la firma es la tercera parte de la dote.

Fue frecuente en Aragón, durante la Edad Media, la comunidad de bienes entre cónyuges, designada aquí, como en Castilla, con el nombre de hermandad (germanitas). En virtud de ella, ponían en común todos sus bienes habi-

18 Franco y Guillén, Instituciones del derecho civil aragonés, Zaragoza, 1841.- Casajús, El derecho de familia en la legislación aragonesa. Discurso leído en la Universidad de Zaragoza, 1880.- Costa, El derecho consuetudinario del Alto Aragón, en la obra Derecho consuetudinario y Economía popular de España (Barcelona, 1902), tomo I, págs. 1-253. 
dos y por haber, así muebles como inmuebles, o parte de ellos, de suerte que, fuese cualquiera la cuantía de los pertenecientes a cada cónyuge, venían a formar una sola masa, divisible por mitad entre ambos. Cuando la comunidad era universal, el cónyuge sobreviviente no tenía derecho a las avantajas forales, nombre que se daba a los bienes que éste podía sacar de la masa común antes de la división. Eran estos, si se trataba del marido, sus ropas de vestir, un lecho con sus accesorios, las armas y los libros, las bestias de silla con sus arreos y una yunta. Este derecho del marido pasaba siempre a sus herederos, mas no el de la mujer, sino en el caso de sobrevivir al marido.

El régimen de bienes de la sociedad conyugal, cuando no es determinado por la voluntad de los cónyuges en las capitulaciones otorgadas antes o después de celebrado el matrimonio, ha de acomodarse a las prescripciones de los Fueros, y se denomina consorcio foral. En el Fuero municipal de Teruel de 1175 se encuentra ya este régimen de bienes con sus caracteres fundamentales $^{19}$. Con arreglo a él, el marido hace suyos los bienes muebles y administra los inmuebles. Su facultad de disponer de los bienes de la sociedad no es absoluta, pues es nula la enajenación gratuita y sin motivo justificado de los inmuebles, y la de los muebles si perjudica a la mujer, o dispone de ellos en la última enfermedad. La mujer no los administra sino en ausencia del marido. Puede donar a este sus bienes, incluso la dote, bien que esta última con autorización de los parientes; le es lícito obligarse por deudas del marido y ser fiadora de otras personas, si aquel la autoriza, cuando sirve de garantía la dote. No responde por los delitos del marido con la mitad de los inmuebles y muebles de la sociedad conyugal, ni con las avantajas forales.

Institución común a Aragón y Navarra es la viudedad, que consiste en el derecho del cónyuge sobreviviente a usufructuar durante su vida los bienes inmuebles del difunto.

En Navarra ${ }^{20}$ las arras eran antiguamente tres heredades en el casamiento de los infanzones; actualmente no puede exceder su cuantía de la cuarta parte de la dote. Son de la mujer en plena propiedad, aunque no tenga descendencia, y goza de la libre disposición de ellas; mas no le es lícito reclamar su entrega hasta la disolución del matrimonio. Puede, con autorización del padre, o a falta de este, del hermano mayor o de un tío y tres parientes, hacer donación de ella al marido. Se estipula frecuentemente en las escrituras de

19 Forum Turolii, publicado por Francisco Aznar (Zaragoza, 1905), arts. 181 y 187.

20 Desdevisses du Dèzert, De la condition de la femme mariée en Navarre, en la Revue des Pyrénées et de la France Méridionale, tomo II (Toulouse, 1890), págs. 804-833. 
dote que vuelve esta al dotante cuando la mujer muere sin descendencia o contrae nuevo matrimonio; mas si tiene descendencia, gana en todo caso la propiedad de la dote y dispone de ella libremente.

El régimen de bienes de la sociedad conyugal es casi idéntico al de los gananciales de Castilla, que allí se llaman conquistas. Sólo se diferencia de él en que, al contraer el viudo segundo matrimonio sin dividir antes con los hijos de la primera mujer, éstos entran a participar de las conquistas en la misma proporción que los nuevos cónyuges. Existen también los parafernales con el mismo carácter que en Castilla.

La viudedad, denominada en Navarra fealdat, al principio privativa de los infanzones, según parece, se extendió después a las otras clases sociales. Ofrece los mismos caracteres que la de Aragón. Recae sobre cuantos bienes deja el cónyuge difunto, y sólo se pierde por incumplimiento de los deberes que impone, a saber: inventario, fianza, alimentación y educación de los hijos y conservación de los bienes, o por nuevas nupcias, o mala conducta.

Este derecho de viudedad, reconocido a marido y mujer en el siglo XIII por el Fuero general, se encuentra ya establecido respecto a la mujer en los Fueros municipales de los siglos XI y XII ${ }^{21}$. Es muy de notar a este propósito que, para expresar la cualidad de usufructuaria de la viuda, los mencionados Fueros emplean la frase domina et potens, usada también en Aragón y Cataluña.

La dote en Vizcaya ${ }^{22}$ tiene el nombre de arreo; la lleva aquel de los cónyuges que entra en el caserío, y es constituida por ropas, dinero, aperos de labor y cabezas de ganado. En el contrato matrimonial se consigna "la cantidad que por arras se mandan uno al otro cónyuge, la forma de devolverlas y las seguridades con que el marido afianza la devolución de lo dotado por la esposa y, especialmente, la donación que hace el padre de todos sus bienes". Es frecuente que, en correspondencia al arreo, dé el otro cónyuge la misma cantidad.

$\mathrm{Al}$ constituir la dote, suele estipularse la reversión, al tronco de donde proceden, si consiste en inmuebles. La mujer no es responsable con sus bienes de los delitos del marido. Es frecuente el contrato de gananciales, y en el caso de haber descendientes al disolverse el matrimonio, los bienes que constituyen la masa común se dividen por partes iguales. En otro caso los recobra el cónyuge que los llevó al matrimonio.

21 Fuero de Estella confirmado en 1164, copiado en este punto por el de San Sebastián. Yanguas, Diccionario de Antigüedades del reino de Navarra, tomo I. (Pamplona, 1840), págs. 439-440.

22 Vicario, Derecho consuetudinario de Vizcaya (Madrid, 1901), págs. 29-66. 
El marido administra los bienes de la comunidad, mas no puede enajenarlos sin autorización de la mujer, excepto los adquiridos durante el matrimonio. El cónyuge sobreviviente que ha llevado algunos bienes tiene derecho a usufructuar por un año y un día los del difunto, y a conservar el usufructo hasta que se le entreguen sus bienes propios, a menos que pase a nuevo matrimonio; sólo tiene lugar cuando no hay hijos.

Subsistió en Cataluña ${ }^{23}$ la dote visigótica del diezmo hasta principios del siglo XIII. Ya en el siglo XII aparece, a veces, juntamente con ella, el esponsalicio de cuantía variable ${ }^{24}$. Consistía generalmente en la mitad del importe del exovar. Se concedía a la mujer, ya en plena propiedad, ya en usufructo vitalicio con la obligación de reservarlo para los hijos, y a falta de estos, para los parientes del marido o las personas designadas por él, ya parte en propiedad y parte en usufructo con la misma obligación de reservarlo.

La mujer usufructuaba en vida el esponsalicio, a menos de pacto en contrario estipulado antes del matrimonio, aunque el marido no se lucrase de la dote o exovar de la mujer a la muerte de esta. A la del marido, tenía derecho a mantenerse de los bienes de este durante un año, si la dote consistía en dinero

23 Oliver, Código de las Costumbres de Tortosa, tomo II (Madrid, 1878), págs. 253344.- Brocá y Amell, Instituciones del derecho civil catalán vigente, 2. ${ }^{\mathrm{a}}$ ed. (Barcelona, 1886), tomo I, págs. 182-396. - Brutails, La Coutume d’Andorre (París, 1904), págs. 118136.

24 ... Ego Almoravith dono tibi Marie sponse mee pro tuo sponsalicio. D. solidos bone monete barch. valentes marchas argenti XLIIII solidos in cunctis rebus meis mobilibus quas modo habeo vel inantea Deo largiente ubique locorum adquisiero. Quos. D. solidos tu vel amici tui per te de cunctis rebus iam dictis mobilibus et inmobilibus accipias et habeas eos teneas possideas et explotes cunctis diebus vite tue, et obitu tuo habeas pro tuo proprio ad tuam voluntatem faciendam medietatem istorum. D. solidorum. Alia vero medietas istorum. D. solidorum post obitum tuum remaneant infantibus de me in te procreatis. Si vero infantes de me in te procreati superstites non fuerint, predicta medietas istorum. D. solidorum post obitum tuum remaneant michi vel meis propinquis vel cui verbis aut testamento dimissero Conditor omnium Deus cum inicio mundi cuneta creasset ex nichilo ex osse viri dormientis formam fecit mulieris; ex uno duos faciens duos unum esse deberé mostravit, ipso atestante qui ait: relinquet homo patrem suum et matrem et adherebit uxori sue et erunt duo in carne una. Quapropter... ego Almoravith amore creandorum filiorum, elegi michi sumere sponsam nomine Mariam, et fació ei dotem vel donationem décime partis omnium rerum mearum mobilium et inmobilium quas modo habeo vel inantea Deo largiente ubique locorum adquisiero.- Archivo del Monasterio de Santa Clara, en Barcelona.- Véanse los documentos de esta misma clase de fines del siglo XII que traduce Balari, Orígenes históricos de Cataluña (Barcelona, 1887), págs. 526-528. 
contante (pecunia numerata), en el caso de que no se le pagasen por entero la dote y el esponsalicio; mas si consistía en inmuebles, entraba inmediatamente en posesión de ellos, juntamente con la de los bienes obligados por el esponsalicio, y desde entonces no se alimentaba de los bienes del marido.

Según las Costumbres de Gerona, la viuda no podía pedir la dote mientras se la permitiese poseer las cosas obligadas para asegurarla, salvo si tenía la cualidad de heres, que entonces le era lícito pedirla aun contra la voluntad de los herederos del marido. Si le quedaban hijos menores, no estaba facultada para exigir el pago de la dote mientras retuviese los bienes de aquel, percibiendo los frutos, y pudiese vivir suficientemente de ellos, de los bienes parafernales y del ejercicio de una industria. Si no tenía hijos no le era dado reclamarla dentro del año, si durante él se le daban alimentos de los bienes del marido. Transcurrido este plazo, podía pedirla, y retenía los bienes y percibía los frutos hasta que se le pagase.

Los bienes que la mujer llevaba al matrimonio se denominaban indistintamente dote o exovar. Solían constituirlo los padres y, en su defecto, los hermanos de la mujer. Era condición ordinaria que fuese para los hijos de la dotada, y si moría sin ellos, que volviese a los parientes de esta. El marido no se lucraba del exovar, muerta la mujer, a menos que se hubiera pactado algo en contrario antes del matrimonio. A veces no se entregaba inmediatamente, sino que se prometía, consignándose esta promesa en las capitulaciones matrimoniales, y se daba fiador para garantizar la entrega.

La dote en Cataluña después de la recepción del derecho romano ofrece el mismo carácter que en Roma. Es la suma de bienes que la mujer recibe, al casarse, de sus padres o de otra persona, para sostener las cargas de la sociedad conyugal. Si procede de los padres, se considera como anticipo de legítima. Cabe aumentarla después de verificado el matrimonio. Los padres, o el hijo heredero en su defecto, deben dotar a la hija o hermana. Cuando no hay bienes comunes, dotan el padre o la madre de los suyos propios. Donde, como en el Campo de Tarragona, en Tortosa y en el Valle de Arán, existe la comunidad de bienes, la constituyen los padres con los bienes de la sociedad. Se acostumbra a pactar la reversión de la dote al dotante, o a sus herederos, si no hay hijos, y, aun habiéndolos, si mueren antes de la edad necesaria para otorgar testamento. La mujer tiene derecho a que se le restituya el fundo dotal, aunque lo haya enajenado el marido con anuencia de ella.

La donación del marido a la mujer en correspondencia a la dote, excreix, no es obligatoria, sino potestativa. Su cuantía variaba según las regiones: en 
Barcelona solía ser la mitad de la parte no revertible de la dote; en Tortosa, la mitad, si la dote se constituía en metálico o era estimada, y disminuía con ella, si mermaba la dote sin culpa del marido. En algunas comarcas, como la de Vich, en que sólo disponía libremente la mujer de la tercera parte de la dote, el excreix consistía en el tercio. El cónyuge que pasaba a segundas nupcias no podía dar en este concepto sino tanto, a lo sumo, como lo que dejaba en herencia al hijo del matrimonio anterior que heredaba menos.

Correspondía al marido el usufructo del esponsalicio; pero si llegaba a extrema pobreza, podía la mujer exigir su importe y, en caso de ejecución de los bienes del marido, hacer uso de la opción dotal. A la muerte de la mujer, heredaban el esponsalicio los hijos; a la del marido pertenecía el usufructo a la mujer, y la propiedad a los hijos. No habiéndolos, pasaba a los herederos del marido, después de usufructuarlo la mujer, la cual podía renunciar el usufructo total, quedándose con la mitad del esponsalicio. En Tortosa regían disposiciones especiales sobre el particular.

Las donaciones hechas con ocasión de los esponsales las recobran los esposos si no se verifica el matrimonio, a menos que deje de celebrarse por culpa de uno de ellos, cuyo derecho caduca entonces. En el caso de osculo interveniente, muerto el esposo, la mujer adquiría la mitad. De las ropas y joyas sólo correspondía a la mujer el anillo de boda, una joya de oro o plata de mediano valor y los trajes de uso ordinario.

El derecho de la mujer catalana conocido con el nombre de opción dotal es la facultad de designar los bienes de que se ha de sacar su dote y esponsalicio, caso de ser ejecutados los del marido. Procede de una Pragmática de Jaime I del año 1241 relativa a Barcelona, reiterada por Alfonso IV en 1432 y por Fernando el Católico en 1481. La principal condición para ejercitarlo es que la mujer no haya firmado la obligación que da lugar a la ejecución, ni haya prometido por juramento no hacer valer contra ella sus derechos a la dote y al esponsalicio. Lo mismo sucede si se obligó de mancomún, donde, como en Barcelona, por virtud del privilegio del Recognoverunt proceres, no siendo suficientes los bienes del marido, responde la mujer sólo con la mitad de los suyos, aunque haya renunciado el Veleyano.

La opinión más corriente y autorizada entre los glosadores italianos fue que la mujer podía renunciar al beneficio del Senadoconsulto Veleyano y de la auténtica Si qua mulier, como introducido en su favor, y que esta renuncia era válida con sólo que se la advirtiera previamente que podía acogerse al Senadoconsulto, lo cual se presumía o suponía además cuando no constaba lo 
contrario. Los jurisconsultos catalanes aceptaron esta doctrina, y la práctica se acomodó a ella. De ordinario se menciona el Senadoconsulto, juzgando comprendida implícitamente la Auténtica; pero, en algunos casos, se renuncia expresamente a esta última.

La hermandad de bienes entre cónyuges (agermanament) existió en Tarragona (Tortosa y Mirabet), en Gerona, en el Rosellón y en Andorra ${ }^{25}$. Se pactaba, a veces, sin hacer mérito de si se tenía o no descendencia ni esperanza de ella, y sin prever siquiera el caso de que la hubiese; otras, sólo cuando el matrimonio había sido estéril. En este último caso se declara que cada cónyuge tendrá la facultad de disponer por testamento de cierta cantidad. No fue raro reservarse cada cónyuge el derecho de testar sobre la cantidad necesaria para el entierro y funerales, declarando nulo el agermanament caso de tener hijos.

En virtud de este contrato, cuantas adquisiciones hacen los cónyuges mientras dura el matrimonio por cualquier concepto, vienen a constituir una masa común que se distribuye luego por partes iguales. Según el Código de Tortosa, es incompatible con el sistema dotal, y no es válido si no se concierta al verificarse el matrimonio.

Las Costumbres de Mirabet establecían que, cuando existía el agermanament, los bienes de la mujer, como los del marido, pudieran ser generalmente materia válida de contratos celebrados y de obligaciones contraídas por éste durante el matrimonio, cuando no reclamaba la mujer contra la administración del marido. No era lícito, sin embargo, al marido vender los inmuebles de la mujer sin consentimiento de ella.

La asociación de compras y mejoras, usada en la comarca designada con el nombre de Campo de Tarragona cuando menos desde el siglo XVI, se diferencia principalmente del sistema de gananciales de Castilla en que ha de establecerse mediante contrato, y no nace como aquél ipso facto con la celebración del matrimonio. Cuanto adquieren los cónyuges mientras persevera la sociedad, divídese entre ellos al disolverse esta; mas no es esencial que la división se haga por partes iguales entre el sobreviviente y los herederos del difunto. Es frecuente que los padres del marido entren en la sociedad, a condición de que los esposos habiten con ellos, adquiriendo de este modo partici-

25 Oliver, Código de las Costumbres de Tortosa, tomo II, página 329.-1460. Tarifa de derechos de las escribanías del vizcondado de Bas: "Por carta de mancomunidad (agermanament), cada parte 1 sueldo".- Monsalvatje, El Vizcondado de Bas (Olot, 1893), página 31.- Brutails, Etude sur la condition des populations rurales du Rousillon au moyen âge (París, 1891), pág. 207. 
pación en las ganancias. Al morir la mujer, cesa la asociación necesariamente; pero puede continuar entre la viuda y los hijos con los padres del marido al fallecimiento de este.

Según el derecho consuetudinario del Valle de Arán, confirmado por el Rey de Aragón D. Pedro, el marido podía asociarse a la mujer en convinensa o mitja guadanyaria al principio, medio o fin del matrimonio y, en este caso, ella y sus herederos tenían derecho a la mitad de los bienes muebles e inmuebles adquiridos por los cónyuges durante el matrimonio. Si después de concertada la convinensa contraían deudas, las pagaban por partes iguales, del mismo modo que partían las mejoras y aumentos. Este pacto ha caído en desuso, sustituyéndole el sistema dotal.

Por virtud del Usaje Vidua, la viuda tenía el usufructo de todos los bienes del marido, con tal de que no pasara a segundas nupcias y viviese honestamente, consagrada a la educación de sus hijos. A mediados del siglo XIV, ésta institución deja de tener carácter legal obligatorio, perseverando como contractual hasta nuestros días en la designación del marido a favor de la mujer como senyora majora y usufructuaria. De este modo, la autoridad familiar, necesaria y conveniente para mantener la cohesión de los miembros de la familia en interés de todos, no desaparecía a la muerte del padre, sino que se continuaba en la madre, de forma que aun el hijo casado, heredero del hogar paterno, quedaba sometido a ella. Se prevé el caso de que la convivencia no fuera posible.

La mujer catalana goza del derecho de ser mantenida por espacio de un año, a contar desde el fallecimiento del marido, por los herederos de este, a menos de que pase a segundas nupcias u observe mala conducta. Este derecho se conoce con el nombre de any de plor.

El derecho civil de Mallorca es idéntico en algunos puntos al catalán y en otros ofrece mucha semejanza con él ${ }^{26}$.

La intensidad del espíritu de familia y las circunstancias económicas modificaron en puntos esenciales la influencia de los dos factores principales del derecho mallorquín, el derecho catalán importado por los conquistadores y primeros pobladores y el romano traído directamente a la Isla por los juristas mallorquines que estudiaban en las Universidades de Cataluña y Mediodía de Francia.

26 Antoni Moll, Sumari deis Ordinacions y Privilegis del Regne de Mallorca (Palma, 1667).- Legislación foral de España. Derecho civil vigente en Mallorca, con una introducción de D. Antonio Maura. Madrid, 1888. 
La dote visigótica del diezmo, ofrecida por el marido a la mujer y unida como en Cataluña al excreix o esponsalicio, se encuentra en los primeros tiempos de la conquista ${ }^{27}$. Era muy variable la cuantía de este. Al principio, la determinaba a su arbitrio el marido, y consistía generalmente en la mitad del valor de la dote. El rey D. Sancho la fijó en 1316 en la cuarta parte. Entre los judíos conversos se usó en el siglo XV, además del excreix, otra donación del marido a la mujer como aumento de dote, que se encuentra también alguna vez entre los cristianos viejos a principios del siglo XVII. Este aumento, que era, desde luego, propiedad de la mujer, se agregaba a la dote para computar la cuantía del excreix. Hasta 1316 fue frecuente ceder el marido en propiedad a la mujer parte del excreix, de ordinario la mitad o la cuarta parte. Desde esta fecha no se acostumbró concederlo sino en usufructo vitalicio, debiendo pasar a la muerte de la mujer, si no quedaban hijos, a los herederos del marido, o a otras personas que este designara en el testamento. Por excepción se consigna en algunas capitulaciones matrimoniales del siglo XIII la donación que hace el marido de la mitad o la tercera parte de las mejoras o acrecentamiento de sus bienes propios a favor de la mujer ${ }^{28}$.

La dote aportada por la mujer llamose, como en Cataluña, exovar; era estimada o inestimada y consistía generalmente en bienes muebles. Hasta el siglo XVI se acostumbró a entregarla en el acto del casamiento; pero desde esta fecha fue usual la estipulación de que no se entregara sino a la muerte del padre de la mujer. Hoy, según las noticias que he podido adquirir, no se usa sino raras veces y sólo en el pueblo de Pollensa.

27 1240. Ego Arnaldus de Bagnariis dono tibi Caterine sponse mee pro tuo sponsalicio trescentos solidos melgurienses et fació tibi dotem et donacionem décime partis omnium rerum mearum mobilium et inmobilium habitum et habendorum.- Documento particular del Convento de Dominicos de Palma de Mallorca, núm. 75.- Archivo Histórico Nacional.

28 1242. Berengarius de Uyastreto... profiteor tibi Ermesendis filie Bernardi de Parelliata, te atulisti mihi tempore nuptiarum tuarum pro tuo exovario ducentos quinquaginta solidos melgurienses... Et ego addo tibi centum triginta solidos melgurienses; et ita sunt inter dotem et augmentum trecenti octuaginta solidi Et habeas dictos CCCLXXX solidos teneas possideas et explotes cum marito et sine marito Et ad obitum tuum habeas medietatem dictorum CCCLXXX solidorum melguriensium ad tuas voluntates faciendas; alia medietate infantibus, et si infantes defuerint habeas CCCXXX solidos ad tuas voluntates, et residui L solidi revertantur proximis meis. Item dono pro bono amore tibi tertiam partem in omnibus emptionibus et adquisitionibus quas de cetero faciam te vívente, quam tertiam partem habeas ad tuas voluntates faciendas.- Archivo de Protocolos de Palma de Mallorca. 
Los bienes que lleva, hereda o adquiere por cualquier otro concepto la mujer casada tienen el carácter de parafernales.

El agermanament, con caracteres idénticos al de Cataluña, se practicó en Mallorca en los siglos XIII, XIV y XV²9. Los últimos casos de él que conozco hasta ahora son del siglo XV y tienen lugar entre libertos. Se usó también el nombre de agermanament para los contratos en que los cónyuges sin hijos se

29 1260. Nos Raymundus Stefanus de Castilione de Impurias et Castiliona, filia Carbonelli de Felenizio... nostrarum tempore nuptiarum, facimus inter nos societatem et fralernitatem racione sponsalicium nostrorum de omnibus bonis mobilibus et inmobilibus quos nunc habemus et de cetero Deo concedente habituri vel adquisituri sumus... in hune videlicet modum, quoi ambo insimul dum vixerimus predicta omnia bona... habeamus et teneamus prout decet virum et uxorem, et in obitu nosti o quisque nostrum habeat medietatem omnium predictorum bonorum pro voluntate sua facienda.- Documento particular del Convento de Dominicos de Palma de Mallorca, núm. 172.- Archivo Histórico Nacional. 1478. Nos Bartholomeus Frontera, notarius, et Margarita, coniuges, cives Maioricarum, qui ad invicem mutuo amplectimur amore coniugali et cupimus in dies ampleri, et sic de bonis nobis comunibus vivere et in illis superstitem nostrum premorienti succedere, et dictis bonis uti et ea possidere ad suas voluntates faciendas omnimodas... facimus et contrahimus inter nos fraternitatem et germaniam... de et super omnibus et singulis bonis nostris mobilibus et inmobilibus ac semoventibus, ubique habitis et habendis, ita quod nos ambo pariter, dum vixerimus et nostrum duraverit matrimonium, habeamus et possideamus omnia ipsa bona nostra qua nunc nos ambo simul vel divisim habemus et alter nostrum habet et de cetero habebit... quavis ratione titulo sive causa, et ea sint inter nos communia, et ex eis vivamus... sanos et egros, prout decet virum et uxorem. Altero vero nostrum mortem obeunte sine liberis legitimis et naturalibus, omnia et singula bona ipsa nostra sint et remaneant titulo huiusmodi agermanamenti alteri nostrum supraviventi ad suas voluntates omnímodas inde libere faciendas pleno iure, quia nos ambo volumus titulo huiusmodi agermanamenti omnia bona alterutrius premorientis superstiti nostrum in hoc casu adquiri, et titulo etiam reciproco donationis quam alter nostrum alteri facit eadem vicisitudine irrevocabiliter causa mortis. Hoc itaque agermanamentum et reciprocam donationem causa mortis, ut prefertur, facimus nos predicti coniuges alter alteri ad invicem... Retinemus tamen nobis predicti coniuges ab hoc agermanamento penitur exclusas, scilicet, ego dictus Bartholomeus Frontera sexaginta libras monote regalium Maioricarum minutorum de bonis meis; et ego dicta Margarita, in proprietate et pensionibus, illas octo libras dicte monete Maioricarum censuales quas recipio super universitatem ville et parrochie Sancti Johannis de Sineu; de quibus retentionibus, singula singulis referendo, volumus nos dicti coniuges quod fiat premorientis sepulturam, notitia et cognitioni alterius qui supravixerit et exsolvantur pia et profana que disposuerimus, sive verius premoriens disposuerit suis in ultimis diebus.- Archivo de Protocolos de Palma de Mallorca. Libro de contratos del Notario Martín Terrers.- Debo copia de este documento y del transcrito en la nota 28 a D. Estanislao Aguiló. 
instituían mutuamente herederos. Pactábase a veces, al contraer matrimonio, el agermanament de las ropas de vestir de los cónyuges y las de casa y cama.

Los bienes de la cámara, que es como se designaba a las ropas de cama, eran por mitad de ambos cónyuges, y cada cual reivindicaba su parte a la muerte del otro. No era raro que se las donasen mutuamente.

La mujer casada en Mallorca tenía y tiene derecho a la administración y la libre disposición de sus bienes propios; pero, apartándose de lo preceptuado por el derecho romano acerca de los parafernales, el derecho consuetudinario ha atribuido al marido la administración de dichos bienes, aun sin que la mujer se los entregue con este objeto.

El rey D. Sancho restringió el derecho de goyda, semejante al denominado tenuta en Cataluña, por virtud del cual la viuda, mientras no se le entregaran los bienes dotales, usufructuaba los propios del marido, limitando la duración del usufructo a un año, pasado el cual sin que los herederos del marido la entregasen la dote, cesaba aquel, y sólo tenía derecho la viuda a los alimentos.

El derecho mallorquín, como el catalán, tomó del romano la institución de la cuarta marital a favor del cónyuge viudo sin medios de fortuna, convirtiéndola, hacia mediados del siglo XIV, en una pensión vitalicia proporcionada a la cuantía de los bienes dejados por el cónyuge difunto y a su posición social, para evitar el fraccionamiento de los predios rústicos, que constituían y constituyen el principal elemento de prosperidad de las familias mallorquinas de la clase media.

En 1351, el rey Pedro III estableció que, pasado el any del plor, en el cual deberá proveérsela de todo lo necesario, hiciera suyos los frutos de los bienes del marido hasta que se le pagase la dote y el esponsalicio enteramente, salvo si el marido la hubiera asignado otros bienes para seguridad de ellos de que pueda sacar renta, en cuyo caso la posesión se había de limitar a estos bienes.

Era y es muy frecuente en Mallorca, como en Cataluña, dejar el marido el usufructo vitalicio de todos sus bienes a la mujer, con la facultad de disponer de ellos libremente inter vivos, o de designar herederos entre ciertas personas. Así, el "testador conserva a la viuda a perpetuidad los respetos que merece", y deja "apiñada y sometida en torno de ella la familia que creó"30.

En Valencia, que perdió su derecho especial en el siglo XVIII ${ }^{31}$, la fortuna de la mujer casada consistía en los bienes que aportaba, llamados, como

30 Maura, op. cit., pág. 13.

31 Tarazona, Institucions dels furs y privilegis del regne de Valencia (Valencia, 1580), págs. 217-223. 
en Cataluña, dote o exovar, y la donación del marido, sponsalitium, donatio propter nuptias, augmentum dotis, creximent o creix, de cuantía igual a la mitad de la dote, que había de darle necesariamente el marido si era doncella. Cuando el matrimonio no llegaba a celebrarse por muerte del esposo, ni la esposa ni sus herederos tenían derecho al creix. Jaime I equiparó a doncellas y viudas en cuanto a la necesidad del creix; pero Alfonso IV en 1429 prohibió que se otorgase a las viudas so pena de nulidad.

Lo más interesante y característico del derecho valenciano, considerado desde el punto de vista de nuestro estudio, es la gran importancia que tuvo en él, la extraordinaria difusión que alcanzó, y las curiosas modalidades que presenta la institución del agermanament, o sea la comunidad universal importada de Cataluña.

Por virtud del contrato de hermandad de bienes, denominado germanitas, fratischa, fraternitas, unitas, societas, agermanament y germania ${ }^{32}$, que solía celebrarse al tiempo de contraer matrimonio, los cónyuges ponían en común todos sus bienes, así presentes como futuros, conviniendo en que se partieran por mitad entre el cónyuge sobreviviente y los herederos del difunto, lo mismo si hubiera descendencia que si no la hubiese (cum prole et sine prole). Por excepción, se limitaba la comunidad a los bienes adquiridos

32 1285. Nos Johannes Terre et Berengaria uxor mea, modo in nostrarum tempore nuptiarum, facimus et ordinamus societatem, fratrischam et germanitatem inter nos observandam, ita que dum ambo vixerimus vivamus et utamur comuniter de bonis nostris que habemus et habebimus, et qui prior nostrum obierit habeat suam partem ad omnes suas voluntates, et qui plus vixerit similiter.- Archivo general del Reino de Valencia, Protocolo de G. Molere.

1342. Ego Dominicus Raymundi... vicinus Valentie, ex una parte, et ego Francischa filia Francisci Brotons... vicini dicte civitatis, ex parte altera, insimul... facimus et contrahimus fraternitatem et germaniam inter nos firmiter tenendam et observandam diebus omnibus vite nostre super omnibus bonis et rebus nostris mobilibus et inmobilibus que modo habemus vel de cetero Domino annuente ubique habere et lucrari potuerimus quolibet modo causa vel ratione. Ita quod omnia dicta bona, simul et pariter dum vixerimus, habeamus teneamus possideamus utamur et vivamus de prefatis bonis prout decet inter virum et uxorem. Et qui prior nostrum ab hoc seculo decesserit habeat tunc et accipiat medietatem bonorum omnium predictorum, quam possit dare dimitiere distribuere vel legare verbo vel scripto cum prole et sine proie ad omnes suas voluntates perpetuo faciendas sine contradictione et impedimento alterius nostrum qui supravixerit vel alterius cujuslibet persone. Et qui supravixerit alteri eodem modo habeat tunc similiter et accipiat aliam residuam consimilem medietatem bonorum omnium predictorum cum infantibus et sine infantibus ad omnes suas voluntates perpetuo faciendas. - Archivo de la Catedral de Valencia. 
durante el matrimonio, viniendo a ser como una sociedad de gananciales, reservándose expresamente los cónyuges la propiedad exclusiva de los bienes que respectivamente habían aportado.

En cuanto a las facultades de los cónyuges respecto de los bienes del matrimonio en el régimen dotal, los derechos de opción y de tenuta, la herencia del cónyuge sobreviviente, las relaciones personales entre ambos y la potestad y la tutela sobre los hijos, no hay diferencia digna de ser notada entre el derecho valenciano y el catalán.

$\mathrm{Al}$ investigar las vicisitudes del régimen de bienes de la sociedad conyugal en España, se observa la oposición radical entre los países donde impera el sistema de la comunidad de bienes, la libertad de donaciones entre esposos y la viudedad, persistiendo hasta nuestros días con sus caracteres esenciales, no obstante las modificaciones debidas a la influencia romana, y aquellos otros en que, habiendo regido estas instituciones en los primeros siglos de la Edad Media, se modifican luego bajo la influencia del sistema dotal romano, singularmente en lo relativo a la incapacidad de la mujer casada. Puede asegurarse que el sistema genuinamente nacional, como lo demuestra el hecho de encontrarse en todos los Estados de la Edad Media española con caracteres más amplios o más restringidos, es el régimen de la comunidad, expresión la más adecuada de la idea de la sociedad en el orden patrimonial, cuyos orígenes pueden referirse con fundamento a la acción combinada del Cristianismo y de las costumbres germánicas.

Varias causas influyeron en la mejora de la condición personal y patrimonial de la mujer en los Estados romano-germánicos y en las naciones que de ellos se derivaron; por una parte, la acción lenta pero constante de las ideas cristianas; por otra, las modificaciones que experimentan la autoridad del jefe de la familia y la estrecha cohesión entre los miembros de ésta, cuando el Estado, con plena conciencia de su misión, reivindica para sí la protección y el amparo de los débiles, $\mathrm{y}$, finalmente, la recepción del derecho romano con sus instituciones favorables a la independencia económica de la mujer.

La tutela perpetua de las mujeres desaparece por completo, o queda sólo para los efectos judiciales, o se trueca en mera asistencia, cesando en absoluto respecto a las viudas, desde el punto en que la edad, y por consiguiente la falta de desarrollo intelectual y de experiencia del mundo, y no la incapacidad por razón del sexo, viene a ser el fundamento de la tutela. La corriente favorable a la supresión de la tutela del sexo recorrió las mismas etapas en casi todas las naciones cultas de Europa, así latinas como germánicas. Comenzó por 
atenuarse hasta desaparecer a fines de la Edad Media respecto de la soltera mayor de edad y de la viuda, no sin perpetuarse vestigios de ella hasta nuestra época en algunas regiones de Alemania y Suiza, mientras que la potestad del marido sobre la mujer, aunque reducida a límites más razonables, impera aún en la mayoría de los Estados de Europa y América ${ }^{33}$.

Transformaciones económicas de índole análoga a las que hoy exigen reformas trascendentales en la condición civil de la mujer casada, y comunes como ellas a todos los pueblos cultos de Europa, produjeron en la Edad Media modificaciones tan importantes en este orden como el reconocimiento de cierto grado de capacidad civil a la mujer dedicada al comercio, algunos cambios en el régimen de bienes de la sociedad conyugal favorables al crédito, que surgieron y se desarrollaron en los municipios al compás de los progresos de la industria y el comercio, y la admisibilidad y la práctica frecuente de las renuncias a los beneficios del derecho romano en favor de la mujer, pero que consistían esencialmente en limitaciones de su capacidad para obligarse, como el Senadoconsulto Veleyano, la Auténtica Si qua millier y la Epistola Divi Adriani.

Nuestro Código civil ${ }^{34}$ ofrece vestigio apenas de la influencia de las corrientes que, ya en la época de su redacción definitiva, se dejaban sentir, así en la esfera científica como en la legislativa, en cuanto a la mejora de la condición civil de la mujer casada, acerca de las relaciones patrimoniales. Sus prescripciones descansan sobre las del Código francés, y son, a veces, mera reproducción de ellas, sin las atenuaciones del Código italiano, que sirvió de fuente al nuestro en otras materias, como en el derecho de sucesión del cónyuge sobreviviente, única mejora que introdujo en este orden.

En cuanto a las relaciones personales copia, como tantos otros, el artículo del Código Napoleón que tanto excita las iras de los feministas, sobre la obligación de la mujer de obedecer al marido, que podrá suprimirse sin inconveniente alguno. Respecto a las patrimoniales, establece la misma desigualdad entre los derechos del marido y de la mujer acerca de los bienes de la sociedad conyugal. El marido, administrador de los gananciales, puede enajenarlos u obligarlos sin la mujer; mas no esta sin autorización del marido, si no existe pacto en contrario, salvo en algunos casos. No puede adquirir ni enajenar sin permiso del marido, o del juez, ni pedir partición de bienes, ni obligar sus

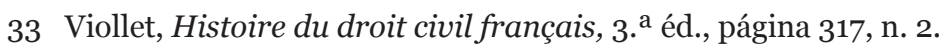

34 Sánchez Román, Estudios de derecho civil, tomo II (Madrid, 1889-96), págs. 179181, y tomo V (Madrid, 1898), págs. 594-680. 
bienes inmuebles, ni disponer de ellos mientras dura el matrimonio, aunque esté separada judicialmente, sin autorización del juez. Si contrae segundas nupcias, pierde la potestad sobre los hijos, a menos que el marido difunto en su testamento la facultase para seguir ejerciéndola. Es incapaz para ser tutora, salvo de sus hijos y nietos, y, en todo caso, para formar parte del Consejo de familia.

Esta situación desventajosa debe modificarse en armonía con el progreso de las ideas y de la legislación.

¿Qué orientación deberíamos tomar para la mejora de nuestro derecho civil en orden a la condición de la mujer casada? No hay duda que la legislación extranjera de los tres últimos decenios, singularmente la inglesa, el Código civil alemán y el proyecto de Código civil suizo ${ }^{35}$ ofrecen puntos de vista y soluciones muy dignos de ser tenidos en cuenta, por responder a ideales y exigencias hijas de la transformación del estado económico en todas las naciones cultas, y conformes en parte también a las tradiciones patrias.

Las relaciones personales entre los cónyuges tienden en las legislaciones modernas a una equiparación cada vez mayor, manifestada singularmente en la sustitución de la potestad exclusiva del padre por la potestad parental. El poder de dirección, que es justo reconocer al marido, no debe extenderse más allá de la órbita en que su empleo sea preciso y beneficioso para la sociedad conyugal. Conforme a esto, le corresponde la elección de domicilio y la decisión en los asuntos que conciernen al régimen general de la vida doméstica, como si el contrato de servicios celebrado por la mujer se armoniza con el cumplimiento de sus deberes en la esfera del hogar. Este poder de dirección, fundado en la naturaleza misma de la sociedad conyugal, puede degenerar en tiránico; en vez de emplearse, que es el fin de su institución, en bien de las personas sometidas a él, puede ejercitarse en su daño. De aquí la necesidad de que la ley ponga coto a su uso indebido, amparando a la mujer contra las violencias posibles de parte del marido. Dos tendencias se disputan el predominio en cuanto a la solución de este importante y difícil problema. Consideran

35 Lyon-Caen, La femme mariée allemande, Paris, 1903.- Huber, Condition de la femme dans le futur Code civil suisse en la Revue de Morale Sociale, núm. 1 (Paris, 1899), págs. 19-34, y Code civil suisse. Exposé des motifs de l'avant-projet (Berna, 1901), págs. 93-110 y 130-200.- Dicey, Leçons sur les rapports entre le droit et l'opinion publique en Angleterre au cours du XIX ${ }^{e}$ siècle (Paris, 1906), págs. 359-373. La obra de Aftalión, La femme mariée. Les droits et ses intérêts pécuniaires, Paris, 1899, contiene una excelente exposición del derecho comparado de Europa y América sobre el régimen de bienes de la sociedad conyugal. 
unos que la autoridad pública es la llamada a intervenir en estos casos. Los que, con Stuart Mill, en su célebre obra antes citada, y Laurent en su Proyecto de revisión del Código civil defienden la equiparación absoluta de los cónyuges, creen que debe remitirse a los jueces y tribunales la resolución definitiva de todos los conflictos que la discordancia de pareceres entre marido y mujer pueda suscitar en el seno de la sociedad doméstica. No reparan en los graves inconvenientes que acarrearía la frecuente injerencia de la justicia civil en la vida del hogar y la ineficacia de su acción en la mayoría de los casos, y en que esta intervención ha de considerarse como un recurso extremo a que no se debe apelar sino en casos excepcionales. No conviene, por otra parte, prescindir de él, antes bien hay que amparar el derecho de la mujer con disposiciones semejantes a las del Código alemán y el Proyecto suizo. Cierto es que esto no remediará enteramente el mal; pero es indudable que lo conseguirá en muchos casos, y que las violencias posibles del marido encontrarán un dique en las medidas tutelares respecto de la mujer. Aunque esta reforma no dé todos los resultados apetecidos, pues hay siempre factores que dificultan el logro de las aspiraciones del legislador, se conseguirá cuando menos, mediante ella, atenuar algunos de los males desarrollados y arraigados a la sombra de la legislación.

No desaparecerá la cualidad del marido de jefe de la familia, exigida por el buen orden de la sociedad conyugal, consagrada por los Códigos que han establecido y sancionado el principio de la igualdad del hombre y de la mujer ante el derecho civil, como no desaparecerá la autoridad política por grandes que sean los progresos de la democracia; pero la autoridad marital con el carácter que le dio el Código civil francés, y que aún hoy conserva en la mayoría de los Códigos civiles de Europa y América, como limitación injusta e innecesaria de la capacidad civil de la mujer, está llamada a desaparecer en breve plazo, como desapareció la tutela del sexo.

Cuando se trata de las ventajas e inconvenientes de las varias formas de régimen económico de la sociedad conyugal, no se piensa generalmente sino en las personas que, al contraer matrimonio, poseen ya un caudal algo importante, heredado o adquirido, no en el número, muy considerable en nuestro tiempo, de los que se casan sin fortuna y se enriquecen luego con el ejercicio de una profesión o industria, ni menos en la masa enorme de los proletarios reducidos al escaso producto del trabajo de sus manos, del cual sólo en casos raros pueden ahorrar alguna pequeña parte. No se considera bastante que las condiciones del trabajo de la mujer se han modificado esencialmente 
durante el siglo XIX. Su actividad económica, limitada en épocas anteriores, casi exclusivamente, a los cuidados del hogar y a las industrias domésticas, ha adquirido extraordinaria extensión. La situación de la mujer de las clases proletarias dedicada al trabajo en la fábrica y en el taller; la de la clase media como profesora, escritora, telegrafista, telefonista, actriz, cantante, exigen reformas en el derecho civil en armonía con esta transformación.

Debe tenerse en cuenta, además, al tratar de los sistemas de bienes de la sociedad conyugal, que la inmensa mayoría de las mujeres -todas las de la clase proletaria y gran número de la clase media- no celebran capitulaciones matrimoniales y quedan, por tanto, sujetas al régimen legal.

En punto a reclamar la separación de bienes como régimen económico de la sociedad conyugal, hay casi completa unanimidad entre los representantes de los varios matices del feminismo. Vemos formulada esta aspiración en las obras más importantes de los escritores feministas de todos los países y, sobre todo, en los Congresos nacionales e internacionales dedicados al estudio de las cuestiones feministas. Citaré como ejemplo el Congreso celebrado en París con motivo de la Exposición Universal de 1900 y el de la Sociedad Internacional de Economía social de 1901. No tienen en cuenta los defensores de la separación de bienes como régimen legal los inconvenientes que ofrece el considerar a los cónyuges en el orden de las relaciones patrimoniales como personas extrañas, asociadas temporalmente para vivir en un mismo hogar, y que, en la mayoría de los casos, este sistema ha de resultar desventajoso para la mujer, pues no tendría participación en las ganancias del marido, que suelen ser las de mayor importancia.

Hay que conservar al sistema de gananciales el carácter de sistema legal ${ }^{36}$, o sea el de aplicable a los casos en que los cónyuges no pacten otro en las capitulaciones matrimoniales, por ser el vigente de antiguo en la mayor parte del territorio español, y responder mejor que otro ninguno a las exigencias

36 Véase el prólogo de D. Antonio Maura a la obra Derecho civil vigente en Mallor$c a$, págs. 15-16, donde declara preferir "mil veces el régimen económico del matrimonio castellano al seco régimen dotal que se conserva en Mallorca”, y se inclina a la aceptación inmediata de la sociedad de gananciales en Mallorca, como derecho voluntario, para que la transición de uno a otro régimen sea menos brusca. "Pero el término definitivo de la evolución - añade - tiene que ser la forzosa é ineludible sociedad legal; porque sin ella, la organización del patrimonio familiar pugna con el derecho natural, y aun, en ocasiones, compromete la armónica ponderación de derechos y deberes recíprocos, de preeminencias protectoras y de dignas sumisiones, en que deben consistir las relaciones personales de los cónyuges y en que estriban la paz y el decoro de las familias”. 
del estado económico y social de nuestro tiempo. Es, sin duda, el que se armoniza mejor con la importancia que ha adquirido en nuestros días la fortuna mobiliaria, sobre ser el más favorable a la mujer, porque estimula en mayor grado su colaboración en el acrecentamiento del patrimonio social, y garantiza mejor su porvenir al disolverse el matrimonio. Estas son las razones que mueven a eminentes jurisconsultos a proponer su adopción como régimen legal en Francia ${ }^{37}$, donde goza de gran favor en las capitulaciones matrimoniales. Siendo la mujer asociada del marido en el trabajo dentro de la esfera que le es propia, colaborando con su esfuerzo al bienestar y prosperidad del hogar, es no sólo conveniente, sino justo que compartan los resultados de esta fecunda labor común.

Sería necesario reconocer la capacidad civil de la mujer casada, sin perjuicio de las limitaciones derivadas del sistema de bienes adoptado por los cónyuges. La ilimitada libertad de que goza el marido para disponer de los bienes comunes a ambos cónyuges en el sistema de gananciales, y en todo otro sistema de comunidad de bienes, deja enteramente indefensos los intereses de la mujer. Para remediar este mal, hay que darle una intervención eficaz en la administración del patrimonio conyugal. Conforme a esto, la intervención de la mujer sería imprescindible, así para hipotecar y enajenar los inmuebles de la sociedad, como para la pignoración y venta de los muebles, y muy especialmente de los valores públicos.

El carácter inalienable de la dote, la prohibición de obligarse y la hipoteca tácita de la mujer, deben ceder el puesto a estas otras garantías, más adecuadas y eficaces. La hipoteca legal, como garantía contra los abusos del marido, único administrador de los bienes de la sociedad conyugal, es enteramente ilusoria cuando éste carece de bienes inmuebles; ineficaz cuando la mujer renuncia a ella, y perjudicial para el crédito del marido por las dificultades que opone a la libre disposición de los bienes inmuebles.

Otra reforma necesaria y urgente, exigida por el desarrollo de la actividad económica de la mujer en los tiempos actuales, y realizada ya, aunque de diversa manera, en Inglaterra, el cantón de Ginebra y Alemania, es el recono-

37 Aftalión, La femme mariée, págs. 395-402.- Thaller, Le contrat de mariage et le régime normal des biens à établir entre époux en La Réforme Sociale de $1^{\circ}$ de Octubre de 1901, págs. 473-474.- Saleilles, en La Réforme Sociale de $1^{\circ}$ de Julio de 1901, pág. 91, y en la introducción a la obra de Lyon-Caen, La femme mariée allemande, págs. XXI-XXIV.Tissier, L'émancipation civile de la femme. La loi française et la loi anglaise, en la obra de Dicey, Leçons sur les rapports entre le droit et l'opinion publique en Angleterre au cours du XIX $X^{e}$ siècle, págs. 486-487. 
cimiento del derecho de la mujer casada a disponer libremente del producto de su trabajo, sin perjuicio de contribuir en la proporción debida a los gastos del hogar.

La admisión de la mujer, así soltera como casada, a la tutela y al Consejo de familia y su capacidad para actuar como testigo en los documentos civiles, debe ser plenamente reconocida siguiendo el ejemplo de las legislaciones alemana y suiza.

Sírvanos de estímulo para no demorar la reforma de nuestra legislación civil en el sentido de las codificaciones alemana y suiza la consideración de que cuanto se haga por mejorar la condición de la mujer contribuye a la dignificación del matrimonio, institución educadora del género humano y, según la frase exacta y profunda de Goethe, "base y coronamiento de toda cultura". 


\title{
CONTESTACIÓN
}

\author{
DEL EXCMO.
}

SEÑOR MARQUÉS DE PIDAL

\section{SEÑORES:}

Una decidida vocación manifestada desde la juventud, y a la que permaneció fiel toda su vida, ha llevado a D. Eduardo de Hinojosa a consagrarse, en primer término, al estudio por tantos conceptos interesante y fecundo de la historia del Derecho; y los resultados de esta vocación han sido tales que, aun antes casi de alcanzar la alta reputación científica de que goza hoy entre nosotros, el nombre del nuevo Académico había traspasado, sin más ayuda que sus obras, las fronteras de la Patria, y los sabios que con más autoridad se consagran a los estudios históricos y jurídicos en Europa se habían apresurado a recomendar y a ensalzar públicamente sus diversos trabajos.

En estas circunstancias, que no suelen reunirse fácilmente, no cabe mayor homenaje al que hemos llamado a compartir nuestras tareas, ni mayor justificación de la elección de la Academia, que recordar rapidísimamente estos merecimientos de nuestro nuevo compañero, y formar, por decirlo así, las efemérides de su vida científica y de sus obras.

Conoció quien os habla al Sr. Hinojosa en los primeros años de su juventud, recién venido de Granada, donde sabios de la autoridad y fama de D. Leopoldo Eguílaz, cuya reciente pérdida lloran a la par las ciencias, las letras y las artes, habían tomado con especial empeño dirigir acertadamente sus primeros pasos. Le apellidaban sus amigos el bibliógrafo, porque ya en tan temprana edad no había libro que no conociera, ni estancia para él más agradable y frecuentada que la de las bibliotecas y librerías. Recuerdo a este propósito que en una ocasión, sin él buscarlo ni saberlo, hubo de figurar su nombre en las candidaturas para uno de los cargos honoríficos del Ateneo, y los muñidores de oficio, los oradores de junta, como entonces se llamaban, pusieron el grito en el cielo ante esta designación de un desconocido, que nunca habían visto en los salones de su tertulia. Pero olvidaron que había en el Ateneo otro recinto que ellos no solían frecuentar, y de los encargados y concurrentes a 
la biblioteca de aquel ilustrado centro, testigos presenciales de la asiduidad y competencia del joven Hinojosa, salió la más espontánea y enérgica protesta contra esta imputación de extraño y de desconocido que los verdaderamente extraños a los fines científicos del Ateneo le dirigían.

Después, treinta años hace, justamente, publicaba el señor Hinojosa como primer fruto de sus trabajos el comentario a los fragmentos de la ley Colonial de Osuna, escrito en colaboración con el Sr. Rada y Delgado, y el ilustre romanista francés Carlos Giraud se apresuraba a proclamar que "honraba a la erudición española".

Comisionado por el Gobierno al año siguiente, en 1878, para estudiar en Alemania las publicaciones relativas a España, muy numerosas e importantes por la conexión de nuestra Historia con la general de los pueblos germánicos en el período visigótico, y por el íntimo enlace entre las vicisitudes políticas de España y de Alemania en los siglos XVI y XVII, el trato con jurisconsultos e historiadores distinguidos confirmó su vocación, amplió sus horizontes y le sirvió de excelente preparación para la obra, que concibió ya entonces, de vulgarizar en España los resultados de la ciencia alemana sobre la Historia del Derecho romano. Realizó este propósito poco tiempo después, publicando en la Biblioteca jurídica de Autores españoles, fundada por D. Emilio Reus, la Historia del Derecho romano según las más recientes investigaciones. Notables romanistas de Francia, Italia, Bélgica y Alemania acogieron con elogio esta obra, considerándola como exposición fiel del estado de la ciencia y muestra del renacimiento de los estudios jurídicos en España.

La plausible modificación que introdujo el Sr. Gamazo en el plan de estudios de la Facultad de Derecho en 1883, dando a la Historia del Derecho español el carácter de asignatura independiente, movió al Sr. Hinojosa a publicar una obra que pudiera servir de base a esta enseñanza. Abarca el primer volumen, que vio la luz en 1887, la reseña de las fuentes del Derecho y de las instituciones de la España primitiva y romana y el bosquejo de las fuentes del período visigótico. En armonía con el fin de la obra, que es, como manifiesta el autor en el prólogo, "iniciar y orientar en el estudio de la Historia del Derecho español”, pone especial cuidado en indicar las principales fuentes de conocimiento y las obras donde se tratan más amplia y profundamente las materias que abarca. Su interés, lo que constituye su valor permanente, consiste en la exposición detallada y metódica de la organización política y administrativa de la España romana, basada principalmente en el estudio de los monumentos epigráficos. Este trabajo, que ocupa la mayor parte del vo- 
lumen, y que el Sr. Hinojosa ha sido el primero en realizar, fue muy elogiado por la más grande autoridad en estas materias, el profesor de la Universidad de Berlín y doctísimo editor de las inscripciones latinas de España Emilio Hübner. En el artículo que le dedicó en la Gaceta Bibliográfica Alemana de 1888 dijo lo siguiente: "Cuando se forme una generación de jóvenes historiadores y jurisconsultos que se apropie realmente el contenido de este libro, y aprenda a utilizarlo con juicio independiente para ulteriores investigaciones, entonces podrá España colaborar de nuevo en la resolución de los problemas científicos a que dedicaron sus esfuerzo, figurando en primera línea, hombres como Antonio Agustín en el siglo XVI y Mayáns y Campomanes en los siguientes".

¿Qué razones pudieron mover al Sr. Hinojosa a desistir de la continuación de esta obra, tan útil y necesaria, acogida con benevolencia por jueces autorizados que, al elogiarla, estimulaban al autor para que la llevase a término? Tengo por indudable que la principal fue el convencimiento del autor de que prestaría mayor servicio a la cultura patria y al progreso científico consagrándose a llenar, en la parte que le fuese dable, mediante estudios especiales sobre puntos obscuros o inexplorados, las muchas lagunas que ofrece aún nuestra historia jurídica, que dedicándose a exponer el resultado de las investigaciones ajenas. Quizá le arredró también la suma dificultad, que no tuvo en cuenta al emprender su obra, de hacer, pasado el período visigótico, trabajo análogo al que había hecho sobre el romano, dado que sobre estos dos períodos existen trabajos importantes nacionales y extranjeros que utilizar y un ciclo completo y depurado de fuentes, mientras que respecto a los tiempos posteriores a la Reconquista carecemos de tales auxilios. El investigador de vocación se siente más atraído que a los trabajos de vulgarización científica a los estudios monográficos, en que la posibilidad de dominar las fuentes y la esperanza de llegar a resultados nuevos ofrece más compensación al esfuerzo empleado.

Conocida y debidamente estimada era ya, sobre todo desde que la puso en relieve Enrique Wheaton en su Historia del Derecho de gentes, la importancia de las doctrinas del insigne dominico Francisco de Vitoria para el Derecho internacional. Mas faltaba estudiar desde otros puntos de vista sus doctrinas y su influencia; examinar sus teorías acerca del Estado y de las relaciones entre las potestades eclesiástica y civil, y la intervención que tuvo en la vida política de su tiempo. A esta tarea consagró el Sr. Hinojosa el discurso de recepción que leyó ante la Real Academia de la Historia en 1889. Su estudio 
sobre el sabio restaurador de los estudios teológicos en el siglo XVI, maestro de Melchor Cano y de Domingo de Soto, contiene datos interesantes, desconocidos de los anteriores biógrafos, sobre aspectos no tratados de su actividad científica, y aporta elementos de juicio para la apreciación exacta del lugar que corresponde a Vitoria en la historia de la ciencia. Este trabajo fue calificado por el profesor de la Universidad de Bonn, Ernesto Landsberg, continuador de la Historia de la ciencia jurídica en Alemania, de Stintzing, como "lo mejor y más completo" que se ha escrito sobre Vitoria.

Fue felicísima idea de la Real Academia de Ciencias Morales y Políticas señalar como tema para uno de sus concursos, el de 1889, "La influencia que tuvieron en el derecho público de su patria, y singularmente en el derecho penal, los filósofos y teólogos españoles anteriores al siglo XIX”. Esta influencia, considerada con razón en España y en el extranjero como uno de nuestros más indiscutibles títulos de gloria, había sido estudiada ya magistralmente por Balmes en algunos capítulos de su Protestantismo comparado con el Catolicismo, y por D. Antonio Cánovas del Castillo en sus artículos de la Revista de España sobre "Las ideas políticas de los españoles en tiempo de la Casa de Austria”; pero carecíamos de una obra que, tomando como punto de partida estos trabajos, ampliase la investigación en cuanto a las doctrinas políticas, e incluyese en su cuadro las otras ramas del Derecho. A esta necesidad quiso proveer la Academia con el anuncio del referido tema, que dio por resultado la Memoria del Sr. Hinojosa premiada por esta Corporación.

La influencia de los teólogos en el Derecho requiere como condiciones cierto grado de florecimiento de la ciencia teológica, y la armonía entre la Iglesia y el Estado, por virtud de la cual pueda hacerse sentir la acción de las doctrinas de los teólogos en la esfera de la legislación. Estas condiciones no se han dado juntas más que en dos períodos de la Historia de España: el visigodo y el de la Casa de Austria. De aquí que a ellos se limite casi exclusivamente la Memoria de que tratamos. Su parte principal, que es la exposición de las doctrinas de nuestros más insignes teólogos de los siglos XVI y XVII acerca del Derecho político, del penal y del internacional, fruto del estudio de los escritos de la época, demuestra cumplidamente la verdad de la afirmación del Sr. Cánovas, que, al caracterizar el mérito y la importancia de la escuela teológico-jurídica española, se expresaba en los términos siguientes:

"Durante el siglo de oro de nuestra literatura predominó en España la doctrina de la escuela político-religiosa, cuyos principales representantes fueron ciertamente el sabio Francisco de Vitoria, maestro de Melchor Cano; el insig- 
ne dominico Domingo de Soto; el jesuita Francisco Suárez, llamado el doctor Eximio. Ella echó con Alfonso de Castro los cimientos de la ciencia del Derecho penal y la del Derecho de gentes con Francisco de Vitoria y Baltasar de Ayala. Ella dio de sí innumerables tratados de Derecho político, entre los cuales se cuentan muchos dignísimos de estima aun hoy en día Ella será, cuando profundamente llegue a estudiarse y conocerse del todo, el timbre mayor quizá del reinado de Felipe II, y uno de los mejores, si no el más celebrado fruto, del talento español hasta ahora".

Asociado con el sabio historiador y literato D. Aureliano Fernández-Guerra para escribir en la obra colectiva de Historia de España dirigida por D. Antonio Cánovas del Castillo la parte relativa a la dominación de los pueblos germánicos, tomó a su cargo el Sr. Hinojosa el período que se extiende desde la invasión hasta la venida de los Bizantinos. Ocupa este trabajo la mayor parte del tomo I, publicado en 1890. Precede a la exposición histórica un extenso estudio crítico de las fuentes que se nos han conservado acerca de los pueblos germánicos en nuestra Península, desde los primeros tiempos de la invasión, descritos con tanta riqueza de detalles y viveza de colorido por Idacio, hasta la irrupción de los árabes, cuyos comienzos conocemos por la preciosa crónica de autor anónimo, atribuida inexactamente a un Obispo de Pax Julia (Beja), y llamada por esto del Pacense hasta mediados del siglo XIX. El trabajo del Sr. Hinojosa no es mera reseña del estado de las investigaciones sobre el particular, sino que abunda en observaciones originales, alguna de las cuales ha sido reforzada luego con la autoridad de críticos eminentes. Tal sucede con la opinión sobre el origen y carácter de la crónica anónima antes citada, que coincide en lo esencial con la sostenida algunos años más tarde por Mommsen, al publicar una nueva edición del texto en los Monumenta Germaniae historica. Los capítulos relativos a las instituciones sociales y políticas de los germanos y a las peculiares de los visigodos descansan sobre el estudio de las fuentes y de los trabajos modernos, y contienen también ideas nuevas dignas de atención.

Sus excursiones a través de los documentos publicados e inéditos de la Edad Media española le han revelado, unas veces la existencia, otras la difusión y la importancia de instituciones y prácticas, o enteramente desconocidas, o en que hasta ahora no se había fijado suficientemente la atención, a cuyo estudio ha dedicado breves monografías, interesantes por la novedad de

1 Cánovas del Castillo, Bosquejo histórico de la Casa de Austria, en el Diccionario general de política y administración, tomo I, Madrid, 1868, págs. 888-889. 
los resultados. Tal es la relativa a La privación de sepultura de los deudores, que muestra vigente en todos los Estados cristianos de la España medioeval, y usada aún en Salamanca en el siglo XVI, según testimonio del célebre jurisconsulto Antonio Gómez, la bárbara costumbre, que se encuentra también en otros países, y rigió en Inglaterra hasta muy entrado el siglo XIX, de impedir el acreedor la sepultura del cadáver del deudor hasta que se le pagaba la deuda. A este mismo género pertenecen los trabajos sobre La comunidad doméstica y La fraternidad artificial en España en la Edad Media, que dan a conocer curiosas formas de posesión y explotación de la tierra, reveladas en otros países por el estudio comparativo de las instituciones, y cuya existencia en España era totalmente ignorada, con relación a la época en que las estudia el autor. Fúndanse ambos trabajos en documentos, inéditos en su mayor parte, y en algunos publicados ya, pero cuyo valor no se había apreciado debidamente hasta ahora. El relativo a la historia de la comunidad doméstica demuestra el vínculo que une algunas instituciones de nuestro actual derecho consuetudinario con las que rigieron hace muchos siglos, y explica las transformaciones que han sufrido en el transcurso del tiempo y las causas de su subsistencia.

La importancia del estudio sobre Los orígenes del régimen municipal en León y Castilla radica en la refutación de la teoría, defendida principalmente por Herculano, que lo considera de procedencia romana. Son también de notar en él la característica de los fueros municipales y de su importancia como fuentes de la historia social y jurídica de la Edad Media, el cuadro, no trazado antes en conjunto, de las luchas que sostuvieron para lograr la emancipación política las ciudades episcopales del antiguo reino de León, y la reseña de las principales fases del régimen municipal hasta fines del siglo XVI.

La monografía sobre El Derecho en el Poema del Cid es interesante ejemplo de cómo las investigaciones sobre aspectos diversos de la vida de los pueblos, cómo la historia y la literatura se enlazan íntimamente y se prestan recíproco apoyo.

El gran escritor francés Taine, singularmente autorizado para dar opinión sobre esta materia, como maestro al mismo tiempo en la historia literaria y la historia política (baste recordar sus obras la Historia de la literatura inglesa y Los orígenes de la Francia contemporánea), se ha expresado bellamente acerca de estas relaciones: "La Historia - decía en 1863- se ha transformado desde hace cien años en Alemania, y desde hace sesenta en Francia, merced al estudio de las literaturas. Se ha descubierto que una obra literaria no es un 
mero juego de la fantasía, el capricho aislado de una cabeza ardiente, sino una copia de las costumbres de la sociedad contemporánea y la señal de un estado de ánimo. Se ha deducido de aquí que, valiéndose de los monumentos literarios, es posible averiguar el modo de sentir y de pensar de los hombres hace muchos siglos Se ha visto que estaban relacionados con los acontecimientos más importantes, que los explicaban y que, a su vez, eran explicados por ellos; que era menester darles en adelante un lugar, y uno de los lugares más elevados en la Historia. Se les ha dado y, desde entonces, todo ha cambiado en la Historia: el objeto, el método, los instrumentos, la concepción de las leyes y de las causas".

Y ciertamente, el estudio de las obras de la amena literatura ha dilatado el horizonte de la historia política y de la historia de las instituciones, revelándoles una fuente preciosísima, así como estos aspectos de la historia han mostrado al investigador de la literatura ideas, hechos y conexiones que han transformado la historia literaria, no reducida ya, como en otros tiempos, a una mera colección de datos biográficos y de títulos de libros. En todas las historias generales modernas dignas de este nombre, la literatura no sólo es utilizada como fuente, sino que ocupa el lugar de honor que le corresponde como una de las manifestaciones más importantes de la vida de los pueblos.

Aunque el fin inmediato del trabajo del Sr. Hinojosa sobre el Poema del Cid fue quilatar en la piedra de toque de los monumentos jurídicos las opiniones relativas a la fecha de redacción del Poema, sus investigaciones con este motivo han sido fecundas en resultados para la historia de las instituciones. La comparación de los datos que ofrece el Poema con los que proporcionan los diplomas públicos y privados y los fueros municipales de los primeros siglos de la Reconquista acerca del Rey, de las Cortes, de la jerarquía nobiliaria, de las expediciones militares y de la familia, ilustra aspectos obscuros o enteramente inexplorados de la organización social y política de los reinos de León y Castilla en el período menos conocido de su historia. Condensando el resultado de su investigación, afirma el autor el carácter genuinamente nacional del Poema, manifestado en su perfecta concordancia con los monumentos jurídicos de León y Castilla, la verosimilitud de la opinión que le cree redactado en la segunda mitad del siglo XII, a cuya época, mejor que a principios o mediados del siglo XIII, se acomoda el estado social y jurídico reflejado en la obra, y la importancia de ésta como fuente de la historia de las instituciones, ya en cuanto amplía las noticias que poseemos sobre algunas conocidas incompletamente por otros testimonios, ya en cuanto revela la existencia de 
instituciones de que no se encuentra mención más que en el Poema. Críticos eminentes, como los Sres. Menéndez Pelayo y Morel-Fatio, han calificado de admirable este trabajo.

Asunto predilecto de los estudios de nuestro nuevo compañero en los últimos años ha sido la condición de las clases rurales en España durante la Edad Media. Los trabajos de esta índole no pueden ser verdaderamente sólidos y fructuosos sino mediante el empleo del método geográfico, estudiando separadamente las instituciones de cada uno de los territorios que tuvieron en otro tiempo vida política propia e independiente. Importa, además, no limitarse, ni dar preferencia excesiva, a una sola clase de fuentes, sino utilizarlas todas, apreciando debidamente su valor, para trazar un cuadro exacto, completo y armónico. A estas normas ha procurado atemperarse el Sr. Hinojosa. Resultado de sus investigaciones, basadas principalmente sobre materiales inéditos, son las monografías sobre los Mezquinos y Exaricos, nombres con que respectivamente se designaba hasta el siglo XIII a los siervos adscritos de origen cristiano y de origen árabe en Aragón, sobre La servidumbre de la gle$b a$ en este antiguo reino, y su reciente obra El régimen señorial y la cuestión agraria en Cataluña durante la Edad Media.

Comprende bajo el nombre de régimen señorial el conjunto de las relaciones de dependencia de unos individuos respecto de otros, ya por razón de la persona, ya de la tierra, con exclusión de las que se establecían en las clases nobiliarias por virtud del contrato feudal, y la organización económica, social y política derivada de aquellas relaciones. La exposición del régimen señorial es el fondo sobre el cual se destaca con sus verdaderos caracteres la cuestión agraria, que tan poderosamente agitó los ánimos en Cataluña durante los reinados de Alfonso V, de Juan II y de Fernando el Católico, que dio origen a las dos guerras sociales que ensangrentaron los campos del Principado en la segunda mitad del siglo XV, y que terminó con la famosa sentencia arbitral dictada por el último de dichos Monarcas en 1486.

Como punto de partida natural de su investigación, estudia el autor el establecimiento de los españoles en la Septimania bajo la legislación tutelar de los Monarcas francos, la fundación y organización de la Marca Hispánica, el proceso de la colonización en los territorios de Cataluña reconquistados de los árabes y el papel capitalísimo que desempeñaron en esta obra eminentemente civilizadora, aquí como en otras regiones de Europa, los monasterios benedictinos, atrayendo pobladores a las soledades yermas, e impulsando vigorosamente la repoblación y el cultivo. Dedica especial atención a las formas 
de posesión y cultivo de la tierra y a la varia condición social y jurídica de los elementos de la población rural; precisa por vez primera las diferencias entre las varias clases de señorío, distintas del puramente feudal; da a conocer la condición económica de los colonos o payeses, tan importante para juzgar de la verdadera situación de las clases rurales, y muestra cómo las dos instituciones más características del derecho catalán, la forma de arrendamiento hereditario conocida con el nombre de establecimiento y la herencia de uno solo de los hijos o heredamiento, nacieron y se desarrollaron como consecuencia de las circunstancias económicas y sociales de los primeros siglos de la Reconquista.

El capítulo relativo a la violencia y el fraude en el régimen señorial da a conocer la degeneración de este régimen, forma de organización social y política necesaria y aun beneficiosa durante el período de anarquía general que se extiende desde el siglo IX al XII, en el cual, de tutelar que fue en su origen, se convierte en arbitrario. En Cataluña, como en otros países, el absenteísmo de los grandes propietarios rurales fue una de las principales causas, primero de la relajación de los vínculos, y luego del antagonismo entre señores y aldeanos.

$\mathrm{Al}$ reseñar las principales etapas de la emancipación de los payeses y determinar los factores que influyeron en ella, fija imparcialmente la parte que tuvieren en esta obra el factor ideal y el económico, la Monarquía, los señores eclesiásticos y los señores laicos, y muestra claramente cómo sin la prudencia y firmeza del Rey Católico el resultado de la guerra social en Cataluña habría sido, como en la guerra de los aldeanos alemanes, la derrota de los payeses y el fracaso de sus aspiraciones. La sentencia dictada por el Rey en 1486, que el jurisconsulto catalán del siglo XVI, Solsona, califica de "santa", puso feliz término al antagonismo de clases que tan funestos resultados había producido, restableció sobre sólidas bases la paz y la armonía entre señores y payeses, e inauguró una era de prosperidad para la agricultura catalana. Por virtud de ella, se encontraron ya en el último tercio del siglo XV los labradores catalanes en posesión de la libertad personal, que, en España mismo, no habían de lograr los aragoneses hasta principios del siglo XVIII, y grandes masas de la población rural de otros Estados de Europa hasta la segunda mitad del siglo XVIII o principios del XIX.

Este es, en brevísimo resumen, el contenido de tan interesante estudio de historia social y económica. La comparación que el autor establece frecuentemente entre las instituciones de Cataluña y las de otros Estados de la Europa 
cristiana le sirve para precisar las causas de las semejanzas y analogías que entre ellas se observan, que son, en suma, la base común romanogermánica de la organización económica y social y la influencia de unos mismos factores económicos, políticos y jurídicos.

Tal es, señores, el inventario, el "bagaje" científico, como ahora se dice, que acompaña al nuevo Académico. Juzgad hasta qué punto su cooperación ha de ser útil para nuestros fines y tareas, y cómo sin exageración puede decirse que la Academia de Ciencias Morales y Políticas, al honrar al señor Hinojosa llamándole a su seno, se ha honrado al mismo tiempo a sí propia.

La exposición que acaba de hacer el Sr. Hinojosa de las vicisitudes de la condición civil de la mujer casada en la historia y del estado actual del derecho de los pueblos cultos sobre esta materia, aporta datos y conclusiones nuevas a la historia del Derecho patrio, y ofrece materiales y direcciones para la reforma de la legislación vigente. En esta segunda parte de su trabajo ha procurado no perder de vista que el punto de partida necesario y el criterio seguro para discernir en el conjunto de aspiraciones formuladas para mejorar la condición de la mujer cuáles son viables y cuáles no, es la noción clara y exacta de la misión de la mujer en la familia y en la sociedad.

El feminismo radical que pide la equiparación absoluta de la mujer al hombre, así en el derecho privado como en el derecho público, se enlaza íntimamente con las teorías igualitarias de los enciclopedistas y de la Revolución francesa. Condorcet fue el primero en hacer aplicación de ellas a la condición de la mujer en 1769, y, simultáneamente en el año 1792, una escritora alemana, Teodora de Hippel, y otra inglesa, Mary Wollstonecraft, publicaron libros exponiéndo las mismas ideas. Con ellas concuerda fundamentalmente el más notable y uno de los más apasionados defensores del feminismo, el filósofo y economista inglés Stuart Mill, que, en su célebre obra La esclavitud de la mujer combate la subordinación de la mujer al hombre en la esfera doméstica y su exclusión de los derechos políticos, y afirma que esta situación no tiene otra base que el derecho de la fuerza ejercido por el hombre sobre la mujer en todos los tiempos, opresión intolerable, de la cual hay que librarla a toda costa.

Conforme a esto, el feminismo radical aspira a la equiparación completa de la mujer con el hombre en todos los órdenes, sacando las últimas consecuencias del principio de igualdad proclamado por la Revolución francesa. El programa de los socialistas alemanes, publicado en 1891, dice textualmente que su fin principal es "luchar por la abolición del dominio de unas clases 
sobre otras y por la igualdad absoluta de derechos y deberes sin distinción de sexo ni de raza, y singularmente por la abolición de todas las leyes que postergan la mujer al hombre, así en la vida pública como en la privada”. Esta idea ha sido desarrollada por uno de los principales jefes del partido socialista alemán, Bebel, en su libro La mujer y el socialismo. La teoría del amor libre es otro de los postulados del feminismo radical socialista. El matrimonio, tal como existe en todos los pueblos cultos, es para los adeptos de esta tendencia una institución inmoral, que debe ser sustituida por las uniones disolubles a voluntad de las partes.

Doctrinas tan disolventes y utópicas están en abierta oposición con las enseñanzas de la religión y de la filosofía La diversa situación del hombre y de la mujer en la familia y en la sociedad no es obra, ni de la diferencia de la educación, ni de la violencia, sino que se funda esencialmente en la diversidad de las condiciones y aptitudes de los sexos. La naturaleza misma ha trazado la línea divisoria entre ellos, y todo lo que tienda a borrarla es contrario a la razón y a la justicia, es una perturbación del orden providencial. El centro de la esfera de acción de la mujer es el gobierno de la casa y los cuidados del hogar, como el del hombre la dirección de la familia y las atenciones de la vida pública.

La revelación cristiana enseña claramente la subordinación de la mujer respecto del hombre, no como sierva, sino como compañera, dentro de la unidad e indisolubilidad esenciales del matrimonio. Allí donde estas no existen, la mujer se ve degradada y envilecida, como lo demuestra el ejemplo de los pueblos, así salvajes como cultos, antiguos y modernos, en que reina la poligamia, o en que el vínculo conyugal es disoluble a voluntad de los cónyuges. No hay sino recordar cuál era la situación de la mujer, inferior aún de hecho a la de derecho, en el mundo romano al aparecer el Cristianismo, tal como la dan a conocer los escritores paganos y los cristianos, los monumentos literarios y los jurídicos, para juzgar de la inmensa transformación llevada a cabo en este orden por la doctrina evangélica.

El criterio que hemos expuesto acerca de la misión de la mujer da la clave para resolver los problemas relacionados con la mejora de su condición económica, ya se trate de la mujer obrera, ya de la mujer de la clase media.

Los maravillosos progresos técnicos realizados durante el siglo XIX han privado de condiciones de existencia a la industria doméstica, trasladando en masa del hogar a la fábrica a las mujeres que en ella se empleaban, y dificultándoles, cuando no impidiéndoles en absoluto, dedicarse al cuidado de 
la familia y a las faenas domésticas. El trabajo, frecuentemente excesivo para sus fuerzas por la índole y duración, y ejecutado en pésimas condiciones higiénicas, ha ocasionado peligros y daños para su salud y su moralidad. El Estado ha procurado atenuar, ya que no pueda remediar enteramente el mal, en el nuestro como en otros países de Europa, a fin de que la mujer trabaje en condiciones menos incompatibles con la vida del hogar.

La sustitución de la industria doméstica por la fabril no ha procurado a la mujer de la clase media, como a la de la clase proletaria, nuevo aunque más inadecuado empleo, en compensación de su actividad anterior en el seno de la familia. Los elementos más numerosos de la clase media apenas cuentan con otros recursos que sueldos u honorarios escasos, que cesan, como el salario del jornalero, cuando el cabeza de familia se inutiliza o muere, y que rara vez consienten ahorrar lo necesario para asegurar el porvenir de la familia. Por otra parte, las condiciones económicas y sociales de nuestra época dificultan el casamiento de las mujeres de la clase media. De aquí la legítima aspiración a ampliar la esfera de su actividad en el orden económico. La norma más segura en este punto es reconocer a la mujer el derecho a aspirar a cuantos oficios y profesiones puedan procurarles una subsistencia decorosa y no se opongan al cumplimiento de su misión. En términos generales, conviene facilitarle el acceso a todas las ocupaciones que ensanchen beneficiosamente el ámbito de su actividad.

Objétase a esto que, siendo peor remunerado de ordinario el trabajo de la mujer que el del hombre, la admisión de aquélla a ciertas profesiones condenaría a muchos hombres a la inacción, y dificultaría los casamientos, perturbando el orden natural de las cosas; pero la estadística demuestra que, en los países donde es más considerable el número de mujeres empleadas en trabajos de escritorio y mostrador y en los servicios de correos, teléfonos y otros semejantes, con sueldos aún más escasos de los que suelen ganar los hombres, no por eso han decrecido los casamientos. Se exageran, por lo demás, los efectos de la concurrencia del trabajo de la mujer, al cual están trazados ciertos límites naturales. Hay ocupaciones que, por ser incompatibles con su debilidad física, le están enteramente vedadas, y la necesidad de atender a los cuidados del hogar como mujer y como madre le obliga a abandonar las profesiones que ejerce. Por esta razón, muchas familias de la clase media no se deciden a dar a sus hijas una educación larga y costosa que les permita dedicarse a profesiones que acaso no han de ejercer nunca, o sólo por breve tiempo. 
Siendo fin esencial de la educación el desarrollo de las facultades y aptitudes del individuo para que pueda realizar debidamente su fin, importa, para saber cuál haya de darse a la mujer, no perder de vista su misión principal en el mundo y las condiciones especiales de que Dios la ha dotado. Ponerla en estado de llenar cumplidamente los deberes de esposa y madre es el fin a que ha de encaminarse en primer término su educación. Mas aunque este sea su destino, por decirlo así, normal, hay muchas mujeres que no se casan, y muchas otras que, por muerte de sus maridos, vienen a quedar en situación idéntica a las que han permanecido solteras, y a esta situación, que es frecuentísima, debe atenderse también cuando se trata de fijar el sistema de educación más adecuado para la mujer. Dado, pues, que infinidad de mujeres se ven necesitadas de procurarse con el fruto de su trabajo los medios necesarios de subsistencia, hay que prepararlas convenientemente para este fin, y procurar el desarrollo de sus facultades intelectuales y morales mediante el cultivo del arte y de la ciencia. En suma, para resolver este, como los demás problemas relacionados con el mejoramiento de la condición de la mujer, hay que tener siempre presente su misión especial en el mundo. Como decía, en ocasión solemne, ante el Congreso de Madres, celebrado en Washington el 13 de Marzo de 1905, el Presidente Roosevelt, "hay verdades añejas que serán verdades mientras el mundo exista, y que ningún progreso, por grande que sea, podrá jamás alterar. Una de ellas es que el deber elemental del marido es constituir el hogar, ganando el pan necesario para su mujer y para sus hijos, y que el deber elemental de la mujer es ser apoyo del hombre, señora del hogar y madre. La mujer debe gozar de las ventajas de una amplia educación; pero el hombre debe ser educado para afrontar la carrera de una larga vida, durante la cual proveerá el pan de la familia; mientras que aquella no debe ser educada con tales propósitos sino en circunstancias excepcionales. En su consecuencia, salvados ciertos límites, la educación de los dos debe ser normalmente diversa, porque los deberes de ambos son también normalmente distintos, lo cual no significa desigualdad de funciones, sino que normalmente debe existir diversidad de dichas funciones. Y para decirlo todo, concibo el deber de la mujer como el más importante, difícil y honroso de los dos en el hogar y por eso también me inspira mayor respeto la mujer que ha llenado su deber que el hombre que lo cumple a su vez"2.

De todos modos, no en vanas ni peligrosas utopías, sino dentro del orden

2 Roosevelt, Discursos: El divorcio, en la Revista de Derecho, Historia y Letras de Buenos Aires de Junio de 1905, págs. 485-494. 
social cristiano, abierto a todos los progresos, pero asentado sobre firmísimas bases, es donde viene a hallarse la solución de este como de todos los problemas fundamentales de la época presente. 



\section{PROGRAMA HISTORIA DEL DERECHO PUBLICACIONES \\ ISSN: 2255-5137}

1. Luis Grau, Origenes del constitucionalismo americano. Corpus documental bilingüe / Selected Documents Illustrative of the American Constitutionalism. Bilingual edition, 3 vols., Madrid 2009, 653+671+607 pp.

http://hdl.handle.net/10016/5669

2. Luis Grau, Nosotros el pueblo de los Estados Unidos. La Constitución de los Estados Unidos y sus enmiendas. 1787-1992. Edición bilingüe / We the People of the United States. The U.S. Constitution and its Amendments. 1787-1992. Bilingual edition, Madrid 2010, $338 \mathrm{pp}$.

http://hdl.handle.net/10016/8517

3. Carlos Petit, Fiesta y contrato. Negocios taurinos en protocolos sevillanos (1777-1847), Madrid 2011, 182 pp.

http://hdl.handle.net/10016/10145

4. Pablo Mijangos y González, El nuevo pasado jurídico mexicano. Una revisión de la historiografía jurídica mexicana durante los últimos 20 años, Madrid 2011, 110 pp. http://hdl.handle.net/10016/10488

5. Luis Grau, El constitucionalismo americano. Materiales para un curso de historia de las constituciones, Madrid 2011, xxii+282 pp.

http://hdl.handle.net/10016/11865

6. Víctor Tau Anzoátegui, El taller del jurista. Sobre la Colección Documental de Benito de la Mata Linares, oidor, regente y consejero de Indias, Madrid 2011, 175 pp.

http://hdl.handle.net/10016/12735

7. Ramon Llull, Arte de Derecho, estudio preliminar de Rafael Ramis Barceló, traducción y notas de Pedro Ramis Serra y Rafael Ramis Barceló, Madrid 2011, 178 pp.

http://hdl.handle.net/10016/12762

8. Consuelo Carrasco García, ¿Legado de deuda? A vueltas con la Pandectística, Madrid 2011, 158 pp.

http://hdl.handle.net/10016/12823

9. Pio Caroni, Escritos sobre la codificación, traducción de Adela Mora Cañada y Manuel Martínez Neira, Madrid 2012, xxvi + 374 pp.

http://hdl.handle.net/10016/13028

10. Esteban Conde Naranjo (ed.), Vidas por el Derecho, Madrid 2012, 569 pp.

http://hdl.handle.net/10016/13565

11. Pierangelo Schiera, El constitucionalismo como discurso político, Madrid 2012, 144 pp. http://hdl.handle.net/10016/13962 
12. Rafael Ramis Barceló, Derecho natural, historia y razones para actuar. La contribución de Alasdair MacIntyre al pensamiento jurídico, Madrid 2012, 480 pp.

http://hdl.handle.net/10016/13983

13. Paola Miceli, Derecho consuetudinario y memoria. Práctica jurídica y costumbre en Castilla y León (siglos XI-XIV), Madrid 2012, 298 pp.

http://hdl.handle.net/10016/14294

14. Ricardo Marcelo Fonseca, Introducción teórica a la historia del derecho, prefacio de Paolo Cappellini, Madrid 2012, 168 pp.

http://hdl.handle.net/10016/14913

15. Alessandra Giuliani, Derecho dominical y tanteo comunal en la Castilla moderna, Madrid 2012, 134 pp.

http://hdl.handle.net/10016/15436

16. Luis Grau, An American Constitutional History Course for Non-American Students, Madrid 2012, xx + 318 pp.

http://hdl.handle.net/10016/16023

17. Antonio Ruiz Ballón, Pedro Gómez de la Serna (1806-1871). Apuntes para una biografía jurídica, Madrid 2013, 353 pp.

http://hdl.handle.net/10016/16392

18. Tamara El Khoury, Constitución mixta y modernización en Líbano, prólogo de Maurizio Fioravanti, Madrid 2013, 377 pp.

http://hdl.handle.net/10016/16543

19. María Paz Alonso Romero/Carlos Garriga Acosta, El régimen jurídico de la abogacía en Castilla (siglos XIII-XVIII), Madrid 2013, 337 pp.

http://hdl.handle.net/10016/16884

20. Pio Caroni, Lecciones de historia de la codificación, traducción de Adela Mora Cañada y Manuel Martínez Neira, Madrid 2013, 213 pp.

http://hdl.handle.net/10016/17310

21. Julián Gómez de Maya, Culebras de cascabel. Restricciones penales de la libertad ambulatoria en el derecho codificado español, Madrid 2013, 821 pp.

http://hdl.handle.net/10016/17322

22. François Hotman, Antitriboniano, o discurso sobre el estudio de las leyes, estudio preliminar de Manuel Martínez Neira, traducción de Adela Mora Cañada, Madrid 2013, 211 pp. http://hdl.handle.net/10016/17855

23. Jesús Vallejo, Maneras y motivos en Historia del Derecho, Madrid 2014, 184 pp.

http://hdl.handle.net/10016/18090

24. María José María e Izquierdo, Los proyectos recopiladores castellanos del siglo XVI en los códices del Monasterio de El Escorial, Madrid 2014, 248 pp.

http://hdl.handle.net/10016/18295 
25. Regina Polo Martín, Centralización, descentralización y autonomía en la España constitucional. Su gestación y evolución conceptual entre 1808 y 1936, Madrid 2014, 393 pp. http://hdl.handle.net/10016/18340

26. Massimo Meccarelli/Paolo Palchetti/Carlo Sotis (eds.), Il lato oscuro dei Diritti umani: esigenze emancipatorie e logiche di dominio nella tutela giuridica dell'individuo, Madrid 2014, 390 pp.

http://hdl.handle.net/10016/18380

27. María López de Ramón, La construcción histórica de la libertad de prensa: Ley de policía de imprenta de 1883, Madrid 2014, 143 pp.

http://hdl.handle.net/10016/19296

28. José María Coma Fort, Codex Theodosianus: historia de un texto, Madrid 2014, $536 \mathrm{pp}$.

http://hdl.handle.net/10016/19297

29. Jorge Alberto Núñez, Fernando Cadalso y la reforma penitenciaria en España (18831939), Madrid 2014, 487 pp.

http://hdl.handle.net/10016/19662

30. Carlos Petit, Discurso sobre el discurso. Oralidad y escritura en la cultura jurídica de la España liberal, Madrid 2014, 185 pp.

http://hdl.handle.net/10016/19670

31. Jean-Étienne-Marie Portalis, Discurso preliminar sobre el proyecto de Código civil, Madrid 2014, 53 pp.

http://hdl.handle.net/10016/19797

32. Cesare Beccaria, Tratado de los delitos y de las penas, Madrid 2015, 87 pp.

http://hdl.handle.net/10016/20199

33. Massimo Meccarelli/Paolo Palchetti (eds.), Derecho en movimiento: personas, derechos y derecho en la dinámica global, Madrid 2015, 256 pp.

http://hdl.handle.net/10016/20251

34. Alessandro Somma, Introducción al derecho comparado, traducción de Esteban Conde Naranjo, Madrid 2015, 193 pp.

http://hdl.handle.net/10016/20259

35. A. F. J. Thibaut, Sobre la necesidad de un derecho civil general para Alemania, Madrid 2015, 42 pp.

http://hdl.handle.net/10016/21166

36. J.-J.-R. de Cambacérès, Discursos sobre el Código civil, Madrid 2015, 61 pp.

http://hdl.handle.net/10016/21254

37. Ramon Llull, Arte breve de la invención del derecho, estudio preliminar de Rafael Ramis Barceló, traducción de Pedro Ramis Serra y Rafael Ramis Barceló, Madrid 2015, 233 pp. http://hdl.handle.net/10016/21406 
38. F. C. von Savigny, De la vocación de nuestra época para la legislación y la ciencia del Derecho, Madrid 2015, 130 pp.

http://hdl.handle.net/10016/21520

39. Joaquín Marín y Mendoza, Historia del derecho natural y de gentes, Madrid 2015, 40 pp. http://hdl.handle.net/10016/22079

40. Rafael Ramis Barceló, Petrus Ramus y el Derecho. Los juristas ramistas del siglo XVI, Madrid 2016, $250 \mathrm{pp}$.

http://hdl.handle.net/10016/22197

41. Emanuele Conte, La fuerza del texto. Casuística y categorías del derecho medieval, edición de Marta Madero, Madrid 2016, 194 pp.

http://hdl.handle.net/10016/22261

42. Constituciones españolas: 1808-1978, edición de Javier Carlos Díaz Rico, Madrid 2016, $259 \mathrm{pp}$.

http://hdl.handle.net/10016/22905

43. Giacomo Demarchi, Provincia y Territorio en la Constituyente española de 1931. Las raíces europeas del Estado integral, Madrid 2016, 362 pp.

http://hdl.handle.net/10016/22906

44. Miguel Ángel Ladero Quesada/César Olivera Serrano (dirs.), Documentos sobre Enrique IV de Castilla y su tiempo, Madrid 2016, $\mathrm{xx}+1446$ pp.

http://hdl.handle.net/10016/23015

45. Gustavo César Machado Cabral/Francesco Di Chiara/Óscar Hernández Santiago/Belinda Rodríguez Arrocha, El derecho penal en la edad moderna: Nuevas aproximaciones a la doctrina y a la práctica judicial, Madrid 2016, 217 pp.

http://hdl.handle.net/10016/23021

46. Lope de Deza, Juicio de las leyes civiles, estudio preliminar de Víctor Tau Anzoátegui, edición de María José María e Izquierdo, Madrid 2016, 136 pp.

http://hdl.handle.net/10016/23228

47. Henrik Brenkman, Historia de las Pandectas, estudio preliminar, traducción y notas de Juan Lorenzo, Madrid 2016, 426 pp.

http://hdl.handle.net/10016/23317

48. Massimo Meccarelli (a cura di), Diversità e discorso giuridico. Temi per un dialogo interdisciplinare su diritti e giustizia in tempo di transizione, Madrid 2016, 287 pp. http://hdl.handle.net/10016/23792

49. Beatrice Pasciuta, El diablo en el Paraíso. Derecho, teología y literatura en el Processus Satane (s. XIV), Madrid 2017, 264 pp.

http://hdl.handle.net/10016/24439

50. Maximiliano Hernández Marcos, Tras la luz de la ley: legislación y justicia en Prusia a finales del siglo XVIII. Un modelo de Ilustración jurídica, Madrid 2017, 184 pp.

http://hdl.handle.net/10016/24488 
51. Eleonora Dell'Elicine/Paola Miceli/Alejandro Morin (comps.), Artificios pasados. Nociones del derecho medieval, Madrid 2017, 307 pp.

http://hdl.handle.net/10016/24514

52. Eva Elizabeth Martínez Chavéz, Redes en el exilio. Francisco Ayala y el Fondo de Cultura Económica, Madrid 2017, 145 pp.

http://hdl.handle.net/10016/24715

53. Pierre de Jean Olivi, Tratado de los contratos, estudio preliminar de Rafael Ramis Barceló, traducción de Pedro Ramis Serra y Rafael Ramis Barceló, Madrid 2017, 171 pp. http://hdl.handle.net/10016/25200

54. Daniel Panateri, El discurso del rey. El discurso jurídico alfonsí y sus implicaciones políticas, Madrid 2017, 284 pp.

http://hdl.handle.net/10016/25377

55. Joaquín Costa, El problema de la ignorancia del derecho y sus relaciones con el estatus individual, el referéndum y la costumbre, Madrid 2017, 85 pp.

http://hdl.handle.net/10016/25578

56. Massimo Meccarelli (ed.), Reading the Crisis: Legal, Philosophical and Literary Perspectives, Madrid 2017, $224 \mathrm{pp}$.

http://hdl.handle.net/10016/25705

57. Pablo Ramírez Jerez/Manuel Martínez Neira, La historia del derecho en la Real Academia de Ciencias Morales y Políticas. Los concursos de derecho consuetudinario, Madrid 2017, 322 pp.

http://hdl.handle.net/10016/25809

58. Thomas Duve (coord.), Actas del XIX Congreso del Instituto Internacional de Historia del Derecho Indiano, 2 vols., Madrid 2017, 1681 pp.

http://hdl.handle.net/10016/25729

59. Víctor Saucedo, Conspiracy. A Conceptual Genealogy (Thirteenth to Early Eighteenth Century), Madrid 2017, 350 pp.

http://hdl.handle.net/10016/26095

60. Aurora Miguel Alonso (dir.), Doctores en derecho por la Universidad Central. Catálogo de tesis doctorales 1847-1914, Madrid 2017, 571 pp.

http://hdl.handle.net/10016/26198

61. François Hotman, Francogallia, o la Galia francesa, estudio preliminar y traducción de Tamara El Khoury, Madrid 2017.

http://hdl.handle.net/10016/26321

62. Rafael Altamira, Spain. Sources and Development of Law, estudio preliminar y edición de Carlos Petit, Madrid 2018, lxxxvi + 126 pp.

http://hdl.handle.net/10016/26322 
63. Jesús Delgado Echeverría, Joaquín Costa, jurista y sociólogo. Derecho consuetudinario e ignorancia de la ley, Madrid 2018, 174 pp.

http://hdl.handle.net/10016/26335

64. Rubén Pérez Trujillano, Creación de constitución, destrucción de Estado: la defensa extraordinaria de la II República española (1931-1936), Madrid 2018, 367 pp.

http://hdl.handle.net/10016/27108

65. Eugenia Torijano Pérez, Los estudios jurídicos en la universidad salmantina del siglo XIX, Madrid 2018, 625 pp. + apéndices complementarios.

http://hdl.handle.net/10016/27392

66. Laura Beck Varela/María Julia Solla Sastre (coordinadoras), Estudios Luso-Hispanos de Historia del Derecho. Estudos Luso-Hispanos de História do Direito, Madrid 2018, $543 \mathrm{pp}$.

http://hdl.handle.net/10016/27751

67. Manuel Martínez Neira/Pablo Ramírez Jerez, Hinojosa en la Real Academia de Ciencias Morales y Políticas, Madrid 2018, 279 pp.

http://hdl.handle.net/10016/27810 